\title{
Recognizing Regions: ASEAN's Struggle for Recognition
}

\author{
Bernard Ong
}

Graduate School of Asia-Pacific Studies Waseda University, Tokyo, Japan 


\section{Table of Contents}

List of Abbreviations iii

List of Illustrations $\quad \mathrm{V}$

Acknowledgements vi vi

Abstract vii

Chapter One: Overview 1

1.1 Introduction 1

1.2 Literature review $\quad 5$

$\begin{array}{lll}1.3 & \text { Methodology } & 17\end{array}$

$1.4 \quad$ Contributions and importance of study 20

1.5 Outline of dissertation 26

Chapter Two: Theoretical Framework 36

$2.1 \quad$ Definitions: "Regions", "regionhood" and "recognition" 37

$2.2 \quad$ Personhood: Recognition discourse within a society of individuals 43

2.3 Statehood: Recognition discourse within a society of states 52

$2.4 \quad$ Regionhood: Proposed model for the recognition of regions 58

$2.5 \quad$ Hypotheses and expected outcomes 69

Chapter Three: Misrecognition and Non-recognition of ASEAN 74

3.1 ASEAN and Southeast Asia: The challenge of rival regional groupings 77

3.2 ASEAN and Southeast Asia: The restriction on membership 88

3.3 ASEAN and the communist powers 93

$\begin{array}{ll}3.4 & 104\end{array}$

$3.5 \quad$ Non-recognition of ASEAN 115

Chapter Four: Australia and Japan's Recognition of ASEAN 121

$\begin{array}{lll}4.1 & \text { ASEAN's economic identity } & 124\end{array}$

4.2 ASEAN-Australia: Denial of entry into ASEAN and non-recognition 126

4.3 ASEAN-Australia: The push for a wider regional grouping 132

4.4 ASEAN-Australia: The beginning of recognition 138

4.5 ASEAN-Japan: The struggle for Japan's recognition 143

4.6 ASEAN-Japan: Malaysia's regional approach to solving national problems 150

4.7 ASEAN-Japan: The first ASEAN Summit 155

4.8 ASEAN-Australia and ASEAN-Japan: In retrospect 164 
Chapter Five: EEC and U.S. Recognition of ASEAN

$\begin{array}{lll}5.1 & \text { ASEAN-EEC: The motivations for recognition } & 174\end{array}$

5.2 ASEAN-EEC: The struggle within ASEAN for recognition 177

5.3 ASEAN-EEC: The beginning of recognition 181

5.4 ASEAN-U.S.: The sway in U.S. non-recognition 189

5.5 ASEAN-U.S.: The beginning of recognition 194

5.6 ASEAN-U.S.: The consequence of incomplete recognition 206

$\begin{array}{lll}5.7 & \text { ASEAN-EEC and ASEAN-U.S.: In retrospect } & 217\end{array}$

Chapter Six: Conclusion 223

6.1 ASEAN's struggle for recognition: An overview 226

6.2 Recognition model for regions: A revisit 235

6.3 Recognition: A transformative process 243

6.4 Recognition: ASEAN in the $21^{\text {st }}$ century 249

6.5 Recognition matters: ASEAN's centrality in the regional architecture 256

$\begin{array}{ll}\text { Reference } & 261\end{array}$ 


\section{List of Abbreviations}

\begin{tabular}{|c|c|}
\hline ABC & ASEAN Brussels Committee \\
\hline ADB & Asian Development Bank \\
\hline AFTA & ASEAN Free Trade Area \\
\hline APC & Asia-Pacific Community \\
\hline APCAC & Asian Pacific Council of American Chambers \\
\hline APEC & Asia-Pacific Economic Community \\
\hline ASA & Association of Southeast Asia \\
\hline ASEAN & Association of Southeast Asian Nations \\
\hline ASPAC & Asian and Pacific Council \\
\hline EAC & East Asia Community \\
\hline EAEC & East Asia Economic Caucus \\
\hline ECSC & European Coal and Steel Community \\
\hline EEC & European Economic Community \\
\hline EU & European Union \\
\hline FPDA & Five Power Defense Arrangement \\
\hline FTA & Free Trade Agreement \\
\hline G8 & Group of Eight \\
\hline G20 & Group of Twenty \\
\hline GATT & General Agreement on Tariffs and Trade \\
\hline GSP & Generalized System of Preferences \\
\hline ICJ & International Court of Justice \\
\hline IMF & International Monetary Fund \\
\hline JSG & Joint Study Group \\
\hline LDC & Least Developed Countries \\
\hline MEDSEA & Ministerial Conference for Economic Development in South-East Asia \\
\hline MFN & Most Favored Nation \\
\hline MTN & Multilateral Trade Negotiations \\
\hline NAA & National Archives of Australia \\
\hline NARA & National Archives and Records Administration \\
\hline OPEC & Organization of the Petroleum Exporting Countries \\
\hline PNG & Papua New Guinea \\
\hline SCCAN & Special Coordinating Committee of ASEAN Nations \\
\hline SEA & Southeast Asia \\
\hline SEAARC & South-East Asian Association for Regional Cooperation \\
\hline SEATO & Southeast Asia Treaty Organization \\
\hline SPCG & Southwest Pacific Consultative Group \\
\hline UN & United Nations \\
\hline UNGA & United Nations General Assembly \\
\hline
\end{tabular}


UNSC United Nations Security Council

USG United States Government

WB World Bank

WTO World Trade Organization

ZOPFAN Zone of Peace, Freedom and Neutrality 


\section{List of Illustrations}

Reference 1 Demand and Supply of Recognition 59

Reference 2 Acharya's Security Community Model 65

Reference 3 Proposed Model for the Recognition of Regions 67

Reference 4 The Transformative Process of Recognition 244

Reference 5 Milestones of U.S. Recognition - ASEAN versus EU 247 


\section{Acknowledgements}

The journey would not have been possible without the tireless guidance of my two academic advisers, Professor Shujiro Urata and Professor Takashi Terada.

A journey of a thousand miles begins with a single step.

The opening tribute goes to my venerable coach, Professor Terada, without whose encouragement and strong support, I would not have gathered the courage to make the intellectual voyage to Tokyo. I thank Professor Terada for believing in my research and showing me the way to arrive at academic excellence.

I had the privilege of learning from one of the brightest minds in economics. Words cannot express my heartfelt gratitude to Professor Urata who had been a kind and supportive mentor in this expedition.

I am also grateful to Professor Hatsue Shinohara for having me in her seminars and for her invaluable advice which motivated me to press on in this scholarly pursuit.

I thank the Government of Japan for awarding me the prestigious Monbukagakusho Scholarship (文部科学省奨学金) to undertake this expedition.

I thank my family and friends in Singapore for their love and support.

I am indebted to my wife, Michelle, for her unceasing prayers and for cheering me on each step of the way. She gave me strength to go the extra mile.

This marathon is dedicated to her.

Above all, I thank the everlasting God, the LORD, the Creator of the ends of the earth, for the power and the strength to run the distance and cross the finishing line.

"But they that wait upon the Lord shall renew their strength; they shall mount up with wings as eagles; they shall run, and not be weary; and they shall walk, and not faint." Isaiah 40:31 (KJV) 


\begin{abstract}
Does recognition matter for a region as much as it does for a state and a person? This dissertation ${ }^{1}$ examines the power of recognition in shaping regional cooperation. Rather than focusing on the behaviours and interactions between member states which most studies have done, the discussion introduces a recognition model to investigate how the social practices of a region with non-member entities promote regional cooperation. By viewing recognition as a tradable commodity and an independent variable, the framework illustrates how the contest for recognition permeates beyond inter-personal and inter-state interactions to include the struggle for recognition by regions. The model hypothesizes that the extent of recognition accorded to a region has an influence on its development. Drawing on newly released U.S. and Australian declassified diplomatic records, this dissertation tests out the soundness of the proposed model for the recognition of regions by analyzing ASEAN's struggle for recognition during its formative years in the 1960-70s with major powers, including the U.S., Soviet Union, Japan, the European Economic Community, China and Australia. The findings suggest that the strengthening of a regional concept is influenced by the willingness of, and the extent to which, foreign powers recognize the entity. The central theme of this dissertation is that external recognition plays an important function in the development of a regional concept.
\end{abstract}

Key words: ASEAN; East Asia; recognition; regionalism; regional cooperation; regionhood.

\footnotetext{
${ }^{1}$ A shorter paper based on the key thrusts of this dissertation has been accepted for publication in a UK peer-review journal. See Ong, B., Recognizing Regions: ASEAN's Struggle for Recognition, The Pacific Review (forthcoming 2012).
} 


\section{Chapter 1: Overview}

\subsection{Introduction}

In a telegram to the U.S. State Department on 18 February 1976, U.S. Ambassador to Indonesia David Newsom proposed for President Ford to sign off a congratulatory letter to be delivered to Indonesian President Soeharto, on the occasion of the first Association of Southeast Asian Nation (ASEAN) Summit Meeting on 23-24 February 1976, with the suggested text below:

Dear President Soeharto,

The first meeting of ASEAN Chiefs of Government in Bali is an event of historic importance. On this occasion I would like to convey through you, as host for the conference, my best wishes to each of the assembled leaders and my sincere hope that their deliberations will yield many positive benefits to the peoples of the ASEAN nations.

Sincerely,

Gerald R. Ford

(U.S. Embassy in Jakarta 1976a)

The proposed presidential message was never delivered to ASEAN. After careful considerations, Washington decided against dispatching the congratulatory note to ASEAN. The U.S. State Department (1976a) explained that its decision not to send the letter was based on "various factors including our awareness of ASEAN concern over its non-aligned image and counter-point of our not wishing to appear 
overly aloof". Crossing over to the other side of the Pacific, the Government of Japan was also trying to ascertain if its closest allies like Australia, New Zealand and the U.S. would be extending a congratulatory message to ASEAN in the weeks leading to that inaugural Summit. How did the question of whether to send such a simple congratulatory letter to the Southeast Asian grouping, formalized more than 10 years ago in 1967, become such a controversial and political decision?

What is at stake here are the effects that such political acts of recognition, in this case, the dispatch of a congratulatory letter, have on the development of regional concepts like ASEAN and how such external recognition or actions influence the attitudes and behaviors of member states within the grouping, as well as that of other external actors toward the entity.

The role and power of recognition is an area which has been largely neglected in the study of regional cooperation. Between states, international law looks at how recognition of a prior-state confers legal status and international personality. International politics also shows how the process of recognizing states has been exploited by great and small powers alike as a form of diplomacy tool. A case in point is the recognition (or non-recognition) of Taiwan. Between people, sociologists and philosophers highlight the pivotal role recognition plays in shaping the identity and development of an individual. Given the centrality of recognition theory in these fields, there is a notable dearth of research on how recognition affects the growth of regional entities. 
With this background, the key research question this dissertation aims to address is: How does external recognition influence the development of a regional concept? In the last two decades, Asia was at the receiving end of a tirade of regional jargons, beginning with Malaysian Prime Minister Mahathir Mohamed's East Asia Economic Caucus (EAEC) in the 1990s to Japanese Prime Minister Yukio Hatoyama's East Asia Community (EAC) and Australian Prime Minister Kevin Rudd's Asia-Pacific Community (APC) proposals in the 2000s. As history unveils, these regional concepts became water under the bridge. They are reminders that not all regional ideas come into fruition. Over time, even those that are formalized (through a declaration or other more formal processes) risk losing their appeal or raison d'être. The short-lived Association of Southeast Asia (ASA), comprising Malaya, the Philippines and Thailand, created in 1961 but dissolved a few years later illustrates the vulnerability of regional concepts.

In contrast to such regional ideas, the notion of states, nationhood or statehood in international relations is significantly more resilient. Walt (1979: 95) reminds us that the "death rate among states is remarkably low" and adds that "ff]ew states die; many firms do". Regional institutions or concepts may be added to the long list of commercial corporations which have failed. In this regard, why do some regional entities display more tenacity to survive while others pass on? How do we explain the longevity of some regional ideas over others? On the acclimation of a regional concept, Terada (2003: 254) writes:

In order to build a regional institution, there must be a consensus or, at least, loose agreement among the potential members on the concept of the region. If there were a move to create a new regional institution with a fresh combination 
of countries, acclimation of the new regional concept may be necessary... Accordingly, a period of acclimation to the new regional concept through the socialization of the concept through such means as official diplomacy, academic or business gatherings, social publications and speeches may be necessary. All the same, there are factors which can encourage the countries within a 'region' to accelerate their acceptance of such a concept.

Evidently, the receptivity of members toward the expressed regional concept is a crucial element to consider. Equally important, but less discussed, is the recognition and acceptance of a regional idea by non-members or external actors, which is the theme of this research. This is not a cursory matter considering that the wielding of recognition by great powers in the past had stalled or brought down initiatives for regional cooperation. A case in point is U.S. strong pronouncements against Japan's proposal in 1997 for the creation of an Asian monetary organization, which was envisaged to be modeled after the International Monetary Fund (IMF). While the acclimation process between members is essential, this dissertation argues that the degree of external recognition also has a direct influence on the way and manner in which a regional concept or entity develops. Departing from the traditional frameworks used by most political-economy theorists, it proposes a fresh analytical model based on the concept of recognition to explain the evolution of regional cooperation. By using ASEAN as a case study and analyzing the Southeast Asian grouping's development during its founding years, the empirical evidence based on source materials from archives of diplomatic telegrams reveals that the strengthening of a regional concept also depends on the willingness of, and the extent to which, non-members acclimate to the regional entity. In short, external recognition and 
socialization with non-members matter as much as the internal process of acclimation between members of the regional grouping.

As an outline, the section immediately following this introduction summarizes the main scholarships heretofore as regards the motivations behind inter-state collaborations and regional institutions with a focus on regional cooperation in Southeast Asia. The rest of the chapter explains the data collection process and methodology of this dissertation (Section 1.3) before detailing how the ensuing findings contribute to the current pool of literature on regional cooperation and ASEAN (Section 1.4). The final section presents the flow of this dissertation, and outlines the main arguments in the respective chapters (Section 1.5). The repeated theme in all the chapters is on the role of external actors and how their recognition (or non-recognition) has affected the development of a regional concept like ASEAN.

\section{$1.2 \quad$ Literature review}

This section reviews the main arguments and key assumptions in current literature on the motivations behind regional cooperation and institutions with a special emphasis on ASEAN given that it is the case study chosen for this dissertation. The vast amount of scholarly works that have been written about inter-state cooperation (especially on ASEAN), in addition to the constraint of space, does not permit the author to tease out the scholarly debate on regional cooperation in its entirety. Rather than casting the net too wide, the discussion here draws out the main ideas in past and current discussion on regional cooperation with two objectives in mind. First, the literature review outlines the independent variables proposed by the main stream 
scholars on inter-state cooperation and on the formation of regional institutions. It highlights the weaknesses of their respective frameworks and how their assumptions have been challenged by the critics. Second, the discussion identifies the connection between their arguments and the way the latter has been used to describe, if not account for, cooperation in ASEAN by their proponents. This organization enables the author to identify the key gaps in ongoing debate on regional cooperation, especially in Southeast Asia, before addressing how the theme and findings of this dissertation contribute to the current discourse in Section 1.4.

Beginning with the realist paradigm, Waltz (1979: 105) assumes that states "worry about their survival, and the worry conditions their behavior". States are driven by self-interests because the international system is fundamentally "decentralized and anarchic" and has no "agents with system-wide authority" (Waltz 1979: 88). In the absence of such an organized and hierarchical structure in international politics, states cooperate only to increase the likelihood of their own survival and to obtain maximum national benefits from participating in regional institutions. On the latter, the realist proponents make a clear distinction between relative and absolute gains. They argue that a state is concerned with "a division of possible gains that may favor others more than itself" (Waltz 1979: 106). In other words, a state chooses cooperation only if it has more to gain than other states. On the former, Mearsheimer (1994: 7) finds that, given a state's fixation on national survival, "institutions have minimal influence on state behavior". The limitations of cooperation apply to not just the smaller states, but to the stronger and more powerful ones as well. To account for great powers' interest in regional cooperation, realist commentators explain that "institutions are set up to serve the interests of the powerful, who adhere to 
institutional rules and norms only when it suits them to do so" (Garofano 2002: 505). With this background, the question is: How has such a pragmatic and nationalistic framework been used by scholars to account for cooperation in ASEAN?

Realists are skeptical about cooperation among Southeast Asian countries and accuse ASEAN of failing to resolve many issues because member states were unwilling to set aside their national interests. The strong resistance of ASEAN members toward the creation of a supranational authority has often been cited by this group of scholars as a clear manifestation of the overarching principle that national interests take precedence over regional ones in the Association. The revelation by Filipino Ambassador Rosario Manalo (2010: 44), who chaired the task force which drafted the ASEAN Charter, that "there had been a general tendency to create a Charter that will keep the inter-governmental character of ASEAN and dispel any suggestion of creating a supra-national body" attests to the reluctance of member countries to place regional interests before national ones. Writing more than two decades ago, Leifer (1989: 153) has already observed that ASEAN "governments have viewed their participation in terms of how their separate interests might best be served". As an institution, ASEAN therefore has no power to influence member states' preoccupation with their national interests. From the realist perspective, "ASEAN is productive when states' interests coincide; when they do not, the organization can, at most, create only the appearance of unity" (Narine 1997: 965). As a result, ASEAN can only progress at the pace of the "lowest common denominator" and its members cannot "push the institution beyond what it can sustain" (Narine 2002: 33). In the realist paradigm, "sovereignty is a necessary constant" (Barkin and Cronin 1994: 108). However, such pragmatic views about the centrality of national interests in 
inter-state cooperation and in ASEAN are rejected by their liberals and constructivist counterparts.

Contrary to the realist school, the liberals argue that genuine cooperation is possible because increasing interdependence has created complementary interests among nations and raised the transaction costs of doing business between states. Koehane and Nye (2001: 8) explain that where "there are reciprocal (although not necessarily symmetrical) costly effects of transactions, there is interdependence". Through cooperation, institutions serve as a means to reduce transaction costs and to facilitate discussion, negotiation and agreement among countries. In an earlier study, Koehane (1984: 244) finds that institutions create the conditions for orderly multilateral negotiations, legitimate and delegitimate different types of state action, and facilitate linkages among issues within regimes and between regimes. They increase the symmetry and improve the quality of the information that governments receive.

According to the liberals, institutions provide the formal settings for agreements to be reached, which in turn lower the transaction costs of all member countries. In contrast to their realist counterparts, the liberals place a premium on the value of absolute gains over relative gains. Cooperation is desirable as long as it increases the welfare of all states. The liberals are doubtful about the realist inference that relative and absolute gains can be neatly calculated. Cost-benefit assessments in most issues negotiated by a group of countries are often not as clear cut as they seem. Even in the area of trade liberalization, there is no foolproof method of assessing which state has the most to gain from such economic pacts considering that they impinge on other national interests such as how such agreements affect the 
socio-cultural strata of the society, existing geo-political relations with non-signatory countries or electoral votes and support for the ruling party. Koehane (1998: 88) therefore questions the practicality of the realist assumption and counter-proposes that "states can be expected most of the time to seek to enhance their own welfare without being worried that others will also make advances". Put another way, states will cooperate with one another as long as they have something to gain from the collaboration. As for the interest of great powers in regional cooperation, the liberals explain that cultivating "information-rich institutions" is regarded as an important step toward confidence-building in the "relations among the superpowers" (Koehane 1984: 247).

From this vantage point, ASEAN works because member states "agree on policies that they believe benefit all even if these benefits are not distributed equally" (Simon 1995: 8). According to Simon (1995: 7), the Southeast Asian grouping is "designed to share benefits among participants". The question of which state has more to gain is irrelevant. Critics, however, point out that ASEAN states "continued to think in balance-of-powers terms rather than in those of the neoliberal paradigm" and that "cross-border interaction rarely entered this equation" (Moller 1998: 1100). They argue that the assumption by the liberals that interdependence motivates cooperation is questionable to begin with. The relatively low level of intra-regional trade among the ASEAN countries reinforces such a perspective. Shee's (1977: 761) analysis of ASEAN's trade volume during its formative years finds that the grouping's "intraregional trade declined from $18.3 \%$ in 1966 to $12.8 \%$ in 1974 ". This finding is corroborated by a later study which confirms that "intra ASEAN trade as a percentage of total ASEAN trade declined from $15.5 \%$ to $12.6 \%$ during the period 
1970-1975" (Khaw 1992: 39). The declining rate of intra-ASEAN trade even during the founding years of ASEAN therefore challenges liberals' claim that regional cooperation is driven by members' desire to reduce transaction cost as a consequence of increased interdependence. In another vindication of the perceived low level of intra-ASEAN interdependence, Thai Foreign Minister Thanat Khoman (1986: 10), one of the founding fathers of ASEAN, concedes that the results of economic cooperation among ASEAN members were "not particularly impressive" from the start. Notwithstanding the theoretical divide between the liberals and realist perspectives, the constructivist scholars on ASEAN would later mount the strongest challenge against their respective themes on national survival and state interdependence.

The constructivist perspective argues that norms or ideas about cooperation are the most crucial independent variables which motivate countries to work together, rather than national interests or the degree of inter-state dependency. By observing the European integration process, Deutsch and his team are the first to argue that a community can be created if there is a sense of a "we-feeling":

The kind of sense of community that is relevant for integration, and therefore for our study, turned out to be rather a matter of mutual sympathy and loyalties; of "we-feeling", trust, and mutual consideration; of partial identification in terms of self-images and interests; of mutually successful predictions of behavior, and of cooperative action in accordance with it - in short, a matter of a perpetual dynamic process of mutual attention, communication, perception of needs, and responsiveness in the process of decision-making (Deutsch et al. 1957: 123). 
However, the concept of "we-feeling" was not crystallized until Wendt points out that a group of states learns to think of themselves as "we" as they internalize a group identity over time. Critically, constructivist scholars reject the realist underlying assumption, which is also accepted by the liberals, that anarchy leads to a self-help world, contending instead that it is the "collective meanings that constitute the structures which organize our actions" (Wendt 1992: 397). For the constructivists, anarchy is just one of many possible conditions in world politics. Instead, these scholars underline the primacy of norms in the creation of new scenarios, including the more cooperative archetypes, through a course of socialization between states. According to Wendt (1992: 405), "the process of signaling, interpreting, and responding completes a "social act" and begins the process of creating intersubjective meanings". Repeated interactions, in turn, provide an avenue for the internalization of norms of behaviors, and contribute to the development of a group identity. At the core of the constructivist proposition is the inter-relationship between interests and identities as Wendt (1999: 231) explains: "Without interests, identities have no motivational force, without identities interests have no direction". This means that a state is capable of assuming both a national and a regional identity. The successful cultivation of a new (or regional) identity therefore creates new (or common) interests between states. Such a perspective is a direct challenge to the realist's assumption on the primary of self-interest. The internalization of a common identity by a group of states over time implies that "members will no longer be selfinterested relative to each other with respect to the issues that define the group" (Wendt 1999: 242). 
For ASEAN, Acharya's writings are representative of the constructivist school. The emphases are on the norms of cooperation and how ideational factors may influence inter-state relations. ASEAN works because the process of socialization between member states helps them to internalize shared norms and foster a common identity. Institutions are important because they "provide crucial settings within which states develop their social practices and make them understood, accepted and shared by others in the group" (Acharya 2009: 9-10). Acharya (2009: 1) uses the concept of security community to describe ASEAN which he defines as "states which have developed a long-term habit of peaceful interaction and ruled out the use of force in settling disputes with other members of the group". Of late, there are several variants to the constructivist arguments. Instead of focusing on the norms of cooperation, $\mathrm{Ba}$ (2009: 29), for instance, maintains that "[i]deas are critical to explaining ASEAN regionalism... ideas are especially useful in helping to explain why diverse and divergent states, as ASEAN state have been, would pursue regionalism as a response to their problems". According to Ba (2009: 65), ASEAN states were willing to share the "idea of [a] region that was nationalist and regionalist at the same time". In this interpretation, ASEAN works because its members believe in the idea of "regional resilience" which is the understanding that regional unity "legitimates" national politics, but is "subordinate" to national interest (Ba 2009: 96). In this sense, the constructivists' focus is all about the intangibles of inter-state relations. The way member states envisage, discuss, talk and think about dealing with one another within an institutional framework can be in itself a catalyst toward promoting greater regional cohesion and cooperation. Scholars on ASEAN like Caballero-Anthony (2005: 43), before she became the director overseeing ASEAN Secretariat's external relations, therefore concludes that "what the constructivist approach offers is a 
broader understanding of ASEAN as a dynamic and changing organization, something which the two other approaches [realist and liberals] are not fully able to do". Despite its pro-institutionalist appeal to scholars and policy-makers, constructivism has not been without its critics.

The constructivist emphasis on the creation of inter-subjective meanings through socialization has been a subject of intense criticism as may be gleaned from Beeson's (2007: 253) rather polite observation that "the process of confidencebuilding, socialization and norm construction may be a bit difficult to quantify". Its harsher opponents have called into question the predictability power of the constructivist model given the lack of hard evidence to prove the prevalence of norms or ideas in inter-state relations. Hamanaka (2009: 16), for example, points out that constructivism "does not predict what kind of region is to be imagined beforehand" and that it "predicts nothing beforehand" but "explains everything in hindsight". The proliferation of the many strands of constructivist scholarship in recent years has prompted Jones and Smith (2006: 5) to describe these scholars as a group of "delusive" regional experts on Southeast Asian studies who "maintains and reinforces belief systems, no matter how misguided they may be". Rather than giving concrete evidence to prove the existence of an ideational or normative ASEAN, it is as though these scholars are themselves ideating about what ASEAN is all about in the hope to realize such a self-belief through the propagation of their works. Tan (2009: 123) therefore concludes that constructivism in the study of Southeast Asian studies has failed because it treats "subjectivity" as a given. More substantially, Narine's (1997: 974) research finds that "ASEAN's growth as an institution was motivated only minimally by internal considerations" which opposes constructivist claims about the 
importance of ASEAN's intra-mural relationship. According to this explanation, constructivists misjudge the historical, external and structural environment under which ASEAN has developed because member states themselves "recognized the benefits of creating the appearance of a unified front when dealing with external actors" (Narine 1997: 975). Opponents of constructivism also take issue with the fact that constructivist studies have not shown how cooperation in ASEAN has benefited Southeast Asia, highlighting instead the fragility of the grouping to overcome real problems affecting the region. Jones and Smith (2006: 72), for instance, suggest that ASEAN

can make no decisions and enforce no rules. ASEAN is, then, an imitation community. ASEAN, moreover, is not a modish constructivist project, as its apologists often claim. It cannot even sustain an 'ideational' discourse of regionalism, which believes that only to 'imagine' a community is to have it somehow materialize. It is an anti-constructivist project.

In summing up the theoretical divide between realists and constructivists, Eaton and Stubbs (2009: 10) point out that their empirical disagreement is due to the different interpretations of power and time perspectives. According to Eaton and Stubbs (2009: 25), realism assesses "ASEAN's worth against its present inability to coerce other regional or international actors" while constructivism views "power as essentially the ability to act in a concerted way". They explain (2009: 27):

If ASEAN's actions are viewed through the neo-realist lens of power as coercion or dominance then the Association is not seen as powerful. If, however, ASEAN's actions are viewed in constructivist terms as the ability to act, including the ability to generate norms that define and regulate the behavior of 
the Association and its members, then ASEAN can be thought of as relatively powerful.

The preceding literature review highlights the key ideas and criticisms in main stream scholarships on regional cooperation and institutions. While it is not possible to sketch out their arguments in more details given the limitation of space, the brief discussion nonetheless has highlighted the tendency in existing scholarship, including in the literature related to ASEAN, to account for regional cooperation based on the analyses of why and how members cooperate with one another in the grouping - whether they be the case of member states working with one another because of national interest, increased interdependence or a belief system of norms and ideas. Overall, existing scholarship on regional cooperation focuses on addressing overwhelmingly one side of the equation, which is, why member states cooperate with one another in ASEAN. In other words, there is no or very little discussion on whether and how non-members can influence the development of regional cooperation, which is the theme that this dissertation is investigating. While not explicit, such frameworks assume that non-members have little or no role to play in shaping regional cooperation in ASEAN. For example, the security community model, as described by Acharya (2009: 21), "implies a relationship of peace and stability among a group of states without any sense of how they might collectively relate to external actors". Such a conclusion about the limited influence of external actors over the development of a regional concept warrants a deeper investigation.

On closer examination, however, scholars on ASEAN from the respective camps and their critics have acknowledged the importance of external powers' attitude toward a 
regional concept although there have been no attempts to incorporate such exogenous elements in their models to account for why and how non-members can influence regional cooperation. Realist scholars on ASEAN, for example, concede that the Association "appeared effective because its actions coincided with superpower interests" and that "ASEAN was actually a convenient front for external actors and interests" (Jones and Smith 2006: 55). Of greater significance is Leifer's (1989: 86) acknowledgement that the "more that regional and external states brought ASEAN within the compass of their calculations, the more its member governments responded by conducting themselves as if they were part of a diplomatic community". Leifer (2009: 220) would assert, in his later writings, that ASEAN was "an acceptable interlocutor to all the major regional powers". While the existing frameworks fail to explain in details how external influence affects internal behaviors, there is a strong consensus in both realist and constructivist scholarships that the degree of cooperation in ASEAN is at least responsive to how the association is being perceived externally. The academic inquiry then is to understand whether and how external actors are able to stimulate or retard the development of a regional concept. Similar to their realist counterparts, constructivists like Acharya and $\mathrm{Ba}$ also recognize the significant of external actors although their frameworks do not address the impacts of such exogenous elements. On extra-ASEAN relations, Ba (2009: 236) acknowledges that "members also viewed ASEAN, even during its earliest years, as providing an important framework with which to deal with the outside world". Alluding to the critical role of external actors on regional cooperation, Acharya (2009: 192193) also concedes that the "fortunes of regional organizations throughout the world have risen and fallen depending on how they have related to extra-regional actors". Put simply, the frameworks proposed by the main stream scholars heretofore do not 
adequately explain how exactly external actors have shaped ASEAN's development, focusing instead their arguments on intra-grouping interactions whether they be based on the concepts of national interest, interdependency or norms. Even if these independent variables are indeed the key considerations of member states in their dealings with one another within a regional grouping, it raises the logical academic question as to whether the same considerations are also prevalent in the grouping's interaction with non-member states. Section 1.4 will elaborate further on the

contributions of this dissertation to current discourse while outlining how the proposed framework and findings will cover such a research gap on regional cooperation. The next section details the methodology and data-collection methods used in this research to support its arguments.

\subsection{Methodology}

The period of this analysis covers the formative years of ASEAN from its establishment in 1967 to its institutionalization in 1976. The methodology adopted in this dissertation is content-analysis, of which the bulk of the analyzed data is drawn from 3,172 declassified diplomatic records recently released by the U.S. government through the National Archives and Records Administration (NARA), in addition to 5,634 pages of official documents (mainly diplomatic folders and telegrams) made available by the National Archives of Australia (NAA). NARA and NAA are the respective U.S. and Australia national agencies responsible for the preservation and maintenance of official documents that records important events in the country. Due to the close relations and frequent sharing of diplomatic notes between the Australian 
and New Zealander governments, the Australian archives also comprised several useful official documents originating from Wellington.

Archives provides a "rich and complex understanding to the political sphere, an understanding that is necessary in order to engage in theorizing about political questions" (Hazareesingh and Nabulsi 2008: 150). However, the archival collection of this research is confronted with two challenges. As with all archival projects, the first hurdle is the minimal duration (usually 30 years) imposed by the respective archival authorities before any documents may be declassified and released for public scrutiny. The focus on the period from 1967-1976 is to some extent limited by the availability of raw archival data. For example, as of August 2011, NARA has declassified and released documents on matters pertaining to U.S. foreign policy up to the year 1976. Second, even if the information has met the release dateline, not all documents in the period are declassified. The most sensitive national records are naturally exempted from disclosure under the U.S. Freedom of Information Act and the Australian Archives Act. Some records are also withheld even if they have fulfilled the 30-year mark to avoid likely embarrassment or other possible impacts to personalities who are still alive. The Australian archival regulation of 1983 also exempts the disclosure of diplomatic folios which affects the security and international relations of the country, compromises on intelligence operations or breaches the sharing of information in confidence by a foreign government.

Notwithstanding the inaccessibility to the complete set of primary data, the rigorous and stringent process of vetting undertaken by NARA and NAA implies that only the most relevant information are kept. According to NARA (2011a), of all the 
"documents and materials created in the course of business conducted by the United States Federal government, only $1 \%-3 \%$ are so important for legal or historical reasons that they are kept by us forever". Similar to the Australian Department of External Affairs, all the archives retrieved from NARA in this research are created by the U.S. Department of State "to facilitate the conduct of American foreign relations by the Secretary of State, American Ambassadors in foreign countries, and other employees of the Department of State" (NARA 2011b). This means that records which fulfilled the criteria for release by NARA and NAA comprise information that offers valuable insights into the country's foreign policy considerations.

To the extent possible, the use of secondary sources in this research has been avoided in order to present the facts and events of history as they are. The goal of such stringency in the selection of source materials is to ensure the objectivity of the analysis to the best it can. To be sure, it would have been much easier to anchor the arguments of this dissertation by drawing on all available resources, including secondary sources or third-party reports, given that so much has been written about ASEAN in its more than 40 years of existence. By resisting the urge to fall back on arguments put forth by secondary or third-party sources, the aim is to present the developments and argue the case as the events happened. Indeed, the advantage of this archival research through the use of newly released cables has confirmed the prevalence of biases in some of the early studies on ASEAN and identified several errors to actual events which took place in some cases. It is for this reason Jones and Smith (2006: 22) recognize that "there are those whose work in hindsight affords a more accurate interpretation of its object of concern". Finally, any remaining information gaps or discrepancies are corroborated with primary data from first- 
person accounts and news sources published during the period of analysis (400-500 articles). In this case, the National Library of Singapore with its rich database of digitalized newspaper reports on ASEAN has been an extremely useful data source.

\subsection{Contributions and importance of study}

This dissertation makes two key contributions to current works on regional cooperation in Southeast Asia. As highlighted in Section 1.2, there is a stark gap in existing scholarship on how external actors or non-members may influence cooperation in a regional grouping like ASEAN. Broadly summarized, existing literature on ASEAN uses conventional frameworks which rely on national interest, interdependence or norms as the key independent variable to account for the progress of cooperation in the grouping. While some of these analyses have attempted to explain great powers' interest to participate in a regional structure, their theoretical approaches, in general, have not taken into account adequately the influence that non-members or external actors has on the development of a regional concept like ASEAN. Does the absence of a great power or a particular country in the membership of a regional entity imply that it is powerless to influence its development? The empirical evidence of this research suggests otherwise. Critically, the scholars highlighted in Section 1.2 have also not denied the influence that nonmembers may wield on a regional idea although their frameworks have not dealt with the issue.

Therefore, the first of the two main contributions in this dissertation is to cover such a gap in current discourse by elucidating the role and power of external recognition in 
shaping the development of regional concepts - an area which has been overlooked in the study of regional cooperation. This requires the construction of a fundamentally different model in order to account for the relationship between member states belonging to a regional entity and the external actors, and how recognition is traded between both sides. The study offers a new analytical framework to examine the role of recognition in regional cooperation. By viewing recognition as a tradable commodity and an independent variable, the analysis shows how the demand for and supply of recognition permeates beyond inter-personal and inter-state interactions to include the struggle for recognition by regions. The aim is to piece together a coherent recognition model to understand how foreign powers' reactions to a regional concept affect the latter's development. This is not to deny the importance of other variables such as norms, interdependence or national interests, but to allow this research to focus on recognition as the main parameter in assessing its viability as an impetus for regional cooperation. In addressing causation issues in international relations, Kurki (2008: 280) argues that

we should not treat causal forces as 'separable' and 'independent' but must always relate different kinds of causes to others. The key question becomes, not which factor matters more than another 'independently', but how and why the factors are interlinked.

By accounting for the motivations of why powerful states recognize some regional concepts but not others and why member states pursue such recognition, the discussion assesses the impacts that recognition has on the development of a regional concept. Further, the proposed theoretical framework in this dissertation is able to capture the compounding effect of causes. In other words, it addresses the 
effects, if any, of country X's recognition of a regional concept have on country Y's recognition policy and so on. Kurki (2008: 281) explains that

we need to search for 'compound explanations' and to get away from the idea that explanations that emphasize different causal factors (materials, ideational, structural, agential) should be conceived as in competition with each other... [A]nalyses that take as their starting point the examination of single variables and measure their effects, without consideration of the causal contexts of these factors, are bound to provide unnecessarily narrow accounts that cannot be sustained by evidence.

In addition to the fact that states may be driven by different motivations or causes in their recognition decision on a regional concept, the model illustrates how cumulative recognition or what Kurki describes as "compounding effect of causes" has on the development of a regional concept. The objective is to measure the effects of a series of consecutive or simultaneous recognition by external actors on a regional concept or grouping. By doing so, the discussion moves away from traditional analyses on regional cooperation that focused solely on material or ideational factors. It offers a fresh theoretical framework to analyze regional cooperation, marking a major shift from traditional analyses.

Second, this dissertation is the first scholarly work on ASEAN based on newly released U.S. and Australian declassified diplomatic cables. Beeson (2007: 26) observes that all "states and societies are products of their particular historical circumstances"; a society of states coming together to forge an identity and to realize a regional concept is no exception. By scrutinizing historical documents during the founding years of ASEAN, the archeological exercise aims to unravel the reasons 
sustaining the longevity of the Southeast Asian grouping. As mentioned in the preceding section, the materials collected in this research are in the form of telegrams or cables which reveal "official information about policy proposals and implementation, program activities, or personnel and post operations" by the respective foreign services (NARA 2011b).

The focus on the use of official cables, as highlighted in Section 1.3, in this research is intentional. Most works on international relations, in particular on regional cooperation, are based on what has been openly discussed or announced by national governments. In reality, what is externally said and internally discussed on any subjects by a national government, in particular on a sensitive foreign policy matter, can be quite different, as the findings of this dissertation will show. By contrast, cables or telegrams reveal the true nature of why countries pursue a certain set of foreign policies because there is no reason for a diplomat in a foreign country to feed back to the home country information which does not help in foreign policy planning. The heavy reliance on telegram reporting by diplomats in the formulation of national foreign policies is evident from the following remarks by the U.S. Department of State:

Our diplomats are just that, diplomats. They represent our country around the world and engage openly and transparently with representatives of foreign governments and civil society. Through this process, they collect information that shapes our policies and actions. This is what diplomats, from our country and other countries, have done for hundreds of years (The New York Times 2010: A1). 
In other words, cables or telegrams detail and reveal the real motivations and considerations of what government apparatuses had in mind when they made those policies. For example, in the case of the U.S. archives, the materials used in this research relate to "all aspects of American bilateral and multilateral foreign relations and routine administrative and operational activities of the Department of State and its Foreign Service posts" (NARA 2011b).

As of February 2012, there are only a handful of scholarly works on regional cooperation which are based on the use of internal government documents. Acharya (2009), Tarling (2006) and Thompson (2011) are the only three other known scholars who have utilized diplomatic records extensively to interpret regional cooperation in Southeast Asia. The first two scholars, however, utilized archives made available by the British Foreign \& Commonwealth Office in their studies. In brief, Acharya's analysis of the British diplomatic records laid the foundation of his security community concept. (Acharya's framework will be elaborated in Chapter 2). Tarling's (2006: 215) historical narrative, on the other hand, led him to conclude that ASEAN "has been shaped and reshaped over time in largely creative response to changing circumstances, economic and political, in the wider world". Finally, Thompson's archival analysis only relates to the immediate post-war period from 1945-1967, and explains the reason for the genesis of Southeast Asian cooperation; it discusses the events leading to the formation of ASEAN but not the actual development of ASEAN, which is the theme of this research. Thompson's analysis (2011: 76) shows that "Western interest and influence" were "vital in influencing the move towards closer regional integration" in Southeast Asia. 
The two key distinctions separating this archival research from the three earlier works are, first, its unique reliance on the U.S. and Australia archives; and, second, its focus on the founding years of ASEAN from 1967-1976, as opposed to the formation of ASEAN. Following the tradition of such historical theorizing, this dissertation offers a new perspective to understand regional cooperation in Southeast Asia by building upon "what actually happened" (Tarling 2006: 226). In this case, the decision to advance the arguments in this dissertation based on U.S. and Australia archival records is intentional because the U.S. government has always been wary of the creation of new regional groupings or sub-groupings in Asia. For example, in a telegram to the ASEAN-5 ambassadors (comprising Indonesia, Malaysia, the Philippines, Singapore and Thailand) in January 1975, U.S. State Secretary Henry Kissinger instructed:

Department has continuing interest in receiving current information on the activities of ASEAN, including reports of any significant meetings of ASEAN sub-groups. At the same time, we hope embassies can continue their valuable reporting on host country attitudes toward general question of regionalism in East Asia (U.S. State Department 1975a).

The Australian government, on the other hand, has also maintained a deep interest in monitoring the formation of regional groupings and pushing for its inclusion in any Asian forums. An internal Australian policy planning paper in 1969 confirms that Australia consulted widely with ASEAN states "to ensure that Australia would not be excluded from any process of international consultation that might take far-reaching decisions affecting the future stability of the region" (Australian Department of External Affairs 1971a). The extent and fullness of the reporting by both the American and Australian diplomats on the formation of regional groupings, to be discussed in 
the next few chapters, illustrate the priority that the two governments have given to the issue of regional cooperation in Southeast Asia. The analysis of the newly released declassified diplomatic records in this research affirms that the strengthening of a regional concept like ASEAN depends very much on the willingness of, and the extent to which, non-members like the U.S. and Australia interact with the regional entity. Before going into the theoretical approach and empirical findings, the final section of this introductory chapter summarizes the flow of the discussion in this dissertation.

\subsection{Outline of dissertation}

This section outlines the plan for this dissertation. The next chapter presents the theoretical framework of this research by employing current recognition theories on personhood and statehood to elucidate a recognition model for regions. The purpose is to understand the motivations of both claimant and recognizing entities, and the methods employed in the struggle for recognition. The discussion begins by proposing the inclusion of "regions" as the unit of analysis in the study of regional cooperation. As mentioned in the earlier section, the theorizing on why states cooperate, heretofore, has focused on the primacy of state as the main actor. Accordingly, their positions and aspirations are revealed through the respective national governments. Chapter 2 makes the case that the voices and actions of "regions" are conveyed through the representative regional institutions. The key issue here is not how well a region may be represented by an institution, but which regional organization is regarded as the legitimate actor or messenger for a region at a given point in history. Chapter 2 also introduces "recognition" as an independent variable 
affecting the level of cooperation in a region, which is the dependent variable of this investigative study. By incorporating "regions" as the unit of analysis and "recognition" as the independent variable, the discussion proposes a new analytical model to interpret inter-state cooperation through institutions. The analysis in this chapter facilitates the conceptualization of a theoretical approach to examine the role of external recognition in regional cooperation.

The model proposed in Chapter 2 accounts for the reasons recognition is sought for by a region and offered by external actors, and how the outcome of such a contest for recognition may influence the extent of cooperation in a regional grouping. It finds that, for an aspiring region, recognition leads to material benefits and elevates status. In addition to the attainment of legal rights, recognition allows a region greater access to funding and commercial opportunities. It may also serve as a means to rectify a distorted image of the region portrayed by the international community, and reduce instances of unfair treatment by powerful states. Further, cumulative recognition increases the stability and prestige of the region. On the other hand, manipulating acts of recognition enables stronger states to maintain their preferred pattern of behaviors, dominate the region and entrench their hegemony. For powerful states, recognition policies are often affected by foreign policy considerations, domestic pressures or regional interests. These factors lead to an intense struggle for recognition between the region and the external actors. In addition, the framework also suggests that a region will try to harness public support and raise public awareness in its struggle for recognition. Based on the proposed model for the recognition of regions, the chapter concludes by presenting the hypotheses, assumptions and expected outcomes to be examined in the rest of the dissertation. 
Going back to the research question, the model hypothesizes that the degree of external recognition accorded to a region directly affects the level of cooperation between member states.

Drawing on newly released U.S. and Australian declassified diplomatic records, $\underline{\text { Chapter } 3}, \underline{4}$ and $\underline{5}$ assess the soundness of the proposed recognition model for regions by analyzing ASEAN's struggle for recognition during its formative years in the 1960-70s with major powers, including the U.S., Soviet Union, Japan, the European Economic Community (EEC), China and Australia. Why limit the discussion on ASEAN's external interactions to only these great powers but not other states? Instinctively, the effects of recognition by state actors are not equal. Hypothetically, the impact of U.S. policy of recognizing Republic of China cannot be the same as Tuvalu's recognition of the Taipei government. Far from it, the empirical data illustrates the importance of compounding effects that great powers' recognition has on the development of ASEAN based on the theoretical model proposed in this dissertation. Great powers, as defined by Zakaria (1986: 348), are countries which "are all external to the region, and yet each has the capacity to influence events in Southeast Asia". While not exhaustive, the external actors selected for analysis in these chapters possessed the greatest potential and capacity to influence ASEAN during the latter's formative years. The central question posed in these chapters is: Why did the great powers engage ASEAN if it was perceived to be an ineffective organization? In a cable to the U.S. State Department in 1976, for example, U.S. Ambassador to Singapore John Holdridge reported that "it seems apparent that any ASEAN/U.S. government forum may just degenerate into a formality at which we communicate on subjects on which we are already in contact" (U.S. Embassy in 
Singapore 1976a). For foreign powers like the U.S., it was clear that many of the issues pertaining to the region could be dealt with through existing bilateral mechanisms. In other words, there was no extenuating reason for the U.S. or other external actors to engage ASEAN as a regional grouping, but they did. In addition, these three chapters also account for why ASEAN countries adopted a strategy of engaging foreign powers through the grouping when they were at the same time also trying to reduce the influence of their former colonial powers as evident from Filipino Secretary of Foreign Affairs Carlos Romulo's plead in 1976:

To the great powers, we say simply: 'Please leave us alone. Kindly refrain from making South-east Asia an arena of your competing ambitions. All we want is to proceed unhampered with our own development' (The Straits Times 1976a: 1). By elucidating the reasons for the supply of recognition to ASEAN by the foreign powers, as well as the motivations driving ASEAN's demand for recognition, the discussion draws out the relevance of the proposed recognition model for regions in accounting for the level of cooperation in the Southeast Asian grouping.

Chapter 3 begins the discussion by addressing the ontological question as to whether ASEAN is a suitable unit for analysis in terms of the extent it represented the voice of the Southeast Asian region during its formative years. The analysis here is critical given that the very concept of a "Southeast Asian region" was a delicate and contestable one in the 1960-70s. What constitutes Southeast Asia? Why should regional cooperation be viewed through the lens of ASEAN? The five-member grouping's rejection of several parallel institutions including the ASA, its non-support for other proposed groupings and its careful selection of ASEAN members during its formative years strengthened its positioning as the authoritative voice of Southeast 
Asia. The analysis describes how ASEAN deliberately curtailed the composition of its membership despite external pressures to expand the grouping and the strong interests expressed by the governments of India and Korea to join ASEAN. More significantly, the chapter also addresses the geopolitical structure which affected considerably ASEAN's interactions with both the anti-communist powers and the communist bloc. It highlights the importance of structural changes and ideological differences which guided the calculations of ASEAN and those great powers which had a stake in the region. Here, the discussion examines how communist powers like China and Soviet Union viewed and dealt with ASEAN in relations to the grouping's struggle for recognition. The final section of the chapter addresses the failure of ASEAN's first attempt at seeking external recognition for the region through a proposal for a zone of neutrality. The empirical evidence in Chapter 3 reveals that foreign powers from both the communist and non-communist blocs, in particular the U.S., resisted the recognition of ASEAN to maintain their hegemony by persistently projecting an image of inferiority toward ASEAN during the grouping's formative years. In addition to their refusal to acknowledge the zone of neutrality, the archival evidence suggests that countries like the U.S. made a considered decision not to engage ASEAN as a collective unit in international forums such as the United Nations (UN). The research also finds that, since the formation of ASEAN in 1967, the foreign powers, especially the U.S., repeatedly emphasized and portrayed an image of inferiority to the Southeast Asian countries. Such images of inferiority began to be internalized by the ASEAN states, and reinforced the post-colonial view that Southeast countries were too fragile to reduce their reliance on the Western powers as highlighted in the proposed model of this dissertation. 
The next two chapters account for why cooperation in ASEAN continued to develop despite foreign powers' refusal to recognize the grouping in the political realm, as evident in the latter's rejection of the zone of neutrality and refusal to deal with ASEAN as a whole unit in international forums. Given the central theme of this dissertation that external recognition matters in the development of a regional concept, $\underline{\text { Chapter } 4}$ and $\underline{5}$ account for why ASEAN's initial failure to obtain recognition through the promotion of the zone of neutrality did not lead to its disintegration. Instead of attributing ASEAN's survival to the grouping's unique intra-mural relationship based on a set of norms known as the "ASEAN Way" which has been prescribed and developed by several scholars, the discussion highlights the importance of ASEAN's socialization with foreign powers. It challenges the assumption by these scholars that external actors have no role to play in the development of ASEAN as presented in Section 1.2 of this introductory chapter. The findings in $\underline{\text { Chapter } 4}$ and $\underline{5}$ reveal how ASEAN's success in obtaining recognition from Australia, the EEC and Japan on the economic front in turn swayed U.S. recognition decision on ASEAN. The empirical evidence highlights the importance of cumulative recognition and reveals how the process motivated member countries to increasing view ASEAN as a regional approach to solving national problems, rather than regional ones. The empirical data suggests that external recognition has both a direct and compounding impact on cooperation within ASEAN.

Chapter 4 outlines how recognition was traded between ASEAN and Australia, and between ASEAN and Japan in the 1960-70s. Beginning with ASEAN-Australia relations, the empirical data reveals how ASEAN's rejection of Australia's initial request to join the grouping resulted in Canberra's decision not to recognize ASEAN. 
To avoid its exclusion from regional discussions, the Australians resorted to pushing for a wider regional body, which further incurred the wrath of the ASEAN countries. This rocky start to the interaction and informal socialization process between the two sides would lay the foundation for Australia's gradual recognition of ASEAN. The discussion also reveals how ASEAN was driven by a desire for tangible benefits in its struggle for Australia's recognition. Next, the ASEAN-Japan example illustrates how ASEAN's joint economic action against Japan compelled Tokyo to change its course of not recognizing the five-nation grouping. As the proposed model suggests, an instance of unfair treatment by a non-member country toward an ASEAN member triggered a collective ASEAN response, which in turn reinforced the attitude and behaviors of member states toward the grouping. Specifically, it highlights Malaysia's success in escalating Japan's unfair industrial practice to the regional level which motivated ASEAN governments to increasingly view the grouping as a useful platform to tackle national problems. The discussion also reveals the extent to which the Southeast Asian grouping succeeded in its recognition strategy by airing the issues in the public and intensively engaging the media. These successes were critical in the development of ASEAN in that it would have a compounding effect in swaying the recognition decisions of foreign powers which had refused to recognize ASEAN.

Chapter 5 traces ASEAN's struggle for EEC and U.S. recognition. First, the archival data reveals that the EEC was motivated to recognize ASEAN in an attempt to strengthen its position in Southeast Asia at a time when the U.S. was perceived to be withdrawing from the region. ASEAN, on the other hand, was struggling to secure EEC's recognition of Southeast Asia as a collective regional bloc in order to 
overcome what ASEAN had deemed as unfair economic distribution by the European grouping which favored other developing regions over ASEAN. In particular, ASEAN countries were unhappy with EEC's willingness to extend favorable trade benefits to developing regions like Africa, but refused to do the same for Southeast Asia as a region. The perceived prejudice against Southeast Asia triggered ASEAN's demand for recognition as outlined in the proposed framework. Second, the archival results suggest that the U.S. was at first reluctant to engage ASEAN as a regional grouping through its refusal to recognize ASEAN's political existence. To maintain its supremacy in negotiations, the U.S. preferred the bilateral approach and assessed that regional arrangements would unnecessarily hinder its foreign policy objectives. Accordingly, it withheld recognition from ASEAN so as not to legitimize the role of the grouping as a regional actor in Southeast Asia. However, EEC and Japan's forays into Southeast Asia, in particular the European grouping's willingness to extend recognition to ASEAN, began to change U.S. recognition policy toward ASEAN. The archives also reveal that while ASEAN valued U.S. recognition in that it would raise the status and prestige for the region, the grouping repeatedly highlighted to the U.S. government the importance of equality and fairness in the latter's dealings with ASEAN. On another front, the discussion details how the degree of external recognition also had a negative impact on ASEAN states' commitment toward the grouping. U.S. "incomplete" recognition of ASEAN by its withdrawal of preferential trade benefits to Indonesia dampened the latter's desire for regional cooperation in Southeast Asia. Taken together, the examples in $\underline{\text { Chapter } 4}$ and $\underline{5}$ bring to the fore how a series of recognition from major powers strengthened the level of cooperation in ASEAN. Based on the proposed model for the recognition of regions, these 
examples highlight the role of external influence and actors on the development of a regional concept like ASEAN.

The concluding chapter summarizes the key ideas and findings of this dissertation while highlighting the usefulness of the proposed model for future studies on regional cooperation. In addition to reviewing the significance of external recognition on the progress of ASEAN during its founding years, this chapter shows how the struggle for recognition is a continuous and transformative process. It identifies and discusses more recent endeavors by ASEAN to secure external recognition for the grouping. The orchestrated formalization of the grouping's legality through the conclusion of an ASEAN Charter is a case in point. The discussion also reiterates the significant role of cumulative recognition in the development of a regional concept. In addition to the archival examples taken from the Cold War period, the chapter discusses how foreign powers' slow but gradual recognition of the various facets of ASEAN (for example, on the diplomatic, economic or security front) since the 1990s had a catalytic effect on the progress and status of the grouping. For instance, it is telling that it was China's willingness to recognize ASEAN as a collective common market in 2001 through its proposal to have an FTA with the grouping that led to similar recognition efforts by other powers like Japan and India, rather than the grouping's own initiative to formalize an ASEAN Free Trade Area (AFTA) in 1992. Recognition by great powers therefore has the effect of strengthening the raison d'être of the grouping and encouraging greater cooperative behaviors between ASEAN members. Finally, this dissertation does not claim that the proposed recognition model for regions explains the rise and fall of all regional concepts. Instead, it simply offers a new analytic tool to discuss the development of regional entities. The main assertion 
that is made in this dissertation is that, if the conditions for a struggle of recognition exist, the proposed model best explains the growth of a regional entity like ASEAN. 


\section{Chapter 2: Theoretical Framework}

This chapter presents the theoretical framework of this dissertation. The first section introduces and defines the key concepts which will be used in the proposed model. It begins by proposing the inclusion of "regions" as the unit of analysis to the study of regional cooperation. The discussion highlights the tendency in existing scholarships to account for the evolution of regional cooperation by anchoring their arguments on explaining the dynamics between member states in a regional grouping. It proceeds to define the concepts of "recognition" and "regionhood" before explaining how the two ideas are pertinent to the analysis on the role of external actors in the development of a regional concept. On "recognition", Section 2.2 and 2.3 outline the key findings in current studies on the demand and supply of recognition in a society of individuals and a society of states. Given the lack of theorizing in current literature on the effects of recognition for regions as highlighted in the introductory chapter, the objective of such an analytical exercise is to understand the motivations of both the claimant and recognizing entities, and the methods employed in their struggles for recognition. This background provides the setting for Section 2.4 to develop a model for the recognition of regions which highlights the importance of understanding how external actors can influence the development of a regional concept by way of recognition. The proposed model offers the perspective that a region's relations and social interaction with the international community and the outcome of its struggle for external recognition have a direct effect on the way member states cooperate with one another. The final section introduces the three main hypotheses to be tested in this dissertation and highlights the expected outcomes based on the proposed model for the recognition of regions. 


\subsection{Definitions: "Regions", "regionhood" and "recognition"}

This section introduces "regions" as the unit of analysis in this dissertation. As highlighted in the preceding chapter, the theorizing on regional cooperation heretofore has converged on studying the interaction among member states in a grouping to account for the evolution of regional cooperation. The realists find that cooperation in ASEAN is weak because member states are unwilling to forgo their national interests. The liberals explain that ASEAN works because member states are only concerned with increasing the absolute welfare of their societies. The constructivists argue that ASEAN has been successful because member states have gradually assumed a regional identity and have internalized a set of common norms through repeated dealings with one another. Broadly summarized, these frameworks are united in their inherent assumption that participating states are the most crucial players in determining the outcome of a regional idea. Naturally, such a member state-centric approach has limited the discourse on regional cooperation through interpreting events based on how member states cooperate with one another in an institution. Adding to the inclination of using "states" as the unit of analysis, the spectrum of literature defining such terms related to regional cooperation like "institutions" or "regionalism" also alluded to the central role of member state in shaping the development of regional institutions. The latter, for example, is seen as "state-led projects of cooperation that emerge as a result of intergovernmental dialogues and treaties" (Breslin and Higgot 2000: 344). Also emphasizing the linkages between member governments, Ravenhill (2009: 111) defines regionalism as a process of "intergovernmental collaboration on a geographically limited basis". 
An institution has also been understood as "patterned behavior among the members of a group" which is "constructed" when member states behave in a predictable manner in their dealings with one another or when they begin to reflect the accepted behaviors of other members (Yamamoto 2008: 22). Here again, the definitions provided by theorists on regional cooperation tend to focus on the actions and behaviors of member states as represented by their governments. The common thread in current theorizing on regional cooperation is their emphasis on the way member states transact, socialize or interact with one another within the region. Critically, the impact of the socialization process between the region (as a whole) and non-member actors has been largely overlooked in current literature on regional cooperation. The proposed model in this chapter therefore highlights the importance of such an external socialization process functioning as a way to secure the international community's recognition of the region. It explains how a regional entity's social practices with the international community (and vice-versa) contribute directly to the region's development.

With the objective to measure the effects of socialization at the regional level, this dissertation proposes the inclusion of "regions", in addition to the conventional usage of "states" as the unit of study in international relations. In Theory of International Politics, Waltz (1979: 95) observes that "states are the units whose interactions form the structure of international political systems". In anarchy, states therefore worry about their survival and are solely driven by national interests in their foreign policy calculations. Likewise, in Wendt's constructivist framework, states are also accepted as the unit of analysis. Where the two scholars differ is their interpretations on the sequence of causality. Wendt (1999: 15) asserts, first and foremost, that "states are 
people too" with "human qualities like identities, interests, and intentionality". As a result, repeated interactions can adjust behaviors and expectations of states, as they do for human beings. (In contrast, Waltz argues that states are innately selfish). Further, to defend the human-like characterization of a state, Wendt (1999: 216) explains:

What we see is at most government, the aggregate of concrete individuals who instantiate a state at a given moment. State action depends on the actions of those individuals.

With this background, this section proposes the notion that "regions are people too". To paraphrase Wendt, a region is the aggregate of concrete state leaders representing the region in the form of a regional institution or grouping at a given moment. Its interaction with non-member states or other existing political entities has the capacity to affect behaviors and outcomes within the region.

Evidently, whether the aspirations and actions of a region can be completely embodied in the form of a regional institution is a highly controversial matter to say the least. However, the key question here is not whether a region may be fairly represented by an institution, but which regional entity is regarded as the authoritative voice of the region by the external actors, if one exists. Such an approach to the study of regional cooperation is not new. For example, some scholars in the field of Asia-Pacific regionalism such as Higgot and Stubbs (1995: 517) view the Asia-Pacific Economic Cooperation (APEC) and EAEC groupings as competing to be "the 'voice of the region' on international economic matters". According to this group of scholars, the key issue is "which of these two 'inventions' 
best serve the governments and peoples of the region" (Higgot and Stubbs 1995: 526).

In the case of a state, the electoral process legitimizes the elected leaders to speak on behalf of the people. Even in the absence of such democratic exercises like in the example of an authoritarian regime or monarchy, the perception of the government to act as the legitimate voice of the country is not in doubt because of the ability of the state apparatus to control security forces and to mobilize national resources. In the same way, a region is legitimized through an institution by the participation of state leaders from member states who collectively possess the capacity to mobilize people and resources in the region they represent, and to speak, as it were, for the region (whether or not they have the will to do so is a separate matter). Normatively, Seyersted's (2008: 49) research has shown that:

intergovernmental organizations do not differ essentially from States, many of which exist, and exercise full international personality, notwithstanding the fact that their written constitution do not cover all the subjects... or that they have no written constitution at all.

The justification of using regional institution as a proxy to understand the struggle for recognition by a region in this dissertation is also explained by Levine (2008: 130): "The fact that institutions are essentially vehicles we use to instantiate ideas makes them likely settings for the struggle over the use of recognition".

Nonetheless, this train of analysis runs into an obstacle when a state joins more than one regional institution. The challenge then is to assess which regional entity is regarded and accepted as the rightful voice of the region in the eyes of the external 
actors. For example, even before the formation of ASEAN and right through its founding years, several formalized groupings in Southeast Asia, including ASA, competed with the five-member association for a role in the region. However, over time, these parallel institutions began to fade into the shadow as ASEAN began to gain prominence. The task is to show how a regional concept like ASEAN succeeded to take on the role as the legitimate voice in Southeast Asia - this will be elaborated in $\underline{\text { Chapter } 3}$. For now, the aim of the remaining chapter is to illustrate how the proposed model in this dissertation uses "regions" as the unit of analysis. By studying a region's social practices in the international system, the model explains how such an external socialization process may also influence behaviors between members in the region.

In framing "region" as the unit of analysis, it is essential to define what makes a region a "region". This is no different from asking the question: What constitutes the "regionhood" of a group of countries? Some scholars like Dent (2008: 33) have referred to "the idea of region" as "regionness". In this dissertation, "regionhood" is defined as the condition of being a region, in the same way that statehood refers to the condition of being a state (this will be discussed in the next section). Why is the study of "regionhood" important? Van Langenhove (2003: 5), who is probably the first scholar to coin the term, explains: "Without a clear view of what constitutes a region, it becomes difficult to analyze what regional integration is and how that is realized". To answer these questions, the discussion that follows will illustrate how the outcome of the struggle for recognition of a regional concept by a group of countries directly influences the development of its regionhood. In this chapter, the deeper meaning of recognition in inter-personal and inter-state relations will be analyzed. By adapting 
current recognition theories on statehood and personhood to the analysis on regionhood, the discussion examines how the contest for recognition affects the pace and development of regional cooperation. It teases out the key ideas of recognition theories in existing studies and uses them to conceptualize a recognition model for the study of regions.

As for "recognition", Oxford Dictionaries (2011) defines the term as "the action or process of recognizing or being recognized" or "the acknowledgement of the existence, validity or legality of something". It should be highlighted here that recognition is not an imagined or normative process; it demands formal acknowledgments in the form of concrete actions. Jaffe (1933: 101) uses the term "to describe a systematic conception, or to indicate a practice in international politics". Diplomatic recognition in inter-state relations, for example, refers to the formal acceptance by a state that another political entity meets the conditions of statehood and is entitled to be dealt with as a member of the international community. Even in such state recognition, the recognizing government is expected to formally announce its willingness to conduct business with the new entity and to accede to the latter's request to establish an overseas post in the country, along with other recognition protocols. While state recognition is a fairly well established process, recognition becomes an untidy and difficult affair for regions because there are no formal protocols in place or a higher authority regulating such recognition decisions. However, this should not imply that recognition has no role to play in the development of a regional concept. Far from it, it is precisely the lack of a set of procedures governing the recognition of regions that magnifies the importance of the 
role that external actors can play to support or stall the development of a region. (Section 2.4 will elaborate on the purpose of recognition in regional cooperation).

For now, based on the above definitions, the next two sections examine current studies on the struggle for recognition in a society of individuals, followed by the contest for recognition in a society of states. On statehood, it considers the discourse from the legal perspective - how a recognition decision may be cloaked with some normative content and purpose. It also looks at recognition as a type of "political action" which may be based on factors such as foreign policy objectives, domestic pressures, regional interests and international status (Hammer 2007: 31). The discussion also examines the role of recognition in the context of a society of individuals. It addresses the Hegelian interpretation that recognition comprises "the identity of both inner and outer relations" and "depends upon the view and will of another" (Dyde 1896: 337). This means that a person, a state or a region exists only in relation to other existing entities. By scrutinizing and adapting current recognition theories on statehood and personhood to the analysis of regionhood in the remaining chapter, the discussion examines how the contest for recognition influences the development of a regional concept. The aim is to sieve out the key ideas of recognition theories in existing studies and use them to conceptualize a recognition model for the study of regional cooperation in Section 2.4 .

\subsection{Personhood: Recognition discourse within a society of individuals}

This section underlines the key ideas in current debates surrounding the concept of recognition in the context of a society of individuals. On the recognition of persons 
and states, Morris (1887: 109) explains: "Just as the single human being is not an actual person except in relation to other persons, so the State cannot be an actual individual without relation to other States". There is no reason why this train of logic cannot be extended to regions. As mentioned earlier, the objective of this section is to develop a model for the recognition of regions by building on what past and current scholars of recognition theories in other fields have identified as critical elements in such recognition discourse. The intention here is not to highlight the differences in their theoretical approaches, but to put together a comprehensive toolkit which could be utilized for the chapter's later analysis on recognizing regions. Further, since the "notion of who we are arises from social interactions" (Kenny 2004: 151), examining the concept of recognition in the respective context of a society of individuals, and of states (in the next section), may unveil critical directions as to how a regional institution's socialization with non-member entities shapes the course of its "regionhood".

Beginning with a society of individuals, Blum (1998: 77) argues that it is "human beings who require recognition - of their distinctive identity(ies) - for their flourishing". It implies a direct connection between the success of a human life and the level of external recognition accorded to it. On personhood, there are three major conceptual frameworks explaining the struggle for recognition. Each carries its own emphasis and ideals about how the contest for recognition among individuals occurs in the society. First, Fraser's (1998: 19) theoretical approach suggests that an individual or a group of individuals demands recognition as a means to overcome existing material and status inequality in the society: 
Demands for "recognition" fuels struggles of groups mobilized under the banners of nationality, ethnicity, "race", gender, and sexuality... Struggles for recognition occur in a world of exacerbated material inequality... It is also increasing globally, most dramatically across the line that divides North and South.

Fraser associates the source of all struggles for recognition to social injustice. The lack of social standing and unfair economic arrangements prevent an individual from participating fairly in the society. Remedying such injustice calls for the maintenance of a norm of "parity of participation" in the society. Fraser (2003: 36) argues that justice requires a "social arrangement" which allows all "members of society to interact with one another as peers". In other words, the absence of such parity ultimately leads to struggles for recognition.

Fraser (2003: 36) identifies two conditions to guarantee parity of participation in the society. First, a "distribution of material resources" which does not deny a person the "means and opportunities to interact with others as peers". Second, "institutionalized patterns of cultural value" which expresses "equal respect for all participants and ensure equal opportunity". The former entails efforts to restructure economic arrangements such as redistributing income and reorganizing the division of labor within the society to level the conditions for equal participation. An arrangement which extends preferential economic advantages to one group of individuals over another is an outright violation of this principle. On institutionalized practices, Fraser (2003: 29) elaborates:

To view recognition as a matter of justice is to treat it as an issue of social status. This means examining institutionalized patterns of cultural value for their 
effects on the relative standing of social actors. If and when such patterns constitute actors as peers, capable of participating on a par with one another in social life, then we speak of reciprocal recognition and status equality. When, in contrast, institutionalized patterns of cultural value constitute some actors as inferior, excluded, wholly other, or simply invisible, hence as less than full partners in social interaction, then we should speak of misrecognition and status subordination.

In other words, existing arrangements which categorically prescribe a group of individuals as incapable or inferior defies the second principle. A case in point is the baseless prescription of black slaves as only good for manual labor in plantations in North America. To be misrecognized or subordinated is to be precluded from the status of a full partner in social interaction. Demands for recognition are therefore calls for the removal of status hierarchy in the society, or the correction of institutionalized patterns of cultural value which "pervasively deny some members the recognition they need in order to be full, participating partners in social interaction" (Fraser 2003: 48-49). Claimants are therefore motivated to remove established norms which undermine their status while seeking their fair share of economic distribution.

As for the rest of the society, the dominant group may resist efforts to change established patterns of cultural value in order to maintain their higher social standing or the subordinated status of the individual by refusing recognition. For example, established practices like slavery kept open the access to cheap labor for white plantation owners. For claimants to have a case in their pursuit for recognition, they have to show how such entrenched cultural values "deny them the intersubjective 
conditions of participatory parity and that replacing those patterns with alternative ones would represent a step in the direction of parity" (Fraser 2003: 47). This requires the abolishment of unfair material distribution and rejection of established patterns of cultural value. As a summary, Fraser's model points to the prevalence of inequality in social status and unfairness in distribution of economic resources as the motivations for a group of individuals demanding recognition in the society. These factors will be scrutinized and tested later to assess if they are also applicable to the study of a region seeking external recognition in this dissertation.

Next, in Taylor's model, recognition is a critical element which shapes the identity of an individual. Taylor's (1992: 32) main proposition is that the perception of the society on an individual has a direct impact on the development of the latter's identity and character because of the underlying condition that human life is "fundamentally dialogical" in character. The crux of the framework may be summarized by the argument that

our identity is partly shaped by recognition or its absence, often by the misrecognition of others, and so a person, or group of people can suffer real damage, real distortion, if the people or society around them mirror back to them a confining or demeaning or contemptible picture of themselves. Nonrecognition or misrecognition can inflict harm, can be a form of oppression, imprisoning someone in a false, distorted, and reduced mode of being (Taylor 1992: 32).

Deeply influenced by Hegel's interpretation that "the identity of the self is entirely dependent on its recognition by others" (Thompson 2006: 11), Taylor suggests that misrecognition or non-recognition drives all struggles for recognition. This means that 
the deliberate projection of an image of inferiority by members of the society toward an individual (or misrecognition) has the effect of reinforcing the latter's impression of himself or herself to be inferior. This proposition resonates with Fraser's observation above that existing patterns of cultural value which view a group of individuals as inferior obstruct their participation as equals in the society.

More significantly, Taylor (1992: 36) finds that the "projection of an inferior or demeaning image on another can actually distort and oppress, to the extent that the image is internalized". From this perspective, an individual's desire to correct an identity distorted by misrecognition or non-recognition drives the struggle for recognition. The aim of such struggles is to secure "a regime of reciprocal recognition among equals" (Taylor 1992: 50). Here again, failures by members of a society to view someone as an equal is a reflection of the former's desire to maintain supremacy over the person. The dominant groups seek to "entrench their hegemony by inculcating an image of inferiority in the subjugated" (Taylor 1992: 66). Since recognition forges identity, maintaining the status quo of projecting an inferior image enables the stronger group in the society to continue their dominance over the individual. In brief, Taylor's framework highlights the failure of this group to affirm an individual as their equal in the society as the main motivation driving an individual's pursuit for recognition. The question pertinent to this dissertation is whether misrecognition or non-recognition may also compel an oppressed region to press for external recognition and to demand for its rightful status in the international community. 
Finally, in Honneth's (1995: 169) framework, an individual demands recognition to acquire self-confidence, self-respect and self-esteem, which in turn enables the realization of himself or herself as "both an autonomous and an individuated being ... with his or her goals and desires". According to Honneth (1995: 168), the "feeling of being unjustly treated and the experience of being disrespected" drive an individual's struggle for recognition. In this case, the struggle should not be viewed as once-off without any relations to subsequent struggles because each successful contest for recognition has the capacity to reinforce the identity of the individual. Therefore, each social struggle has to be "measured in terms of the positive or negative contribution that each has been able to make to the realization of undistorted forms of recognition" (Honneth 1995: 170). This conceptual framework highlights the importance of cumulative recognition:

The only way in which individuals are constituted as persons is by learning to refer to themselves, from the perspective of an approving or encouraging other, as beings with certain positive traits and abilities. The scope of such traits - and hence the extent of one's positive relation-to-self - increases with each new form of recognition that individuals are able to apply to themselves as subjects (Honneth 1995: 173).

By perceiving historical processes "as stages in a conflictual process of formation", cumulative social struggles will lead to "a gradual expansion of relationships of recognition" (Honneth 1995: 170). In other words, the more recognition an individual is able to receive, the greater his self-confidence and esteem.

This framework is distinct from Fraser and Taylor's approaches in that greater emphasis is given to the role of social confrontations in the struggle for recognition. 
Honneth (1995: 167) suggests that "social confrontations can in principle be understood in terms of moral pattern of a struggle for recognition”. Each successful struggle has the snowball effect of strengthening the individual's case for recognition. Further, in the course of such struggles, Honneth highlights the importance of drawing on the power of collective action and public attention. On the former, personal experience of unfair treatment can result in collective actions or resistance "if the individual is able to articulate them within an intersubjective framework of interpretation that they can show to be typical for an entire group" (Honneth 1995: 163). Put another way, an individual's experience of disrespect, if perceived as typical for an entire group, can "motivate collective demands for expanded relations of recognition" (Honneth 1995: 162). This means that personal experience of disappointment can be exploited to harness group support if the affected individual can convince others that they may be the next potential victim:

As soon as ideas of this sort have gained influence within a society, they generate a subcultural horizon of interpretation within which experiences of disrespect that, previously, had been fragmented and had been coped with privately can then become the moral motives for a collective 'struggle for recognition' (Honneth 1995: 164).

As for raising public awareness, the framework suggests that the sufferer should "publicly discussed the denial of basic rights from the perspective of how withheld recognition undermines the opportunity for individual self-respect" (Honneth 1995: 120). To succeed, they should strive to influence public attention because the more successful social movements are at drawing the public sphere's attention to the neglected significance of the traits and abilities they collectively represent, 
the better their chances of raising the social worth or, indeed, the standing of their members (Honneth 1995:127).

In Honneth's worldview, struggles for recognition are inevitable because some members of the society will "resist others' attempts to gain recognition" in order to maintain deeply rooted expectations about behaviors (Thompson 2006: 160). Since each successful struggle strengthens recognition efforts, an individual desires continuous "effective approval or encouragement" from others by "means of repeated and ritual invitations to adopt precisely that self-conception that conforms to the established system of behavioral expectations" (Honneth 1995: 95 and 2007: 324). In sum, Honneth's model points to the failure of members in the society to show proper respect to an individual as the main reason driving the demand for recognition and the cause of social confrontations. By tapping on the power of collective action and raising public awareness, personal encounters of disappointment can be employed to acquire support from other members and recognition for the entire group from the society. The question pertinent to this chapter is whether these elements are also observable in the struggle for recognition of a regional concept designed by a group of countries?

Taken together, the intellectual discourse on the recognition of personhood, heretofore, suggests that the demand for recognition is motivated by a desire for fairer economic access and equal social status, prior experience of disrespect and the society's distortion of an individual's identity. The recognizer, on the hand, seeks to suppress calls for recognition in order to maintain its preferred cultural values, subordination of the weaker individuals and hegemony over the claimants. In terms 
of methods, the individual seeking recognition may press for changes to social practices in order to achieve parity of participation while inciting collective actions and raising public awareness. These elements which are crucial to the recognition of personhood will be revisited again in Section 2.4 to assess if they are also relevant to the recognition of regions. The next section turns to the recognition discourse in the context of a society of states. It accounts for why recognition matters to states in international relations. By understanding the issues pertinent to the struggle for recognition by individuals and states, a recognition model could then be designed to explain the pursuit for external recognition of a regional concept.

\subsection{Statehood: Recognition discourse within a society of states}

Between states, there are three political approaches to the recognition of statehood. The two longstanding political concepts on the recognition of statehood are the declaratory theory and constitutive theory. Supporters of both schools seek to explain when a prior-state may be considered to be a state with legal duties and rights in the eyes of international law. The discussion in this section describes the key tenets proposed in both theories before elucidating the third perspective on the recognition of statehood which views recognition as a political and transformative process, in addition to its normative or legalistic function.

The constitutive theory of statehood suggests that a prior-state comes into existence only when existing states recognize it. Here again, the argument resembles the Hegelian principle that the existence of an identity depends on others. In practice, Kelsen (1941: 605) explains that the "political act of recognition of a state or 
government means that the recognizing state is willing to enter into political and other relations with the recognized state or government". Under the constitutive theory, the birth of a state is conditional on the willingness on the part of existing states to perform concrete acts of recognition. It requires existing states to carry out formal transactions, such as signing a treaty, negotiations or dialogues, with the aspiring state. The "first agreement is the act of recognition. It is a treaty. It is reciprocal and constitutive" (Lauterpacht 1975: 310).

The declaration theory, on the other hand, suggests that statehood does not depend on recognition. As long as an entity meets "the factual criteria of statehood, it automatically becomes a state irrespective of whether it has been recognized as such by other states" (Bocek 2005: 101). The four universal criteria of statehood, as enshrined in Article One of the 1933 Montevideo Convention on the Rights and Duties of States, requires an aspiring state to possess a defined territory, a government, a permanent population and a capacity for diplomacy. Under the declaratory theory, a prior state therefore comes into being once it meets the conditions for statehood regardless of whether it is recognized by other states. Recognition becomes "declaratory" in the sense that it only serves as an expression of the willingness of existing states to deal with the political entity as a state. Consequently, a customary declaration suffices to signal the existence of such entities.

In practice, however, the absence of a supranational agency to assess the four qualities of statehood means that it has become a common practice to consider a successful application by an aspiring state for a seat in the United Nations (UN) as 
international endorsement of an entity's statehood. Warbrick (2003: 251) observes that "entities which are States (and some which are not) and which want to be regarded by other States as States generally make an immediate application for member of the UN". Membership in international organizations is thus turning into an increasingly crucial part of "diplomatic recognition and socialization" (Jönsson and Hall 2005: 133). Other political commentators continue to emphasize the importance of state recognition since there is no "central institution which is competent to determine whether the criteria for statehood are met" (Raic 2002: 30). This means that existing states all the more have to assume this function by way of the act of recognition. However, unilateral and unorganized recognition practices by existing states have led to problems within the international diplomatic community. Embarrassing situations occur when some states recognize the statehood of an entity but others do not. In brief, both the constitutive and declaratory theories differ on the purpose of recognition in a society of states. In constitutive theory, recognition by existing states has a direct influence on the development of a political entity. In the second case, recognition takes on a passive role; it merely "declares" the fact that the entity has met the conditions of statehood. In both cases, the effects of recognition are legalistic and normative.

In contrast to the two theories above, which alluded to recognition as a static process, the third perspective, which is gaining ground among several scholars, suggests that state recognition is neither static nor mere formality. Based on a Foucauldian interpretation, Hammer (2007: 43) argues that recognition is "part of the ongoing process of development of the entity". On a practical plane, Hammer's framework raises the question as to whether there is anything to gain for existing states to 
"recognize" a political entity. While it may be obvious why political entities demand external recognition, it is less clear why existing states are willing to participate in the recognition process given that it is not a costless exercise. Hammer's model suggests that recognition is a responsive and transformative process, which entails an ongoing dynamic exchange of real benefits to not just the claimant states, but recognizing states too:

An international lawyer for example might refer to recognition as assisting in the legal decision regarding the existence of a state, in an attempt to cloak the recognition decision with some normative content. Yet, at the same time, recognition is a political action, being that it is essentially a decision left in the hands of the state without any clear delineated guidelines. It can be based on considerations of foreign policy (does a state desire to support a newly formed regime or autonomous region?), domestic interests (might support for an autonomous entity appease constituents of a certain religious or ethnic background?), regional interests (how will the decision affect state neighbors and their geo-political interests?), and international standing (how will the recognition affect decision play in the UN and what effect will it have on other entities or regions?) to name but a few of the issues involved (Hammer 2007: $31)$.

In short, the decision to recognize a political entity (or not) depends on several national objectives. Such national goals, whether legal, political or domestic related, aim to influence a "regime's policies by trading recognition for concessions" (Peterson 1997: 155). Hammer's perspective corroborates with the observation by other scholars that larger or stronger states "may use recognition as a tool for their 
continued domination of other states" (Worster 2009: 120-1). Further, refusal to recognize or non-recognition "may be, and is, used as a political weapon against a state" (Jaffe 1933: 112). At the base level, non-recognition denies the entity an opportunity to engage in "customary international social and economic intercourse", and thereby deprives it from any material benefits which may arise from such interactions (Jaffe 1933:122). Briggs' (1949: 121) findings also reveal that "collective recognition by the Great Powers has been sparingly employed in the past and has sometimes savored of collective intervention". A case in point is how the controversial issue of whether to recognize Taiwan, Israel and Palestine is often used by great powers as a tool of leverage and diplomacy. Even small and middle powers have manipulated recognition policies to maximize their access to economic markets or developmental aids as often seen in their decisions on whether to have diplomatic ties with China or Taiwan. Existing states therefore trade or withhold recognition for a host of tangible benefits. Hammer (2007: 29-30) concludes that the

decision to recognize is usually linked to a state's political policy or desire, and not associated with whether a state actually "exists" as such pursuant to the international legal criteria of statehood.

For the above reasons, existing states are willing to expend efforts, and in most cases to invest time and resources, as a way of formally recognizing another political entity. Where recognition works against national interests, states will refuse recognition and, in some cases, launch a counter-campaign against any organized efforts to confer recognition on the entity. This explains why recognition or seating proceedings in the UN General Assembly often involved intense lobbying and campaigning. 
In the same manner, the third perspective on the recognition of statehood also poses the question: What is there to gain for the entity seeking recognition? Here, the motivations for the recognition of statehood are also the tangible outcomes which may arise from the recognition process. Beginning with the normative perspective, Oppenheim (1955: 128) suggests that recognition "marks the beginning of the international rights and duties of the recognized community". Under international law, it endows international personality on a state by conferring on it the "capacity to perform international functions independently of its member states" (Bourne 1978: 285). In addition, recognition is also of "great importance politically, especially for the prestige of the state or government to be recognized" (Kelsen 1941: 605). It raises the prestige and confers status on a political entity as Crawford (2006: 27) suggests: Recognition is an institution of state practice that can resolve uncertainties as to status and allow for new situations to be regularized ... Even individual acts of recognition may contribute towards the consolidation of status.

Here again, as in the case of personhood, the importance of cumulative recognition is emphasized. A series of successful attempts to acquire recognition or cumulative recognition has the effect of increasing the stability of the entity. Patel (1959: 47) observes that recognition "by a large number of states in the world gives to the entity recognized a high degree of stability and assures its place in the family of nations". Apart from legal rights, prestige, status and stability, recognition also endows a host of other material benefits on the claimant state including the "capacity for commercial and diplomatic discourse, membership in international financial institutions, status in foreign courts, and some form of state and diplomatic immunity" (Hammer 2007: 29). These are the reasons motivating a political entity to pursue after external recognition. 
Within a society of states, the above discussion therefore suggests that recognition plays an important role in the development of a state. Rather than a once-off decision, the recognition process comprises a host of transactions and a dynamic exchange of concessions between the recognizing states and the claimant entity. For the latter, in particular, the demand for recognition is driven by its desire for concrete benefits which include international legal rights, access to material opportunities, prestige, status and stability. Similarly, existing states supply or withhold recognition for a multitude of tangible payoffs like continued domination, foreign policy objectives or domestic interests. The central inquiry in this chapter is whether these factors are also applicable to the recognition of regional concepts. At this juncture, it is intriguing to observe the similarities in past and current theoretical debates surrounding the motivations behind the claimant and recognizing entities for recognition in the first account on personhood and the later discussion on statehood. The repeated themes on the desire for prestige, status, material gains, stability, power and fairness, as well as the emphasis on cumulative recognition, are a strong indication that these elements ought to be incorporated into the conceptual framework to be used to explain the role of recognition for regions in the next section.

\subsection{Regionhood: Proposed model for the recognition of regions}

The discussion in this chapter has thus far outlined the factors influencing the demand and supply of recognition in a society of individuals and of states. By eliciting the determinants shaping the recognition of personhood and statehood, a conceptual framework to explain a region's struggle for recognition may be developed. The 
motivations behind the contest for personhood and statehood are summarized in Reference 1. Accordingly, the last column outlines the critical areas to consider in constructing a framework to analyze the recognition of regions.

\begin{tabular}{|c|c|c|c|}
\hline \multicolumn{4}{|c|}{ Reference 1: Demand and Supply of Recognition } \\
\hline & & Motivations of Entity & \\
\hline & Personhood & Statehood & Regionhood \\
\hline $\begin{array}{c}\text { Demand } \\
\text { by } \\
\text { claimant }\end{array}$ & $\begin{array}{l}\text { Overcome material and } \\
\text { status inequality (Fraser } \\
\text { 2003) } \\
\text { Regain identity distorted } \\
\text { by misrecognition or } \\
\text { non-recognition (Taylor } \\
\text { 1992) } \\
\text { Reduce disrespect and } \\
\text { unfair treatment; } \\
\text { cumulative recognition } \\
\text { reinforces personhood } \\
\text { (Honneth 1995) }\end{array}$ & $\begin{array}{l}\text { Acquire international } \\
\text { rights and duties } \\
\text { (Oppenheim 1955) } \\
\text { Increase access to } \\
\text { commercial and financial } \\
\text { opportunities (Hammer } \\
2007 \text { ) } \\
\text { Gain prestige and status } \\
\text { (Kelsen 1941, Crawford } \\
2006 \text { ) } \\
\text { Cumulative recognition } \\
\text { increases stability (Patel } \\
\text { 1959) }\end{array}$ & $\begin{array}{l}\text { Obtain better and } \\
\text { fairer access to } \\
\text { material } \\
\text { opportunities? } \\
\text { Secure prestige } \\
\text { and equal status? } \\
\text { Reduce unfair } \\
\text { treatment? } \\
\text { Correct distorted } \\
\text { identity? } \\
\text { Obtain legal } \\
\text { rights? } \\
\text { Cumulative } \\
\text { recognition } \\
\text { increases stability? }\end{array}$ \\
\hline $\begin{array}{l}\text { Supply } \\
\text { by } \\
\text { recognizer }\end{array}$ & $\begin{array}{l}\text { Entrench hegemony by } \\
\text { portraying an image of } \\
\text { inferiority in others } \\
\text { resulting in such image } \\
\text { being internalized } \\
\text { (Taylor 1992) } \\
\text { Support existing } \\
\text { institutionalized patterns } \\
\text { of cultural value; } \\
\text { maintain subordination } \\
\text { (Fraser 2003) } \\
\text { Maintain deeply rooted } \\
\text { expectations about } \\
\text { behaviors (Honneth } \\
\text { 1995) }\end{array}$ & $\begin{array}{l}\text { Continue domination of } \\
\text { other states (Briggs } \\
\text { 1949, Worster 2009) } \\
\text { Use of non-recognition } \\
\text { as a political weapon } \\
\text { (Jaffe 1933) } \\
\text { Foreign policy } \\
\text { considerations, } \\
\text { domestic/regional } \\
\text { interests (Hammer } \\
\text { 2007) } \\
\text { Political motivations; } \\
\text { recognition in exchange } \\
\text { for concessions } \\
\text { (Peterson 1997) }\end{array}$ & $\begin{array}{l}\text { Exert continued } \\
\text { hegemony? } \\
\text { Internalize image } \\
\text { of inferiority in } \\
\text { regions? } \\
\text { Preference for } \\
\text { status quo of } \\
\text { behaviors and } \\
\text { expectations? } \\
\text { Exchange } \\
\text { recognition for } \\
\text { other } \\
\text { concessions? }\end{array}$ \\
\hline
\end{tabular}




\begin{tabular}{|c|c|c|c|}
\hline $\begin{array}{l}\text { Methods } \\
\text { and aims }\end{array}$ & $\begin{array}{l}\text { Promote parity of } \\
\text { participation by social } \\
\text { changes (Fraser 2003) } \\
\text { Secure reciprocal } \\
\text { recognition among } \\
\text { equals (Taylor 1992) } \\
\text { Obtain approval and } \\
\text { encouragement through } \\
\text { repeated and ritual } \\
\text { invitations; use of } \\
\text { collective action; raise } \\
\text { public attention } \\
\text { (Honneth 1995, 2007) }\end{array}$ & $\begin{array}{l}\text { Ongoing process in the } \\
\text { development of entity } \\
\text { (Hammer 2007) } \\
\text { Constitutive by concrete } \\
\text { acts of recognition or } \\
\text { transactions (Kelsen } \\
\text { 1941) } \\
\text { Declaratory by four } \\
\text { qualities of statehood } \\
\text { (Bocek 2005) } \\
\text { Apply for UN } \\
\text { membership (Warbrick } \\
\text { 2003) }\end{array}$ & $\begin{array}{l}\text { Press for social } \\
\text { changes? } \\
\text { Demand to be } \\
\text { treated as an } \\
\text { equal? } \\
\text { Appeal for } \\
\text { collective action? } \\
\text { Promote public } \\
\text { awareness? }\end{array}$ \\
\hline
\end{tabular}

In the absence of an avenue to lobby for formal recognition through a supranational authority, as in the case of applying to the UN for statehood, aspiring regions have to rely on existing states or regions for external recognition of their regionhood. These external actors, on the other hand, are compelled to respond to such overtures for recognition. Even a non-reply may be perceived as a rejection or no-confidence vote for a regional concept. More often, however, existing states recognize regions for a host of reasons. The discussion on the struggle for recognition of an individual and a state in the preceding two sections has demonstrated that there are clear benefits in the recognition (or in some cases non-recognition) process to both the claimant and recognizing parties. It reveals several elements which are useful to the analysis on the role of recognition in regional cooperation.

As indicated in Reference 1, for the aspiring region, recognition may lead to better and fairer access to material opportunities. Besides the attainment of legal rights, recognition may increase the prestige of the region and raise its status in the 
international community. It may also function as a means to reduce cases of unfair treatment toward any member states or to rectify any distorted images on the region portrayed by external actors. More substantially, cumulative recognition may increase the stability of the region over time as it gains greater legitimacy internationally. On the supply-side, external states may exploit the recognition process to exert continued hegemony and to dominate the region while maintaining their preferred status quo of behaviors and expectations of member states associated with a regional concept. Further, misrecognition or non-recognition policies enable powerful states to internalize images of inferiority among member states in the region. For these external actors, recognition is also often traded in exchange for other concessions related to their foreign policy objectives, domestic pressures or regional interests. At the same time, recognition of a regional concept may result in a more impactful diplomatic payoff for bigger states internationally than to manage ties with the individual states on a bilateral basis, which is both time and resource consuming. In terms of the methods deployed to harness external recognition, members belonging to a regional concept may exploit avenues to press for social changes, demand for the region to be treated as an equal, call for collective action or solicit for public support in their struggles for recognition.

A conceptual framework to account for the recognition of regions, therefore, has to include an assessment of the propositions outlined in the last column of Reference 1. The elements associated to regionhood in the last column of the table are represented in the interrogative form because they have yet to be tested empirically. The struggle for recognition of a region may be said to be prevalent if such motivations and behaviors are observed in the development of its regionhood. As 
discussed in Section 2.3, rather than viewing recognition as a single state decision (whether a state should formally recognize a regional entity), the model analyses recognition as a continuous process of interaction between the claimant and recognizing entities. On this point, Hammer (2007: 40) suggests that

recognition in its various shapes and guises as articulated by states and other international actors reflects attitude shifts that alter over time depending on the circumstances. An entity's capacity will rise and fall due to the modulations of recognition and its important practical and symbolic validity.

Similar to statehood, recognition of regions involves concrete and successive transactions such as treaties, dialogues and negotiations as highlighted in Section 2.1. To use recognition as an independent variable, Honneth (2007: 329) explains that

an act of recognition cannot consist in mere words or symbolic expressions, since it is only through corresponding modes of comportment that the credibility so normatively significant for the recognized subject can be engendered.

Not unlike inter-state relations, for example, the appointment of an ambassador or establishment of a trading post typically follows after the conferment of diplomatic recognition or exchange of diplomatic notes. In addition, recognition is an ongoing process because "no act of recognition ever achieves the completion of the recognized identity, and so it must be repeated, even if always different" (Thomassen 2011: 328). The regular attendance of the diplomatic corps who represent their governments at state events organized by the host government reinforces the recognition that both countries have for each other, even if these functions do not achieve any substantive outcomes. Successive transactions, in turn, strengthen the legitimacy of a political entity. Likewise, when the growth of a regional concept 
impinges on any of the elements cited in Reference 1 for the recognizer, recognition will be withheld or adjusted. The swing in the European Union's (EU) recognition policy on ASEAN and the way they have dealt with the Southeast Asian grouping with the entry of Myanmar in 1997 is a case in point. (This will be discussed in Chapter 6). For regionhood, the lack of a supranational authority or international rules governing the accreditation of regional concepts or regions all the more magnifies the gravity of recognition by existing states or external actors.

The framework described in this section thus far has elicited the importance of recognition to both a region and the external actors, and highlighted why the struggle for recognition matters to both parties. The discussion has not yet shown how such a struggle may influence the attitudes and behaviors between member states belonging to a regional concept, which is the subject of the analysis in the remaining section.

By applying "region" as the unit of analysis and recognition as the independent variable, the model suggests that the extent of recognition accorded to a region affects its development. The degree of recognition, in turn, is underpinned by the socialization process between the region and the external actors. Socialization serves as a means to secure or confer recognition. The model hypothesizes that the strengthening of a regional concept depends on the extent of recognition it obtains from existing states. The trading of recognition between the two parties, in turn, may be observed by examining the interaction process between a region and the external actors. In this sense, the model suggests that external socialization is intricately linked to the contest for recognition. In other words, a region's social practices with 
non-members through the process of socialization are crucial to the understanding of recognition strategies. Such a definition differs significantly from most scholars' rather limited interpretation that socialization is an internal phenomenon. For example, the concept of socialization as envisaged in Acharya's security community model is restricted to members belonging to the same grouping. In this case, socialization is described as a

regular, formal or informal interaction (dialogue, negotiations, institutionalization) among a group of actors to manage mutual problems, realize a common purpose, achieve some collective good, and develop and project a shared identity (Acharya 2009: 24).

If interactions between member states can be expected to change mindset and adjust behaviors according to these scholars, there is no reason why such a process cannot be extended to external actors. In this way, the definition used in this dissertation is a much broader one which resonates with Snyder's (1997: 33) description that "[i]nteraction is any behavior that impinges on or is influence by some other party". In sociology, for example, socialization is simply understood "as what the individual learns, when he learns it and how he learns it, and the personal consequences of this process for him" (Dowse and Hughes 1972: 179). For an individual, the process of interaction with the inner group such as family members is therefore as important as with his wider or external social networks. The investigative goal of this dissertation is thus to assess whether a region's socialization with external actors has any effect on the cooperation level between member states.

The model proposed in this dissertation suggests that socialization with nonmembers confers recognition on the region, shapes the development of a regional 
concept and affects the way regional cooperation evolves within the grouping. Given the growing interest in constructivist scholarship on ASEAN of late and its emphasis on internal socialization, it is useful to tease out the main propositions of Acharya's model and explain what it predicts in order to show how it differs from the usage in the proposed model for the recognition of regions. The security community model examines the socialization process between member states belonging to a regional concept. A summary of Acharya's (2009) security community model is illustrated in Reference 2.

\begin{tabular}{|l|l|}
\hline $\begin{array}{l}\text { Socialization } \\
\text { based on norms } \\
\text { (2009: : 9) }\end{array}$ \\
\hline Independent variable & ASEAN norms (non-interference, non-use of force) (2009: 54) \\
\hline Process & $\begin{array}{l}\text { Socialization within ASEAN-5 through the ASEAN Way (decision- } \\
\text { making by consensus) (2009: 79) }\end{array}$ \\
\hline Motivation of state & Manage conflicts among ASEAN-5 members (2009: 18) \\
\hline Assumption & External forces have no role to play in the community (2009: 192) \\
\hline Limitation & Internal conflicts are managed bilaterally most of the time \\
\hline
\end{tabular}

In this model, the independent variable is norms. Through a process of socialization between members in ASEAN, norms create collective interests and identities. Drawing on examples from the way ASEAN dealt with security/political issues, Acharya describes how ASEAN-5 leaders were able to manage intra-regional 
conflicts among themselves, and in doing so, internalized a shared ASEAN identity. In such a community, external forces have no role to play in the development of ASEAN cooperation. Acharya (2009: 192) acknowledges that the model "does not tell us how such a community may be related to external pressures". In terms of limitation, the model also faces a challenge of explaining why the most difficult issues in ASEAN were resolved bilaterally in Southeast Asia most of the time, rather than through cooperation in ASEAN. Thailand's persistent refusal to discuss its longstanding territorial dispute over Preah Vihear with Cambodia in ASEAN while Malaysia and Singapore's decision to bring their competing claims to the outlying islands of Pedra Branca to the International Court of Justice (ICJ) instead of negotiating through ASEAN illustrate this constraint. More importantly, Acharya (2009: 192), himself, concedes that security communities are "basically inwardlooking constructs". Although Acharya does not elaborate on why this should be the case, he submits that identity formation "involves securing outside recognition of the community's own distinctiveness" (Acharya 2009: 28), which is the subject of investigation in the proposed model of this dissertation. Current scholarship on regional cooperation tends to downplay the influences the socialization process between a region (as a whole) and non-member entities may have on the development of a regional concept.

In the proposed conceptual framework of this dissertation, the emphasis on the socialization process is shifted from between members affiliated to a regional concept to between the regional grouping and the international community. The proposed recognition model for regions to be tested against the empirical data in the next three chapters is illustrated in Reference 3. 


\begin{tabular}{|l|l|}
\hline Regional \\
approach \\
to national \\
problems
\end{tabular}

While Acharya views socialization as a process which takes place and helps to internalize norms of cooperation between members, the proposed model in this dissertation suggests that socialization on the external front is a reflection of the contest for recognition. ASEAN's interaction with existing states confers recognition on the grouping which, in turn, drives cooperative behaviors among members. The degree and quality of socialization with non-members becomes a measure of the level of recognition which is traded between the entities. As described earlier, acts of recognition comprise a whole range of transactions, which are not to be understood as "a mere side-effect of an action" but has to be viewed as "the expression of an independent intention" (Honneth 2007: 330): 
Whether they be gestures, speech acts, or institutional policies, such expressions or measures are always cases of recognition if their primary purpose is somehow to affirm the existence of another person or group.

This means that a letter congratulating a region on the occasion of its first leaders' summit, while important as a first step toward recognition, has to be accompanied by concrete initiatives such as dialogues, bilateral treaties or the setting up of an overseas post. In the recognition of statehood, for example, the appointment of an ambassador typically follows after an exchange of diplomatic letters, among other substantive engagements.

In this model, recognition motivates ASEAN-5 countries to increasingly view ASEAN as a feasible regional platform to solving national problems. Increased recognition of a regional concept triggers the desire among members to cooperate with one another. The model assumes that an identity exists only to the extent that it is recognized by others. While it is possible that some regional concepts are created to deal with only internal issues, the focus here is on how socializing with non-members may influence the degree of cooperation between members. Recognition matters because it creates more policy options and widens the range of resources a region may tap on for its security and socio-economic development. Statehood, for example, is often viewed as a prerequisite to membership in funding organizations like the IMF. In the same way, regionhood brings about more economic and developmental opportunities for a group of countries than what a single member state is able to harness on its own. As explained in Reference 1, these are some of the factors which may trigger a region's demand for recognition. 
By making "region" the main subject of analysis and "recognition" the independent variable, the proposed model suggests that the development of a regional concept is influenced by the extent of recognition it obtains from existing states. Taking this course is not to dilute the utility of other variables such as norms, interdependence or national interests, but to enable this research to measure the robustness of using recognition as the main parameter in studying the evolution of regional cooperation. The goal of the remaining dissertation then is to examine if the nature of a regional grouping's interaction with the rest of the world (as opposed to within the group in Acharya's model), especially with the foreign powers, reflects the characteristics of the table in Reference 1. If the contest for recognition may be verified, the next logical step is to assess if such a struggle has changed the behaviors of member states toward regional cooperation as illustrated in Reference 3 . The concluding section of this chapter outlines these objectives, along with the hypotheses and expected outcomes based on the proposed model, to be addressed in the rest of the dissertation.

\subsection{Hypotheses and expected outcomes}

The discussion here details the two key objectives of the data analysis which will be carried out in the next three chapters. It also outlines the hypotheses and expected outcomes of this dissertation based on the conceptual framework presented in the preceding section.

To assess the soundness of the proposed model, the necessary first step in the data analysis is to scrutinize the social practices of a region with the international 
community. As highlighted earlier, the two pertinent questions to address may be summarized as follows: On the demand-side, what prompts a group of countries to seek regionhood? On the supply-side, what motivates existing states to recognize a regional concept? To find answers to these questions, the first goal of the data analysis is to analyze the diplomatic materials for the following (as presented in

\section{Reference 1):}

i. Were there initiatives by ASEAN to obtain fairer distribution of and equal access to economic resources?

ii. Were there efforts by ASEAN to raise its status and prestige in Southeast Asia?

iii. Were there instances of unfair treatment by any foreign powers toward an ASEAN member?

iv. Did foreign powers create and internalize a distorted image of the ASEAN countries?

v. Were there persistent efforts by foreign powers to exert continued hegemony over ASEAN countries?

vi. Did foreign powers trade recognition with ASEAN for other concessions?

vii. Were there any social struggles and confrontation initiated by ASEAN?

viii. Did any ASEAN country appeal to the grouping for collective action against an external actor?

ix. Were there any efforts to engage the public sphere in ASEAN's struggle for recognition?

If the above actions may be validated through the archival data, this dissertation will be able to conclude that an exchange of recognition was driving the process of interaction between ASEAN and the external actors. In other words, this list of 
questions is the litmus test to the elements of regionhood set out in Reference 1. If such an exchange of recognition may be ascertained, the second step is to investigate whether the outcome of a region's struggle for recognition has affected the attitudes of member states toward regional cooperation. Here, the aim is to examine whether increasing external recognition has changed ASEAN members' perceptions and behaviors toward regional collaboration especially in relation to how it may be exploited to overcome national problems as illustrated in Reference 3 . Accordingly, the tenth question which should be added to the list above in the data analysis is:

x. Did the outcome of the struggle for external recognition affect the desire for regional cooperation among ASEAN members and cause them to view the association as a suitable regional platform to solving national problems?

Based on the proposed model for the recognition of regions encapsulated in Reference 1 and Reference 3 , this dissertation will test the following three hypotheses:

1. The development of a regional concept depends on the grouping's socialization process with external actors;

2. The supply and demand of recognition between a region and the external actors underpins the socialization process; and

3. The extent of external recognition received by a region influences the attitudes and behaviors among member states toward regional cooperation.

As for the expected outcomes, the first hypothesis suggests that ASEAN's interaction process with non-member states has a direct influence on the way the Southeast Asian grouping has developed as a regional concept. Socialization with foreign 
powers shapes the regionhood of ASEAN and is as important as the interaction process among members in ASEAN, which is argued by Acharya. Second, the hypothesis suggests that ASEAN's social practices with the international community is a measure of the way recognition is contested and traded between the fivemember grouping and the foreign powers. This means that the outcome of the struggle for recognition can be quantified by analyzing whether and how foreign powers have dealt with ASEAN and how the latter has initiated or responded to such external overtures. Finally, the hypothesis predicts that the degree of external recognition obtained by ASEAN affects how member states perceive the grouping and cooperate with one another. In other words, increasing external recognition has motivated ASEAN countries to view the grouping as a useful regional platform to solving national problems, rather than regional ones.

As a summary to this chapter, recognition by the international community, in particular by the great powers, through the process of socialization reinforces the legitimacy in the construction of a regional idea. The recognition model developed in this dissertation works in a way that "allows for external influences and changes as the entity acquires surer footing or becomes a legitimate international actor" (Hammer 2007: 43). This chapter has illustrated how the recognition process functions as a dynamic exchange of concrete benefits between a region and the external actors. Rather than viewing recognition as a static event, the aim of the proposed recognition model for regions is to critically examine "the process by which the recognition occurs, and the reactions to the decision" because they are "in essence what are important for recognition as a doctrine due to the ever changing and reactionary manner of the process" (Hammer 2007: 41). Taken together, the 
model suggests that an entity is motivated to demand recognition for several reasons including to gain fairer and better access to economic benefits, to attain an equal status, to rectify a distorted identity and to reduce incidents of disrespect. On the other hand, the supply-side of recognition highlights the recognizer's resistance toward granting such recognition in order to maintain its hegemony and existing institutionalized patterns of cultural values or expected behaviors. Finally, the outcome of such an external recognition process directly affects the way members belonging to a regional concept respond to the notion of regional cooperation. The next three chapters illustrate the key findings of this dissertation based on the content analysis of the declassified diplomatic archives. The empirical findings, through the case study on the formative years of ASEAN in the 1960-70s, will be used to see if they support the theoretical framework proposed in this chapter. The next chapter begins the analysis of the empirical data with a discussion on the feasibility of associating the ASEAN grouping with Southeast Asia as a region. It outlines the critical structural environment which divided the communist and anti-communist poles, and how it had constrained the behaviors of ASEAN and resulted in the grouping's first act of pushing for political recognition through its proposal for a zone of neutrality in Southeast Asia. 


\section{Chapter 3: Misrecognition and Non-recognition of ASEAN}

The dissertation has thus far devised a model for the recognition of regions by drawing on the main components of existing scholarly works on personhood and statehood to elucidate the concept of regionhood based on external recognition. The proposed theoretical framework in Chapter 2 highlights the intimate relationship between the development of a regional concept and the way a region interacts with the outside group. It suggests that the quality of a grouping's socialization process with external actors is an indication of the extent that recognition has been traded between the two sides. It also predicts that external recognition received by the grouping, in turn, motivates member states to increasingly view the regional entity as a feasible platform to tackle national problems rather than regional or bilateral ones. However, the discussion has not yet established the prevalence of an intense struggle for external recognition by regional entities nor provided anecdotal evidence to illustrate how the outcome of such a struggle influences the way member states cooperate with one another. This task will be carried out in Chapter $3, \underline{4}$ and $\underline{5}$. Together, these three chapters put the proposed model for the recognition of region, described in $\underline{\text { Chapter 2, }}$, to the test by examining the way in which ASEAN interacted with the international community during its formative years from the 1960 s to 1970 s. The aim is to ascertain whether there had been a contest for recognition by ASEAN during this period, and if so, whether the extent of recognition received by the Association affected the way member states cooperated with each other.

The archival analysis in this dissertation begins by addressing the question as to whether it is prudent to use ASEAN as the unit of analysis that represented the 
voices and actions of the Southeast Asian region. As mentioned in Chapter 2, it is debatable whether recognizing ASEAN as an organization is tantamount to recognizing Southeast Asia as a region. As an overview of this chapter, the underlying argument in Section 3.1 and 3.2 is not whether an organization like ASEAN is a qualified regional actor in Southeast Asia, but which regional entity was positioned or accepted as the authoritative and legitimate actor in a particular region at a given point in history if one existed. The anecdotes from the diplomatic archives will illustrate how the ASEAN-5 member states embarked on a consistent strategy of limiting the membership of the grouping and fobbing off external pressures to expand ASEAN while withholding their support for other rival groupings and curtailing their involvement in parallel regional institutions. These efforts pivoted the role of ASEAN in Southeast Asia against the offerings by other competing regional entities. They were of utmost importance to the creation and articulation of ASEAN as the legitimate regional body for Southeast Asia in the eyes of the foreign powers. In a way, by drawing out the importance of internal recognition, as emphasized by Terada (2003), to the realization of a regional concept, these examples reinforce ASEAN as an appropriate actor for the Southeast Asian region. Critically, the discussion will show that there was no other suitable regional entity to take on this role in Southeast Asia, which makes ASEAN an appropriate unit of analysis in this dissertation.

The chapter then moves on to discuss how the foreign powers maintained a consistent policy of portraying Southeast Asia as a region of instability incapable of defending itself against "the enemy". It highlights how the geopolitical divide between the communist and anti-communist blocs constrained and affected ASEAN's interactions with the foreign powers in Section 3.3. The analysis looks at how 
communist powers like China and Soviet Union dealt with ASEAN during the latter's formative years. The archives reveal that the two communist strongholds refused to recognize the Southeast Asian grouping directly despite maintaining an accommodating attitude toward ASEAN. It highlights the effects that the existing geopolitical structure had on the recognition policies of external powers. Section 3.4 and 3.5 examine the genesis and outcome of ASEAN's first struggle for external recognition. During its formative years, the Association was zealously pursuing foreign powers' recognition of the Southeast Asian region and its right to exist as an equal in the international system. These efforts were targeted at remedying foreign powers' misrecognition of the fragility of the Southeast Asian region. In its pursuit for political recognition, ASEAN advocated the ideas of non-interference and non-use of force in the region through the promotion of a zone of peace and neutrality. Sharp ideological differences and the prevalence of power contests between China, the U.S. and Soviet Union led to the rejection of ASEAN's overtures for recognition in the political realm. Even middle powers like Japan and Australia also withheld their recognition of ASEAN's political regionhood. This image of inferiority, in turn, came to be internalized by the ASEAN countries. Such a process of misrecognition reinforced the conviction in some ASEAN states that their political desire for non-interference in the region remained to be a mirage. In addition to misrecognizing the region, Section 3.5 also highlights the deliberate policy of some foreign powers like the U.S. not to recognize ASEAN as a political entity in international forums like the UN. These findings lend support to the predictions of the proposed model presented in the preceding chapter. The non-recognition and misrecognition policies of the foreign powers led to the failure of ASEAN's earliest struggle for external recognition. 


\subsection{ASEAN and Southeast Asia: The challenge of rival regional groupings}

Section 3.1 and 3.2 justify the application of ASEAN as the legitimate actor for the Southeast Asian region in the 1960s and 1970s. Both sections aim to address the fundamental question as to whether recognition of a regional organization can be regarded in the same manner as the recognition of a region. The analysis that follows suggests that it does - in the same way that recognizing a government, whether elected or not, carries the same meaning as recognition of a geographical area which it has a jurisdiction over. It echoes the following observation by Beeson (2007: 6):

If regions are to amount to anything more than fairly arbitrary geographical demarcations, then they necessarily have a discursive and ideational component that gives some sense of what it means to belong to the region, and what factors distinguish members from non-members. Formal institutional development at the regional level is a power market of this process.

Both sections examine how the ASEAN-5 countries maintained a three-prong strategy of fobbing off external pressures for membership in the grouping, withdrawing support for existing regional forums and rejecting new proposals for regional cooperation. These efforts were critical in the founding years of ASEAN in that they set out the perimeters which distinguished ASEAN members from the society of states, and gradually positioned the grouping as the primary regional actor for Southeast Asia. The discussion supports the conventional interpretation that acclimation among member states is a critical first step toward the realization of a regional concept. Given the proliferation of regional groupings and overlapping membership at that time, this section first looks at how the five-member Southeast Asian grouping came to take on a prominent role over other rival regional bodies. 
Several regional organizations existed at the time when ASEAN was formed. However, many of these organizations which existed prior to 1967 such as the Southeast Asia Treaty Organization (SEATO) and Maphilindo were defunct or already on the decline by the time ASEAN was established. While these groupings existed alongside ASEAN during its founding years, at least in name, they were hardly of any threat to the newly formed five-member Southeast Asian grouping. In particular, support for SEATO was going downhill with U.S. withdrawal from South Vietnam, which led to its eventual dissolution in 1977. Sensing the dwindling support for SEATO among Asian countries, the U.S. State Department suspected as early as in 1969 that "ASEAN might have greater potential than SEATO as a vehicle for cooperation" (Australian Embassy in Washington 1969). Likewise, regional cooperation within Maphilindo, comprising the Malay states of Malaysia, Philippines and Indonesia, came to a halt with Indonesia's Konfrontasi policy against Malaysia in the early 1960s.

In the immediate years following the formation of ASEAN, the most prominent entities which competed with the Southeast Asian grouping for a regional role included the Association of South-East Asia (ASA), the Asian and Pacific Council (ASPAC) and the Ministerial Conference for Economic Development in South-East Asia (MEDSEA). Together, these three regional bodies possessed the greatest potential to challenge the role of ASEAN at that time, and will therefore be examined in detailed in this section. While several member states of ASEAN belonged to either one or more of these regional groupings, the empirical findings of this research will show that the interest of ASEAN countries in these rival groupings began to dwindle with the 
founding of the Association in 1967. The discussion that follows aims to illustrate how ASEAN came to assume a higher stature over these rival organizations.

First, the Association of South-East Asia or ASA was formed in 1961 between the countries of Malaysia, Thailand and Philippines. The stated goal of ASA was to promote cooperation in various areas of common interests including in the fields of culture, science and tourism (as was ASEAN). Shortly after its formation, however, ASA meetings began to lapse due to the unresolved territorial dispute over the state of Sabah between Malaysia and the Philippines. Provisions were later made for other Southeast Asian countries, in particular Indonesia and Singapore, to join the grouping. Wishing to avoid having to take sides in the Malaysia-Philippines territorial conflict, both countries declined the invitation. Even before the formation of ASEAN, Indonesian officials shared with their Australian counterparts that it was "impossible for Indonesia to join ASA even in modified form" (Australian Embassy in Jakarta 1967a). The Indonesian officials explained: "Considering its role as the biggest country in the area, Indonesia would need to be a founder member of whatever new regional co-operation association emerged". The extent to which the Indonesian government desired to position ASEAN as a distinct regional body for Southeast Asia and to disassociate it from other regional groupings like ASA could be seen from a meeting which decided on the naming acronym for the new association. Abu Bakar Lubis, who was the Head of Personal Staff to Indonesian Foreign Minister Adam Malik, revealed that

it was Malik who had suggested the name ASEAN. The Malaysians had then suggested ASAS, which in both Malaysian and Indonesian means "base" or "foundation", but this was rejected by Indonesia because it sounded too like 
ASA and because it had been proposed originally and rejected as the name for ASA... Malik had then come up with the generally acceptable ASEAN (Australian Embassy in Jakarta 1967b).

The archives also reveal that in the same month that ASEAN was formed, the $4^{\text {th }}$ meeting of the ASA foreign ministers in 1967 "agreed to a procedure for the gradual phrasing out of ASA activities, and requested the Malaysian ASA Secretariat to inform the ASEAN standing committee of the intention to transfer ASA programmes and projects to ASEAN" (Australian High Commission in Kuala Lumpur 1967a). This was one of the earliest indications that the ASEAN grouping would soon take precedent over ASA. After ASEAN was formed, representatives from Indonesia and Singapore met with the ASA group to discuss how to deal with several overlapping projects between the two groupings. There was an explicit agreement between ASEAN and ASA that regional efforts should not be duplicated in Southeast Asia. In one such meeting in March 1968, Malaysian Head of ASEAN National Secretariat Ismail Ambia disclosed that the representatives from the five countries decided that "ASEAN should take over the ASA projects" (Australian High Commission in Kuala Lumpur 1968a). This decision was significant in that it signaled a clear preference for regional cooperation through ASEAN rather than ASA. It sent the message that henceforth, cooperation in the region would be directed by ASEAN. It also reinforced the idea of a Southeast Asian region which included Indonesia and Singapore; an image which the ASA framework did not provide.

In retrospect, the failure of ASA, similar to Maphilindo, was due to the competing territorial claims by Malaysia and the Philippines. From this perspective, Malaysia's 
declared preference for ASEAN over ASA came as a surprise because the same territorial problem was expected to roll over into the new five-member grouping. This begs the question as to what prompted Malaysian policy makers to choose ASEAN over ASA? According to the archives, the Malaysian government decided that it would pursue a course of seeking to "prevent her differences with the Philippines from disrupting ASEAN" because of Indonesia's membership in ASEAN. According to Ismail, Malaysia would attempt in the "worst case" to ensure that

it was Philippines and not Malaysia which was excluded from the organization. Malaysia would not cut off her nose to spite her face over ASEAN. The continuation of ASEAN was important to Indonesia as it provided her [the] only bridge with the region. It was therefore important to Malaysia in terms of her bilateral relations with Indonesia (Australian High Commission in Kuala Lumpur 1968b).

With the founding of ASEAN, the empirical data finds that Malaysia was keen to cease its interest, as well as support, for ASA in an effort to strengthen its links with the region, especially with Indonesia, the largest ASEAN member. The decision to bring ASA activities under the auspices of ASEAN, in turn, reinforced the latter's role as the legitimate actor in Southeast Asia.

Second, the first meeting of the Asian and Pacific Council or ASPAC was held in Seoul from 14 to 16 June 1966. Australia, Japan, Malaysia, New Zealand, the Philippines, Thailand, South Korea, South Vietnam and Taipei were members of ASPAC. The objective of ASPAC was to strengthen the solidarity of countries in the region and to provide an opportunity for members to develop solutions to common problems. Here again, Indonesia and Singapore were not members of ASPAC due to 
the Council's heavy anti-communist undertones. Seeing the potential of ASEAN overtaking ASPAC as the engine for regional cooperation, ASPAC members like Japan and Australia attempted to invite Indonesia and Singapore to join ASPAC or participate in its meetings as observers. At a Diet session on 10 August 1968, Japanese Foreign Minister Takeo Miki announced that "Japan would work for the expansion of ASPAC's membership, seeking the participation of Indonesia, Singapore, Cambodia, Burma as well as Laos" (Australian Embassy in Tokyo 1968a). If realized, the expanded ASPAC was expected to challenge and weaken the role of ASEAN in Southeast Asia. With this objective in mind, Miki extended an invitation to the Indonesian and Singaporean leaders to join ASPAC during their visit to Japan in October 1968. However, both Southeast Asian countries turned down the invitation. The Indonesian foreign ministry indicated that "Indonesia would only be interested in ASPAC if the Japanese decided to use the organization as a channel for substantial new aid funds; but the Japanese had indicated that they had no such intention" (Australian Embassy in Jakarta 1969a). In a more direct response to the overtures by Miki, Indonesian President Soeharto said on 13 March 1969:

Considering her independent and active foreign policy, Indonesia will not enter ASPAC. Indonesia believes that it would be more useful and beneficial to establish regional co-operation by focusing her attention on activities in social and economic fields (Australian Embassy in Jakarta 1969b).

Likewise, Singapore Prime Minister Lee Kuan Yew replied to Miki that Singapore was "not interested in joining such an organization if it was concerned primarily with political or security matters" (Australian Embassy in Tokyo 1968b). Singaporean 
Permanent Secretary of Foreign Affairs Harry Chan further elaborated on the island state's attitude toward regional cooperation at that time:

Singapore's fundamental objection to ASPAC was that it had been political and anti-communist in its origin and continued to be so if to a lesser degree in its present operation. The difference between ASEAN and ASPAC, as they saw it, was that ASEAN went to the heart of Singapore's relationship with its close neighbors with whom its whole future was closely bound and ASPAC... did not go to the heart, of, for instance, New Zealand's relationship with other members - nor would it for Singapore. In any case member countries of ASPAC were not bound up with each other's future in the same way as ASEAN countries (New Zealand High Commission in Singapore 1968).

Singapore and Indonesia were not alone in their desire to remain non-aligned during this period. An internal Australian report confirms that other countries including Cambodia were suspicious of ASPAC because "most of its members were supporting the United States in Viet Nam" (Australian Department of External Affairs 1968a). Sensing the growing potential of ASEAN to challenge the regional role of ASPAC, Japan began to dissuade its ASPAC members from participating in ASEAN activities. In one instance, the Japanese advised South Vietnamese Minister for Foreign Affairs Tran Van Lam that "it would be unwise [for Vietnam]... to seek admission to ASEAN which duplicated the work of ASPAC" (Australia Embassy in Saigon 1969). These efforts were, however, insufficient to halt the growth of ASEAN.

With the formation of ASEAN, the Southeast Asian countries began to increasingly view ASPAC as an inappropriate vehicle to advance their regional objectives. This turn of event surprised the Australians who had in 1967 assessed that ASEAN 
countries like "Malaysia might see its continued membership of ASPAC as a safeguard against the threat of any Indonesian hegemony of ASEAN" (Australian Department of External Affairs 1967a). This was not to be the case as the Australian government would soon find out. As with ASA and ASEAN, the issue of ASEAN members holding overlapping membership in ASPAC was deliberated at official meetings between the ASEAN members. In March 1971, the five-member Southeast Asian grouping turned down a suggestion by Thailand and the Philippines, which were both ASPAC members, to "establish some form of association between ASPAC and ASEAN" (Australian Embassy in Jakarta 1971a). As a result, ASEAN member states with concurrent representation in ASPAC including Malaysia began to take a lesser interest in the Council's activities. This is evident from an assessment by diplomats from the Australian High Commission in Kuala Lumpur (1968c), who after repeated discussion with their interlocutors in Malaysia, concluded that "in Malaysian thinking, ASPAC occupies a subordinate position to ASEAN". Indonesia's continued disinterest to join ASPAC proved to be a major factor in encouraging the three ASEAN states to reconsider the level of their participation in ASPAC, as revealed in an internal Australian report:

Malaysia will not become deeply involved in ASPAC as long as Indonesia is not a member... their attitude towards the organization since its foundation has been unenthusiastic... The special significance which ASEAN has for them is as a bridge to Indonesia; they see ASEAN as providing a means for drawing Indonesia into an acceptable relationship with her regional neighbors... ASEAN is therefore attractive to the Malaysians (or at least to the Malay policy formulation) because of its political and security implications... ASPAC has no 
such appeal for the Malaysians (Australian High Commission in Kuala Lumpur 1969a).

It was no coincident that the reason for Malaysia's diminished interest in ASPAC also explained its withdrawal of support for ASA after the founding of ASEAN. The heavyweight of Indonesian membership in ASEAN gravitated Southeast Asian countries toward ASEAN. The outcome was a positive disposition toward ASEAN, instead of the broader Asia-Pacific grouping, which in turn calved out the perimeter of a Southeast Asian region centering on the five-member Association as the primary actor.

Finally, Japan mooted the idea of a Ministerial Conference for Economic Development in South-East Asia or MEDSEA. Terada (1998: 341) observes that Japan proposed the conference "partly to respond to the U.S. demands to contribute to stability in Southeast Asia". The first conference, convened in April 1966, was participated by Japan, Laos, Malaysia, Philippines, Singapore, Thailand and South Vietnam; Indonesia and Cambodia attended the conference as observers. MEDSEA served as a means for Japan to channel economic assistance to the region. However, when the membership of MEDSEA was first announced, the proposal was regarded as an attempt by Japan to exert its influence in the region. For example, nonfounding members like Australia assessed that it was not invited to the conference during its formative years because Japan was "anxious to confine these meetings to the South-East Asian countries and to avoid the appearance of their having been inspired by the United States" (Australian Department of External Affairs 1967b). 
Shortly after the establishment of ASEAN in 1967, the diplomatic records suggest that Japan undertook swift and aggressive moves with the intention of turning the conference into a permanent organization. During the $3^{\text {rd }}$ MEDSEA Conference from 9 to 11 April in 1968, less than a year after the formation of ASEAN, Miki made several proposals which would formalize the conference, including the creation of a standing committee, a study group to promote regional cooperation and an official acronym for the conference (Australian High Commission in Singapore 1968). The close timing of Miki's proposals to ASEAN's founding was perceived as a last ditch effort by Japan to disparage the newly formed ASEAN grouping. The Australian Embassy in Jakarta (1968a) reported back to Canberra that Miki's proposals created a public perception that "the Japanese were pressing to 'institutionalize' the conference in such a way that it could emerge as a rival to ASEAN". Evidently suspicious of Japan's real motivations for making these proposals, Indonesian Finance Minister Frans Seda, who led the Indonesian delegation to attend the MEDSEA conference, issued a stern statement to the Japanese host on behalf of the five ASEAN states:

Ministers of ASEAN countries shared the view that the formation of a permanent conference organization should be avoided and that Indonesia was only prepared to accept initiatives of the conference if they did not pose a danger to ASEAN (Australian Embassy in Jakarta 1968a).

While only at its infancy stage, the ASEAN grouping undertook a consistent strategy of protecting the relevancy of the Association as the legitimate actor for Southeast Asia. As a result, Japanese attempts to strengthen the MEDSEA structure were futile. At a meeting with Australian Deputy Secretary of External Affairs Richard Woolcott 
on 18 April 1974, Malaysian Secretary-General for ASEAN Yusoff Ariff pointed to the "strong Japanese influence in MEDSEA" and reiterated that "ASEAN states considered it important to ensure ASEAN was and remained the principal regional organization" (Australian Department of External Affairs 1974a). According to Yusoff, ASEAN felt that "MEDSEA was becoming too institutionalized" and "did not want that body to take over ASEAN initiatives". Yusoff further disclosed that the Southeast Asian grouping would therefore "adopt a low posture at MEDSEA". By November 1976, at a meeting of Japanese Southeast Asian Chiefs of Mission in Bangkok, the Japanese diplomats themselves acknowledged that MEDSEA no long had any "great utility" and agreed that it had become a "moribund" (U.S. Embassy in Singapore 1976b).

The preceding ASA, ASPAC and MEDSEA examples reflect the solidarity of the five Southeast-Asian member states toward the young ASEAN grouping, which in effect legitimized its regional role in Southeast Asia. The analysis has thus far highlighted how the five Southeast Asian states successfully positioned ASEAN as the primary vehicle to realize their regional agenda. In the midst of multiple regional bodies, the five ASEAN states decided to either withdrew their support or curtailed their involvement in other institutions. There would be no except to this policy even for Indonesia, the largest member in ASEAN. New Zealander Prime Minister Norman Kirk, for example, had asked for Indonesia's support for the creation of a "Southwest Pacific Consultative Group" (SPCG) during Indonesian Foreign Minister Malik's visit to New Zealand in 1973 (U.S. Embassy in Canberra 1973a). The proposed grouping was expected to include Australia, Indonesia, New Zealand, Papua New Guinea (PNG) and the South Pacific islands. During the meeting, Malik gave tacit approval to 
the formation of such a grouping because it "would be able to cooperate with ASEAN and would not arouse reaction of 'jealousy' on the part of ASEAN members" (U.S. embassy in Jakarta 1973a). To preempt any possible fallout with ASEAN, Indonesia sought the support of ASEAN members at the Seventh ASEAN Ministerial Meeting in May 1974 for Indonesia's membership in the SPCG. The ASEAN meeting acknowledged "Indonesia's special association with Australia but asked that Indonesia respect its membership in ASEAN and not allow membership in another association to conflict with ASEAN" (U.S. Embassy in Bangkok 1974a). The U.S. Embassy in Jakarta (1974a) reported that "Indonesia's ASEAN friends were not altogether happy about this but Indonesia had been able to reassure them while assuring them how vital it was that she should be able to sit down with PNG, Australia and New Zealand". This anecdotal account reflects the intense pressure impressed on member states of the need for their regional endeavors to take second place after ASEAN. The primary consideration of the ASEAN states during this period could be summarized in a confession by the Malaysian Ministry of Foreign Affairs that "while Malaysia remained unhappy about the proliferation of regional bodies, their interest in regional co-operation was now firmly centered on ASEAN" (Australian High Commission in Kuala Lumpur 1971a).

\subsection{ASEAN and Southeast Asia: The restriction on membership}

In addition to the withdrawal of support for competing groupings as discussed above, this section illustrates how ASEAN states also undertook the strategy of limiting the membership of ASEAN in order to realize its vision of a Southeast Asian region. 
Shortly after ASEAN's formation in 1967, Indonesian Foreign Minister Malik gave the following response to a question on the admission of new members:

ASEAN is an organization of South East Asia and of South-East Asian countries, which consists, as I have said before, of Ceylon, Burma, the Philippines, Thailand, Indonesia, Singapore and Malaysia - including Vietnam after she has solved her problems... But in this South East Asia, - the ASEAN, we cannot bring in Japan, Australia, New Zealand, Taiwan, India, Pakistan, and what's more, the U.S. (Australian Embassy in Jakarta 1967c).

By reducing its support for other competing institutions and fobbing off external pressures to expand the grouping, ASEAN was able to strengthen its status as the legitimate regional actor in Southeast Asia. After its formation, the archives reveal that several countries including Australia, India, Japan and Korea expressed an interest to join ASEAN. However, their advances were rejected by the ASEAN grouping. The discussion here explains how the attempts by Korea and India to join ASEAN were turned down by the Association which, in turn, allowed the five-member grouping to project its status as the primary vehicle for cooperation in Southeast Asia. (Australia and Japan's interest in ASEAN will be discussed in the next chapter). These examples highlight ASEAN's vigor in preserving its central role in the region.

The Koreans first tried to push for its participation in the ASEAN grouping during an official visit by Filipino Foreign Minister Carlos Romulo to Seoul in August 1974 when he met with the South Korean leadership at the highest level, including President Park Chung-hee, Prime Minister Kim Jong-pil and Minister of Foreign Affairs and Trade Gim Dong-jo. During the visit, the Korean host requested Romulo to "sound out members' views on Republic of Korea membership [in ASEAN]" (U.S. Embassy 
in Seoul 1974). At that time, Romulo responded that "membership in ASEAN would be granted only by unanimous agreement and that Government of Philippines would not solicit members" (U.S. Embassy in Seoul 1974). Another attempt to seek membership in ASEAN was made by Gim during a visit to Jakarta in 1975. A telegram from the U.S. Embassy in Jakarta (1975a) to Washington reporting on Gim's visit informed that the "Republic of Korea has 'knocked on ASEAN door' and been refused".

By 1975, it became clear to the Koreans that ASEAN did not desire to expand its membership beyond Southeast Asia. The Korean embassy in Manila conceded that the "Koreans are anxious for membership in regional grouping to replace defunct ASPAC, but fully aware that ASEAN is barred to them" (U.S. Embassy in Manila 1975a). After its failure to join ASEAN, Gim resorted to promoting an "Asian Forum of a non-military, political, cultural, and economic nature", but these overtures were again rejected by the ASEAN leaders who began to be wary of new regional bodies that might challenge ASEAN's regional role in Southeast Asia as discussed in the previous section (U.S. Embassy in Seoul 1975).

Next, the formation of ASEAN in 1967 also triggered an interest in New Delhi to reexamine India's engagement in the region. Shortly after the declaration by the five Southeast Asian foreign ministers, India indicated informally its interest to join the grouping. After a discussion with the Indian Ministry of External Affairs, the Australian diplomats in New Delhi observed that "the creation of ASEAN has perhaps piqued India and caused her to look more closely at her policy toward South-East Asia and to make public utterances which could be cited as proof of India's interest in the area" 
(Australian High Commission in New Delhi 1968a). In addition to the foreign affairs ministry, Australian High Commissioner to India Arthur Tange also reported back to Canberra that the Indian "Ministry of Commerce is activated by a fear lest the subregional groupings of ASPAC and ASEAN should begin to develop a framework for preferential trade and other arrangements from which India is excluded" (Australian High Commission in New Delhi 1967). The Indian High Commission in Canberra also disclosed that a conference involving the Indian heads-of-mission in Asia came to the conclusion that

formerly India used to concern itself over much with Europe and the capitals of the major powers and ignore South-East Asia. But this would no longer be the case... India's objective was to be in South-East Asia and not to be shut out by Japan (Australian High Commission in New Delhi 1968b).

There was a clear concern in New Delhi that ASEAN would be manipulated by foreign powers like Japan which would curtail its influence in Asia.

The overtures from the Indian government were, however, rejected by ASEAN. An internal memo from the Australian Department of External Affairs (1967c) noted that informal expressions of interest received from the Indian Government have met with resistance from the Indonesians and Malaysians who fear that the scale of India's problems would overshadow those of other members and distort the purpose of ASEAN. In the Indonesians' case, they also see Indian membership as a threat to their own position in ASEAN - one of first among equals.

Notwithstanding the initial rejection, Indian Foreign Minister Swaran Singh continued to reiterate India's interest in the developments of ASEAN and, like the Koreans, suggested for the possibility of creating a broader Asian cooperation during 
Indonesian Foreign Minister Malik's official visit to New Delhi in April 1974 (U.S. Embassy in New Delhi 1973). Similar to Japan's attempt to institutionalize MEDSEA as discussed in the preceding section, India's call for a larger Asia forum was viewed by ASEAN as another external endeavor to weaken the Association. The U.S. Embassy in New Delhi (1975) detected a deep-seated suspicion among their Malaysian and Filipino counterparts "that the Indians may be attempting to split ASEAN". The Malaysian foreign affairs ministry, in particular, expressed strong reservations regarding the "participation of any non-ASEAN nation in the organization meetings because this would leave the door open to requests from other nations in greater Asia, such as India, to be invited" (U.S. Embassy in Kuala Lumpur 1976a).

Taken together with the archival evidence presented in the earlier section, the discussion has thus far shown that the more foreign powers tried to promote parallel regional bodies or pushed for their involvement in ASEAN, the stronger the grouping defended its birthright as the legitimate actor for Southeast Asia. ASEAN states' curtailment of their involvement in parallel regional bodies began to legitimize ASEAN as the primary regional actor in Southeast Asia, which in turn compelled foreign powers to reexamine their recognition policies toward the grouping. The desire to keep out the foreign powers from ASEAN, and from the region, started from the onset of ASEAN's formation when the ASEAN-5 governments emphasized that they were only interested to expand its membership to include the Indo-China states in the long-run (U.S. Embassy in Jakarta 1973b). It was also evident from Malaysian Foreign Policy Adviser and Minister of Home Affairs Ghazali Shafie's dismissal in October 1973 of the possibility of an Asian-Pacific region serving as a cohesive economic-political unit because the region had "no acknowledged leader, no 
common historical tradition, no acknowledged enemy" (U.S. Embassy in Kuala Lumpur 1973a). The findings heretofore reflect the following observation by Barkin and Cronin (1994: 109-111):

The way in which political actors define the political and geographical boundaries of legitimate authority over territory and populations strongly affects the principles on which the international system will function... Legitimation stems not from the boundaries but from the community of sentiment.

The archival anecdotes and accompanying analyses have therefore illustrated how ASEAN succeeded to gain legitimacy as the regional actor of Southeast Asia from the "community of sentiment" in the 1960s-1970s, which qualified ASEAN as a suitable case study to test the proposed recognition model for regions presented in Chapter 2. Yet, this period was also a time when the region underwent a phase of ideological warfare between the ethos of capitalism and communism. To fully appreciate the context in which ASEAN struggled for external recognition during its founding years, the next section assesses how the geopolitical environment at that time affected the grouping's interaction with the communist bloc. (ASEAN's dealings with the non-communist countries will be discussed in the next two chapters).

\subsection{ASEAN and the communist powers}

The contest for external recognition in the 1960s-1970s was a long and difficult process for ASEAN. The structural environment during its formation years severely constrained the degree to which the ASEAN grouping was able to receive external recognition. This section addresses the exogenous factors which inhibited the way 
ASEAN pursued recognition for Southeast Asia. The ideological divide between the communist and anti-communist powers became a constant consideration in ASEAN's struggle for recognition. As a result, one of the key priorities for the five ASEAN states was the creation and development of a regional body which was not aligned to any powers. The ASEAN states had to be wary of giving away any impression that it was an anti-communist bloc. Such an outcome would invite the immediate wrath and condemnation of communist powers in the North like China and the Soviet Union. At the same time, ASEAN had to be careful not to send the message to the anticommunist powers that the Southeast Asian region was moving closer to the communist powers, especially in light of U.S. withdrawal from South Vietnam and the cessation of British military bases in Southeast Asia. On the bilateral plane, with the exception of Indonesia, the individual ASEAN states still depended on foreign military installation, in varying degrees, to cope with the growing assertiveness of the communist powers. Even Indonesia was reliant on the U.S. for its military purchases. Realistically, and perhaps conveniently, it was therefore only at the regional level that the five Southeast Asian states could broadcast their credential as a non-aligned grouping to accommodate both sides. In other words, ASEAN became an ideal vehicle to achieve this goal.

With the above backdrop, this section outlines the reactions of communist powers like China and Soviet Union toward the Southeast Asian grouping during its formative years. (The analysis on ASEAN's struggle for the recognition of non-communist powers will be done in the next two chapters). While the two communist powers were critical of regional groupings and viewed them as U.S. stooges during the initial years of ASEAN, they gradually took on a more accommodating approach toward ASEAN 
in the 1970s. The discussion here is important because the underlying structural constraint would later lead to ASEAN's first attempt at seeking political recognition. (This will be discussed in the next section).

The initial reaction of Soviet Union toward the formation of ASEAN was a highly critical one. Australian Ambassador to Soviet Union Frederick Blakeney reported back to Canberra after his meeting with Russian Minister of Foreign Affairs Andrei Gromyko in December 1968:

Soviet Union was opposed to regional organizations ("blocks" as Gromyko called them) of any kind (economic, cultural, political or defense) in South East Asia or anywhere else, including Europe. It favored cooperation on a "broad basis" between individual countries... "Blocks" even for economic cooperation had "without exception" led to political domination by the big powers (Australian Embassy in Moscow 1968).

It was evident from the meeting that Soviet Union was against the formation of ASEAN despite the latter's stated objective on economic cooperation. This view was repeated by Gromyko's deputy, Vasili Kuznetsov, who re-affirmed on 9 May 1969 that Soviet Union "opposed all military pacts and "closed" organizations (like the common market) which excluded other countries and gave special privileges to members, pursued selfish purposes and undermined international co-operation" (Australian Embassy in Moscow 1969). Kuznetsov's hostile response was clearly directed at the ASEAN grouping which, in the same year, had started discussion on the possibility of creating an ASEAN free trade area. This ASEAN initiative was mooted by Filipino Foreign Minister Romulo who suggested the idea of creating a "regional aggroupment - an ASEAN Free Trade Area". In making the case for the 
proposal, Romulo argued that once "the economies of ASEAN states are welded into a united and progressive union, the security of the member states could be assured" (Australian Embassy in Manila 1969). Russia's antagonistic posture toward ASEAN was no doubt triggered by its suspicion of the grouping's motivations in trying to create such a closed economic union.

Shortly after its formation, the Australian Embassy in Moscow (1967) reported that the Soviet Union "propaganda organs have continued to portray ASEAN as a trap set by Washington for unwary South East Asians". These included Russian newspapers denouncing regional groupings in Asia as platforms for Western hegemony. The communist power was suspicious of ASEAN's links to the West and concerned about its anti-communist posture. Thai Foreign Minister Thanat revealed that he had to personally assure his Soviet Union counterpart shortly after the ASEAN Bangkok Declaration that "there had been no prior consultation with the United States, and it was untrue to say that the Association was backed or encouraged by the United States in any way" (Australian Embassy in Bangkok 1967). On the other hand, the Australian government assessed that the Russians also hoped "to take advantage of the British withdrawal and the apparent doubts of some South-East Asian countries over placing their security solely in the hands of the United States" (Australian Department of External Affairs 1968b). This prognosis was revealed in an internal report by the Australian Department of External Affairs (1968b) on Soviet Union's attitude toward ASEAN:

Current schemes for South-East Asian regional cooperation on which the Russians look with disfavor, regarding them as attempts to construct an antiCommunist grouping and as instruments for the extension of United States 
influence. They are well aware of the theme of developing a non-communist regionalism in South-East Asia and they have no intention of being excluded from the area.

Adding to the doctrinal standoff between the communist and anti-communist blocs, the opposing views on the interpretation and practice of Marxism between Soviet Union and China also deteriorated relations between the two major communist powers. By 1970s, the ideological divide within the communist camp was so great that it surpassed Soviet Union and China's respective perceptions of the U.S. as the only threat in the region. In an attempt to calve out "for the Soviet Union an apparently moderate posture between the extremes of China's revolutionary crusade and what the Russians represent as American militarism in Viet Nam", the Russian government now desired "to counter the strong American presence in the region and any re-assertion of Chinese influence" (Australian Department of External Affairs 1968b). In the strategic calculations of Russian policy makers, the threats of China had by then outweighed that of the U.S.

By the early-1970s, Soviet Union therefore began to take on a less aggressive posture toward ASEAN as an insurance against China's active cultivation of the region. The withdrawal of U.S. and British troops from Southeast Asia, as well as ASEAN's careful efforts to promote Southeast Asia as a non-aligned region and its resistance towards the inclusion of foreign powers in its membership as highlighted in the earlier section, also prompted the change in Soviet Union's disposition toward the grouping. In particular, ASEAN's proposal for a zone of neutrality and peace, which will be elaborated in the next section, offered some assurance that the region 
endeavored to be a non-aligned grouping. A memo by the Australian government addressed to its embassies in Moscow and Beijing observes:

Earlier, the Soviet Union represented ASEAN as a potential military bloc and as a front for U.S. influence. It formerly criticized the ASEAN zone of peace as unrealistic compared with the Soviet collective security proposals. More recently, the Soviet Union seems to have adopted a more favorable attitude towards the zone of peace proposal and to have sought to reconcile it with its own security proposals. The USSR is clearly seeking to improve its relations with the ASEAN countries. Concern about China would be an important factor in its thinking (Australian Department of External Affairs 1973a).

At the turn of the decade, Soviet Union began to display a desire for a role in the creation of new regional forums. Soviet Union President Leonid Brezhnev's proposal for the creation of an Asian collective security system in June 1969 was the result of such a shift in its policy stance. While lacking details in the proposal, Moscow insisted that the "cessation of imperialist aggression in Asia and withdrawal of American troops from this region" was the condition for such a forum to take place (U.S. State Department 1973a). Singapore Foreign Minister Rajaratnam observed that Brezhnev's proposal was "intended to demonstrate that the Soviet nation was an Asian power and that it intended to increase its activity and influence in Asia" (Australian High Commission in Kuala Lumpur 1969b). Soviet Union's greater accommodation toward regional cooperation and interest to take the lead in the creation of new regional bodies in the 1970s were geared at preempting the U.S. and China from asserting a regional role in Asia. Responding to a question on the creation of a wider grouping in the Asian region, the Russian embassy in Canberra 
affirmed that the "Soviet Union would not wish to be excluded from such an arrangement" (Australian Embassy in Moscow 1973). As mentioned above, with the pending withdrawal of U.S. troops from Vietnam, the Soviet Union began to shift its focus on China as the greater threat in the region. This swing in Russia's perspective may be observed from the revelation of one of its diplomats that the inclusion of U.S. and Russia in any regional grouping would be "acceptable" to the Soviet Union because "[w]hat the USSR could not accept was the inclusion of China and exclusion of the Soviet Union" (Australian Embassy in Moscow 1973). Apart from highlighting Russia's concern over U.S. presence in the region, the analysis here suggests that Moscow's ideological standoff with Beijing also prompted the former to adopt an accommodating posture toward ASEAN.

As for the Chinese perspectives of ASEAN, while withholding its strong support, the Beijing government did not undertake a hostile position in denouncing the grouping in the way that the Soviet Union had done initially. The Chinese desire for ASEAN countries' recognition of the mainland, as well as for them to break off diplomatic relations with the Republic of China, restrained China from adopting an aggressive approach against the newly formed grouping. While ASEAN as a regional body was not institutionally prepared to accredit statehood, unlike its more mature European counterpart, the Beijing government recognized that any negative attitudes toward ASEAN would raise the suspicious of Southeast Asian countries and further diminish their support for the Chinese at a time when they needed it.

As a background, diplomatic ties between Indonesia and China were suspended in 1967 because of Chinese support for the communist movement in Indonesia. The 
rest of the ASEAN-5 countries also had no diplomatic ties with communist China during the grouping's formative years. Fears of communist insurgents delayed ASEAN members' recognition of China. With an estimated 13 million overseas Chinese during this period, the host governments were doubtful of their loyalty and generally regarded these overseas Chinese as continuing to receive support from the Beijing government to carry out subversive communist activities. This corroborates with Chia's (1988: 194) research which finds that "Chinese support for local communist insurgency groups in ASEAN countries" and the "presence of large ethnic Chinese population in the ASEAN region" limited the scope of Chinese relations with ASEAN".

However, China's admission into the UN in November 1971, followed by the issuance of the Shanghai Communiqué announcing the normalization of Sino-U.S. relations during U.S. President Richard Nixon's visit in February 1972 set off a series of diplomatic recognition of China by the ASEAN countries. Malaysia became the first ASEAN country to announce its interest to recognize China and have formal ties with the Beijing government. Malaysian Prime Minister Abdul Razak explained in December 1970 that "recognition of the international rights of Communist China would encourage a more responsible Chinese attitude to South-East Asia" (Australian Department of External Affairs 1971b). However, the Malaysian government was acutely aware that its plan to be the first ASEAN state to recognize China would upset the other four member states given their sensitivity to the Chinese subversive movement. With their sizeable Chinese population, Indonesia and Singapore were among the most skeptical about formalizing relations with China. The Australian Embassy in Jakarta (1972) reported that "the Indonesian position at 
the top policy-making level is officially that China is a threat to the ASEAN member countries and that they should exercise great caution and reserve in any discussions or dealings they have with China". There was also a deep-seated belief that recognizing China would necessitate the establishment of a Chinese diplomatic outpost, along with other exchanges in the host country which, in turn, could be exploited by the Chinese to advance their communist agenda. Singapore Prime Minister Lee, for example, feared that "the presence of a China embassy will inevitably retard the assimilation of local Chinese and possibly strengthen their attachment to the ancestral motherland" (Australian Department of External Affairs 1973b). Singapore Defense Minister Goh Keng Swee would later express in private discussion with the Americans that Singapore would be the "last or next to last" of ASEAN countries to recognize China and would put it off for as long as possible (U.S. Embassy in Singapore 1974a).

To alleviate such concerns, ASEAN member states came to a decision to "consult with each other before entering into diplomatic relations with PRC" (Australian High Commission in Kuala Lumpur 1972). Henceforth, the five Southeast Asian nations would update one another and share their views about normalizing ties with China at ASEAN meetings. Nevertheless, ASEAN states, themselves, accepted that the recognition of China was a matter of time and not of choice. Singapore Foreign Minister Rajaratnam explained in a parliament session in March 1972:

Since we recognize and support China's admission into the United Nations, we must have some form of relations with China sooner or later... ASEAN has discussed this and there's an agreement that before any member states enters 
into diplomatic relations with China, we must consult with and co-ordinate our actions (Australian High Commission in Singapore 1972).

Likewise, Indonesian President Suharto also shared with U.S. Deputy Secretary of Defense Bill Clements in 1974 that despite some differences in national interests among members,

ASEAN countries had coordinated policies and had reached consensus that steps taken would not be detrimental to peace in area... There was general agreement among ASEAN countries that recognition of existence of communist China is necessary and that isolation of China lessens China's responsibilities toward peace (U.S. Embassy in Jakarta 1974b).

The tendency within ASEAN to consult one another on matters related to the recognition of China added to the perception of the grouping's increasing capability to present a common international front. It was clear to the Chinese that any provocative attacks on ASEAN members, whether as a collective unit or bilaterally, in particular against Indonesia, would be a step back for China's desire and efforts to obtain recognition.

At the first ASEAN Intelligence Meeting in February 1973, Indonesian Head of State Intelligence Agency Sutopo Juwono revealed that Malaysia had received assurances from Chinese Premier Chou En Lai with respect to "China's attitude toward the overseas Chinese and the Malaysians considered that they had their internal Chinese problem under control" and "were therefore ready to move on recognition" (Australian Embassy in Jakarta 1973a). According to the U.S. Liaison Office in Beijing (1973), Chou believed that China's decision to end dual nationality for overseas Chinese would be "a major contribution to normalization of relations with 
ASEAN". On the issue of Chinese residents in Southeast Asia, ASEAN countries had long been wary of China's policy of permitting dual citizenship. In August 1973, Malaysian Prime Minister Razak shared with U.S. Ambassador to Malaysia Jack Lydman his concern that the 200,000 Chinese who had permanent resident rights in Malaysia at that time might "turn out to be constituents of the Chinese embassy" (U.S. Embassy in Kuala Lumpur 1973b). With the cessation of the policy, Malaysia finally established diplomatic ties with China in May 1974. The Australian Department of External Affairs concluded (1973a):

In the present context of international relations, we believe that China would likely to avoid interventionist policies in dealing with the ASEAN countries. China is conscious of Soviet competition and, like the Soviet Union, seems to want to develop its state relations with the ASEAN countries... The opening of relations between China and Malaysia will increase the pressure on the other ASEAN countries to come to terms with China.

After Malaysia, Philippines and Thailand became the next two ASEAN countries to recognize China in June and July 1975 respectively. True to their entrenched suspicion of China, Indonesia only announced the resumption of its diplomatic ties with China in August 1990, which would be followed by Singapore's opening of its formal relations with China two months later.

The discussion in this chapter has thus far explained how ASEAN shaped and asserted its authority as the regional actor for Southeast Asia in the 1960s-1970s. Its withdrawal of support for rival regional groupings and tight control over the admission of new members highlighted the extent to which ASEAN avoided a dilution of the grouping's Southeast Asian character. These efforts not only distinguished ASEAN 
as the legitimate actor for the region, but also indicated to the foreign powers that the previous regional arrangements were no longer acceptable to Southeast Asia and that future dealings with the region would require a whole new policy approach toward ASEAN. The analysis has also demonstrated how the doctrinal standoff between the communist and non-communist blocs had constrained the development of ASEAN. This would soon be the catalyst for the grouping's first attempt at seeking external recognition for the region, which the discussion will now turn to.

\subsection{Misrecognition of ASEAN}

The empirical findings in this section suggest that foreign powers strategically projected a distorted image of Southeast Asia in order to maintain their hegemony in the region. ASEAN's push for foreign powers' recognition of a zone of neutrality was an effort to remedy such a distorted image. Refusing to confer political recognition on ASEAN, the foreign powers instead propagated the view that ASEAN was a region incapable of looking after itself. The projection of such an image of inferiority came to be internalized by some ASEAN members, especially those countries hosting foreign military bases.

In the immediate years following its formation, the main policy preoccupation of ASEAN was to seek foreign powers' recognition of a Zone of Peace, Freedom and Neutrality (ZOPFAN) in Southeast Asia. After the passage of its founding document the Bangkok Declaration - in 1967, ZOPFAN became the second and only declaration made by the ASEAN-5 leaders in the run-up to its institutionalization in 1976. The ZOPFAN declaration in Kuala Lumpur on 27 November 1971 states: 
Indonesia, Malaysia, the Philippines, Singapore and Thailand are determined to exert initially necessary efforts to secure the recognition of, and respect for, South East Asia as a Zone of Peace, Freedom and Neutrality, free from any form or manner of interference by outside Powers (ASEAN 1971).

The declaration called for foreign power's recognition of ASEAN by not interfering with ASEAN's internal affairs. Despite the differing views among ASEAN members on how such a zone might be realized, the ZOPFAN declaration represented the grouping's first attempt at securing recognition for ASEAN.

The initiative was aimed at correcting foreign powers' perception that ASEAN was a region susceptible to power contest because of the inherent weakness in Southeast Asian states. Clearly, the "colonial image of big powers protecting smaller states" was still vivid in the minds of the ASEAN-5 states including Indonesia, the largest member of the grouping (U.S. Embassy in Kuala Lumpur 1973c). ZOPFAN was, therefore, targeted at correcting foreign powers' perception that ASEAN remained to be a region susceptible to power contest because of the inability of Southeast Asian states to defend their own borders. To achieve this goal, ASEAN officials led by Malaysia which was the primary engineer of the ZOPFAN concept, explored possible avenues to secure international recognition of its neutralization proposal. At the fourth committee meeting in March 1974, ASEAN senior official identified three possible means for ZOPFAN to be "recognized and accepted by major powers (U.S., PRC and USSR) as well as other powers" (U.S. Embassy in Singapore 1974b). The proposed methods of securing recognition included, one, passage of a UN resolution recognizing the zone; two, unilateral declaration by the major powers; and, three, bilateral agreements with the recognizing state. On the first proposal, Malaysian 
Prime Minister Hussein Onn explained in February 1976 that ASEAN had considered taking the concept of ZOPFAN to the UN for its acceptance because the realization of the ASEAN concept will depend on the great powers. It is they who create instability. When they create instability in other peoples' territories they do not suffer but other people suffer. We would like to be left alone" (The Straits Times 1976b: 28).

Thai foreign service officials would later add that ASEAN considered tabling a resolution on ZOPFAN in the UN because the Association "felt it necessary to air concept in international forum" (U.S. Embassy in Bangkok 1976a). That ASEAN was prepared to put the issue of recognizing ZOPFAN to an international forum like the UN for a vote highlighted the importance of external recognition to the grouping during its founding years. However, the Southeast Asian grouping eventually had to give up on the idea of bringing the ZOPFAN agenda to the UN because of a concern that the move "might result in outright rejection of the zone" (The Straits Times 1975a: 10). It was then decided that foreign powers' recognition of ZOPFAN would suffice for a start to realize the zone.

External endorsement of ZOFPAN was deemed as necessary by ASEAN to legitimize the grouping and to guarantee peace and stability in Southeast Asia. Acknowledging the intense competition among foreign powers for hegemony and the helplessness of ASEAN states, Singapore Prime Minister Lee concluded on 4 August 1973 that the "big power game is acute in Southeast Asia" and that ASEAN countries "are trapped in the schemes of the great powers" (U.S. Embassy in Singapore 1973a). The ZOPFAN proposal would serve as a means to rectify and correct the false label imposed by foreign powers on ASEAN. In a meeting to discuss "the 
manner in which big power 'recognition' [of ZOPFAN] would be manifested", senior ASEAN officials agreed in June 1973 that initially "the U.S., the Soviet Union and the PRC would be sought to 'recognize and respect' the zone, but other powers which had strategic or economic interests in the region might later be asked" (U.S. Embassy in Kuala Lumpur 1973c).

Except for China which paid lips service to the ZOPFAN concept, foreign powers including the U.S. and Soviet Union, and middle powers like Japan and Australia offered no support to the proposal as noted by Singapore Prime Minister Lee in 1973 that the "only major power that has responded [to ZOPFAN] is China but it is not yet in a position to guarantee" (U.S. Embassy in Singapore 1973a). Lee added that the "other two which can guarantee it, the Soviet Union and America, have not responded". The Beijing government, while not rejecting ZOPFAN outright, paid only lips service to ASEAN's request for China's recognition of ZOPFAN because it was hoping at that time that ASEAN countries would open diplomatic ties with China, as discussed previously. At a meeting with the Australian ambassador on 11 May 1973, Chinese Premier Chou En Lai affirmed that "China supported the neutralization of Southeast Asia" (Australian Embassy in Beijing 1973). In a separate meeting with Indonesian Foreign Minister Malik, Chinese Foreign Minister Chi Peng-Fei also assured the Indonesians that "Peking wanted to support ASEAN in achieving a zone of peace" (Australian Department of External Affairs 1973a). Nonetheless, the Chinese made it clear on many occasions that they considered ZOPFAN to be a "long-term project" which could not be realized for as long as there were foreign military bases in the area (U.S. State Department 1973b). 
As for Japan, while Tokyo took a welcoming position in its public messaging, its foreign ministry was not prepared for the country to recognize ZOPFAN. Shortly after the declaration, the Japanese foreign ministry cabled the following instructions to its missions overseas to set out Japanese attitude towards ZOPFAN:

Japan regards the ASEAN proposal as a healthy initiative and considers it wise that countries of the region should take steps to deal with political as well as economic social matters. ASEAN efforts in this direction are "highly evaluated" by Japan (Australian Embassy in Tokyo 1971a).

However, in private meetings, the Japanese disclosed their belief that the "neutralization of Southeast Asia would tend to create a vacuum which would attract further Soviet interest in the area" (U.S. Embassy in Canberra 1973b). The Japanese shared with the Australians that Japan's "attitude to the [ZOPFAN] Declaration was one of 'respecting the desire' rather than support" (Australian Department of External Affairs 1971a). Japanese Deputy Vice-Minister Shinsaku Hogen would later deliver a even more pessimist assessment of ZOPFAN when he shared in confidence with Australian Ambassador to Japan Gordon Freeth on 6 December 1971 that "the declaration made at Kuala Lumpur was only an expression of hope directed at the larger powers rather than a move towards genuine non-alignment" (Australian Embassy in Tokyo 1971b).

Likewise, the Australians' position was one of non-support for ZOPFAN as reflected in one of its internal reports:

In public statements we have supported regional efforts directed towards peace and stability in Asia, and welcomed the decision of the five ASEAN governments to establish a zone of peace and neutrality in South East Asia. But 
privately we have reservations about the practicality of the ASEAN proposals (Australian Department of External Affairs 1971c).

Canberra was concerned that China would exploit any support for the ZOPFAN declaration as an opportunity to call for the withdrawal of foreign military bases in Southeast Asia and the cessation of Australian defense arrangements in the region such as the Five Power Defense Arrangements (FPDA). An internal memo by the Australian Department of External Affairs (1971a) further assessed that the essential flaw in the neutralization thesis with respect to China is that she cannot be excluded from the region. The Americans can withdraw to the other side of the Pacific, the Russians may be kept nibbling at the northern and southwestern approaches to the region, but China has common borders with three of the Group of Ten... Three of the ASEAN countries - Thailand, Malaysia and Singapore - have significant overseas Chinese communities ... Strategically, commercially, ethnically and culturally, China is locked into the region. Guaranteed neutralization could conceivably blanket the Soviet and the United States presence; but China is part of the region.

The Australians were concerned that the development of ZOPFAN could "if and when they reach a more advance stage, have a limiting effect on Australia's freedom of action", and concluded that it would be "against Australia's interests to encourage developments toward the neutralization or the establishment of a fully neutral zone in South East Asia" (Australian Department of External Affairs 1973c). Here again, foreign powers' fears of losing their influence in Southeast Asia was a major consideration in their assessment of the ZOPFAN proposal. 
Turning to the U.S. perspective, far from endorsing ZOPFAN, Washington consistently maintained the position that ASEAN states were too weak to fend for themselves and refused to recognize the zone. Shortly after the declaration, Thai Ambassador to the U.S. Nai Sunthorn Hongladorom on 10 January 1972 presented a letter to U.S. Assistant Secretary of State for East Asian and Pacific Affairs Marshall Green, requesting for the U.S. government's "considered views and reactions" toward the ZOPFAN proposal. Rather than recognizing the zone, Green's reply to ASEAN merely registered U.S. appreciation of the efforts "to achieve greater peace and stability in Southeast Asia" (U.S. State Department 1975b). When pressed again by the Thai foreign ministry for U.S. official position on ZOPFAN in 1975, the U.S. State Department (1975c) instructed its embassy in Bangkok to give a nonchalant reply that "the ASEAN member states also recognize that much remains to be done before such an objective can be realized; the secure independence of sovereign Southeast Asian nations is its essential precondition".

Internally, U.S. Ambassador to Indonesia David Newsom assessed that the U.S. should maintain its neutrality toward the concept instead of endorsing it:

As in the case of ASEAN, we should say as little as possible and allow it to proceed at its own pace; to succeed or fail in its own good time and as a result of the efforts of the nations concerned... There will be adequate time for the endorsement if the zone approaches reality and other major powers demonstrate a genuine interest in such a concept (U.S. Embassy in Jakarta 1976b).

Like the Australians, Newsom was concerned that any public endorsement would lead to demands and pressures for the cessation of U.S. military activities in the 
region. Given its conspicuous military presence in the Philippines and Thailand, the success of ZOPFAN hinged on U.S. receptivity to the proposal. The U.S. government was acutely aware that its military presence in Southeast Asia was a subject of strong criticism because they were "hypothetically obstacles to ASEAN's desire for a region of peace and neutrality" (U.S. Embassy in Manila 1974a). Publicly, the U.S. government chose therefore to maintain the perspective that the region comprised a group of fragile nations lacking the ability to fend for themselves especially against the tide of communist insurgency. Conceiving the image of a helpless region enabled U.S. to justify the need for its continued presence in Southeast Asia.

Externally, the U.S. government continued to propagate the view that ASEAN was a region incapable of protecting itself. While Washington resisted from making any harsh comments on ZOFPAN by maintaining a neutral position, its diplomats, however, on occasions found it difficult to hide U.S. true assessment of ZOPFAN. In one such revelation, U.S. Ambassador to the Philippines William Sullivan, during a speech given in Manila in September 1973, dismissed ZOPFAN as "not only premature but perhaps idealistic... it did not look to me to be an ideal prescription for Southeast Asia" (U.S. Embassy in Bangkok 1973a). In no time, the press picked up the story and labeled these remarks as U.S. authoritative views on ZOPFAN. Ambassador Sullivan's comments quickly earned him a sharp reproach from Washington. In a follow-up telegram, the U.S. State Department (1973c) reminded Sullivan to keep in step with Washington's official position on ZOPFAN as expressed by U.S. President Nixon in his report to the Congress on 9 February 1972:

Neutralization of the area bears witness to their readiness to discuss even the most difficult issues of common interest. Our own dialogue with the ASEAN 
member states also demonstrates a sober awareness that much remains to be done before such an objective can be realized. The secure independence of sovereign Southeast Asian nations is its essential precondition.

In the history of ASEAN's pursuit for U.S. recognition of Southeast Asia, Washington therefore persisted to propagate the view that ASEAN was a region inept yet to protect its own sovereignty. Evidently, U.S. objective of adopting such a stance was to safeguard its hegemony from the influence of the Chinese and Russians. Yet, such a projection of inferiority to ASEAN states was taking place at a time when the U.S. forces were pulling out of Vietnam. It is telling that even within the U.S. State Department, there were opposing views toward U.S. unhelpful position on ASEAN. This group which was more sympathetic to ASEAN's desire for recognition lobbied for Washington to give a favorable response to ASEAN's overtures. For instance, after assessing the likely consequence of U.S. recognition of ZOPFAN, U.S. Ambassador to Malaysia Francis Underhill argued:

U.S. failure to comment favorably [on ZOPFAN] is disturbing and some Government of Malaysia officials see us as an adversary in this context... the proposal is unquestionably constructive... in that it would inhibit the Soviets and the Chinese as well as ourselves. Furthermore, it is sufficiently imprecise that we can generally endorse it as a worthwhile long range objective; such an endorsement commits us to nothing (U.S. Embassy in Kuala Lumpur 1975a).

However, U.S. State Secretary Henry Kissinger's reply to these internal pressures to recognize ASEAN's ZOFPAN initiative disclosed U.S. continued desire to assert its influence in Southeast Asia. Kissinger explained: 
In view of current communist offensives... this would be particularly poor time to change our public stance on ASEAN proposal for a Southeast Asia neutrality zone. Irrespective of substantive merits, any apparent shift of line we take with ASEAN nations toward greater acceptance of neutrality scheme might well be misinterpreted as evidence of failing US resolve (U.S. State Department 1975d). The projection of the image of inferiority to the Southeast Asian nations was therefore important not only to fob off ASEAN's request for recognition of ZOPFAN but was also at the core of defending U.S. hegemony in the region.

Such an image of inferiority began to be internalized by those ASEAN states which depended on foreign military bases for their security. ASEAN countries began to doubt if it was truly possible for the region to be freed from power competition. There was a growing fear that neutralization would leave Southeast Asia more susceptible to power rivalries and the rise of communist insurgents. U.S. Assistant Secretary of State for East Asian and Pacific Affairs Philip Habib concluded from his meeting with Filipino President Ferdinand Marcos in May 1975 that Marcos was insistent that he does not want to dislodge us from the bases, nor weaken U.S. deterrent power in the region, and would feel naked without that cozy little blanket we provide (U.S. Embassy in Manila 1975b).

Foreign powers' negative reactions to ZOPFAN considerably weakened ASEAN's resolve to push for recognition. Indonesian President Soeharto, for example, shared with Australian Deputy Prime Minister and Defense Minister Lance Barnard during the latter's visit to Jakarta in April 1973 that "it might take another ten years to achieve a really stable peace in the area" before a zone of neutrality might be realized (U.S. Embassy in Jakarta 1973c). Singapore Prime Minister Lee also shared 
with U.S. Deputy Secretary of Defense Bill Clements in 1974 that the security of the region depended on a "countervailing force which can only be the U.S." (U.S. Embassy in Singapore 1974c). Notwithstanding the grouping's sentiment that it would take a long time to realize such a zone, Filipino Foreign Minister Romulo emphasized that the ZOPFAN declaration, as a "statement of intention", was itself of "great political importance for the future of the region" (Australian Embassy in Manila 1971).

The ZOPFAN case study in this section has illustrated the extent to which foreign powers, especially the U.S, tried to maintain their influence in the region by refusing to recognize the zone and portraying ASEAN countries as a region lacking the means to defend themselves. The sustained projection of this image of inferiority suggests that Southeast Asian countries were a victim of misrecognition by the society of states during its formative years. It reinforces the following theoretical analysis in Chapter 2:

Since our notion of who we are arises from social interactions, the experience of repeated disapproval or stigmatization in the gaze of significant others may well compromise our sense of self-worth... Being in a group whose culture is reviled and devalued is to be prone to this kind of moral harm. To make effective repairs to damaged identities requires that the internal self-dislocation generated by malign intersubjective relations be overcome. The despised group must be revalued and publicly acknowledge as a legitimate presence within the body politic (Kenny 2004: 151). 
The findings heretofore support the model of recognizing regions as described in Chapter 2 which contends that one of the primary motivations driving a region's struggle for recognition is to regain an identity distorted by misrecognition.

\subsection{Non-recognition of ASEAN}

In addition to the misrecognition of the region by the foreign powers, the U.S. also carried out a deliberate policy of not recognizing the political identity of ASEAN during its formative years. U.S. non-recognition policy toward ASEAN was reflected in its interactions with ASEAN states in international forums like the UN. In a meeting with Australian Deputy Secretary of External Affairs Richard Woolcott on 18 April 1974, Malaysian Secretary-General for ASEAN Yusoff Ariff disclosed that "ASEAN had for some time been formulating decisions before attending international meetings" (Australian Department of External Affairs 1974a). According to Yusoff, ASEAN foreign ministers instructed that "prior to any international conference the ASEAN Secretary-General [from each member state] should meet to discuss common approaches to the matters under consideration". In this regard, the ASEAN states had therefore developed a habit of consulting with one another on UN matters and often voted on the same side in the UN General Assembly (UNGA) even prior to its institutionalization in 1976. While the ASEAN countries might not vote in the same way all the time, these regular consultations were deemed as useful lobbying opportunities by the foreign powers. Naturally, the U.S. saw the importance of drawing on ASEAN countries' support to ensure the safe passage of resolutions it supported in the UNGA. Apart from the five votes that the U.S. could possible pick up, the ASEAN states in their capacity as developing or Muslim countries also 
possessed varying degrees of influence over the voting decision of like-minded countries. This was one of the reasons why U.S. Ambassador to the UN John Scali conceded in 1974 that ASEAN countries were aware that "U.S. policy interests require ASEAN actions perhaps more than they need ours... we are continuing to exercise care in manner in which we concert with ASEAN here" (U.S. Mission in the UN 1974).

While recognizing the significance of making sure that ASEAN states voted alongside the U.S. in UNGA resolutions, the State Department refused to lobby ASEAN directly as a group. Its modus operandi to gain their support in defeating hostile resolutions in the UN was to lobby ASEAN states on a bilateral basis. In order to secure all the ASEAN's votes without putting U.S. in the position of having to recognize the grouping, Washington resorted to lobbying the Southeast Asian grouping through a third country like Indonesia or Japan. In one instance, the U.S. State Department tasked its embassy in Tokyo to highlight "the importance of close Japanese consultation with ASEAN in effort to defeat hostile resolution" and went on to stress to the Japanese government that it "should lead effort to assure ASEAN cooperation, avoidance of any moves without prior consultation" (U.S. State Department 1975e). On another occasion, Washington also urged Indonesia to "use its influence with other ASEAN countries to bring them to similar position" as the U.S in the UNGA. (U.S. State Department 1975f). In these lobbying efforts, the U.S. State Department carefully avoided giving the appearance that the U.S. was engaging ASEAN countries collectively as one unit, preferring instead to rely on its bilateral channels. Here again, the world's superpower shunned away from boosting the political stature 
of ASEAN by refusing to engage the region as a whole in the UN while instigating a third party to lobby ASEAN directly behind closed doors.

However, the intensification of coordination efforts among ASEAN-5 countries on UNGA matters would soon lead to a recommendation by U.S. Permanent Representative to the UN Daniel Moynihan in September 1975 asking for Washington to make a "coordinated approach to ASEAN countries as ASEAN". Specifically, Moynihan proposed that

each foreign office [in the ASEAN-5 countries] would be told that we are simultaneously approaching the other four in recognition of the commonality of their interests. We could then stress the important role ASEAN as a whole might play in a matter of great interest to the United States (U.S. Mission to the UN 1975).

By lobbying ASEAN states as a collective unit, Moynihan believed that "such direct recognition of ASEAN as an increasingly forceful sub-regional association" would influence them to vote alongside the U.S. in the UNGA. If approved by the U.S. State Department, the proposed outreach to ASEAN would have represented a concrete U.S. recognition of ASEAN's political identity and significantly elevated its status in the region.

However, U.S. Ambassador to Malaysia Francis Underhill gave a rather fatal reply to Moynihan that "we see no place, really, to plug into ASEAN as a collectivity... we appear to be limited to high level bilateral demarches" (U.S. Embassy in Kuala Lumpur 1975b). Underhill's views were supported by his U.S. counterparts in other Southeast Asia locations. U.S. Embassy in Manila (1975c) argued that "ASEAN is 
not yet approachable as a collective entity for political lobbying". Also doubting the effectiveness of a coordinated approach to ASEAN, another U.S. diplomat in Singapore provided the following assessment:

Perhaps when ASEAN has settled down into something more firmly structured than is the case today we might wish to do so, but as matters now stand, ASEAN members states are still in the process of working out among themselves ASEAN's ultimate role... Thus it would be jumping the gun to expect ASEAN member states at this stage to respond on the basis of regional solidarity rather than on individual political calculations (U.S. Embassy in Singapore 1975a).

Equally skeptical, another U.S. diplomat in Indonesia warned that a "U.S. approach to ASEAN could get bogged down in procedural and substantive consultations (among bureaucratically minded ASEAN countries themselves)" (U.S. Embassy in Jakarta 1975b).

As in the case of ZOPFAN, there was a strong resistance within the U.S. diplomatic community against endowing ASEAN with any sort of political identity or recognizing its political standing within the UN. As a result, the U.S. State Department decided that "prospects for useful coordinated approach to ASEAN countries as ASEAN [are] inauspicious at this time". The telegram from Washington further instructed its embassies in ASEAN that "representations to each government should note similar approach being made to other four, but should not leave impression that our approach is to ASEAN as such" (U.S. State Department 1975g). The message was that the U.S. government did not recognize the existence of ASEAN. 
As a summary to this chapter, the ZOPFAN proposal was ASEAN's first attempt at correcting the distorted image of inferiority projected by foreign powers toward the Southeast Asian region. It was the grouping's earliest effort to seek political recognition. From the political perspective, it is evident from the anecdotal archives that foreign powers, great and middle powers alike, refused to recognize the regionhood of ASEAN given their reluctance to support ZOPFAN. The external powers including Australia, China, Japan and the U.S. were not prepared to recognize ASEAN as a regional political entity other than paying lips service to the ZOPFAN initiative. As highlighted in the proposed model in the preceding chapter, the desire to rectify the misrecognition by foreign powers motivated ASEAN's push for ZOPFAN. Washington, in particular, also maintained a strategy of not recognizing ASEAN's collectivity, as seen in its refusal to engage the grouping for UN lobbying so as to preserve its supremacy in the region by dealing directly with each of the ASEAN states. On the supply-side of recognition, the preference of foreign powers like the U.S. for status quo in their dealings with Southeast Asian states reinforces Taylor's (1992: 66) observation that the "dominant groups tend to entrench their hegemony by inculcating an image of inferiority in the subjugated". These findings support the analysis in the recognition model proposed in Reference 1.

Given the strategic importance of the U.S. to the Southeast Asian states, it was all the more surprising that their closest ally was not only reluctant to endorse ASEAN with political recognition of any sort, but launched a deliberate policy of portraying an image of inferiority toward the Southeast Asian region. Yet, why did ASEAN's initial failure to obtain international recognition not lead to the weakening of the grouping during its formative years? How does one explain the continued progress of regional 
cooperation in ASEAN during this period considering that the rejection of the main principles of ZOPFAN on non-interference and non-use of force were also the same ideas encapsulated in the ASEAN norms? The next two chapters account for this by explaining how ASEAN's success in obtaining recognition from other foreign powers like Japan, Australia and the EEC compelled the U.S. to reconsider its strategy of not recognizing ASEAN. 


\section{Chapter 4: Australia and Japan's Recognition of ASEAN}

The preceding chapter has examined ASEAN's earliest endeavor at seeking external recognition during its formative years. From the onset, the grouping's withdrawal of support for parallel regional bodies and its decision not to expand its membership were critical in reinforcing and legitimizing the regional role of ASEAN in Southeast Asia. The archival analysis has found that foreign powers' repeated portrayals of a region too frail to defend itself triggered ASEAN's first attempt at seeking political recognition through its proposal for a zone of peace. However, ASEAN failed to correct both communist and anti-communist powers' misrecognition of the region as the empirical data has shown. Instead, the evidence suggests that foreign powers like the U.S. instituted and maintained a non-recognition policy of ASEAN in international forums like the UN. Together, these empirical findings lend support to the model for the recognition of region outlined in Chapter 2. A strategy of nonrecognition and misrecognition of ASEAN enabled the external powers to maintain their respective interests and hegemony in Southeast Asia.

In retrospect, ASEAN's failure to secure political recognition ought to have weakened its institutional building efforts, but it did not. The aim of $\underline{\text { Chapter } 4}$ and $\underline{\text { Chapter } 5}$ is to account for this by explaining how ASEAN succeeded to obtain external recognition of its regionhood on the economic front, and how it in turn motivated member states to deepen regional cooperation in Southeast Asia. Foreign powers, which resisted initial efforts to have formal relations with the grouping, began to recognize ASEAN's regionhood in consideration of their own interests. The empirical evidence in these two chapters will show that the growing recognition of ASEAN was not driven innately 
by shared norms, as Acharya proposes in his security community idea. Rather, the five countries sought recognition of ASEAN as a means to solve their own national problems. The member states understood that without securing foreign powers' acceptance of ASEAN, access to funding, technology, capital, trade concessions and other development aids would not have been possible beyond what was already offered on a bilateral basis. However, the modus operandi of a "regional approach to national problems" also caused delays in obtaining foreign powers' recognition of ASEAN during its formative years. This implies that where national interest was threatened by such external recognition of ASEAN, member states demonstrated less enthusiasm toward regional cooperation. The discussion in the two chapters centers on ASEAN's relations with Australia, Japan, the EEC and the U.S.

As a brief outline to this chapter, the next section continues the archival analysis by examining ASEAN's economic importance to the foreign powers. It discusses the economic strength of ASEAN by highlighting its importance as a source of natural resources. The rest of the chapter looks at the genesis of ASEAN's socialization with Japan and Australia. (The analysis on the EEC and the U.S. will be done in the next chapter). The discussion unfolds the motivations driving the interactions between ASEAN and the two regional powers. Japan and Australia's substantial stakes in Southeast Asia and their proximity to the region are the main reasons for beginning the case study with these two countries. Broadly summarized, Japan had maintained closer economic ties to the region while Australia had developed stronger security linkages with the ASEAN states. In his dealings with the respective ASEAN governments, for example, Australian High Commission to Malaysia John Rowland highlighted in 1971 that Australia was regarded by ASEAN as the "outer circle of 
countries supporting and linked with the neutralized area [ZOPFAN]" as discussed in the preceding chapter. In comparison with Japan, Rowland further explained that we were more closely involved than Japan; we were smaller; we had a common frontier in Indonesia; we were more involved with the security of Malaysia and Singapore than any of their neighbors; we were also involved with the security of the SEATO and Indo-China countries (Australian High Commission in Kuala Lumpur 1971b).

Further, according to the Australian Department of External Affairs (1971d), the Australian "government has maintained a policy that we have an important role to play in the South-east Asian region of which we see ourselves as geographically a part". In contrast to Australia, Indonesian Secretary-General for ASEAN Umaryadi gave the following reflection:

Japan was still very tied to the U.S. and the west and therefore tend to be less independent in the way which it looked at Asia. This had very significant influence on the way in which the ASEAN partners were prepared to deal with the two countries (Australian Embassy in Jakarta 1974a).

Notwithstanding ASEAN's perspective above, the inclusion of Japan in this study is a straightforward one given its geographical proximity to ASEAN and sizeable business interests in the region. A study by Ikema (1980: 461) finds that in 1976 "ASEAN countries exported to Japan 26 per cent of their total exports, and imported from Japan about 23 per cent of their total imports". Further, the study also reinforced the earlier observation in this dissertation that the portion of ASEAN's trade with Japan was significantly higher than those of intra-ASEAN imports and exports. 
The discussion outlines the events and factors leading to the development of ASEAN's economic socialization with Australia and Japan. It attributes the development of ASEAN to the grouping's success in obtaining foreign powers' recognition of its regional economic identity. Despite its failure to secure political recognition as discussed in the preceding chapter, the success of its socialization with the two regional powers boosted the legitimacy and identity of ASEAN during its founding years. Such external recognition increased the propensity for cooperation in ASEAN.

\subsection{ASEAN's economic identity}

Economic cooperation in ASEAN during its formative years has been an area overlooked by scholars because of the modest achievements and low level of intraregional trade activities. As pointed out in Chapter 1, ASEAN countries traded more with non-members than among themselves since its formation. ASEAN's intraregional trade saw a decline in the first two decades of its existence. While foreign powers' trade volume with ASEAN was not high, the region's control over key natural resources like rubber, tin, palm oil and wood was a significant consideration by the foreign powers. Quantitatively, Sours' (1981: 178) research concludes that ASEAN provided a major share of some of the world's critical raw materials. Most notable are tin (63 percent of the world's supply), and tropical plantation products (82 percent of the world's natural rubber, 52 percent of the palm oil, and 50 percent of the tropical hardwoods).

The EEC's interest in ASEAN, for example, was predominantly driven by the supply of raw materials in the region as Harris and Bridges (1983: 28) observe: "Over 60 per 
cent of the EC imports of ASEAN products consists of primary products, with lumber, rubber, manioc (tapioca), tin and palm oil - in that order - the major items".

Qualitatively, the diplomatic archives also point to the dependence of foreign powers on ASEAN for these critical natural resources. A 1970 report by the Australian government made the following assessment about the economic potential of ASEAN: Member countries dominate world production and export of certain commodities (Thailand is the world's leading rice exporter, Malaysia and Indonesia produce more than half of the world's tin, and Indonesia, Malaysia and Thailand together produce about 80 per cent of the world's natural rubber), and ASEAN may be able to bargain for higher and more stable prices for its members' exports (Australian Department of External Affairs 1970a).

There was a concern among the foreign powers that the Southeast Asian grouping might hurdle together to control the world's supply and price of these critical resources. The possibility of collective action within ASEAN to control and manipulate the distribution of these resources was revealed when Thai President of the Board of Trade Charoon Sibunruang hinted to the Australians in January 1970:

ASEAN could be the vehicle by which South East Asian nations resisted the growing economic might of Japan. Japan, after all, was heavily dependent on South East Asia for raw materials such as tin, timber and oil. This put the ASEAN nations in a position of strength. At the moment, however, the Japanese were playing each ASEAN nation against the others, and this position of strength was not being utilized. Collective bargaining by the ASEAN nations would put a stop to this practice, would lead to higher prices, and in time would 
enable the ASEAN nations to become an effective counterweight to Japan in Asia (Australian Embassy in Bangkok 1970).

Further, the sea lanes plying through the ASEAN region were also vital gateways through which oil and other essential raw materials flowed through to Australia and Japan. Given ASEAN's economic strength, external powers were naturally concerned and carefully watching over possible collusive actions by ASEAN. Furthermore, any overtures to the region by one country to extend its influence in the region were met with suspicious by the other foreign powers. Shortly after ASEAN's formation, for example, Australian Minister of External Affairs Paul Hasluck in November 1968 revealed his concern over the "ambitions of the Japanese to organize common markets in the area which would only have the effect of assisting Japan to dominate the area economically" (Australian Embassy in Bangkok 1968). The U.S. also reflected similar concerns over EEC's dealings with ASEAN (this will be discussed in $\underline{\text { Chapter } 5}$ ). With this background, the remaining chapter outlines ASEAN's struggles for the recognition of Australia and Japan on the economic front.

\subsection{ASEAN-Australia: Denial of entry into ASEAN and non-recognition}

The discussion here and in the next two sections looks at the genesis of ASEAN's interactions with Australia. It details how ASEAN struggled for Australia's recognition of the Southeast Asian grouping. This section begins by presenting Australia's first assessment and response to the formation of ASEAN in the 1960s. While not optimistic about the prospect of ASEAN's development, the Australian government led by the Labor party attempted to join the grouping. However, following its failure to gain access into the ASEAN grouping, the Australian government began to call for 
the creation of a wider Asian grouping. The section outlines how ASEAN responded negatively to these overtures and started pushing for Australia's formal recognition of the Southeast Asian grouping.

When ASEAN was first founded, the Australian Department of External Affairs (1968c) assessed internally that it was "not likely that ASEAN will develop into a powerful or exclusive economic union... its significance will, in the long term, lie in its contribution to political unity in the region". Further, an internal submission to the Australian foreign minister recommended that "it would be premature now to seek observer status at proposed ASEAN summit meeting" (Australian Department of External Affairs 1971d). The Australian government assessed that ASEAN's greatest chance for success is to remain a small, tightly-knit, subregional organization concentrating on common practical problems, as free as possible from complications deriving from extraneous political and economic factors. The possibility of Australia sending aid in an ASEAN context is quite another question. We see no objection in principle to this form of relationship (Australian Department of External Affairs 1970b).

Yet, shortly after ASEAN's founding, Gough Whitlam, in his capacity as the leader of the Australian Labor Party before he became the premier in 1972, informed Indonesian President Soeharto on 26 January 1968 during a visit to Jakarta that "all parties in Australia strongly favored regional co-operation and therefore welcomed ASEAN and he hoped that in the years ahead ASEAN would be extended to include for example Burma and Cambodia and Australia and New Zealand" (Australian Embassy in Jakarta 1968b). Also present at the call with Whitlam, Australian 
Ambassador to Jakarta Max Loveday reported that "Soeharto gave no response" to Whitlam's suggestion. A subsequent internal report confirmed Australia's interest to join ASEAN: "Whitlam has expressed himself in favor of Australia seeking membership of ASEAN as soon as possible" (Australian Department of External Affairs 1969a). This was the earliest revelation of Australia's desire to join ASEAN. Sensing the possibility of winning some support within ASEAN for Australia's membership, Australian High Commissioner to Malaysia Allan Eastman in February 1968 gave the following recommendations to Canberra:

ASEAN would appear to us to have potential as organization for regional cooperation along desirable lines with which Australia could associate itself advantageously. Concurrence of other members - essentially Indonesia - in Australian membership would of course be necessary, as would clarification of possible defense and security considerations. Granted these uncertainties we should suggest that idea could usefully be explored further (Australian High Commission in Kuala Lumpur 1968d).

As highlighted in Chapter 3, ASEAN was not in favor of expanding its grouping to include any foreign powers. In spite of this, a draft policy paper, prepared by the Australian Department of External Affairs (1971a), revealed that Australia had continued to push for its inclusion in various ASEAN meetings and committees, including a request for an observer status:

ASEAN resents any attempt by other nations to prise their way into the club and that among some, particularly the Malaysians, we are not regarded as forming part of the region, despite our own insistence over the years that we are part of the South East Asian region. In the event, however, we were not able to 
obtain observer status at the ASEAN meeting... In our approaches to be included in any wider follow-up meeting or to be consulted by any roving ASEAN committee we encountered reserve, particularly from the Malaysians. [Malaysian Prime Minister] Razak, for example, told our High Commissioner that 'as a bigger country' we stood somewhat outside the region and that 'we want you out'... Even so, Malaysia seems more intent than her partners on making it plain that we are not regarded as suitable members of the South East Asian group. They in particular are irritated by our attempts to be included in every regional initiative, particularly ASEAN initiatives. They are not convinced of our commitment to the region.

The above revelation reiterates the findings in the preceding chapter that ASEAN made significant efforts to fob off external pressures for its membership expansion. It became clear to Canberra that Malaysia and Indonesia "would not favor Australian membership of ASEAN, and would be even more opposed to the membership of India, China or Japan" (Australian Department of External Affairs 1973d).

However, ASEAN's rebuff of Australia's interests to join ASEAN during its formative years caused Canberra to withhold its support for and recognition of ASEAN. This created a perception among ASEAN states that Australia was averse to support regional organizations which it was not a part of. The Australian Department of External Affairs (1968d) reported from a meeting with Indonesian Counselor Basri Haznam from the Indonesian Embassy in Canberra in March 1968 that the latter had two impressions about the Australian attitude to ASEAN which led to our putting up a 'wall' about ASEAN. He contrasted what he thought was our attitude to ASEAN to our active role in ASPAC. Because we were a member of ASPAC we 
participated and contributed actively. But in respect of ASEAN, we did not seem to be interested positively unless we were a member. In addition, there seemed to be some doubt on our part that ASEAN would prove an effective organization in practice.

Another cable confirmed Indonesia's unhappiness with Australia's refusal to recognize ASEAN:

There have been one or two signs that the Indonesians may suspect Australia of being opposed to the projected Association and the absence of any official Australian comment might be construed by them and others as implying opposition, or resentment at our exclusion. It would be unfortunate if any impression were to develop abroad or at home that there is some incompatibility of interests between the Association and ourselves (Australian Department of External Affairs 1967d).

In retrospect, it was unavoidable that ASEAN took offence at Australia's narrow regional focus on fostering the ASPAC grouping. Truth be told, Australia and its closest neighbor New Zealand were more involved and committed to the agenda of ASPAC which they considered to be "one of the most promising organizations through which a regional consciousness can be developed" (Australian Department of External Affairs 1968e). Clearly, it was not in their interest to recognize or support a grouping which they were not a member of and was competing with ASPAC for a regional role. Their shared purpose to develop ASPAC into the main engine for regional discussions was reflected in a cable originating from the Australian Department of External Affairs (1967e): 
From Australia's point of view it is important that everything possible should be done to support ASPAC and to assist in its successful functioning... ASPAC is an Asian organization which includes Australia (and New Zealand) as full members but not the major Western powers, so that our membership associates Australia with the Asian countries on a basis of equality.

Like Australia, New Zealand also desired ASEAN membership. New Zealander Defense Minister Arthur Faulkner shared with his U.S. counterpart his confidence that Australia and New Zealand would be invited to join ASEAN in time to come, although he conceded that it would be difficult to seek ASEAN membership because "we can't change our white faces" after his tour of Southeast Asian countries in 1973 (U.S. Embassy in Wellington 1973a). It was evident that ASEAN had no intention of expanding its grouping as pointed out in a report by U.S. Deputy Chief of Mission Andrew Killgore in Wellington:

New Zealand's geographical remoteness precludes any sort of meaningful integration with East Asia... The Government of New Zealand quickly learned that Southeast Asian nations did not favor either New Zealand or Australia joining ASEAN and the Government of New Zealand policy now is to strengthen bilateral relationships in the area. There is little prospect that New Zealand will become regionally integrated with East Asians (U.S. Embassy in Wellington 1974).

In the same vein, Malaysian Secretary-General of Foreign Affairs Zaiton Ibrahim made it plain to U.S. Assistant Secretary of State for East Asian and Pacific Affairs Robert Ingersoll in February 1974 that "Australia and New Zealand were not suitable additions to ASEAN" (U.S. Embassy in Kuala Lumpur 1974a). During Ingersoll's 
meeting with Malaysian Prime Minister Abdul Razak, the latter also expressed his concerns that "enlargement of ASEAN beyond its ten potential members would lead to endless series of demands for additional membership" (U.S. Embassy in Kuala Lumpur 1974a).

The discussion in this section has shown how ASEAN's refusal to expand its membership caused Australia to hold back its recognition for the grouping. Instead of according ASEAN with the recognition it desired after failing in repeated attempts to obtain membership and participate in ASEAN-related meetings, Australia proceeded to push for the creation of a wider regional body in Asia in order to avoid its exclusion from the region. This course of action would elicit a harsher response from ASEAN as the next section will show.

\subsection{ASEAN-Australia: The push for a wider regional grouping}

Under the new labor government in 1972, Australia intensified its efforts to create a wider Asian grouping. By this time, the Australian government was resigned to the possibility of joining the Southeast Asian grouping:

We must accept that we are simply not regarded as part of the region. It is not contested by the nations of the regions that we have firm interests in the area (trade, investment, security) but by temperament we are seen as being on the periphery - as are the Japanese... ASEAN is a sensitive and in-bred body, and we can only do our interests harm by trying to muscle in on it (Australian Department of External Affairs 1971a). 
Having been snubbed by ASEAN about Australia's interest to join the grouping, Whitlam upon assuming the Australian premiership embarked on a campaign, together with his New Zealander counterpart, to surmount support for the creation of a broader regional grouping.

Just a month into his appointment, Whitlam approved an internal submission on 10 January 1973 to canvass "guidelines for a new regional political organization" (Australian Department of External Affairs 1973e). According to the report, the main objective of the new strategy is to "promote a spirit of regional cooperation between communist and non-communist countries". Through this proposal, the Australians hoped to develop a

framework for regular discussions, not just another organization set up in the aftermath of some regional crisis... it should be genuinely representative of the region and should not have ideological overtones... it was proposed that ASEAN should continue as a subregional body whose individual members could participate in a wider association including Japan and China.

During a speech given to the Australian Institute of Political Science in Canberra on 27 January 1973, Whitlam called for the formation of a wider regional forum to free the region from "great power rivalries that have bedeviled its progress for decades" (U.S. Embassy in Canberra 1973c). Whitlam's label of ASEAN as a "sub-regional organization" during the speech, however, offended the Southeast Asian countries. As highlighted in Chapter 3 , ASEAN already suffered a setback in its attempt to obtain political recognition when the foreign powers refused to recognize the zone of neutrality. Whitlam's underlying message was that ASEAN had been an unsuccessful experiment. The poor report card on ASEAN upset the member states. Evidently, 
Whitlam's initiative was a reflection of the new Labor leadership's concern over Australia's position in the region. The Australian Department of Foreign Affairs revealed that "Australia is beginning to feel itself alone in the world and wishes to show some initiative in forming new friendships based on mutual interests with other countries in the region" (U.S. Embassy in Canberra 1973c).

Australia's increasing sense of insecurity about its position in the region was also felt by its closest neighbor, New Zealand. The weakening of ASPAC, to which Australia and New Zealand were members of, also prompted both countries to collaborate on finding a new regional platform. As discussed in the preceding chapter, with the acceptance of China into the international community since the early 1970s, beginning with its accession into the UN and reopening of diplomatic relations, support for the ASPAC grouping began to dwindle given its problematic membership of Taiwan. The Australian Department of External Affairs (1973f) assessed: "With ASPAC certain to wither away, we saw it as very much in our own interests that there should be a new political forum in the Asia/Pacific region to which Australia could belong". A meeting between the foreign affairs departments of Australia and New Zealand in 1972 proposed

to find some substitutes for ASPAC which would give Australia and New Zealand access to a regional political forum... Naturally, if all five ASEAN members wanted us to join [ASEAN], we would be very interested indeed and would look at the possibilities very hard... Another possibility would be to try to organize a grouping which would include the ASEAN members, Australia, New Zealand and Japan but remain quite separate from ASEAN (Australian Department of External Affairs 1973g). 
This meeting was followed by an exchange of letters between Whitlam and New Zealander Prime Minister Norman Kirk in February 1973 in which the two leaders agreed to "plan and coordinate our next moves" for the formation of a new regional organization which included China (Australian Department of External Affairs 1973g). In their correspondence, Kirk further suggested for the proposal to be first made with the Indonesians. This exchange of letters set the motion for Australia and New Zealand to work together to realize the goal of a broader regional grouping. Following this exchange, another meeting took place between New Zealander Secretary of Foreign Affairs Frank Corner and his Australia counterpart, Keith Waller, to discuss how "to achieve an Asian Forum" which included China and the Pacific island nations (U.S. Embassy in Wellington 1973b).

The denial of entry into ASEAN propelled the administrations of Australia and New Zealand to collaborate on the creation of a wider regional grouping. Their suggestion for a larger regional forum was, however, met with hostility by ASEAN which viewed these initiatives as attempts to undermine the Southeast Asian grouping. ASEAN's response was sharp and critical. Malaysian Secretary-General for ASEAN Yusoff explained that "Whitlam's proposal for a wider regional organization" was seen as "in conflict with ASEAN" because ASEAN desired to "reduce super power involvement in the region and the proposal could work against that objective" (Australian Department of External Affairs 1974a). In January 1974, Malaysia Prime Minister Abdul Razak reminded Whitlam during his official visit to Kuala Lumpur that "the consolidation of ASEAN was an essential first step if Southeast Asian nations are to develop confidence and capacity to play a meaningful role in Asia" (U.S. Embassy in Kuala Lumpur 1974b). In a separate meeting with Faulkner in March 1973 when the 
issue of a "broader regional arrangement" was raised, Razak reiterated that even as a long term objective, such a proposition "would increase rather than decrease great power pressures on the region" (Australian Embassy in Bangkok 1973a). Razak added that it was not possible "to bring in China and Japan and leave out Russia" and highlighted that such an arrangement would make the Russians "very angry". During the meeting, Razak also made it clear to the New Zealanders that they could expect "no support" from Malaysia if they continued to pursue such an idea with the Australians.

ASEAN also took issue with Whitlam's suggestion to include China and Japan in a larger regional grouping. As discussed in the preceding chapter, ASEAN states remained wary of Chinese subversive activities in Southeast Asia and were hesitant to establish or resume official ties with the Beijing government. Indonesia Foreign Minister Malik responded to Whitlam's proposal with caution:

The time is not ripe. Some countries in the area have not yet really worked out their economic relations with Japan, and some have no economic relations with China. It is going to be some time before they do ... It is far too early for regional arrangements in the Pacific and Southeast Asia to include China" (U.S. Embassy in Canberra 1973d).

At a private meeting on 22 February 1973, Singapore High Commissioner to Australia Arumugam Rajah further explained that in putting forward the idea of a wider organization, Australia was placing too much importance on the position and role of China, and paying too little regard to the fears and apprehension of South-East Asian countries with regard to China... Singapore would like at least five years before it had to accept a 
Chinese embassy. Australia, on the other hand, seemed to be interested in China to the exclusion of everyone else, including her South-East Asian friends (Australian Department of External Affairs 1973f).

ASEAN states were also unhappy that Australia and New Zealand chose to seek the endorsement of Indonesia instead of making a simultaneous approach to the Association as a whole. Their strategy of targeting the largest member state was seen as a bias move which threatened to divide rather than unite the ASEAN grouping. At another meeting on 26 February 1973, Arumugam disclosed that "countries of South East Asia were anxious about Australia's motives in seeking a new regional community and were resentful of the fact that Mr Whitlam had chosen to discuss his ideas in the first instance with Indonesia" (Australian Department of External Affairs 1973h). According to the memo, there was a sense that "the Australian policy on regional association included the breaking up or replacement of ASEAN". It was evident from ASEAN's responses that Australia's proposal was viewed as an outright attempt to undermine the young regional grouping.

By February 1974, Whitlam was resigned to the hope of harnessing support for a wider regional grouping when he conceded that "time would prove the value of a wider Asian and Pacific forum" and clarified that it was not his intention for the proposed forum to "supplant ASEAN" (U.S. Embassy in Bangkok 1974b). In a facesaving exercise, Whitlam conceded at a press conference in Bangkok on 1 February 1974:

It is satisfactory for ASEAN and also for Australia that we have been asked to consult as I just said on ASEAN projects, projects which are put up on a collective basis or projects which might affect more than one ASEAN country. 
Now, those are fruitful association between Australia and ASEAN. There is no need to make them more formal by joining the body" (U.S. Embassy in Bangkok 1974c).

In Singapore, Whitlam also explained to Prime Minister Lee Kuan Yew that Australia "did not wish to intrude but hoped to cooperate with ASEAN imaginatively, offering any skills that might be needed" (U.S. Embassy in Singapore 1974d). It was the light at the end of the tunnel for ASEAN's struggle for Australia's recognition of the grouping. From here on, the Australian government realized that it needed to change its recognition policy toward ASEAN and reconsider the forms of its engagements with ASEAN. From ASEAN's perspective, the curtailment of foreign pressures for the grouping to expand or to support larger regional forums was vital to its development as a Southeast Asian grouping and its ability to eventually secure external recognition for the region as the next section will elaborate.

\subsection{ASEAN-Australia: The beginning of recognition}

The two preceding sections have outlined the futility of Australia's efforts to join ASEAN and to promote a wider regional grouping. Member states spoke out strongly against any initiatives which would undermine the ASEAN grouping. Yet, the

prospect of receiving some forms of assistance from Australia prompted ASEAN to desire Canberra's recognition of the region. This was subject to Australian government's willingness to accord recognition on ASEAN and to deal with the association like a regional economic entity. In mid-1973, ASEAN began to sound Australia out on the idea of offering economic assistance and holding regular consultations with the grouping to discuss economic cooperation. 
Malaysian Secretary-General for ASEAN Yusoff Ariff in June 1973 revealed that "Australia's standing in regional economic and aid matter was very high" and that ASEAN states viewed Australia's assistance as being "without ulterior motives and not a means for seeking commercial advantages, as was the case with the Japanese" (Australian High Commission in Kuala Lumpur 1973). Malaysia took the lead on behalf of ASEAN to sound the Australians out on the idea of creating an economic linkage between the grouping and Australia. In a follow-up meeting with First Assistant Secretary of South Asia Division Richard Woolcott, who later became Secretary of the Australian Department of External Affairs, on 26 September 1973, Yusoff explained that Malaysia "strongly favored bringing Australia into region affairs, partly as 'balance' to Japan... one reservation among Malaysian ministers was that Australia, because of its own interest in its bilateral relations with Japan, was sometimes suspected in Malaysia of being a 'spokesman for Japan'" (Australian Department of External Affairs 1973i). It was somber reminder to Australia that its dealings with ASEAN should not be dictated by the needs of its close ties to Japan. During the meeting, Yusoff proposed for a discussion between the five ASEAN national secretaries-general and senior Australian officials before a meeting of ASEAN foreign ministers in April 1974. Yusoff emphasized that "an informal meeting of this type was a first step to associating Australia economically with ASEAN". ASEAN believed that Australia's recognition of the grouping on the economic front would open up greater material opportunities for all member states in the form of material aids or financial contributions above what was already offered on a bilateral basis. As highlighted in the recognition model for regions in Reference 1 of $\underline{\text { Chapter } 2}$ one of the motivations for the demand of external recognition is the possibility of 
better access to material opportunities. Australia, on the other hand, was keen to trade material concessions with ASEAN in exchange for its involvement in the ASEAN circuit, an objective it had tried unsuccessfully to achieve earlier by courting ASEAN membership and calling for a broader regional grouping.

Australia and the five ASEAN national secretaries-general met in Bangkok on 11-12 January 1974 for the first "informal meeting" to work out the principles to govern such a co-operation. According to an internal memo, the Australian Department of External Affairs (1974b) considered the officials' meeting to be of utmost significance because it was "the first occasion on which the Secretaries-General had met as a group with representatives of a non-member country". Canberra believed that the meeting provided Australia the opportunity to "demonstrate in a tangible way its support for ASEAN as a model of successful regional co-operation". During the meeting, the five ASEAN national representatives highlighted the fundamental aims, philosophy and principles governing ASEAN's acceptance of assistance from external sources. The emphasis on national interests over regional ones was clear from details of the agreement reached during the meeting. According to an Australian record of the proceedings, the ASEAN side premised the cooperation on the conditions that:

assistance would be acceptable only from a country friendly to all ASEAN members; assistance should not be at the expense of assistance given to any individual member; assistance should be for projects conceived by ASEAN which are of a regional character and for the benefit of all ASEAN member countries; assistance should be carried out within the ASEAN region; and assistance should supplement ASEAN capability (Australian Department of External Affairs 1974b). 
Evidently, ASEAN's primary concern was that any foreign assistance to the grouping should not undermine the bilateral assistance already received by the individual ASEAN states. For the individual member states, it was vital that their commitment to ASEAN did not jeopardize their national interest in any way.

Within a few months of the initial discussion, the Australian government in April 1974 made a formal pledge of $\$ A 5$ million to the grouping for economic cooperation. During the announcement, the Australians carefully positioned the offer as for the development of joint Australia-ASEAN projects, rather than labeling it as a form of economic aid. From its past endeavors, Canberra finally understood the sensitivity of ASEAN and respected the grouping's desire for recognition. In this regard, the Australian High Commission in Kuala Lumpur (1974a) cautioned:

We should be careful however not to get ahead of the ASEAN countries in publicizing the venture. We should avoid giving them any cause for offence...We should also emphasize that our economic projects with ASEAN are co-operative ventures and not Australian charity for ASEAN.

At the Seventh ASEAN Ministerial Meeting in May 1974, ASEAN formally announced the outcome of ASEAN-Australia dialogue for the first time. ASEAN accepted Australia's offer of $\$ A 5$ million for joint economic projects in areas such as transportation, quality assurance, trade and agriculture (U.S. Embassy in Jakarta 1974c). The proposal represented Australia's first concrete recognition of ASEAN as a regional economic entity. For ASEAN, it was a fait accompli which demonstrated clearly to the member states the tangible benefits that regional cooperation brought to Southeast Asia. 
Internally, the Australian government assessed very highly the establishment of "a link with ASEAN in the sphere of economic co-operation" because:

Australia became the first country to have discussions with ASEAN about economic co-operation. Attempts by Japan and New Zealand to establish a similar special status have been rebuffed by ASEAN. We are thus in particularly advantages position, despite the fact that our relationship with ASEAN is still very much in the embryo stages... The Australian Government regards this opportunity for co-operation with ASEAN as a particularly valuable one. (Australian High Commission in Kuala Lumpur 1974b)

Here again, Australia achieved its desire to be involved in regional discussion by formalizing a communication channel with Southeast Asia. The chapter has thus far illustrated how Australia's initial failure to join ASEAN led to its promotion for a wider regional grouping. The proposal was again met with fierce objection from ASEAN. Canberra became mindful that while ASEAN desired external recognition, the grouping was not prepared to accept a lower status in respect to its relations with the foreign powers. The futility of its attempts to infiltrate and enlarge the ASEAN grouping caused Australia to realize that its best chance of engaging ASEAN was by according recognition to the grouping in the form of an aid donor-recipient relationship. Looking back at its interactions with ASEAN in November 1976, Australian Foreign Minister Andrew Peacock shared with a visiting U.S. congressional delegation that "ASEAN generally has been a successful step by step experiment so far" (U.S. Embassy in Canberra 1976a).

While fearful of great powers' intervention into its regional affairs, ASEAN was motivated to obtain Australia's recognition as it would open up more opportunities for 
material assistance. Such behaviors resonate with the recognition model for regions proposed in Reference 1. The empirical evidence supports the theoretical underpinning that "individual members can be regarded as identifying with various groups in order to gain material and symbolic benefits" (Kenny 2004: 150). On the other hand, Australia's strong desire not to be excluded from the region compelled the Canberra government to recognize ASEAN as a tight economic entity, having tried unsuccessfully to gain entry into the Southeast Asian grouping. Its decision to recognize ASEAN reflects Hammer's (2007: 31) observation that recognition by foreign powers is often based on how such decision affects "their geo-political interest". Australia's decision to recognize ASEAN as a region through the establishment of a donor-recipient relationship was an important one in that it would also influence Japan's recognition policy toward ASEAN.

\subsection{ASEAN-Japan: The struggle for Japan's recognition}

The discussion here and in the next section details the events leading to Japan's recognition of ASEAN. The Fukuda Doctrine announced by Japanese Prime Minister Takeo Fukuda at the first ASEAN-Japan summit meeting in Kuala Lumpur on 7 August 1977 was often regarded as the genesis of Japan's interaction with the grouping. The empirical evidence in this section, however, suggests that Japan had not always been willing to recognize and transact with ASEAN during its formative years. It also reveals how ASEAN states like Malaysia supported regional cooperation through ASEAN in an attempt to solve its national problems. Increasing foreign recognition of ASEAN, in turn, motivated the Southeast Asian states to view ASEAN as a useful regional platform to solve their respective national problems. 
Shortly after the formation of ASEAN in 1967, Japanese Ambassador to Malaysia Kai Fumihiko expressed Japan's expectation for ASEAN membership at a press conference. According to Ikema (1980: 471), Kai indicated that Japan would consider joining ASEAN if it were invited to do so. The suggestion, however, was rejected by Indonesian Foreign Minister Malik on grounds of Japan's geographical location (Hamanaka 2009: 457). In the same year, Japanese Foreign Minister Takeo Miki launched an Asia-Pacific policy where he defined "Japan's role as a bridge between developing Asian and developed Pacific rim countries, based on his perception of Japan's international identity as the only industrialized nation in Asia" (Terada 2000: 200). Miki's announcement was in reaction to the momentum which was building among Southeast Asian countries to create a South-East Asian Association for Regional Cooperation (SEAARC), the predecessor of ASEAN. Indonesia first discussed the idea of setting up SEAARC with Thailand in 1966 which resulted in the drafting of a declaration that

speaks in familiar language of the need for co-operation on a regional basis in economic, cultural and technical fields. In addition, however, the draft contains a statement that the security of South-East Asia is primarily the responsibility of the countries of the area themselves, and a paragraph disassociating SEAARC from any power bloc, proclaiming foreign bases as temporary in nature, and stating that collective defence arrangements should not be allowed to serve a particular interests of any big power (Australian Department of External Affairs 1967f)

Jakarta also launched a series of diplomatic missions to promote the SEAARC proposal to Southeast Asian countries, which was subsequently renamed ASEAN 
with the formalization of the Bangkok Declaration on 8 August 1967. Having been refused entry into ASEAN and concerned about the weakening of existing regional groupings (like Australia), the Asian Regional Policy Division disclosed that there had been a

thinking in the Japanese foreign ministry... if ASPAC were to fade away, there would be a need for a new regional organization to replace it... membership of such an organization should be the ASEAN countries, New Zealand, Australia, Japan and the ROK (Australian Embassy in Tokyo 1972).

With the decline of ASPAC, the Japanese government dispatched a special envoy to the five ASEAN countries from 13 to 19 October 1972 with the mission to push for its inclusion in the Southeast Asian grouping. According to Asa Sarasin, Head of Southeast Asia Division from the Thai foreign ministry, Kiichi Aichi in his capacity as Special Envoy of Japan had called for the "expansion of ASEAN to include Japan, Australia and New Zealand" during the Bangkok-leg, to which the Thais gave a polite reply that consultation with existing members would be necessary (Australian Embassy in Bangkok 1972).

Following its unsuccessful attempts to join the grouping, Japanese interactions with ASEAN as a regional unit was restrained and kept to a minimal until 1973 when ASEAN registered its unhappiness with what it considered to be an "indiscriminate expansion of the synthetic rubber industry by Japan" (ASEAN 1973a). This initiative was spearheaded by Malaysia who made a strong case to ASEAN that the expansion of Japanese production of synthetic rubber caused a tailspin in the price of natural rubber, of which Malaysia was a major producer. At a private meeting between Malaysian Prime Minister Razak and Indonesian President Suharto in May 
1973, both leaders discussed the problem and agreed that "ASEAN as a body should make an approach to Japan" (U.S. Embassy in Jakarta 1973d). In a communiqué issued at the Sixth ASEAN Ministerial Meeting in April 1973, the foreign ministers considered the indiscriminate expansion of the synthetic rubber industry by Japan and the accelerated export of such rubber and recognized that they posed a serious threat to the economies of the ASEAN countries. In expressing their grave concern, they urged Japan to review its policy of indiscriminate expansion and accelerated export of synthetic rubber. They agreed that ASEAN officials would work out appropriate measures to meet this threat (ASEAN 1973a).

It was the first time that such strong language had been used in an ASEAN communiqué and also unprecedented that Japan's action was categorically labeled as a "serious threat" to the ASEAN region. It was also the first time that ASEAN made a collective negative expression of its displeasure with the economic practice of a non-member country. The harshness of the language used in the communiqué was deliberate and details of the protest were promptly featured by the major newspapers in the region. Japan was undoubtedly caught by surprise and displeased with the negative media reports, especially in light of rising anti-Japanese sentiments and protests taking place in Southeast Asian countries like Indonesia and Thailand.

In his capacity as chairman of ASEAN Standing Committee, Indonesian Foreign Minister Malik presented to the Japanese ambassador in Jakarta an ASEAN aide memoire in August 1973 registering the concern of ASEAN natural rubber producers. Identical aide memoires were simultaneously delivered to the Japanese embassies in the other four ASEAN countries. The aide memoire pointed out that "Japanese 
synthetic rubber industry would have adverse effects on ASEAN countries' economies" and pressed for "regular Government of Japan-ASEAN consultations on the problem" (U.S. Embassy in Tokyo 1973a). In response to the strong protest, Japan reluctantly ceded to ASEAN's request to meet. In its reply to Malik, Japan expressed its understanding of ASEAN's concerns and willingness "to have a dialogue directly with ASEAN countries" as opposed to a consultation which ASEAN requested (U.S. Embassy in Tokyo 1973a). Positioning the meeting as a dialogue avoided the expectation that Japan had to consult ASEAN on any changes to the level of its synthetic rubber production domestically. Nonetheless, this was a significant decision because it marked the first joint ASEAN approach on an economic issue against a third country and also the first time that the idea of an ASEAN-Japan meeting was mooted. Up to this point, Japan had refused to recognize the regionhood of ASEAN and, like the U.S., preferred to deal with ASEAN countries on a bilateral basis.

On 27 November 1973, Malik led an ASEAN delegation to meet with Japanese Foreign Minister Masayoshi Ohira in Tokyo. The ASEAN delegation included officials from the five Southeast Asian countries and the five ASEAN ambassadors in Tokyo. During the meeting, Malik reiterated that "Japanese production and export of synthetic rubber could be very harmful to ASEAN economies" and that "increased Japanese production of particular kind of synthetic rubber directly competitive with natural rubber would be dangerous to ASEAN economies" (U.S. Embassy in Tokyo 1973b). Ohira responded by expressing his understanding of "ASEAN's greatest concern" and reiterated Japan's willingness to have a "forum for dialogue on this question at government officials/experts level" (U.S. Embassy in Tokyo 1973b). 
However, despite its willingness to address the rubber issue with ASEAN, Japan was not prepared to deal with ASEAN as a regional bloc on other issues. The Japanese foreign ministry officials, who attended the meeting, revealed that while Japan "agreed to a direct dialogue on synthetic rubber, it was not willing to enlarge discussion to embrace other issues" (U.S. Embassy in Tokyo 1973b). Instead, the Japanese had hoped that the meeting would be a "once only affair" and disclosed that they had "no other plans for initiating consultations with ASEAN" (Australian Embassy in Tokyo 1973a). The Japanese trade and industry ministry, in particular, was "very unhappy about the continuing dialogue in rubber but had been persuaded by the foreign ministry to yield for the sake of overall Japan/ASEAN relations" and "would strongly oppose extension of the dialogue to other commodities" (Australian Embassy in Tokyo 1973b). Tokyo's reluctance to recognize ASEAN could also be seen in the way that the Japanese government deliberately restricted media coverage on the meeting which it had assessed was not in "Japan's interest to publicize" (Australian Embassy in Tokyo 1973b). Extensive media coverage on the matter would have legitimize the role of ASEAN as the regional voice of Southeast Asia which was in conflict with Japan's longstanding modus operandi of bilateral diplomacy. The move to restrict media reporting during the meeting was deliberate as was with the choice of the meeting location. The grouping had indicated its preference for the talks to be held in an ASEAN capital instead of in Tokyo as proposed by the Japanese (U.S. Embassy in Jakarta 1973e). The request was, however, turned down by the Japanese on grounds that their foreign minister had a hectic schedule which did not permit a visit to an ASEAN country. Having the meeting in Tokyo gave the Japanese host complete control over the extent of press coverage on the rubber issue. Consequently, the Japanese revealed that the ASEAN 
delegation were evidently "disappointed" with the lack of Japanese press coverage during Malik's visit.

ASEAN's strong desire for external recognition was, however, felt by Japan at the meeting. The regional policy division of the Japanese foreign ministry shared with the Australians on 30 November 1973 that "it was evident that ASEAN's concern in this matter [rubber] was primarily political not economic, and was related to its desire to establish a continuing dialogue with Japan" (Australian Embassy in Tokyo 1973b). It was apparent to the Japanese that some "ASEAN countries had felt that the principle of direct ASEAN-Japan discussions (such as have been held between ASEAN and EC) was more important than specific issue of rubber" (U.S. Embassy in Tokyo 1973b). These anecdotal accounts illustrate the extent to which the Association was capitalizing on the rubber episode to press for Japan's recognition of ASEAN. Despite its agreement to meet with ASEAN, the Japanese foreign ministry was confident that the matter would not turn into a "serious Japan-ASEAN" spat, and shared with its U.S. counterpart Japan's internal assessment that

ASEAN countries other than Malaysia do not seem so interested in the matter; Malaysia is taking the lead and other countries are following... Japan will continue bilateral talks with Malaysia. Once Malaysia has been 'appeased'... the problem will be resolved (U.S. Embassy in Tokyo 1973a).

The Japanese came to the conclusion that "Malaysia is the only ASEAN country really concerned [about Japanese synthetic rubber production], with Thailand and Indonesia having some minor interest and the Philippines and Singapore none at all" (U.S. Embassy in Jakarta 1973e). Within the Japanese foreign ministry, there were fears that 
ASEAN would become a persistent pressure group seeking concessions from foreign countries... Their action over Japanese production of synthetic rubber was a case in point. ASEAN had definite advantages but Japan did not want it to develop in that way (Australian Department of External Affairs 1973j).

Following the Malik-Ohira meeting, the first ASEAN-Japan dialogue on rubber took place in Kuala Lumpur from 19 to 21 February 1974. ASEAN was, however, disappointed with Japan's official position during the meeting. Malaysian SecretaryGeneral for ASEAN Yusoff Ariff shared with the Australians that the Japanese delegation insisted that they "could only listen to the ASEAN views" and was not in a position to negotiate (Australian High Commission in Kuala Lumpur 1974c). Displeased with Japan's lack of sincerity and genuine interests to work out a solution, Malaysia, prior to the second ASEAN-Japan dialogue, put out a "firmly worded press release" on behalf of the five ASEAN members affirming that the grouping would not accept "any development leading to counterfeit optimism" (Australian High Commission in Kuala Lumpur 1974c). This episode again highlights how ASEAN was quick to exploit the media as a means to publicize the ill-treatment of the region by the external powers as suggested in the recognition model for regions in this dissertation.

\subsection{ASEAN-Japan: Malaysia's regional approach to solving national problems}

Japan clearly underestimated Malaysia's resolve to utilize ASEAN as a regional platform to tackle its national problem. In this regard, even foreign powers like the 
U.S. did not believe that ASEAN could sustain an effective negotiation with Japan. Reporting back to Washington on the outcome of the Malik-Ohira meeting, U.S. Ambassador to Malaysia Jack Lydman provided the embassy's assessment that it "does not believe meeting is indicator of frequent and continued used of ASEAN as negotiating vehicle" (U.S. Embassy in Kuala Lumpur 1973d). Yet, Malaysia's tenacity to escalate the rubber issue to the regional level could be seen from a Thai senior officer's revelation in July 1973 that ASEAN had agreed that "whether there would be a boycott of the Ministerial Conference [MEDSEA] meeting in October [to be hosted by Japan] would be influenced in part by the Japanese reaction to aide memoire" (Australian Embassy in Bangkok 1973b). Malaysia was intent on making it clear that the ASEAN grouping would not hesitate to undertake punitive action against Japan if its concern over Japanese rubber production was not addressed. To be sure, Malaysia was responsible for 55 percent of the world's rubber production at that time. Malaysian Minister of Primary Industries Musa Hitam explained that the rubber issue was of "special political sensitivity" because "rubber touches almost every aspect of Malaysian life" (U.S. Embassy in Kuala Lumpur 1975c). With the unfolding of the rubber crisis, Musa himself had been in a series of non-stop meetings with the rubber producers, traders, plantations workers and associations. According to Malaysian Deputy Minister of Primary Industries Paul Leong, almost one-third of the 10.5 million Malaysians were economically dependent on natural rubber (U.S. Embassy in Kuala Lumpur 1975d). In addition to its economic importance, the rubber issue was of "social and political importance" to the government because it involved a substantial number of "indigenous Malays who poses special political considerations" for the government (U.S. Embassy in Kuala Lumpur 1975d). Given the national importance and urgency of the rubber issue, Malaysia had pursued the matter directly with the 
Japanese government on a bilateral basis, but decided to undertake a regional strategy, having failed in direct talks to resolve the issue with Japan. For instance, during the visit of Japanese Prime Minister Eisaku Sato in 1967, the Malaysians "sought unsuccessfully from Sato some commitment to limit Japanese production of synthetics and/or to give Malaysian rubber some assistance in the Japanese import market" (Australian High Commission in Kuala Lumpur 1967b). The futility of such bilateral diplomacy prompted the Malaysian government to escalate its national problems to a regional level.

While Malaysia had the most stake in the rubber issue, it made a tactical decision to obtain ASEAN's buy-in to escalate this matter to a regional level knowing that Indonesia and Thailand were also substantial producers of natural rubber. Malaysia's articulation to ASEAN of what it perceived to be an unfair treatment by Japan led to what Honneth (1995: 132) describes as a "motivational impetus for social resistance and conflict, indeed, for a struggle for recognition". The ASEAN grouping including non-rubber producing countries was convinced that Malaysia's experience could be typical for the entire group in other areas and therefore rallied together. At one point, Malaysian Secretary-General for Foreign Affairs Tan Sri Zaiton even raised the possibility of ASEAN applying "economic sanctions against outside powers if need be" (U.S. Embassy in Kuala Lumpur 1974c).

At the second ASEAN-Japan experts' meeting on synthetic rubber in Tokyo on 18-20 March 1974, Japan relented to giving guidance to its industry on synthetic rubber production to avoid any detrimental effect on the natural rubber market, and offered technical assistance to help ASEAN countries develop new uses for natural rubber. 
The two sides also agreed to continue "dialogue with yearly meeting at experts' level if circumstances should require" (U.S. Embassy in Tokyo 1974a). Japanese concessions to ASEAN were viewed by the five Southeast Asian countries as a major victory and reinforced their commitments to ASEAN. According to a U.S. diplomatic cable, the Malaysian delegates came away from the ASEAN-Japan meeting with "generally good feelings about [the] usefulness of ASEAN" (U.S. Embassy in Kuala Lumpur 1973d). The cable also highlighted a "consensus" in the Malaysian government "to try and use ASEAN as vehicle for future negotiations with Japan and EEC as well as other countries" (U.S. Embassy in Kuala Lumpur 1973d). On the Japanese side, its foreign ministry's Asian Regional Policy Division disclosed that "the Japanese Government had been very worried about the discussions" and stressed that ASEAN had an "idealistic anticipation of a constructive dialogue with Japan" (Australian Embassy in Tokyo 1974).

The decision by ASEAN to pursue the rubber issue on a regional basis precipitated Japan's recognition of ASEAN's regionhood. By January 1974, the Japanese government conceded that Japan would "increasingly have to deal with ASEAN as a unit on certain issues" (U.S. Embassy in Tokyo 1974b). Having made some concessions to ASEAN, Japanese foreign affairs officials in-charge of Asian affairs also expressed Japan's hope that "any reference to synthetic rubber problem in [the] communiqué of forthcoming ASEAN's ministerial [meeting] will be more moderate than last year's" (U.S. Embassy in Tokyo 1974a). In return for Japan's recognition of the grouping, the ASEAN communique in the following year duly noted "the cooperation and understanding of the Japanese government" on the rubber issue (ASEAN 1974a). In late-1973, the Japanese embassy in Jakarta further 
recommended "to Tokyo the attachment to the embassy of two or three officers who would be solely engaged on ASEAN affairs and perhaps even accredited to the ASEAN Secretariat once it is established" (Australian Embassy in Jakarta 1973b). The proposal demonstrated a growing awareness within the Japanese government to recognize and engage ASEAN effectively. According to the cable, a key reason for the recommendation was "the increasing need to deal with ASEAN as a whole".

This episode shows how Malaysia was able to harness ASEAN's support in what it considered to be an instance of unjust treatment by a non-member. Japan, on the other hand, was compelled to recognize and transact with ASEAN as a unit in exchange for a favorable representation of Japanese industrial practices by the grouping. Together, these findings support the predictions of the recognition model proposed in Chapter 2. An instance of unfair treatment was exploited by an ASEAN member in the grouping's struggle for recognition. When asked why ASEAN had "pressed its case so hard", Malaysian Secretary-General for ASEAN Yusoff Ariff explained that "ASEAN had been determined to extract from Japan recognition that ASEAN had to be taken seriously" and added that this was achieved at the second ASEAN-Japan meeting on rubber in Tokyo (Australian High Commission in Kuala Lumpur 1974c). In addition to the use of collective action, ASEAN utilized the media to raise public awareness of the issue by sounding the alarm of a "serious threat" from a non-member in its communiqué. It put the pressure on the Japanese government to give a fair response to the grouping in order to limit the damage to its international reputation. This episode was also significant in that it would lay the foundation for the development of ASEAN-Japan relations. 


\subsection{ASEAN-Japan: The first ASEAN Summit}

The communist victory in Vietnam was another event which expedited Japan's recognition of ASEAN. At a bilateral meeting on 12 July 1976 with the U.S., Japanese Foreign Minister Kiichi Miyazawa observed that the "fall of Saigon had given the [ASEAN] organization a new start" and led to an increase in its activities (U.S. Embassy in Tokyo 1976a). With the withdrawal of U.S. troops from Vietnam, there was a growing concern that the rest of Southeast Asia would turn communist. This section details how foreign powers like Japan began to see it in their interests to accord formal recognition on ASEAN. There was greater pressure to cultivate and support the Southeast Asian countries in order that they would not be swayed by the communist movement which would inevitably affect their interests in the region. The discussion shows how the anxiety culminated to a strong lobbying by foreign powers like Japan and Australia for their representation at the inaugural ASEAN Summit in 1976

In July 1975, Japanese ambassadors in Asia met in Tokyo to discuss the impact of a communist Indo-China in the region. The meeting agreed that the ASEAN governments would become more resilient and would maintain tighter control over capital flows from outside, but assessed that ASEAN governments knew that national developments would not be possible "at acceptable rate without foreign help" (U.S. Embassy in Tokyo 1975). Given this window of opportunity, Japanese diplomats agreed that the "possibilities for ASEAN as a regional organization should be explored more fully by Japan" including provision of aid to ASEAN as a regional grouping in the same way that other countries like Australia had already done (U.S. 
Embassy in Tokyo 1975). Some representatives were also in favor for the "scope of consultations to be expanded beyond discussion of economic development to include trade, primary products, political subjects" (U.S. Embassy in Tokyo 1975). The meeting spelled out the pressing need for Japan to work out an effective mechanism in cultivating the ASEAN grouping.

Following the ambassadors' meeting, the Japanese government began to sound ASEAN out on a proposal for Japanese Prime Minister Takeo Miki, who was formerly the foreign minister, to participate in "informal consultations, immediately following the [inaugural] ASEAN summit schedule in Bali in Feb 23-34" (U.S. Embassy in Tokyo 1976b). This proposal was made in response to an announcement by ASEAN that the grouping would hold a head-of-state summit in view of the rapidly changing geopolitical environment. Facing the prospect of a "resurgence of communist subversive activity in ASEAN region" with the pending withdrawal of U.S troops from Vietnam, Indonesian President Suharto had proposed to the ASEAN heads-of-state to convene an ASEAN summit as early as in 1975 (U.S. Embassy in Manila 1975d). According to Japanese Deputy Vice Foreign Affairs Minister Bunroku Yoshino in January 1976, Japan hoped to use the opportunity to encourage "closer association between ASEAN and advanced industrial countries of region" (U.S. Embassy in Tokyo 1976b). Yoshino conceded that while "such closer association with ASEAN might prompt more insistent demands" for economic assistance and trade concessions, Japan decided to proceed with the proposal because "pressures to this effect can be expected to increase in any event". Through such high-level meetings, the Japanese side also hoped to create "a spirit of informality among Asian leaders" (U.S. Embassy in Tokyo 1976c). 
The idea for an informal consultation between the Japanese and ASEAN heads-ofstate was first broached with the Singapore prime minister in December 1975 who responded positively to the proposal. Subsequent approaches to Thailand, Philippines and Indonesia also received encouraging responses. In the meeting with Indonesian Foreign Minister Malik, Yoshino expressed Japan's desire to support the development of ASEAN and willingness to extend economic and political cooperation to the Association. According to Yoshino, Japan would consider favorably "economic cooperation with any 'ASEAN projects' which might emerge in the future" (U.S. Embassy in Tokyo 1976d). This was an unprecedented offer given Japan's long reluctance to be drawn into a regional discussion with ASEAN as a grouping even on solely rubber issue as presented in the earlier section. In lobbying support for the initiative, Yoshino also raised the possible participation of Australia, Japan and New Zealand, but clarified that Japan did not foresee "actual participation in ASEAN discussions" and only hoped for "an opportunity for an informal exchange of views with ASEAN leaders" (U.S. Embassy in Tokyo 1976d). In response, Malik said that "he had to give consideration to ASEAN's future relations with other countries" such as Korea which had expressed interest in developing a closer relationship with ASEAN (U.S. Embassy in Tokyo 1976d). ASEAN was concerned that agreeing to a leaders' meeting with Japan would lead to greater pressures for the grouping to include other foreign powers, which was the outcome ASEAN had hoped to avoid. As for the Japanese side, Yoshino believed that Japan ought to "extend its frontiers" by playing a more constructive role in Southeast Asia. 
Yoshino also sought the views of U.S. Ambassador to Japan Thomas Shoesmith in January 1976 on whether the U.S. would be keen to engage ASEAN together with the "group of advanced industrial countries" (U.S. Embassy in Tokyo 1976b). The U.S. State Department told the Japanese that the US would "give sympathetic consideration to any offer developed by ASEAN to engage us in consultations" but "would not wish to take any steps to push for consultations at a political level" (U.S. State Department 1976b). Mindful of ASEAN's non-aligned image, the U.S. believed that it should not be involved in the summit and specifically requested that "the Japanese would not indicate in any way that they were speaking for U.S." (U.S. State Department 1976b). The State Department's internal assessment was that ASEAN would not be "receptive to such a summit meeting with the industrialized countries as the Japanese think". U.S. State Secretary Kissinger assessed that Miki's initiative did not have "a promising future" (U.S. State Department 1976b). (Details of U.S. engagements with ASEAN will be elaborated in the next chapter). Evidently, Japan had a preference to include its allies in forging a relationship with ASEAN but this was not what ASEAN desired.

Working in tandem with the Japanese, Australian Foreign Minister Peacock during his visit to Jakarta on 29-30 January 1976 also asked Indonesia if newly elected Australian Prime Minister Malcolm Fraser could be invited to attend the closing ceremony of the ASEAN Summit and stay on for an informal talks with the ASEAN leaders (U.S. Embassy in Jakarta 1976c). Indonesia replied that it would have to confer with its ASEAN counterparts. Filipino President Marcos would later affirm that it would be better for countries "like Australia" to wait until ASEAN was "integrated and organized" before pressing for greater involvement in the grouping (U.S. 
Embassy in Manila 1976a). There was an evident concern that the presence of foreign powers in ASEAN would elicit external interferences into regional discussion. It was a scenario which ASEAN was trying to avoid earlier by not admitting larger members into the grouping. In a separate statement to quell rumors of possible Japan and Australia's participation at the inaugural ASEAN summit, Marcos stressed the importance for ASEAN to "become an organic unit of cooperation" before different countries like the EEC deal directly with ASEAN (U.S. Embassy in Singapore 1976c). Despite Marcos' objection, the Japanese embassy in Manila affirmed that Yoshino intended to meet Marcos again to "press Prime Minister Miki's interest in Japanese attendance at ASEAN summit meeting" (U.S. Embassy in Manila 1976b).

At an ASEAN foreign ministers' meeting in February 1976 prior to the inaugural summit, the meeting officially turned down both Australia and Japan's request to participate in a post-summit meeting (U.S. Embassy in Canberra 1976b). As mentioned earlier, ASEAN foreign ministers were concerned about the intentions and possible negative implications of foreign powers' direct involvement in the fivemember grouping. Displaying such distrust, Thai Foreign Minister Pichai Rattakun remarked in April 1976 that he could not "understand why Japan had to show so much eagerness in participating in the ASEAN summit" (U.S. Embassy in Bangkok 1976b). It was equally crucial to signal to the communist Indo-China countries that ASEAN remained non-aligned, favoring neither countries from the communist or noncommunist camps. However, ASEAN was equally mindful that failure to obtain foreign powers' recognition would also be detrimental to the grouping's development. While the timing and mechanism for cooperation were not yet in place, ASEAN 
leaders clearly relished the value of some formal recognition by the external powers toward the grouping. Their rejection for the informal leaders' meeting with ASEAN was therefore "couched in extremely polite verbal messages given to Australian and Japanese Government representatives individually... by Mr. Chartichai Choonhavan, the Thai foreign minister" who chaired the two-day ASEAN Foreign Ministers in February 1976 (The Straits Times 1976c: 1):

The meeting of Asean heads of governments is expected to be concluded in the evening of Feb. 24. Because of exigencies at home, some heads of government will have to leave Bali on the evening of Feb 25. In view of such early departures it is not possible to envisage a meeting of your Prime Minister with ASEAN heads of government. We like to express our gratitude at your government's recognition of Asean as a collective and indigenous body and your desire to make your contribution to our joint undertakings in the economic field.

The latter half of the statement above again reveals the importance that ASEAN attached to the issue of external recognition. Despite ASEAN's outward rejection of Japan and Australia's coordinated request, their interest to engage ASEAN as one collective unit had a catalytic effect on the development of the young grouping. The U.S. Embassy in Tokyo (1976e) explained that Malaysia opposed Japan's participation because it did not want Indochina countries to interpret such an invitation as the formation of an "anti-Indochina bloc" and Jakarta would like to guard its premier role in ASEAN and "consolidate its leadership among ASEAN equals". However, U.S. affirmed that Canberra and Tokyo's gesture would "bolster ASEAN confidence". The Japanese officials from the regional affairs division in the foreign 
ministry also believed that their unsuccessful initiative "served in some measure as psychological encouragement to ASEAN leaders at Bali" (U.S. Embassy in Tokyo 1976f). In response to the rejection, the Japanese government decided to send a congratulatory message from Japanese Prime Minister Miki to the inaugural ASEAN Summit (U.S. Embassy in Jakarta 1976d). The message was conveyed to President Suharto and requested the Indonesian leader to pass on Japanese congratulations to the other ASEAN leaders. According to Ikema (1980: 472), the message congratulated ASEAN on making "a historical step toward the growth and stability of Southeast Asia" and expressed Japan's intention to "further strengthen cooperation with ASEAN". Hoping for the message to be made public, Japanese Ambassador to Indonesia Sunobe Ryozo carried the congratulatory note with him to Bali and presented it to Indonesia prior to the summit opening. It was evident that Japan wanted to declare its strong desire to open up ties with the ASEAN grouping during the summit. More specifically, the Japanese foreign ministry's regional affairs division disclosed that Japan was "anxious to cooperate with the ASEAN organization, including with funds" (U.S. Embassy in Tokyo 1976f). The division envisaged four ways to achieve this goal: i) Bridge communications between Japan and ASEAN by inviting senior ASEAN representatives from each country to visit Japan; ii) Offer technology and fund feasibility studies for ASEAN projects; iii) Increase its contribution for training ASEAN nationals; iv) Channel funds to ASEAN countries by larger Japanese contributions and "bureaucratically favoring ASEAN needs" through the Asian Development Bank (ADB).

Despite Japan's unsuccessful attempt for Miki to participate in the inaugural ASEAN summit, its foreign ministry decided to embark on a plan to inaugurate "a general 
dialogue with ASEAN" in 1976 after consultations with its embassies in Southeast Asia. As mentioned in the earlier section, the Japanese side had only discussion with ASEAN on issues related to synthetic rubber production up to this point. The ministry envisaged that there could be "an annual meeting between Japan and ASEAN which would be general in nature and not confined to any specific topics" (U.S. Embassy in Singapore 1976d). Positioning the meeting at the director-level, the Japanese foreign ministry suggested for its director of Asian affairs to meet with the five directors in charge of ASEAN affairs in the five countries and the newly appointed ASEAN secretary-general. The Japanese also proposed that the dialogue be supplemented by "one or two meetings in Tokyo between the vice minister of foreign affairs and the ambassadors from the ASEAN governments" (U.S. Embassy in Singapore 1976d).

Accordingly, Tokyo began its charm offensive by "serially inviting national ASEAN secretaries" to Japan for a "get-acquainted visit" (U.S. Embassy in Tokyo 1976g). It was during a late-August 1976 visit by the Indonesians that Japan received a "strong hint that a Japanese bid to establish institutionalized link to ASEAN would be timely". Filipino President Marcos became the first ASEAN leader to call for a ministerial-level dialogue between ASEAN and Japan. In a major speech on 30 September 1976, Marcos noted that “Japan's enormous economic power has left her vulnerable to those who control sources of raw materials and routes which they are shipped" (U.S. Embassy in Manila 1976c). Since such a weakness could "revive Japanese interest in rearmament", it would seem to be in the "mutual interest of ASEAN and Japan to begin discussion of a satisfactory arrangement which would ensure Japan's continue access to the raw materials". Marcos argued that ASEAN would, in turn, benefit from 
the generous infusion of capital and "know-how" from Japan (U.S. Embassy in Manila 1976c).

It was at the ASEAN Standing Committee meeting on 17 November 1976 in Singapore that ASEAN agreed "to respond positively to Japan's request for economic consultations" (U.S. Embassy in Singapore 1976e). In arriving at the decision, ASEAN imposed three conditions, namely, i) the continuation of the ASEAN-Japan consultations on synthetic rubber; ii) the assurance that Japanese bilateral aid programs with ASEAN countries would not be affected; and iii) the agreement that the format of the consultation followed that of other foreign powers including Australia and the EEC (U.S. Embassy in Singapore 1976e). Here again, the primary condition for the formalization of ASEAN-Japan consultation was that national interest would prevail over regional interest as was the case in ASEAN's negotiation with Australia discussed in the earlier section. This agreement led to the first leaders' meeting between Japan and the five ASEAN states in August 1977 and instituted the annual ASEAN-Japan Forum in the same year. The Fukuda Doctrine was announced at the leaders' meeting with Japan pledging a total of US\$1 billion to support industrial projects in ASEAN. This amount was significantly larger than the $A \$ 5$ million offered by the Australian government. It marked Japan's first formal recognition of ASEAN as the legitimate actor for the Southeast Asian region. Japan's generous offer was again viewed in ASEAN as a concrete benefit to the region that would not have been possible without securing external recognition of the grouping. It was also a sweet victory for some ASEAN leaders like Singapore Prime Minister Lee who had insisted that "only if Japan could promise to expand its aid would Japanese attendance at the ASEAN Summit [of 1977] be considered" (Sudo 1992: 159). 
This section explains how the fall of Saigon invigorated the Japanese government to reexamine its recognition policy toward ASEAN. Sharing the outcome of the Japanese Southeast Asian Chiefs of Mission meeting in Bangkok on 25-26 November 1976 with his U.S. counterpart, the Japanese ambassador in Singapore revealed that the meeting "highly regarded" the role of ASEAN "to the point where it assumed [that the] whole region would go communist if ASEAN fails" (U.S. Embassy in Singapore 1976b). As a result of the meeting, Japan decided "to broaden its economic ties with ASEAN countries". According to the ambassador, the ministry reached a decision to abandon "balanced diplomacy" in Southeast Asia and focus on creating a "special relationship" with ASEAN (U.S. State Department 1976c). The new policy direction was again reiterated in another meeting involving Japanese diplomats in Bangkok on 17 December 1976: "Japan's ASEAN ambassadors had argued strongly in favor of closer Japanese ties with ASEAN and bilaterally with its individual members" (U.S. Embassy in Bangkok 1976c).

\subsection{ASEAN-Australia and ASEAN-Japan: In retrospect}

As a summary to this chapter, the discussion has outlined ASEAN's struggles for Japan and Australia's recognition. The analysis started by highlighting the economic strength of the Southeast Asian region as a source of critical raw materials. It finds that ASEAN countries had low levels of intra-regional trade with one another and traded more with the external markets. Foreign powers like Japan were heavily reliant on the region for its primary resources. As a result of its dependence on Southeast Asia for raw materials, Japan was skeptical of any regional initiatives that 
might control and influence the supply and price of critical imports. Instead, Japan gave emphasis to the cultivation of bilateral ties so as to ensure a steady supply of these imports. Its policy stance of favoring bilateral engagements over regional ones led to the following comments by Singaporean Prime Minister Lee to Eiji Tomimori, Editor of Asahi Shimbun in April 1974:

Japan should not put importance on particular bilateral relations only because it needs resources of that nation... Japan should make more "multilateral approach" to ASEAN nations regarding the ASEAN as one combined unit (Asahi Shimbun 1974: 2).

In a follow-up report, Eiji reiterated that "Japan should not stick to the present economic relations based on separate bilateral relations" and called for the Japanese government "to regard the ASEAN a nucleus of Southeast Asia" and to "re-examine its diplomacy, adding bolder political judgment" (Asahi Shimbun 1974: 2). ASEAN was clearly intent on securing external recognition for the grouping.

Fearing the possibility of collective bargaining and group action, Japan had been reluctant to accord ASEAN with any recognition from the onset, preferring instead to deal with the Southeast Asian countries on a bilateral basis. Japan's refusal to restrain its synthetic rubber production, however, provided an opportunity for Malaysia to emphasize to ASEAN the importance of staying together and retaliating as a group against any unfair treatments by external powers. ASEAN's victory in its rubber spat with Japan, in turn, encouraged the Malaysians to increasingly view ASEAN as a useful regional platform to solve their national problems. For example, the success of lobbying Japan on the rubber issue through ASEAN motivated Malaysia to adopt the same tactic against possible moves by the U.S. to dispose its 
stockpile of tin, a commodity to which the Malaysian leadership warned was "one of the mainstays of a number of developing tin producing countries, in particular within the ASEAN region namely Malaysia, Indonesia and Thailand" (U.S. Embassy in Kuala Lumpur 1975e). Responding to U.S. possible action, the Malaysian Ministry of Primary Industries explained that "the seriousness of the threat of any major stockpile release... has prompted Malaysia to initiate joint ASEAN concerted approach and representation of the matter both at their respective capitals and in Washington" (U.S. Embassy in Kuala Lumpur 1975e). The rubber saga between ASEAN and Japan has shown that the more member states were able to tackle their domestic problems through the ASEAN channel, the more committed they were to regional cooperation. This was, however, only possible if ASEAN were able to obtain foreign powers' recognition of its legitimacy as a regional grouping in Southeast Asia. Its success in gaining recognition on the economic front encouraged the five ASEAN states to see the benefits of regional cooperation.

Likewise, Australia's deep-seated desire not to be excluded from any regional developments enabled ASEAN to obtain Canberra's recognition of the grouping. In so doing, it also caused the five member states to realize that the more external recognition it gained, the more useful ASEAN could serve as a regional platform to solve their national problems and to extract greater material support from the foreign powers. The degree of external recognition is intricately linked to the level of tangible external support available to ASEAN as suggested in the recognition model of this dissertation. For example, Japan's refusal to recognize ASEAN and accord the grouping with fair treatment was exploited by the grouping to negotiate better deals from other foreign powers. At the beginning of the rubber spat, Japan had originally 
made an initial offer of US\$25,000 to appease ASEAN. Not only was this offer rejected by the grouping, the incident was exploited by ASEAN to highlight to other foreign powers the importance of according the Southeast Asaian grouping with proper respect and fair treatment. In subsequent discussion on the possibility of funding ASEAN activities, Executive Officer of ASEAN Secretariat Rosario Manalo advised the Australians to "show more sensitivity than the Japanese had in recently offering 25,000 U.S. dollars" (Australian Embassy in Manila 1973). Manalo further revealed that the Japanese offer was "badly timed and that Malaysia and Indonesia had been furious". Philippines had then called in the Japanese counselor in Manila to register its dissatisfaction with the Japanese officials who had made the suggestion. The cable further revealed that:

What had particularly annoyed ASEAN members was that the Japanese offer was made at a time when ASEAN had strongly criticized Japan on the question of synthetic rubber. The Japanese offer was seen as a crude attempt to bribe ASEAN... if the Japanese were going to offer bribes they might at least have the decency to make them substantial ones (Australian Embassy in Manila 1973).

Assessing ASEAN's response, Japanese embassy officials in Jakarta, themselves, conceded that "the offer was so modest as to have given offence to the ASEAN members" (Australian Embassy in Jakarta 1973b). In a separate meeting, Malaysian Secretary-General for ASEAN Yusoff also made it plain to the Australians that ASEAN rejected the offer because the "amount was an insult to countries of the region" (Australian Embassy in Jakarta 1973c). At a meeting with Australian Deputy Secretary of External Affairs Richard Woolcott on 18 April 1974, Yusoff explained that ASEAN "was not trying to embarrass Japan but simply asking Japan to face up 
to its responsibilities in the region" (Australian Department of External Affairs 1974a). During the discussion, Woolcott agreed with Yusoff that "ASEAN was in effect applying collective pressure". ASEAN's initial hostility toward Japan would invoke a strong response from several Australian ambassadors in Southeast Asia when a suggestion was made for Australia to invite Japan to join in the meeting with ASEAN, as reflected in the following report from Australian Ambassador to Thailand Tom Critchley on 5 November 1973:

In view of uneasy bilateral economic relations between Japan and most member countries and particularly because of poor impression Japan has so far made as potential economic supporter of ASEAN it would be unfortunate if Australia appeared to wish to bring Japanese into ASEAN consultations (Australian Embassy in Bangkok 1973c).

This brief anecdotal narration of the behind-the-scene negotiation between Australia and ASEAN serves to highlight how ASEAN succeeded to play one foreign power against another and to capitalize on Japanese poor treatment of ASEAN to obtain more foreign aid. As a result, ASEAN was able to secure monetary support to the amount of $A \$ 5$ million from the Australians and subsequently to the tune of US $\$ 1$ billion from the Japanese. The advantages of external recognition and how it would bring about greater benefits for the region was evident to the ASEAN member states.

While recognition was important to the grouping, the anecdotal evidence has also shown that ASEAN was not prepared to accept a lower status in its desire for external recognition. It was also for this reason that the grouping had been unwilling to admit bigger and more powerful nations into the ASEAN membership. Reflecting such a policy stance, Manalo conceded that she 
did not see how any developed country could join ASEAN. The whole strength and concept of ASEAN was that it was an association of equals. To bring in a country such as Australia, New Zealand or Japan, would completely destroy the basis of the cooperation which had been achieved and would make it a completely different organization (Australian Embassy in Manila 1973).

The empirical evidence in this chapter has also accounted for how the grouping was able to fob off pressures from Japan and Australia for the group to be more inclusive. Admitting foreign powers into ASEAN rather than acquiring their recognition of the grouping as a legitimate actor in Southeast Asia would have limited the bargaining power of ASEAN. Indonesian Secretary-General for ASEAN Umaryadi confessed in May 1974 that "Australia's interest and presence would balance the presence of Japan which had tended to become a dominating force" (Australian Embassy in Jakarta 1974a).

The extent of ASEAN's desire for recognition was again reflected in a decision in December 1973 that the meeting of ASEAN foreign ministers would precede Japanese premier's visit to Southeast Asia with the purpose "to agree in a joint approach to put to the Japanese to dispel the Japanese view that ASEAN countries have no common policy" (Australian Embassy in Bangkok 1973d). Following the communiqué criticizing Japanese actions on rubber, a joint press statement by ASEAN affirmed that "the practice of presenting a common ASEAN stand should be further encouraged, particularly in dealing with the more developed countries in international organizations and conferences where economic and technical cooperation are discussed" (U.S. Embassy in Bangkok 1973b). The presentation of 
a collective front to the external powers was viewed in ASEAN as crucial to securing greater recognition for the grouping.

Finally, the discussion has also highlighted the importance of exogenous events like the withdrawal of U.S. troops from Saigon in expediting Japan's willingness to recognize ASEAN as a legitimate regional actor. More importantly, the success of ASEAN's struggle for recognition was assessed in a positive light by the foreign powers. For instance, the outcome of ASEAN's joint economic action against Japan was viewed in the U.S. as a reflection of ASEAN's potential to develop into a formidable regional grouping as explained by U.S. Ambassador to Japan Thomas Shoesmith in 1974:

This leads to what we view as most effective barrier to any Chinese efforts to oust U.S. and Japan and establish hegemony in area: ASEAN nations themselves. We are impressed with [the] way ASEAN nations have taken charge of their own affairs, exhibiting degree of cohesion (however imperfect) and sense of purpose. Their approach to Japanese on synthetic rubber production is case in point, though more for symbolic than practical importance (U.S. Embassy in Tokyo 1974c).

A draft Australian internal policy planning paper suggests that "South East Asia may be weak, but it is no longer an uncontested fact of life that it should be at the mercy of the great powers" (Australian Department of External Affairs 1971a). At a bilateral meeting with Australian Prime Minister Whitlam on 29 October 1973, Japanese Prime Minister Ohira also expressed "great respect for ASEAN as a natural association of regional states which was getting more and more co-operative each year... [in contrast] many other regional organizations had proved to be temporary 
but ASEAN was established as a permanent body" (Australian Embassy in Tokyo 1973c). Furthermore, the shifting attitudes toward ASEAN had the effect of escalating the competition among the foreign powers in recognizing the grouping as a legitimate regional entity in Southeast Asia. Even between allies, the rivalry to cultivate ASEAN also intensified, which further strengthened the bargaining power of ASEAN. The Canberra government, for instance, admitted that "Japan would probably be irritated if Australia were to get in first with formal arrangements with ASEAN" (Australian Embassy in Tokyo 1973a). This highlights the importance of cumulative recognition for a regional grouping like ASEAN as the next chapter will also show by discussing ASEAN's socialization with two other powers - the EEC and the U.S. 


\section{Chapter 5: EEC and U.S. Recognition of ASEAN}

This dissertation started by elucidating a recognition model for regionhood based on past and current theories on the recognition of statehood and personhood. The theoretical framework in Chapter 2 has outlined a matrix to examine the development of regions based on the supply and demand of external recognition (Reference 1). The model predicts that the outcome of ASEAN's struggle for recognition has an influence on the pace of regional cooperation in Southeast Asia. Chapter 3 went on to discuss how foreign powers' misrecognition and non-recognition of ASEAN as the legitimate regional actor in Southeast Asia led to the grouping's earliest initiative for political recognition in the form of a proposal for a zone of neutrality and peace. To maintain their hegemony and interests in Southeast Asia, foreign powers refused to recognize such a zone. Instead, they repeatedly depicted the region as a group of countries too weak to defend themselves against the enemy. It led to ASEAN's failure in its initial quest for external recognition. The empirical evidence presented in Chapter 4 has outlined ASEAN's socialization with Australia and Japan during its formative years. It has highlighted the extent of ASEAN's desire for external recognition, and how Japan and Australia's recognition of the grouping caused the member states to increasingly view regional cooperation as a means to overcome national problems. The grouping demonstrated a strong desire for material gains and an expectation for fair treatment in its interactions with the two regional powers. Australia and Japan, in turn, adjusted their recognition policies toward ASEAN after failing in their attempts to join the regional grouping and harness support for a larger regional grouping. To protect their own interests in the region, both powers moved away from their sole emphasis on developing bilateral ties by recognizing and 
engaging ASEAN as a regional actor. Critically, there was no evidence from the diplomatic archives suggesting that these foreign powers were attracted to establish formal ties with ASEAN because of the growing effectiveness of the grouping or its inculcation of a common set of values or norms among members. The degree of socialization among member states was not a major consideration by these foreign powers in their recognition decisions toward ASEAN. Rather, the discussion highlights the importance of external recognition and how sequential or cumulative recognition had a snowball effect of strengthening ASEAN both in tangible terms and in the way it motivated member states to deepen regional cooperation in Southeast Asia.

This chapter turns the focus of the analysis toward ASEAN-EEC and ASEAN-U.S. relations. The discussion examines the motivations underlying the Southeast Asian grouping's economic interaction with the two major powers. The archival data shows how the struggle for external recognition took place not only between ASEAN and the foreign powers, but also between members within the Southeast Asian grouping itself as a result of conflicting national interests. Together with the evidence presented earlier, the case studies in this chapter support the hypothesis that the level of external recognition influences the behaviors and attitudes of member states toward regional cooperation. While the preceding chapter has demonstrated how external recognition motivated member states like Malaysia to increasing view ASEAN as a regional platform to resolve national problems, the discussion here illustrates how such recognition also negatively affected the attitudes of some members toward regional cooperation in consideration of their national interests. The first part of the analysis centers on the factors leading to EEC's interactions with ASEAN. The 
grouping's success in obtaining recognition from the EEC was pivotal to the sway in U.S. recognition policy toward ASEAN. The second half of the chapter outlines U.S. attitudes toward ASEAN and the events compelling Washington to adjust its nonrecognition policy toward the grouping. By drawing the connection between ASEAN's struggle for recognition and the proposed recognition model in Reference 1 and $\underline{3}$, the discussion here reiterates the significance of cumulative recognition to the growth of a regional concept like ASEAN.

\subsection{ASEAN-EEC: The motivations for recognition}

The EEC was the first external entity to recognize ASEAN's regionhood through its agreement for EEC Commissioner for External Affairs Christopher Soames to have a ministerial meeting with the Southeast Asian grouping in September 1973. That the EEC agreed to the meeting was not a surprise because the Community was itself a relatively young grouping, having established a common market only in the 1950s. EEC's willingness to recognize ASEAN was also motivated by its desire to entrench its position in Southeast Asia at a time when the U.S. was perceived to be withdrawing from the region under the Nixon Doctrine. On EEC's keenness to meet with ASEAN as a group, Thai Deputy Secretary-General of Foreign Affairs Chet Sucharitkun explained that the EEC exploited "an opening in developing the trading partners of the ASEAN countries (indeed all of Southeast Asia) with the withdrawal of the United States from the area, a gap which the EEC hoped it could step in and fill" (U.S. Embassy in Bangkok 1973c). In other words, EEC's willingness to recognize ASEAN was motivated by its desire to entrench its position and protect its economic 
interests in Southeast Asia at a time when the U.S. was perceived to be withdrawing from the region. Harris and Bridges (1983: 45) explain:

The European countries also have interest in the ASEAN countries' strategic position astride one of the vital choke-points of international trade, the Straits of Malacca and Singapore. Most of the region's shipping to and from west Europe passes through these straits... Use of these straits could also be denied to European shipping if one or more of the European countries were to become the target of violent hostility by ASEAN collectively or one ASEAN country individually.

In addition to the above, the EEC was also keen to cultivate the Southeast Asian region given its importance as a critical source of raw materials. As highlighted in the preceding chapter, the EEC "imported a number of strategic commodities from ASEAN countries (e.g., oil, rubber, tin, iron...)" (Robles 2004: 11).

ASEAN, on the other hand, was motivated to obtain EEC's recognition because of the grouping's desire for a fairer and better access into the European markets. Since 1971, the EEC began offering trade concessions to regions such as Africa and the Caribbean under the Generalized System of Preferences (GSP), which provided tariff exemptions to imports from developing countries. However, ASEAN was excluded from these trade concessions because Southeast Asia was not perceived to be a (developing) region by the EEC. The grouping's collective approach was therefore aimed at securing equal treatment from the EEC because there was:

a perception amongst the ASEAN countries that their exports to the EEC were being discriminated against in favor of goods coming from forty-two African 
countries which... were given preferential treatment by the EEC (Dewi Anwar 1994: 64).

In response to EEC's willingness to recognize developing regions like Africa and offer them better terms of trade, ASEAN tried to secure EEC's reciprocal recognition. Chet acknowledged that ASEAN's main objective of the ASEAN-EEC ministerial meeting was to obtain "a promise that the EEC would pursue discussions with ASEAN regarding duty concessions" (U.S. Embassy in Bangkok 1973c). In particular, ASEAN hoped to seek EEC's exemption of import duty on several primary products from ASEAN. Given EEC's desire to have a head-start in expanding its trade link with Southeast Asian economies as highlighted earlier, Chet was hopeful that "the EEC would eventually grant such concessions to ASEAN". Furthermore, ASEAN states had sought to reduce their dependence on Japan as the main export destination in light of the perceived unfair treatment they experienced as outlined in the preceding chapter. By securing better trade deals as a region, the member states hoped to maintain stable prices and expand the basket of export destinations for their products.

With this aim, ASEAN countries decided to diversify their economic relations with as many external entities as possible as Kevasan (1981: 256) explains: "As the EEC was still comparatively unexplored, the ASEAN countries showed much keenness to cultivate relations with it". Evidently, the desire for fair treatment and greater economic opportunities is observed in ASEAN's motivations for EEC's recognition as in the case of its dealings with Japan and Australia presented in the earlier discussion. 


\subsection{ASEAN-EEC: The struggle within ASEAN for recognition}

The preceding section has outlined the motivations driving the demand and supply of recognition between ASEAN and the EEC. The inaugural meeting between the two regions was labeled by the Thai foreign ministry as a "trial balloon" for ASEAN because there was no other instance where the five countries were represented by the grouping (U.S. Embassy in Bangkok 1974d). It was clear from the onset that ASEAN was the side making the move to secure EEC's recognition of the Southeast Asian region as a collective economic entity as Robles (2006: 98) observes: "In the case of the ASEAN-EC/EU relationship, it will be seen that ASEAN was in many cases the partner that put forward, in different areas, proposals that would give substance to the relationship". The prospect for preferential economic access into the European markets accelerated ASEAN's pursuit for EEC's recognition.

With this aim, the ASEAN members appointed Indonesian Minister for Trade Sumitro Djojohadikusumo to be their spokesperson during the latter's visit to Brussels in 1971. Sumitro was instructed by the five ASEAN states to make "a joint approach to the EEC for associate membership or some form of negotiated relationship between the Community and the ASEAN Group" (Australian Embassy in Jakarta 1971b). The goal was to secure EEC's recognition of ASEAN as a developing region. On his return, Sumitro revealed in December 1971 that ASEAN "had obtained a very favorable response" and that "it would be possible to negotiate an arrangement for the ASEAN countries which would give them treatment equal to that accorded to the former French colonies in Africa in respect of their main exports to the United Kingdom and Western Europe" (Australian Embassy in Jakarta 1971b). Sumitro explained that it 
was "essential for the ASEAN group to make such an arrangement to avoid losing existing markets, especially in the United Kingdom, to African and other developing countries which had, or were likely to be given, special status". The agreement reached during the visit would lay the foundation for a series of informal discussion leading to the first concrete act of recognition by the EEC through the inauguration of the first ASEAN-EEC ministerial meeting.

Evidently, EEC's impending recognition of ASEAN gave impetus to the pace of cooperation among member states in the grouping. The Sixth ASEAN Ministerial Meeting in 1973 agreed on the necessity for "a collective approach" in managing external economic issues such as multilateral trade negotiations and deepening of relations with EEC. To strengthen ties with the EEC, the Special Coordinating Committee of ASEAN Nations (SCCAN) was established as the official trade body of ASEAN. SSCAN was supported by two committees. One, ASEAN Brussels Committee $(A B C)$ was set up to "prepare the way for an early dialogue between ASEAN and the EEC" (ASEAN 1972). Two, ASEAN Geneva Committee was established to coordinate their positions at multilateral trade negotiations under the auspices of General Agreement on Tariffs and Trade (GATT). The prospect of EEC's recognition expedited ASEAN's efforts to institutionalize regional cooperation in Southeast Asia. In the run-up to the inaugural ASEAN-EEC ministerial meeting in September 1973, ASEAN senior trade officials under the ambit of SSCAN met for a series of preparatory meetings to coordinate their positions ahead of the meeting.

The struggle for EEC's recognition was the first instance which brought ASEAN member states together with the goal to collectively achieve greater economic 
benefits for the Southeast Asian region from a foreign power. Yet, the ASEAN states never had the experience of engaging a foreign power as a collective entity. Further, there were initial concerns that joint negotiation with EEC would undermine their diverse national interests. Such fears were reflected in the reactions of ASEAN countries toward a SCCAN initiative to train and equip ASEAN officials with the skills to participate in multilateral trade negotiations. This initiative was the brainchild of Indonesian Trade Minister Sumitro who was also the chairperson of SCCAN. Under the proposed program, a group of ASEAN trade officials would be selected to attend a technical seminar on multilateral trade negotiations in Pittsburgh University in mid1973. Although the proposal came from Indonesia, which was regarded as the leader of the ASEAN pack, Singapore and Thailand declined the invitation while Philippines and Malaysia dispatched a small symbolic delegation. Member states were fearful that joint negotiation with the EEC might jeopardize their national interests.

During his term as the chairperson of SCCAN, Sumitro also tried in vain to push for a secretariat to be based in Jakarta to coordinate policy on trade negotiations. This initiative was again rejected by the rest of the ASEAN members. From the outset, some ASEAN states had reservations about the impact of joint ASEAN trade negotiations on national interests. Singapore, for example, was against the idea "on grounds that each country had different trade problems" and argued that "the concerting of overall trade policies was not possible" (U.S. Embassy in Singapore 1973b). Malaysia, on the hand, felt that "as a group, ASEAN can only at best agree on broad outlines on which to approach talks" (U.S. Embassy in Kuala Lumpur 1973e). According to Malaysian Deputy Director, International Trade Division of Ministry of Trade Yee Chee Pong, Malaysia believed that its interests were "best 
served through individual negotiations both in GATT talks and with EEC" although Malaysia was "willing to cooperate and coordinate efforts with ASEAN". These anecdotal accounts reflect the deep-seated concerns of member states toward economic cooperation in ASEAN. Ironically, it was the success of ASEAN's first joint approach to the EEC that allayed member states' reservations toward joint negotiation.

To be sure, some ASEAN countries were hesitant about promoting ASEAN's regionhood through joint economic activities like trade negotiation for fears that they had little to gain and everything to lose in terms of national interest. Singapore, for example, produced hardly any primary products unlike the other four ASEAN countries which meant that the city-state had little to gain if the meeting with EEC only focused on tariff reductions of primary products. However, EEC's agreement to meet with ASEAN as a group to discuss a broad range of trade issues encouraged skeptical ASEAN countries to reconsider their policy stance toward joint negotiation. A case in point is EEC's willingness to discuss and reconsider its rules of origin with the ASEAN countries. The EEC delegation who accompanied Soames to attend the first ministerial meeting with ASEAN disclosed that

the Community was also considering some changes in the rules of origin as they govern the Community's general preference scheme. One possible change would allow for the cumulation of origin within regional groupings such as ASEAN so that products processed in more than one country of a regional grouping could more easily meet the origin rules of the EC general preference system. A second possibility would be to exclude from the normal origin 
calculations that portion of a product which originated in the community itself (U.S. Mission in EC Brussels 1973a).

The prospect of the EEC's applying a cumulative rule of origin formula incentivized Singapore to give its full support to ASEAN's negotiation with the EEC. In 1972, Singapore's share of exports to the EEC accounted for more than 30 percent of EEC's imports from Asian countries (The Straits Times 1974a: 9). Prior to the ministerial meeting, Singapore emphasized that they would press for the EEC's acceptance of "accumulative rules of origin" (U.S. Embassy in Singapore 1973c).

This section illustrates the struggle within ASEAN for EEC's recognition. While member states saw the importance of joint negotiation with the EEC, they were concerned that collective bargaining would subject their national interests to external pressures. However, the realization that EEC's recognition would lead to tangible trade benefits encouraged member states to work with one another in coming up with a unified position in their negotiation with the EEC as the case of Singapore's desire for cumulative rule of origin has shown.

\subsection{ASEAN-EEC: The beginning of recognition}

While ASEAN desired several trade concessions from the EEC, it was careful not to be seen as over-demanding in its requests during the initial meetings. At that point, it was more important to obtain EEC's recognition of ASEAN's regionhood. As mentioned at the beginning of the chapter, the EEC had been willing to offer trade concessions to developing regions like Africa as a whole but not to Southeast Asia. ASEAN members realized the importance of convincing the EEC to recognize the 
Southeast Asian countries as a developing region first. Toward this end, they were willing to put aside their differences in order to project a united front to the EEC delegates. At the first meeting, ASEAN representatives moderated their expectations when they realized that it was more important to secure EEC's recognition of ASEAN. EEC Commissioner for External Affairs Soames came away from the inaugural ASEAN-EEC meeting surprised by "the flexibility of ASEAN representatives and the unwillingness of the group to try to press for too much in these early discussions" (U.S. Embassy in Manila 1973). In particular, the EEC delegation was pleased "to find such a feeling of solidarity among the Five - Thailand, Philippines, Indonesia, Malaysia and Singapore" and was surprised by their request to invite other Southeast Asian neighbors to participate in future meetings (U.S. Mission in EC Brussels 1973b). The EEC delegates further reported that ASEAN's preparations were "solid", including individual country lists of products separating requests for consideration under either GSP or the GATT. In return, the EEC made several tariff concessions on perishables like pineapples and coconut oil to all ASEAN members (U.S. Embassy in Manila 1973). While the gains to ASEAN were relatively modest at the first meeting, the grouping decided not to press the EEC for too many concessions as it was more important at that time to secure EEC's recognition of ASEAN. The plan appeared to have worked.

When asked if the EEC recognized and supported the existence of ASEAN, Division Chief of EEC's Commission for External Relations Tran Van Tinh replied: "Politically yes, technically no" (U.S. Embassy in Jakarta 1973f). Tran went on to explain that there was "no ASEAN organization at the 'technical level' that EEC could talk to" and expressed his hope that ASEAN countries would adopt a "unified bargaining 
approach" to make it easier for EEC to negotiate with and enhance "ASEAN's bargaining power". As mentioned earlier, this was the main reason why the ASEAN governments decided to establish SCCAN. To secure external recognition, it was critical to present a common front to the foreign powers. Nonetheless, ASEAN's cautious strategy enabled the group to obtain "from the EEC the recognition of ASEAN as one region and the preferential access of certain commodities into EEC markets" (ASEAN 1974a).

The success of the first meeting prompted the two sides to hold a second meeting on 24 September 1974. In his opening address, Indonesian Trade Minister and Chairman of SCCAN Radius Prawiro again highlighted ASEAN's concerns over EEC's recent trade agreements with African, Caribbean, Pacific and Arab states (U.S. Embassy in Jakarta 1974d). Radius echoed similar views expressed by the Singapore government which highlighted "ASEAN growing sense of isolation... capable of exercising reason yet find themselves increasingly excluded from beneficial arrangements with main trading blocks" (U.S. Embassy in Singapore 1973c). At the second meeting, ASEAN and the EEC issued a joint statement agreeing to "set up a joint study group for further development and intensification of dialogue" (U.S. State Department 1974a). The study group was aimed at exploring "all possible areas where cooperation could be broadened, intensified, diversified giving special considerations to the development needs of the ASEAN countries and bearing in mind the situations in EEC" (ASEAN 1974b). According to Filipino Ambassador Wilfredo Vega, who was present at the talks, the EEC committed to "working out a scheme of reference prices and reference quantities for ASEAN commodities, possibly involving rebates of the variable levy or some portion thereof 
(U.S. Embassy in Manila 1974b). Reviewing his impression of the second meeting with ASEAN after the visit, Soames said that ASEAN sought "an intensified relationship" and recognized that "no individual European country can provide them with the 'European option' in trade, investments, and assistance that the EC offers and which would lessen their feeling of dependence on the U.S. and Japan" (U.S. Mission in EC Brussels 1974a). Soames was again impressed with the "solidarity of ASEAN nations, even on matters in which their interests appear to differ" (U.S. Embassy in Jakarta 1974d). Malaysia, for example, strongly supported Singapore's pitch for cumulative rule of origin. The EEC was also "positive about developing institutional links with ASEAN, perhaps leading eventually to EEC-ASEAN treaty". On the ASEAN-side, the delegates were pleased by the "evident EEC interest in close institutional link with ASEAN" (U.S. Embassy in Jakarta 1974d). At the meeting, the EEC even extended an invitation for two senior officials from each of the five ASEAN countries to visit Brussels for "orientation on EEC secretariat organization" (U.S. Embassy in Kuala Lumpur 1974d). The EEC also agreed to a common ASEAN rule of origin for purposes of the GPS, which implied that "where the qualification for entry under the GSP was $60 \%$ added value to a raw material, the $60 \%$ could be the total of value added in various ASEAN countries" (Australian Representative to the European Communities 1974). EEC's decision to treat products from any of the five member countries as originating from the ASEAN region highlighted to the Singaporean policy-makers the usefulness of regional cooperation.

In less than three years since the beginning of talks with the EEC, ASEAN was able to secure EEC's approval on tariff reductions as well as the application of a cumulative rule of origin from ASEAN countries for all goods (U.S. Mission in EC 
Brussels 1974b). Beginning from 1 January 1975, the EEC permitted imports from all ASEAN nations to be counted towards meeting the origin requirement under its GSP. This was in sharp contrast to the GSP under the U.S. government where imports had to be directly consigned to the U.S. in order to enjoy duty-free treatment. As mentioned earlier, it was a sweetener for ASEAN economies like Singapore which were heavily reliant on entrepot trade but did not benefit from the EEC's earlier reduction in tariffs on primary products (U.S. State Department 1975h). As for the other economies dependent on the export of primary resources, EEC made a further reduction of tariffs on several commodities including rubber, palm oil, tea, tin and pepper for ASEAN in July 1975. It became clear to ASEAN that EEC's willingness to recognize the region was a win-win outcome for all its members. It motivated ASEAN states to deepen collaboration with the aim of securing greater economic benefits for the region, and brought to the fore the advantages of external recognition.

Into the third year of the EEC-ASEAN relations, the heretofore yearly meetings with Commissioner Soames was reinforced and decorated by the visit of EEC President Francois-Xavier Ortoli to Singapore, Malaysia and the Philippines from 28 August to 8 September 1975 (U.S. Mission in EC Brussels 1975). Prior to his departure, Ortoli reiterated that "the EEC was actively formulating a 'new look' in its relations with ASEAN countries" and that "the new policy would focus on expanding ASEAN exports to the EEC" (The Straits Times 1975b: 5). In addition to the traditional discussion on tariff and non-tariff issues, ASEAN requested the EEC to provide marketing assistance for the promotion of ASEAN exports to the EEC through the establishment of an ASEAN trade promotion center in Europe during Ortoli's visit (U.S. State Department 1975i). Following the agreement at the second ministerial 
meeting, the first session of the EEC-ASEAN Joint Study Group (JSG) was also held in Brussels in June 1975. The JSG was regarded as a means for ASEAN to "know early and take advantage of, any change of EEC policy which could be translated into concrete projects for the benefits of ASEAN" (The Straits Times 1975c: 19). To maintain good rapport, it was agree that the group would meet twice a year, once each in Brussels and an ASEAN country, and at least one of the meetings would be held at a "ministerial or very senior level". The series of high level exchanges and the institutionalization of the study group reflected the completeness of EEC's recognition toward the ASEAN grouping. According to a report from the Australian Representative to the European Communities (1974), the EEC had in fact desired to conclude a "co-operation agreement with ASEAN as a whole, but ASEAN had not yet reached a stage, where as an organization it could sign such an agreement". As discussed earlier, ASEAN was still adjusting to its new-found collective approach in joint negotiation, and turned down EEC's offer to conclude the cooperation agreement in 1974. According to EEC Vice President Wilhelm Haferkamp, the uniform response of ASEAN was that "they would prefer to wait until they could sign an agreement on behalf of ASEAN" (The Straits Times 1978a: 12). At this point, the Southeast Asian grouping did not yet have a structure or capacity to sign such an agreement with the EEC.

Nevertheless, the EEC became one of the first entity to accord to ASEAN the recognition of its status as the regional actor in Southeast Asia. By its formal act of meeting with ASEAN as a grouping, the EEC kick-started the socialization process with the Southeast Asian institution. The discussion has shown that ASEAN's demand for EEC's recognition of the region as a whole was adequately met by EEC's 
willingness to offer the recognition. It was a remarkable achievement because the EEC was ASEAN's third largest trading partner, and accounted for 13 percent of ASEAN's trade in 1980 and 14 percent of its investments in 1977 (The Straits Times 1982: 15). Yet, the recognition of ASEAN by the EEC was not smooth sailing all the time as the discussion has shown. ASEAN countries had initial fears about the negative impacts which a joint ASEAN economic approach might have on their own national interests, as evident from their reluctance to create a joint trade secretariat in Jakarta or to sign a co-operation agreement with the EEC. However, the gradual start and modest gains from its first interaction with EEC informed the five member states of the benefits of regional cooperation on economic issues through the acquisition of external recognition for ASEAN. For the first time in their developmental years, ASEAN countries began to see the real benefits of developing the ASEAN institution and securing international recognition for it. The objective was to reduce the tendency of foreign powers to view ASEAN as a collection of individual statehoods by promoting the togetherness and securing the regionhood of ASEAN on the economic front, a recognition which they had first tried unsuccessfully to obtain by pressing for foreign powers' recognition of ZOPFAN.

The importance that ASEAN attached to the issue of recognition for the region at that time could again be seen from the way it handled a press conference preceding an ASEAN-EEC ministerial meeting in 1978. In the course of the media session, ASEAN made a strong appeal "to journalists attending the press conference to give coverage, in European and American newspapers to ASEAN as a regional grouping instead of the usual coverage on bilateral relations between ASEAN's Five and Europe's Nine" (The Straits Times 1978b: 1). Its appeal reflected the grouping's desire to secure 
greater recognition by raising public attention to the existence of ASEAN. There was a need to emphasize to the international community the unity of ASEAN in Southeast Asia. After the meeting, Indonesian Foreign Minister Mochtar Kusumaatmadja conceded that ASEAN's "viability as an economic unit still depends on the extent of the cooperation from outside the region" (The Straits Times 1978c: 1). By this time, ASEAN was ready to propose a "cooperation pact with the EEC", an initiative mooted at the JSG meeting in May 1978 (The Straits Times 1978d: 15). The ASEAN-EEC dialogue relations were eventually institutionalized with the signing of the ASEANEEC Cooperation Agreement on 7 March 1980 in Kuala Lumpur after the ASEAN Secretariat was established in Jakarta in 1976 (ASEAN 1980).

As an overview, the chronology of ASEAN-EEC relations illustrates how ASEAN's pursuit for recognition of its regionhood facilitated regional cooperation among ASEAN-5 countries. Bagging EEC's recognition catalyzed the pace of cooperation within ASEAN as Robles (2004: 20) argues:

In the early years of the dialogue, it was argued that mere recognition by the EC of ASEAN's legal and political identity was in itself a stimulus to regionalization in Southeast Asia... In the 1980s ASEAN affirmed that such dialogues were a sign of 'growing recognition of institutional viability' and an assurance of its significant role in international affairs... EC recognition is alleged to have conferred tremendous prestige on ASEAN and given it self-confidence.

It was also one of the earliest signals to ASEAN countries that a regional approach might help to secure better national interests. The desire for equal and better access into the European markets motivated ASEAN's push for EEC's recognition. Its overtures to the EEC were driven by what Fraser (1998: 19) describes as struggles 
for recognition in "a world of exacerbated material inequality". ASEAN's modus operandi of elevating the public profile of ASEAN through the media also confirms Honneth's (1995: 127) emphasis that "the climate of public attention" affects the outcome of such struggles as highlighted in the proposed recognition model for regions. It reinforces the findings in the previous chapter on the tendency of regions to exploit public attention and sympathy in their struggles for recognition. EEC, on the other hand, was motivated to strengthen its position in the Southeast Asian region at a time when U.S. supremacy was fading. These findings support the framework for the recognition of regions set out in Reference 1 and $\underline{3}$ of $\underline{\text { Chapter } 2}$. What is interesting about EEC's recognition is that it would influence U.S. recognition of ASEAN as the remaining chapter will show.

\subsection{ASEAN-U.S.: The sway in U.S. non-recognition}

Chapter 3 has outlined U.S. non-recognition policy of ASEAN which may be seen from its strong resistance toward dealing with the grouping in the UN and its rejection of the ZOPFAN doctrine. Being a rather new regional entity, ASEAN desired formal and concrete expressions of support from the international community as the legitimate voice of Southeast Asia. However, there were lingering doubts over the effectiveness of the ASEAN grouping. The U.S. Embassy in Kuala Lumpur (1975b), for example, assessed that "an approach to ASEAN as an organization" would be "very difficult to accomplish". The U.S. therefore resisted endowing the grouping with any forms of recognition, preferring instead to deal bilaterally with the Southeast Asian countries. On the political front, the earlier discussion has shown that the U.S. hesitation toward recognizing ASEAN was driven by its desire to maintain deeply 
rooted expectation about behaviors in its dealings with ASEAN countries. A bilateral approach enabled the U.S. to exert greater supremacy in its dealings with the ASEAN countries. Despite being its closest ally in the region, the evidence has shown that the U.S. was reluctant to endow ASEAN with political recognition of any sort. Yet, ASEAN's initial failure to obtain international recognition in the UN, as well as in its pursuit for ZOPFAN, did not weaken the grouping. This section explains how U.S. shifting recognition policy toward the grouping contributed to the continued progress of ASEAN during its formative years.

EEC's forays into the Southeast Asian region and willingness to recognize ASEAN as a collective unit were closely monitored in Washington. With U.S. pending withdrawal from Vietnam, EEC's deepening of relations with ASEAN aggravated the anxiety in the U.S. that ASEAN member states would begin to adopt an increasing "hostile" attitude toward the U.S. in order to accommodate the communist Indochina countries (U.S. Embassy in Jakarta 1975c). The U.S. was concerned that EEC's extension of GSP to ASEAN would undermine U.S. economic competitiveness. EEC's preferential treatment of imports originating from the ASEAN region would divert significant amount of critical raw resources away from the U.S. market. The extent of its concern could be observed from the frequency of reporting Washington instructed its embassies in ASEAN and Brussels to carry out. Following a memo alerting the U.S. State Department to the inaugural ministerial meeting between ASEAN and the EEC in September 1973, the U.S. State Department instructed its embassies in ASEAN countries to closely monitor and report back any new developments in ASEAN-EEC relations. In particular, the U.S. State Department (1973d) directed its embassies to find out the "intentions of ASEAN nations and EC Commission" and if ASEAN 
intended to seek any special Most Favored Nation (MFN) concessions or preferential arrangements "similar to those between EC and African associates". There was an immense suspicion, at least within the U.S. State Department, toward EEC's recognition of ASEAN and its willingness to put trade issues on the negotiating table with the Southeast Asian grouping.

In what was one of the earliest diplomatic reports on the inaugural ASEAN-EEC meeting, U.S. Ambassador to Indonesia Francis Galbraith gathered from his discussion with ASEAN senior trade officials that ASEAN's main goal for the ASEANEEC meeting was that "EC recognize Southeast Asian as an area with a special personality, and ASEAN as a grouping that can in a sense bridge gaps among the Japanese, EC, and Asian blocs" (U.S. Embassy in Jakarta 1973g). As for the European grouping, U.S. Representative to the European Communities Joseph Greenwald reported in October 1974 that "the Community has chalked up some recent successes in its external relations" and made the following observation:

The rush of countries wanting to conclude preferential or MFN agreements and/or economic cooperation agreements with the Community continues. There have been recent moves by Canada, Mexico, the ASEAN nations and others (U.S. Mission in EC Brussels 1974C).

In the note, Greenwald further warned that economic agreements between the "Community and state-trading countries could raise problems for U.S.". Critically, these reports noted the groundswell of regional initiatives coming out from the Southeast Asian and European groupings, and how they might pose a threat to U.S. interests in the region. 
During this period, Galbraith also met with his fellow ambassadors from Malaysia and Singapore in Jakarta in October 1973. After their joint discussion, the three ambassadors proposed to the State Department that the U.S. should highlight to the Southeast Asian region

the confluence of our ultimate objectives with their own and to bring more consistently into play a frank dialogue with them on all our moves affecting the region... To this end, we should seek to recognize and even promote interdependence. This will involve a recognition by U.S. of the importance of these countries as potential markets for U.S. industrial and agricultural products and as suppliers of oil and gas, minerals, timber, rubber and other raw materials in growing world demand... It will involve a recognition by them that we are a reliable source of support for their development... In order to provide material support for development of such nations... we must strive to improve the tone and style of our economic diplomacy. In this connection, greater efforts are needed to persuade them that we accept them as equals in an interdependent relationship (U.S. Embassy in Jakarta 1973h).

This was the first indication within the U.S. diplomatic community that recognizing ASEAN's role through a "dialogue" might be in the interest of the U.S. The emphasis on the urgency of engaging the region as "an equal" reflected the extent of superiority that the Americans were displaying in their dealings with the individual ASEAN countries.

The gist of the recommendation provided by the three diplomats was that the U.S. should begin to consider accepting and engaging countries in Southeast Asia as "an equal". This would require the U.S. government to "recognize" the importance of the 
Southeast Asian markets and to step up on its economic engagements with the region. However, what was less certain in the discussion was how such a "dialogue" might take place and in what form. Should the U.S. make use of its existing bilateral arrangements, limit its dialogue to only a few key countries in the region like Indonesia or create a totally new dialogue group? While the idea of engaging ASEAN was discussed, it continued to find little support within the U.S. diplomatic community. David Newsom who took over from Galbraith as U.S. Ambassador to Indonesia in early-1974 reflected this position when he supported the status quo of "staying out of ASEAN affairs and letting ASEAN and its meetings run their own course unless some U.S. interests [are] jeopardized" (U.S. Embassy in Jakarta 1974e). Agreeing with Newsom, U.S. Ambassador to Singapore Edwin Cronk reiterated that the U.S. "should stay out of ASEAN business to extent possible" (U.S. Embassy in Singapore 1974e). The preference to maintain as little dealings with ASEAN as possible and to avoid according the grouping with any formal recognition was justified by Newsom's assessment that it was not in the interests of the U.S. to recognize ASEAN. Instead, Newsom argued that U.S. should continue to "endorse policy of demonstrated interest without involvement or overt encouragement" because it was doubtful that "U.S. role to shape ASEAN directions would result in organization much different from that which exists, and might give rise to Indonesian resentment" (U.S. Embassy in Jakarta 1974f). Yet, growing fears of a rising Europe would soon overcome the doubts that U.S. diplomats had about recognizing and endorsing ASEAN as a regional grouping. 


\subsection{ASEAN-U.S.: The beginning of recognition}

The deepening of ASEAN's economic linkage with the EEC and its collective economic action against Japan began to sound the alarm within the State Department by mid-1974. The U.S. government was concerned with the "apparent readiness of many LDCs [Least Developed Countries] to maintain group loyalty" which might have "serious and long-range adverse impact on ability of U.S. to function effectively" (U.S. State Department 1974b). Washington's observation that Southeast Asian countries were showing increasing tendency to apply pressures on foreign powers through ASEAN culminated to the issuance of a telegram by U.S. Secretary of State Henry Kissinger in August 1974 calling on the U.S. embassies in the ASEAN-5 countries to report back to Washington on the "latest status of ASEAN Secretariat and on any information available on present mechanism, nature and degree of ASEAN coordination" (U.S. State Department 1974c). With a better appreciation of the internal workings of ASEAN, Washington was trying to weigh the advantages and disadvantages of engaging the Southeast Asian countries as a grouping. Mounting U.S. concerns eventually led to another directive from Kissinger, with the subject header "U.S.-ASEAN Economic Consultations", carrying the following message on 13 August 1974:

Department has given thorough consideration to proposition that we hold economic consultations with ASEAN. After weighing pros and cons, we believe that on balance there is merit in having such consultations... Heretofore, we have avoided too close tie-in with ASEAN... We also assumed that ASEAN would wish to keep a distance from U.S. as a 'great power'. However, by now both Japan and EEC have held consultations with ASEAN and U.S. would only 
follow as third of major industrial entities... ASEAN countries have recently spoken as a group suggesting that they would welcome recognition (U.S. State Department 1974d).

The cable also highlighted how ASEAN had praised EEC for having held consultations with the Southeast Asian group. The content revealed that the U.S. government was beginning to feel that it was losing out in the competition with other powers like Japan and EEC which had made significant inroads in cultivating ASEAN as a regional grouping. At the same time, the U.S. was acutely aware that ASEAN desired some forms of "recognition" in the international arena. The note also provided the result of a benefit-cost analysis on the usefulness of an ASEAN-U.S. consultation by the U.S. State Department (1974d). It highlighted nine areas in favor of having an economic consultation with ASEAN because it would

i. Shift the focus from aid donor-recipient relationship to a broader economic framework;

ii. Lower "bureaucratic burden" by dealing with ASEAN as a group while carrying out "side talks with ASEAN countries on bilateral issues";

iii. Provide an opportunity to dialogue with ASEAN on more policy oriented issues rather than "bilateral complaints or grievances";

iv. Develop into a "useful instrument to improve U.S. standing with the nonaligned nations";

v. Serve as a useful platform where the U.S. could consult on special topics such as GSP;

vi. Provide the U.S. with addition avenues to "exert some influence on Indonesia";

vii. Boost regional cooperation among ASEAN countries; 
viii. Extend regional cooperation beyond the five ASEAN countries; \&

ix. Reiterate U.S. policy of seeking "non-discriminatory worldwide open economic system".

The assessment also listed five likely costs to the U.S. government for launching an economic consultation with ASEAN:

i. The consultation would present ASEAN an opportunity to pressure the U.S. for economic concessions;

ii. U.S. involvement might adversely "affect the ASEAN initiative" and "hurt ASEAN sensitivities";

iii. Promoting regional economic cohesion in ASEAN might work against "some U.S. interests";

iv. Talks might lack "specificity" because ASEAN was a "loose-knit" grouping; \&

v. No certainty that the discussion would reach key policymakers in ASEAN.

Notwithstanding the above concerns, the U.S. State Department (1974d) concluded that the advantages of having consultation with ASEAN "outweigh disadvantages" and pointed out that "some of the dangers and risks can be mitigated". It was evident from the negative list that U.S. policy-makers realized that its recognition of ASEAN would in effect strengthen regional cooperation in Southeast Asia and work against their national interests.

Based on the above cost-benefit analysis, the State Department made a preliminary assessment that there was "merit" in having a consultation with ASEAN and proposed for its mission in Jakarta to first explore the possibility of an ASEAN-U.S. economic consultation with the Indonesian government. The proposed communication method to convey its proposal for an ASEAN-U.S. consultation 
through Indonesia reiterated the importance that foreign powers placed on Indonesia's role as the leader of the group. In response to the suggestion, U.S. Ambassador to Thailand William Kintner assessed that while Thailand "would welcome this initiative by the United States Government as a significant indication of ASEAN's growing prestige and recognition", breaking the news through Indonesia might work against the U.S. Kintner further explained that while "ASEAN members are not equal in either power or size, the appearance of equality is essential to the success of the ASEAN member countries' regional concept" (U.S. Embassy in Bangkok 1974e). The rest of the U.S. ambassadors in the ASEAN countries also weighed in their views on the suggestion with U.S. Ambassador to Philippines William Sullivan pressing for more urgency in recognizing and engaging ASEAN:

As a matter of economic self-interest, if we wish to deal effectively in future with the yet mild tendency of ASEAN of economic union, we should work out the appropriate machinery soon rather than wait for autarchy to set in due to inattention. The road back from there, as we have learned the hard way with the EEC, is long, tough, and too frequently irritating (U.S. Embassy in Manila, 1974c).

Sullivan's caution reflected U.S. concern over the prospect of ASEAN developing into a close economic unit like the EEC. (U.S. recognition of the EEC, vis-à-vis ASEAN, will be analyzed in the next chapter). Agreeing with Sullivan on the importance of protecting U.S. interest, U.S. Ambassador to Singapore Cronk acknowledged that periodic ASEAN-U.S. consultations would facilitate ASEAN's development into a "more cohesive and effective organization" and necessitate "closer coordination and in-depth consultations within ASEAN", which in turn would accelerate "ASEAN's slow evolution toward a more active and meaningful organization which would be in our 
interest" (U.S. Embassy in Singapore 1974f). The strengthening of ASEAN by formalizing the relations through a consultation was perceived as necessary to protect the economic interests of the U.S within the diplomatic circle.

However, U.S. missions in Malaysia and Indonesia also pointed out some possible obstacles in the proposed consultation. U.S. Ambassador to Malaysia Francis Underhill cautioned that while ASEAN countries had common goals in their consultations with the EEC and Japan, consensus in discussion with the U.S. might be difficult to reach because ASEAN had not "developed positions on many basic world economic problems" (U.S. Embassy in Kuala Lumpur 1974e). Underhill further warned that the U.S. risked conveying the "wrong signal" that it desired to "buy into ASEAN". U.S. Ambassador to Indonesia Newsom concurred with the view that the ASEAN-EEC and ASEAN-Japan consultations were possible because they were based on common interests in the region where "ASEAN has either initiated pressure or seen direct tangible benefit from consultations" (U.S. Embassy in Jakarta 1974g). As previously discussed, such initiatives included lobbying EEC for trade concessions, pressuring Japan to reduce the production of synthetic rubber and securing development aids from Australia. Underhill and Newsom's anecdotal accounts reflected the last remnants of resistance within the U.S. diplomatic community toward recognizing ASEAN as a regional entity with which the U.S. could have an effective dialogue with.

In contrast, the U.S. business community saw immerse potential in recognizing and cultivating the ASEAN grouping as pointed out by Sours (1981: 184): 
ASEAN is the fourth largest U.S. trading partner, behind Canada, the EEC and Japan; ASEAN represents 250 million potential customers, more than all of South America; in 1979 U.S. ASEAN trade ran at 11 billion dollars more than that of Mexico; and the raw materials ... are essential for the American economy.

With the growing importance of the Southeast Asian market and the tendency of their governments to make economic arrangements through ASEAN, U.S. businesses also began to call on the U.S. government to establish some formal linkages with the ASEAN grouping. A case in point is the reactions of U.S. business community toward ASEAN's decision in early-1976 to establish five ASEAN industrial projects which would qualify for "preferential trading arrangements" within the region (ASEAN 1976a). In March 1976, the Second ASEAN Economic Ministers Meeting agreed to establish an Experts Group to look into the feasibility of establishing five ASEAN industrial plants, each to be built and operated by one ASEAN country (ASEAN 1976b). According to Singaporean officials, the basic principle in the five ASEAN projects was to take "advantage of the larger ASEAN market, industries which could not be viably set up in any ASEAN country, could be viable and efficient if established on a regional basis" (U.S. Embassy in Singapore 1976f). The officials revealed that the project was exclusive; only one of each type of production (diesel engines for Singapore) would be designated as the ASEAN project in the region. Each production plant would be "accorded ASEAN trade preference by all member counties", which would in turn provide support in terms of "tariff protection, antidumping provisions and preferential government purchases". Foreign production plants, outside the purview of ASEAN, would not have access to such preferential treatment. In addition, there would be a common external ASEAN tariff for the five 
products, which would deny the market to outside producers (U.S. Embassy in Singapore 1976f). In view of such developments, the U.S. Embassy in Singapore (1976f) warned that U.S. businesses which "fail to get in under the ASEAN umbrella run the risk of being shut out of a large and growing market". This set the alarm bells ringing among the U.S. business community in Southeast Asia.

Following ASEAN's announcement of the five projects, the Asian Pacific Council of American Chambers (APCAC) indicated its desire to the U.S. government for the Chamber to establish a "relationship with the Association" because of "their interests in staying close to the rich emerging markets of SEA [Southeast Asia]" (U.S. Consul in Hong Kong 1976). This suggestion drew a largely negative response from U.S. Ambassador to Jakarta Newsom who argued that it was "premature" for APCAC and its members to begin a relationship with ASEAN and suggested for the U.S. companies to deal directly with the host governments instead (U.S. Embassy in Jakarta 1976e). The State Department cautioned that ASEAN states would lobby the U.S. companies for funding if such formal recognition was accorded to the grouping, citing an earlier request from Indonesia for U.S. financial support for the ASEAN projects amounting to US $\$ 1$ billion (U.S. Embassy in Jakarta 1976f).

By August 1976, however, the U.S. government observed that many U.S. firms had expressed interest in equity participation, construction and equipment supply of the Singapore-led project in diesel engines, which came under the ambit of one of the five ASEAN projects. The U.S. State Department (1976d) disclosed that the government would like to "assist U.S. firms who may be interested in bidding on project" and asked for more information from the five embassies on the stages of 
development of the five projects. The Department instructed its embassies "to assist responsible U.S. companies which seem interested in investing in or offering services for ASEAN-wide projects with host government authorities, just as embassies are assisting firms seeking bilateral contacts" (U.S. State Department 1976e). Evidently, the emphasis was again on the use of bilateral diplomacy to secure business deals initiated by ASEAN.

However, even with the above assistance, the U.S. companies reported that they were unable to engage ASEAN as a grouping because of ASEAN's policy of not dealing with private companies. Singapore Director-General for ASEAN Tan Boon Seng explained in a letter to U.S. Ambassador to Singapore John Holdridge that ASEAN, as a government body of five countries, does not enter into any arrangements with private enterprises. ASEAN, in the past, has dealt either with government or international agencies or organizations only (U.S. Embassy in Singapore 1976a)

On receiving the letter, Holdridge assessed that the outlook for U.S. firms to gain a foothold in the ASEAN projects was "dim". This incident gave the U.S. government added impetus to recognize ASEAN by brokering an economic relationship with the Southeast Asian grouping. Washington realized that in the absence of a direct governmental link with ASEAN, U.S. businesses would lose out on the lucrative projects spearheaded by the Southeast Asian grouping as reflected in U.S. Deputy Chief of Mission to Malaysia Robert Dillon's frank revelation that the U.S. was "interested in increased access to ASEAN markets and commodities" (U.S. Embassy in Kuala Lumpur 1975f). 
By this time, the U.S. State Department had launched and completed an internal consultation with its economic agencies including the agriculture, commerce, trade and treasury departments on the usefulness of having a consultation with ASEAN. After the U.S. Congress passed the Trade Act of 1974 on 20 December, the U.S. State Department (1974e) declared that the time was "now appropriate to explore ASEAN receptivity to suggested [ASEAN-U.S.] talks". Unlike the case with Australia, Japan and the EEC, it should be highlighted here that the initiative for the proposed consultation was not solicited by ASEAN. In December 1974, U.S. Under-Secretary of State for Political Affairs Joseph Sisco instructed the U.S. embassies in ASEAN-5 countries to undertake a "low-key" approach to ASEAN countries by presenting the proposed consultation in such a way that "if ASEAN is interested in consultative meeting in near future, U.S. would be responsive to their invitation" (U.S. State Department 1974e). Critically, the Department heeded the diplomats' earlier advice not to convey the proposal through Indonesia. According to the instructions from Washington, the U.S. government was prepared to send its under-secretary of state for economic affairs with delegation members from the relevant economic departments and to meet in an ASEAN capital, but the condition was that the invitation for the consultation must come from ASEAN. This was a reflection of U.S. desire to maintain hegemony over ASEAN while avoiding any traces of its move being read by other foreign powers as an extension of U.S. influence in Southeast Asia. Sisco explained in December 1974:

We do not wish to give impression U.S. is pressing for discussion with ASEAN. Rather, we are prepared to respond to ASEAN initiative. Additionally, it should be made clear that what we envisage is consultations, not negotiations (U.S. State Department 1974e). 
For the U.S., it was critical that the initiative gave the appearance to the international community that the ASEAN-U.S. consultation took place only at the request of the Southeast Asian grouping in the same manner that ASEAN had initiated interactions with foreign powers like Australia, the EEC and Japan.

The proposed consultation marked the beginning of a shift in U.S. recognition policy on ASEAN. Since its formation in 1967, the U.S. had refused to recognize the regionhood of ASEAN, as reflected in its position on ZOFPAN and refusal to recognize ASEAN for UN lobbying. If realized, the dialogue would represent U.S. first concrete act of recognition toward ASEAN. The U.S. State Department (1975j) affirmed that its objective for the ASEAN-U.S. economic consultations was "to show recognition of and to further enhance ASEAN cohesion".

The U.S. envisaged for the consultation to cover "economic questions of mutual interest", and was pushing for the first consultation to take place as early as in midFebruary 1975 (U.S. State Department 1974e). Acknowledging the importance of treating the five ASEAN countries as equals, Washington called in the five ASEAN ambassadors in Washington to convey the message and instructed its five ASEAN embassies to relay the proposal to their host government at the same time. Interestingly, Washington also called in Teruo Kosugi, Minister of the Japanese Embassy in the U.S., in January 1975 to given Japan a heads-up of the proposed ASEAN-U.S. consultation. During the meeting with Kosugi, the U.S. explained that in light of ASEAN's development and success of Japan-ASEAN and EC-ASEAN consultations, U.S. believed conditions had ripened for U.S.-ASEAN consultations. In addition, given growing radicalization of UN and limited 
opportunities for U.S. consultations with developing countries, there was merit in expanding forums for consultation with moderate developing countries such as those in ASEAN (U.S. State Department 1975k).

The proposed agenda by the U.S. would cover a range of economic issues including the economic trends in the U.S. and ASEAN, economic developments and private investments in ASEAN. The comprehensiveness of the U.S. proposal, which included the envisaged agenda, representation, and meeting format, and the preference to hold the dialogue with ASEAN as early as in February 1975 revealed the extent of U.S. keenness to engage the regional group as quickly as possible. Moreover, the premeditated positioning of the dialogue as an ASEAN-initiative, the pre-empted internal consultation with its economic agencies and its decision to inform the Japanese together indicated U.S. expectation and confidence that ASEAN would not say no to the proposal.

Not surprisingly, U.S. about-turn decision to engage ASEAN on the economic front was viewed by ASEAN as a gesture which would raise the status and prestige of the grouping. When informed of U.S. willingness to have economic consultations with ASEAN in January 1975, Indonesian Foreign Minister Adam Malik and his official responded that Indonesia "welcomed U.S. 'recognition' of ASEAN" (U.S. Embassy in Manila 1975e). As expected, the other four ASEAN countries also replied positively to U.S. overtures. Philippine Foreign Minister Carlos Romulo indicated that "he would be pleased [to] explore proposition with fellow ASEAN foreign ministers" and assumed that their "response would be positive" (U.S. Embassy in Manila 1975f). Singapore Deputy Secretary for Foreign Affairs Tan Boon Seng affirmed that he saw 
no reason why ASEAN countries would not agree to economic consultations with the U.S. (U.S. Embassy in Singapore 1975b).

U.S. proposal to have a consultative meeting with ASEAN was discussed at a meeting in April 1975 between the ASEAN national secretaries-general. To the surprise of the U.S., however, while ASEAN responded positively to meeting formally with the U.S. as a group, Indonesian Secretary-General of ASEAN Umarjadi Njotowijono revealed that ASEAN was "not sympathetic" with the condition for ASEAN to issue an invitation to Washington for the proposed consultation (U.S. Embassy in Jakarta 1975d). The meeting decided that if the U.S. "is interested in a consultative meeting, the channel of communications should be through the Chairman of the ASEAN Standing Committee in Kuala Lumpur" (U.S. Embassy in Bangkok 1975a). The message was that all powers, including the U.S., should adhere to the proper protocols and communication channels within ASEAN. Since ASEAN did not have a secretariat office, the correct procedure would be to put in the request through the ASEAN Standing Committee which at that time was chaired by Malaysia. For ASEAN, it was a matter of prestige, equal status and of respecting the protocol of the grouping. U.S. concurrent approaches to the five ASEAN states were considered inappropriate and not respecting the ASEAN protocol. The Singapore foreign ministry would later explain that the "ASEAN consultations with the EC, Japan, Australia, and others all resulted from formal initiatives by [the] other party" (U.S. Embassy in Singapore 1975c). The underlying implication was that if the U.S. government wanted to have a consultation with ASEAN, Washington would have to be the one to initiate and submit a formal invitation to the grouping in the same way that the other foreign powers had done. Despite its initial refusal to recognize the 
regionhood of ASEAN, the U.S. was compelled to woo ASEAN over by offering some degree of recognition on the economic front in the face of competition from the EEC, and this included giving in to such a request. In view of ASEAN's request, the U.S. State Department in May 1975 tasked its mission in Malaysia to broach the matter with the Chairman of the ASEAN Standing Committee in Kuala Lumpur.

Yet, this was not the biggest hurdle to the proposed ASEAN-U.S. consultation. The largest ASEAN member, Indonesia would soon realize that it would be excluded from the benefits of any trade preferences offered by the U.S. to the ASEAN grouping. This would have an impact on Indonesia's willingness to deepen economic cooperation in ASEAN as the next section will discuss.

\subsection{ASEAN-U.S.: The consequence of incomplete recognition}

The preceding section has detailed how EEC's recognition of ASEAN began to sway U.S. non-recognition policy toward ASEAN, culminating to a U.S. initiative for economic consultation with the Southeast Asian grouping. The earlier chapter has also shown how external recognition enabled member states like Malaysia to exploit the regional grouping as a means to overcome its domestic problems, which in turn motivated them to intensify their commitment toward regional cooperation. The remaining chapter explains how such external recognition might also have a negative impact on members' attitudes and behaviors toward regional cooperation in light of the need to preserve their national interests. 
As the U.S. was sounding ASEAN out on the proposed economic consultation, it became clear that the new U.S. Trade Act of 1974 would exclude Indonesia from being able to enjoy any GSP benefits because of Indonesia's membership in the Organization of the Petroleum Exporting Countries (OPEC). The new trade bills gave the U.S. Administration powers to offer GSP which provided imports from beneficiary countries duty-free entry into the U.S. markets. U.S. Congress' decision to exclude OPEC countries from the GSP benefits was passed in retaliation to the Arab nations' embargo on oil shipments to the U.S. and its allies in the 1970s. The Arab countries declared an oil embargo on the U.S. because of the latter's support for Israel during the Arab-Israeli War in 1973. This meant that the U.S. Administration could not offer GSP to Indonesia although it was a part of ASEAN due to the latter's OPEC membership.

The U.S. Embassy in Jakarta (1975e) was the first to raise the alarm in January 1975 when it pointed out that "Indonesian exclusion from GSP adds potentially unfavorable dimension" to the proposed consultations and the U.S. faced the "risk of setting up divisive forces within ASEAN". In a note to the State Department, U.S. Ambassador to Indonesia Newsom posed the following rhetorical question: "How can we have meaningful and unembarrassing discussions with ASEAN countries when the largest member is excluded from one of key benefits of trade act?" (U.S. Embassy in Jakarta 1975f) The embassy further requested Washington to postpone the approach to the ASEAN governments until Indonesia's exclusion from the GSP had been removed. However, as the proposal for the consultation was already made to some ASEAN countries, the U.S. government had no choice but to see through its initial plan to 
inform all the ASEAN governments. This was the start of a long and painful process in ASEAN's struggle for U.S. recognition.

It was not long before the Indonesian government registered its dissatisfaction with its exclusion from the GSP at the highest level. Indonesian Trade Minister Radius Prawiro described to U.S. Ambassador Newsom "Indonesian sense of puzzlement and concern over U.S. action on GSP" (U.S. Embassy in Jakarta 1975g). In the meeting, Radius also pointed out that "Indonesia as ASEAN member had already participated in joint ASEAN discussions with both EEC and Japan" and obtained favorable GSP benefits. Indonesian trade ministry further explained that the country was only "a minor OPEC partner, contributing 2 per cent of world's petroleum production, and that Indonesia's development needs set her apart from other OPEC members" (U.S. Embassy in Jakarta 1974h). This view was reiterated by Indonesian Minister of Communication Emil Salim who told Newsom in February 1975 that "restrictions in trade act were serious matter for Indonesia since they separated Indonesia from rest of ASEAN countries and threatened to undermine their unity" (U.S. Embassy in Jakarta 1975h). The extent of Indonesia's displeasure with its exclusion from the GSP was highlighted when Indonesian Foreign Minister Malik made it plain personally to U.S. State Secretary Kissinger during an official visit to the U.S. on 29 June 1976 that "the Indonesians had problems with their exclusions from GSP benefits" (U.S. State Department 1976f). As a result, there was no positive response from Indonesia toward U.S. "expression of readiness to enter into economic talks with the ASEAN countries" during Malik's visit although more than 1.5 years had lapsed since the proposal was broached in January 1974 (U.S. State Department 1976g). Instead, the Indonesian delegation broached the sensitive issue 
of U.S. financial assistance to ASEAN and asked if Washington could "help support financially some joint ASEAN exports to the U.S." (U.S. State Department 1976g). This was a thorny issue for the U.S. because right from its formation in 1967, Washington had made it clear that the U.S. government "saw no prospect of ASEAN seeking economic support from the United States" (Australian Embassy in Washington 1967). U.S. Ambassador to the Philippines Sullivan maintained that the U.S. should "avoid any aid commitment or any aid-type of project" to ASEAN (U.S. Embassy in Manila 1976d). Defending U.S. position, U.S. Ambassador to Malaysia Underhill explained that "ASEAN has been in business for ten years, and if it cannot continue without this kind of United States' help, it does not deserve to survive" (U.S. Embassy in Kuala Lumpur 1976b). Indonesia's unhappiness with its exclusion from the GSP, coupled with U.S. refusal to offer any financial assistance, would result in a two-year delay in ASEAN's reply to the U.S.

Internally, the U.S. government identified "Indonesian displeasure with OPEC exclusion under GSP provisions of the trade act" and ASEAN's reservation about "closeness to U.S. because of potential impact on ASEAN's non-aligned image" as possible reasons for the long wait. The U.S. government also did not rule out the possibility that ASEAN was turning down U.S. "politely by insisting on formal approach" as discussed in the previous section. Nonetheless, the U.S remained keen to "preserve relations with them [ASEAN countries] in channels they find useful and unembarrassing" (U.S. State Department 1975I). However, the archival data reveals that the chief cause of ASEAN's delay was Indonesian displeasure with its exclusion from the GSP. Malaysian Secretary-General for ASEAN Mon Jamaluddin disclosed in a private meeting with U.S. officials in May 1975: 
ASEAN members earlier had felt that in principle, economic consultations with

U.S. would have been useful but that in view [of] exclusion of Indonesia from GSP benefits it had considered preferable to delay (U.S. Embassy in Kuala Lumpur 1975g).

In a telegram to the U.S. ambassadors in ASEAN-5 countries, U.S. Under-Secretary of State for Political Affairs Joseph Sisco reiterated U.S. objective of enhancing ASEAN cohesion and cautioned that the proposal "should not become an element of division between ASEAN members" (U.S. State Department 1975j). However, U.S. decision to recognize ASEAN inevitably divided the ASEAN grouping as pointed out by the Indonesians.

To be sure, of the five-member states, Malaysia, Singapore and Thailand were pushing strongly for ASEAN's consultation with the U.S. According to Thai Deputy Secretary General to ASEAN Chet, the ASEAN Standing Group, which met in Manila on 11-12 July 1975, concurred that economic consultations with the U.S. would be useful and that ASEAN would be keen to learn more about "U.S. economic policies, investment policy and generalized special preference aspects of U.S. trade act" (U.S. Embassy in Bangkok 1975b). Chet further disclosed that the three countries pushing strongly for the consultation were Singapore, Malaysia and Thailand. There was thus strong behind-the-scene lobbying for Indonesia to make a concession for the sake of securing U.S. recognition of ASEAN.

At the same time, there were signs that the U.S. government was getting frustrated in its overtures to ASEAN. In an indication that its patience was running out, the U.S. 
State Department issued a memo instructing its embassies in ASEAN to convey the following points to the host government:

For about a year ago, USG [U.S. Government] thought that economic consultations with ASEAN would be mutually beneficial as a means to intensify economic relations, discuss economic policies and policy issues with a view of gaining better understanding and to extend, adapt and modify policies for mutual benefit. We have previously observed that both EEC and Japan have held consultations with ASEAN and we thought that ASEAN might also be interested in having dialogue with U.S. (U.S. State Department 1975m).

The U.S. government explained that "in order not to offend ASEAN's sensitivity", they had approach ASEAN in "a low key" manner. The memo again regretted the insertion of the OPEC clause in the GSP provision of the U.S. trade act, but defended that the U.S. understood that ASEAN itself "is an evolving organization which has a slow and somewhat cumbersome coordinating mechanism" (U.S. State Department 1975m). The memo advised that the U.S. "are quite willing to be patient" and "do not wish to put pressure on ASEAN or any of its members if they do not feel that time has yet come to have consultations with the U.S.".

It was not until late-1976 that a consensus was reached in ASEAN to proceed with the ASEAN-U.S. economic consultation. Singaporean Deputy Secretary for foreign affairs Tan Boon Seng affirmed that the "Indonesians would no longer have any problem with such consultations" (U.S. Embassy in Singapore 1975d). Indonesia was evidently placated by the U.S. government's public expression of "regret over OPEC provision of trade act specifically mentioning Indonesia" and the introduction of an amendment to grant the U.S. president broader latitude over the treatment of GSP 
for OPEC countries (U.S. State Department 1975I). These arrangements enabled the Indonesian government to allay domestic pressures against U.S. unfavorable treatment of its imports over those from the other ASEAN countries.

The about-turn in Indonesia's decision was confirmed in a meeting with Malaysian Secretary General to ASEAN Ali Abdullah on 13 August 1975 who reiterated that "Indonesia now favors ASEAN contact with U.S. and therefore did not raise objection to proposal" (U.S. Embassy in Kuala Lumpur 1975f). Ali explained that "the principal ASEAN interest is to improve trade between ASEAN and U.S." (U.S. Embassy in Kuala Lumpur 1975f). However, the U.S. would still have to respect the protocol of ASEAN. It was again advised to reiterate the request to the Philippines, which had taken over from Malaysia as the chair of ASEAN Standing Committee by that time. The confirmation of Indonesian support finally came on 17 August 1975 at a meeting between Indonesian Trade Minister Radius and U.S. Ambassador to Indonesia Newsom. The Indonesian side assured the U.S. that Indonesia, like their ASEAN partners, "see values in consultations between ASEAN and U.S." (U.S. Embassy in Jakarta 1975i).

On receiving the confirmation from Indonesia, the U.S. registered its interest to have the consultation with ASEAN to the Philippines as advised. This was done through an informal paper which reiterated U.S. expectation that the consultation would take place in an ASEAN capital and that the U.S. delegation would be headed by its undersecretary of state for economic affairs (U.S. Embassy in Manila 1975g). The key points of the informal paper were presented at the ASEAN senior official meeting in Singapore on 15-17 September 1975. However, the ASEAN Standing Committee 
decided not to reply to the informal paper prepared by the U.S. government because it did not "constitute formal signed request which standing committee had anticipated" (U.S. Embassy in Jakarta 1975j). According to Filipino Secretary General of ASEAN Farolan, the "ASEAN standing committee would judge U.S. proposal solely from standpoint of benefits which would come to ASEAN countries from such consultations" and that "ASEAN would study U.S. proposal and make counterproposal" (U.S. Embassy in Jakarta 1975j). ASEAN saw "little use in pursuing" a consultation with the U.S. if the latter was not prepared to be "forthcoming as other countries such as EEC, Australia, New Zealand and Canada". It was a diplomatic way of conveying to the U.S. that ASEAN expected to see some tangible benefits for the region in U.S. proposal. Farolan explained that "all other ASEAN consultations had resulted from formal initiative by other party and that aid was a virtual condition of such discussion". It was evident that ASEAN was unhappy with the U.S. for not addressing the issue of financial assistance in its informal proposal.

There were deep-seated feelings in ASEAN that the U.S. had not given due recognition and fair treatment to the Association. Singapore's ASEAN representative in Geneva Tan Ken Jin shared with William Culbert, the head of U.S. trade delegation in Geneva, his observation in 1976 that "the U.S. has not recognized growing cohesiveness of ASEAN on trade matters, at least not to extent EEC has" (U.S. Delegation to the MTN in Geneva 1976). The Singapore official reiterated that "a formal request for consultations would be necessary" and that the "informal paper ... enjoyed no status". Thai Director-General of Economic Affairs Asa Sarasin revealed that while ASEAN had taken a "step-by-step approach to joint consultations with non-members" like Australia, New Zealand, Canada and EEC, these discussions 
"had been proposed to ASEAN Secretariat by [the] non-ASEAN state" (U.S. Embassy in Bangkok 1975c). Again, ASEAN's message to the U.S. was two-fold. First, if the U.S. government wanted to have a consultation with ASEAN, Washington would have to be the one to initiate and submit a formal proposal to the Association in the same way that the EEC and Australia had approached them, instead of expecting ASEAN to issue an invitation. In other words, the grouping would not treat the U.S. any different because it was a much bigger power. Second, any proposal for consultation with ASEAN would have to offer concrete benefits to the members.

In what might be viewed as a final ultimatum to ASEAN and a show of desperation, the State Department relented to ASEAN's demands albeit reluctantly. A memo from Washington to its embassies in ASEAN disclosed that

we do not wish to be put in a position where we appear to be begging [for consultation]... If for some reasons ASEAN feel that the invitation should come from us, we would have no problem to issue such invitation if it were clear beforehand that ASEAN would respond affirmatively... We have previously indicated that in our consultations with ASEAN we would like to focus on issues other than aid. If, however, ASEAN would wish to talk about aid we would be prepared to review our general East Asian foreign assistance programs as an element of our consultations. We would not wish, however, to have a U.S. aid commitment to ASEAN made a precondition to consultative talks (U.S. State Department 1975m).

This was a significant concession given U.S. earlier insistence that aid matters should not be addressed during the proposed ASEAN-U.S. consultation. 
The official reply to the U.S. finally came on 10 December 1976 . Filipino Secretary General to ASEAN Manalo informed the U.S. Embassy in Manila that the ASEAN Standing Committee decided on 17 November 1976 that "the Philippines should continue further the informal discussions with the United States on a US/ASEAN dialogue" (U.S. Embassy in Manila 1976d). The ASEAN Standing Committee meeting on 20 September 1976 approved a proposal in which every member country would be designated as "the principal contact point with countries or organizations outside of ASEAN" (U.S. Embassy in Singapore 1976g). The meeting designated the Philippines to be responsible for all correspondences with the U.S. with respect to any future dialogue between the two sides. Manalo added that the U.S. should "avoid separate approaches in other capitals because of the confusion this would create".

On learning about Philippines being the contact point, several U.S. diplomats raised concerns over how bilateral relations with the Philippines might impede on the progress of the proposed ASEAN-U.S. dialogue. While recognizing that the Philippines was "uniquely qualified" to be the contact point given the special U.S.Philippine relations, U.S. diplomats in Thailand and the Philippines voiced concerns that "the U.S. and the Philippines are engaged in a complex negotiating process, involving military relations, trade and other matters, which promises to be long and difficult" (U.S. Embassy in Bangkok 1976d). However, the U.S. conceded that it was in no position to change the decision without conveying the "impression that the U.S. is telling ASEAN how to organize itself" (U.S. Embassy in Manila 1976e). Manalo, however, assured the U.S. that the consultations should deal with "subjects of ASEAN on regional interest and not become an umbrella for bilateral matters" and that the top priority for ASEAN pertained to trade issues (U.S. Embassy in Manila 
1976d). Newly appointed ASEAN Secretary-General Dharsono revealed to the U.S. on 4 October 1976 that ASEAN's external relationships with individual countries and regional organizations would be initially opened by a specific ASEAN country. Dharsono added:

In the case of Japan, Indonesia was responsible. In the case of New Zealand, it was Singapore. For Australia, it was Malaysia. Bangkok handles relations with ESCAP [UN Development Programme]. Finally Philippines were responsible for ASEAN/Canadian talks to be initiated shortly and will also eventually be responsible for ASEAN/U.S. contacts. The EEC is not handled by an individual country since it is already covered by SCCAN" (U.S. Embassy in Jakarta 1976g).

Appointing ASEAN countries with the closest bilateral ties to the foreign powers as the main contact point would serve as a check to ensure that bilateral needs were not compromised at the expense of regional initiatives. This line of thinking could also be seen in ASEAN's struggles for Japan and Australia's recognition as discussed in the preceding chapter.

The case study on ASEAN's dealings with the U.S. has illustrated how foreign powers' recognition of ASEAN's regionhood could influence the cooperation level and change behaviors in the Association. U.S. Ambassador to Philippines Sullivan highlighted the importance of the ASEAN-U.S. economic consultation serving "as a means of recognizing and promoting the ASEAN identity, to consider a cooperative venture involving regional development" (U.S. Embassy in Manila 1976d). The ASEAN grouping, on the other hand, was driven to seek external recognition from the world's superpower in both tangible (financial assistance) and intangible forms 
(status and prestige). For example, Filipino Foreign Secretary Romulo had expressed the hope that the U.S. would match Japan's pledge of US\$1 billion in financial support to ASEAN's industrial projects (The Straits Times 1977a: 1). To moderate ASEAN's expectation of any financial assistance at the inaugural ASEAN-U.S. economic consultation, U.S. Under-Secretary of State for Economic Affairs Richard Cooper reiterated that the discussions are "consultative meetings and not for negotiations, or offers or demands or anything of that type" (The Straits Times 1977b: 32). While the outcome was a far fetch from ASEAN's expectation, the ASEAN-U.S. economic consultation in September 1977, nonetheless, represented U.S. first formal act of recognition toward the Southeast Asian grouping.

\subsection{ASEAN-EEC and ASEAN-U.S.: In retrospect}

The analysis heretofore has found that the U.S. deliberately avoided any actions which would strengthen ASEAN as a Southeast Asian bloc. In retrospect, ASEAN's long delay in replying to the U.S. on the proposed consultation vindicated such thinking among U.S. diplomats and policy-makers. For example, while preparing for a visit by U.S. Special Representative for Trade, Ambassador Frederick Dent to Indonesia in 1976, the U.S. embassies were consulted for their view on the possibility of a meeting between Dent and the representatives from ASEAN as a group in Jakarta. The aim of Dent's visit was to consult and to win over the support of officials in host governments responsible for multilateral trade negotiations (U.S. State Department 1976h). However, the U.S. Embassy in Manila (1976f) reiterated that U.S. approach to multilateral trade negotiations was to "negotiate with each as an individual entity and to the extent possible to avoid dealing with blocs". In other words, 
meetings between senior U.S. officials and ASEAN representatives as a group was not in the U.S. interest since they tend to "legitimize bloc bargaining" (U.S. Embassy in Manila 1976f). In light of the strong reactions from U.S. diplomats in Southeast Asia, Dent dropped the idea of meeting with the group of ASEAN ambassadors in Jakarta. By avoiding such acts of recognition, the U.S. believed that it would not strengthen ASEAN as an economic bloc. The U.S. State Department further instructed that the delegation should "not take initiative with any ASEAN delegation to urge such invitation" because the U.S. had on several occasions reiterated its interests to have economic consultations with ASEAN. The US government was convinced that the "ball is definitely in ASEAN's court" (U.S. State Department 1976i). The underlying message was to discourage unnecessary interactions with ASEAN because such acts of recognition would legitimize the grouping as an economic bloc. For this reason, the U.S. was also reluctant to divert any resources toward developing ASEAN as evident from U.S. Ambassador to Jakarta Newsom's recommendation for President Ford, in preparation for his meeting with Indonesian President Soeharto in 1975, to avoid using the term "support for ASEAN" during the meeting as it could be construed to mean U.S. provision of material assistance to ASEAN (U.S. Embassy in Jakarta 1975k).

Yet, the U.S. was compelled to recognize the grouping in light of EEC's overtures to the region and pressures from its business groups as the archival data in this chapter have shown. U.S. recognition of ASEAN would endow the grouping with status and prestige. The firmness of ASEAN's response toward the proposed consultation with the U.S. highlighted the importance that member states placed on the issue of equality in the grouping's dealings with the external powers. Its repeated demands 
for the U.S. to respect the ASEAN process and to initiate the invitation through the proper ASEAN channel testified to the grouping's desire for a fair and equal treatment from all the foreign powers. The U.S. government had to be socialized into dealing with ASEAN in a fair and equitable manner. Assessing U.S. interest in Southeast Asia, an internal Australian Department of External Affairs (1969b) report gave the following assessment: "In our experience, the United States can take rather too simple a view of international relations in the South East Asian region and underestimate the difficulties of developing regional co-operation on any significant scale". Frustrated with ASEAN's delay in replying to the U.S. on the proposed consultation, for example, U.S. Ambassador to Malaysia Francis Underhill in August 1976 wrote:

ASEAN understands clearly our interest and willingness to consult with it on economic matters. By waiting for their initiate and expression of interest, the relationship would be founded on a sounder basis. They will come to us when they are ready and we should wait (U.S. Embassy in Kuala Lumpur 1976c).

In the same rein, U.S. Ambassador to Singapore John Holdridge pointed out that U.S. overtures to ASEAN had fallen on "deaf ears" and observed that ASEAN was "cognizant of our willingness to deal with them as a group but are not yet prepared to deal with us in this manner" (U.S. Embassy in Singapore 1976h). Such anecdotal accounts reflected the superiority and aloofness of the U.S. in its dealings with the Southeast Asian grouping.

When the ASEAN-U.S. consultation finally took place, U.S. Ambassador to Indonesia Newsom noted: "It has taken nearly two years, since first official U.S. government approach, for ASEAN to decide it is ready to begin an economic dialogue with the 
U.S." (U.S. Embassy in Jakarta 1976h). While acknowledging that "the potential payout is much greater for ASEAN", Newsom believed that "U.S. government recognition and further enhancement of ASEAN cohesion has continuing validity and importance". Newsom further observed that the initiative was an "opportunity to demonstrate that the U.S. government does not intend to overlook Southeast Asia in favor of other areas in the world" (U.S. Embassy in Jakarta 1976h). However, it took ASEAN considerable effort to emphasize to the U.S., a superpower, on the importance of giving fair treatment and respecting the protocol of the regional grouping, in the same way that it had dealt with other powers like EEC and Japan. For ASEAN, external recognition was all about obtaining better material benefits, securing prestige and an equal status while reducing instances of ill-treatment.

To achieve these goals, Robles (2006: 110) concludes that the "weaker actor, ASEAN, has deployed considerable resources, primarily time, energy and creativity, in translating the ideas into concrete policies and seeking material resources" from foreign powers like the EEC. Without securing EEC's recognition, ASEAN would not have benefited from the economic assistance and preferential trading arrangements as its interactions with the European grouping has shown in this chapter. The Southeast Asian grouping would also not have been able to receive U.S. explicit recognition of ASEAN.

Recognition of ASEAN by foreign powers like the EEC, Japan and the U.S. was critical to the development of the grouping during its formative years. Such acts of recognition motivated ASEAN members to increasingly consider the grouping as a valuable platform to engage the foreign powers. Growing recognition of ASEAN also 
prompted Southeast Asian countries like Malaysia to begin viewing ASEAN as a suitable regional mechanism for solving national problems as highlighted in the preceding chapter. U.S. external recognition of ASEAN, however, was met with resistance from Indonesia because it had a negative implication on the latter's national interest. The discussion has shown that it was not until the U.S. had taken some steps to allay the concerns of the Indonesian government that ASEAN could secure U.S. recognition of the grouping. More importantly, that Indonesia was willing to make a concession by agreeing to the consultation reinforces the importance of external recognition to ASEAN.

The chapter has also highlighted the importance of cumulative recognition. Robles (2004: 8) observes that once ASEAN and the EEC initiated a dialogue, both sides "formulated common conceptions or understandings of their relations and put in place institutions that influence the course of the relationship". Comparing the willingness of the U.S. to deal with its European counterparts as "dealing with equals", Beeson (2007: 70) argues

In East Asia, by contrast, American policy-makers felt that they were dealing with an alien, inferior set of polities and the bilaterally-based, 'hub-and-spokes' security architecture they effectively imposed on the region expressed this.

However, what Robles and Beeson fail to point out is that cumulative recognition meant that EEC's recognition of ASEAN did not just impact on relations between both regions. Far from it, it was a trigger which swayed U.S. Iongstanding nonrecognition policy toward the grouping. It was also affected by how other powers like Japan and Australia were adjusting their respective recognition policies toward 
ASEAN. Together, such cumulative recognition had a compounding effect on the intensity of regional cooperation in Southeast Asia.

In sum, the struggle for recognition reinforced the raison d'être of ASEAN. Shortly after its institutionalization in 1976, ASEAN reiterated its commitments to "the principles governing ASEAN cooperation with third parties" which it acknowledged were targeted "at strengthening ASEAN capability and enhancing relations for mutual benefit" (ASEAN 1976a). Foreign powers' recognition of ASEAN gave impetus to regional cooperation in Southeast Asia as proposed in the model on the recognition of regions in Chapter 2. The final chapter will summarize the dissertation while elaborating on how the framework could account for the developments of ASEAN in more recent years. 


\section{Chapter 6: Conclusion}

This dissertation started by highlighting the scarcity of scholarly works in current literature on the role of external recognition in the development of a regional concept. Can interactions with non-member countries influence or retard the pace of regional cooperation? The emphasis in the study of regional cooperation has often been on the role of states, as opposed to "regions". As a consequence, the bulk of academic research accounts for the evolution of regional cooperation by studying the relations between member states in a regional grouping. Existing scholarship on regional cooperation in Asia has been skewed toward explaining inter-state cooperation based on independent variables such as national interest, increased interdependency and shared norms. For this reason, Beeson (2007: 14) concludes that "the regional level... is generally neglected in most analyses of international relations". The factors driving the interaction process among member states have been the uniting theme in current scholarship on regional cooperation. There are hardly any authoritative works or influential theoretical approaches looking at how non-member states may accelerate or retard the growth of a regional idea. Is there no role for external actors in the development of regions?

By viewing recognition as a tradable commodity and an independent variable, this dissertation has drawn out the usefulness of analyzing regional cooperation based on the model for the recognition of regions in Reference 1 and $\underline{3}$. The proposed framework contributes to existing scholarship by establishing the link between a region's interaction with the external actors and its effect on regional cooperation. It explains how non-member states can influence the development of a regional idea. 
The literature review in $\underline{\text { Chapter } 1}$ has also found that most analyses on regional cooperation premised their arguments on media reports or public announcements by the member governments. Overt sources, while important, are limited in that they often hide the real agenda of states in their foreign policies as the examples drawn from the archival research in this dissertation have shown. In contrast, all governments formulate foreign policies based on inputs from their diplomatic posts overseas. In this regard, the strict application of cables as the primary source material in this dissertation has enabled the analysis to filter out the true intentions of national governments in their execution of a certain set of regional polices. It has also allowed this study to present the arguments as the events happened during the founding years of ASEAN. In this way, this dissertation stands out from past and current literature through its extensive use of diplomatic cables in presenting the arguments.

Together, the proposed model for the recognition of regions and the archival research on newly released U.S. and Australian diplomatic cables are the two distinct contributions that this dissertation has made to present scholarship in the field of regional cooperation.

As a concluding chapter, the aim of the discussion is to highlight the key arguments of this dissertation and revisit the model for the recognition of regions as described in Chapter 2. The section that follows summarizes the main findings from the archival research. It reiterates the importance that ASEAN places on the issue of recognition in the grouping's socialization with major powers like Australia, China, the EEC, 
Japan, Soviet Union and the U.S. It emphasizes on how the degree of external recognition affected member states' perception of ASEAN as a feasible regional approach to solving their national problems. Section 6.2 returns to the theoretical framework and reviews the three hypotheses proposed in this dissertation. The objective is to assess whether the findings from the archival research gel with the predictions of the model for the recognition of regions as purported in this dissertation. The analysis detects an intense struggle for recognition in the interaction process between ASEAN and the foreign powers in the 1960-70s. It finds a correlation between the outcome of a region's struggle for recognition and the level of support from member states toward regional cooperation.

Moving away from the timeline prescribed in this research, Section 6.3 reviews the underlying assumption in this dissertation that recognition is a transformative and ongoing process. While the forms of recognition may evolve as an entity develops over time, the motivations driving the process remain unchanged. The section illustrates the transformative process of recognition by making two comparisons, namely, the evolving nature of the recognition process in personhood, statehood and regionhood; and, the major milestones of U.S. recognition policy toward ASEAN visà-vis the EU. Finally, Section 6.4 highlights the usefulness of the recognition model for future research. It identifies three recent developments in ASEAN to elucidate the continued importance of recognition to the grouping. It discusses ASEAN's initiative for a legal constitution, EU's shifting recognition policy toward an expanded ASEAN in the 1990s, and China's recognition of ASEAN as a free trade zone. Together, the three prospective research areas highlight the transformative nature of the recognition process. Section 6.5 concludes the dissertation by discussing the new 
challenges in ASEAN's struggle for recognition in the context of an evolving regional architecture in the $21^{\text {st }}$ century.

\subsection{ASEAN's struggle for recognition: An overview}

This section reiterates the key findings of the archival research in this dissertation. The summary brings to the fore the outcomes of ASEAN's struggle for recognition, and highlights how increasing external recognition motivated member states to support regional cooperation in Southeast Asia.

Beginning with $\underline{\text { Chapter } 3}$, the discussion has highlighted how ASEAN was able to position the grouping as the primary regional actor in Southeast Asia. The success of ASEAN's three-prong strategy of fobbing off external pressures for an expanded ASEAN membership, withdrawal of support for competing regional forums and rejection of new proposals for regional cooperation legitimized its regional role in Southeast Asia. These efforts were critical in that they calved out the perimeter of a Southeast Asian region centering on the five-member Association as the primary actor, which in turn compelled foreign powers to reassess their recognition policies toward ASEAN. The discussion has also accounted for how foreign powers' misrecognition and non-recognition led to ASEAN's first initiative for external recognition through its push for a zone of neutrality. The geographical divide between the communist and non-communist blocs, couple with the division within the communist camp between China and Russia, constrained ASEAN's struggle for recognition. While not recognizing ASEAN, China's objection to the grouping was restrained as the Beijing government was seeking ASEAN states' recognition of its 
statehood and the latter's rejection of the statehood of the Republic of China. Russia's recognition policy toward ASEAN was, in turn, affected by China's overtures to Southeast Asia. The discussion has found that in an attempt to justify their military presence in Southeast Asia, the foreign powers from both the communist and anticommunist camps repeatedly portrayed ASEAN as a region too fragile to defend its border against the enemy. The failure in the grouping's proposal for ZOPFAN has illustrated the extent to which foreign powers, especially the U.S, tried to maintain their influence in the region by refusing to recognize the zone and repeatedly portraying ASEAN as an inferior region. These empirical findings support the theoretical model in this dissertation that a region's struggle for recognition is to regain (or restore) a distorted (or lost) identity caused by foreign powers' misrecognition (or non-recognition).

Chapter 4 has outlined how ASEAN's rejection of Australia's request to join the grouping caused Canberra to hold back its recognition of ASEAN. Refusing to recognize ASEAN as a regional body, the Canberra government pursued a strategy of promoting a larger regional grouping which it had hoped would subsume ASEAN. This proposal was again met with hostility from the ASEAN states. The futility of these efforts triggered Australia to reconsider its recognition policy toward ASEAN. Its strong desire not to be excluded from regional discussion resulted in Australia's willingness to recognize ASEAN and to forge a dialogue partnership with the grouping. While skeptical of foreign powers' intervention in Southeast Asia, ASEAN was motivated to secure Australia's recognition for the tangible benefits that came with it, as predicted by the recognition model. Turning to ASEAN's struggle for Japan's recognition, the case study has illustrated how Malaysia succeeded to 
organize ASEAN against an instance of unjust treatment by a non-member. Malaysia's success to mobilize the ASEAN countries triggered the change in Japan's longstanding policy of not recognizing ASEAN. A deeper analysis of the archival data has found that Malaysia escalated a national problem to the regional level. Its success in obtaining Japan's cooperation on the rubber issue motivated the Malaysian government to increasingly view ASEAN as a suitable regional platform for solving its national problems. Further to the call for collective action, the evidence suggests that ASEAN was quick to exploit the media in securing public sympathy and support to the perceived unfair industrial practices by Japan. The chapter has also highlighted how the withdrawal of U.S. troops from Saigon also gave impetus to Japan's willingness to recognize ASEAN as a regional entity. In retrospect, the communist victory in Indo-china had a significant influence on the strategic calculations of both the major powers and ASEAN. Singapore Prime Minister Lee assessed in November 1976 that "the fall of Vietnam had brought home to the leaders of the ASEAN governments the importance of making ASEAN a viable organization" (U.S. Embassy in Singapore 1976i). From the success of its first economic action against a foreign power, ASEAN understood that the extent of external recognition accorded to the grouping was intricately linked to the level of tangible external support available to it. Together, the empirical evidence suggests that instances of disrespect or unfair treatment motivate a region's struggle for recognition as predicted in the proposed framework.

The ZOPFAN and UNGA episodes have illustrated U.S. resistance to recognize ASEAN's regionhood by its portrayal of an image of inferiority toward the region. By refusing to recognize ASEAN as a regional grouping, the U.S. could continue to 
leverage on its supremacy when dealing bilaterally with each of the ASEAN-5 countries. The anecdotal accounts in Chapter 5 have outlined U.S. aversion toward any direct interactions with ASEAN for fears that such acts of recognition would encourage the grouping to become an effective bargaining bloc. However, in the wake of competition from the EEC and pressures from its business community, the U.S. was compelled to court ASEAN by offering the grouping some forms of recognition on the economic front. Even so, the U.S. was against any engagements which might legitimize or strengthen ASEAN as an economic coalition. The archives presented in $\underline{\text { Chapter } 5}$ have also highlighted how ASEAN's struggle for U.S. recognition was delayed by the latter's unwillingness to offer one of its member the same treatment as the rest of the ASEAN states. It reiterates the prediction of the recognition model that the degree of external recognition has an influence over the pace of regional development. As the diplomatic cables have shown in this case, U.S. "incomplete" recognition of ASEAN dampened Indonesia's commitment toward regional cooperation in Southeast Asia. Yet, U.S. willingness to recognize ASEAN was received positively by the grouping as it would increase the legitimacy and prestige of the region. In its dealings with the U.S., ASEAN emphasized that the grouping would not treat the U.S. differently despite the latter's superpower status.

As for the EEC, its recognition of ASEAN was driven by the Community's desire to fortify its presence in Southeast Asia at a time when U.S. influence was declining. ASEAN also desired EEC's recognition to gain equal and better access into the European markets. The prospect of external recognition from the EEC accelerated efforts to institutionalize regional cooperation in ASEAN through the creation of a collective trade body in Brussels. In its struggle for recognition, ASEAN impressed on 
these foreign powers the importance of treating the grouping as an equal partner. The emphasis by the ASEAN grouping gave attention to the importance of fairness and equal status as suggested by the theoretical framework in this dissertation. In addition, the chapter has found that ASEAN was also agile at playing one foreign power against another as evident in Filipino Industry Minister Vicente Paterno's suggestion that "talks with the U.S. should be held before Japan... to use any indications of U.S. concessions on trade or assistance to lever the Japanese" (U.S. Embassy in Manila 1975h). Together with the case study on the U.S., the discussion has also brought out the importance of cumulative recognition. EEC's recognition of ASEAN swayed U.S. non-recognition policy toward the grouping. These are the major findings in $\underline{\text { Chapter } 5}$.

In retrospect, the discussion on Malaysia's push for collective action against Japan and Indonesia's reaction to U.S. "incomplete" recognition have illustrated how the extent of external recognition influenced members' attitudes toward regional cooperation. Given the limitation of space, these examples represented only the tip of the iceberg in the archives. The underlying proposition is that the degree and quality of recognition affects the perception and commitment of member states toward regional cooperation. To reiterate this, the remaining section draws out another instance from the archives in which external recognition for ASEAN enabled the smallest member state - Singapore - to overcome a national emergency during the oil crisis of the 1970s.

In response to U.S. military support for Israel, Arab countries announced an oil embargo on the shipment of petroleum to the U.S. in October 1973 and pressured 
countries dependent on oil from the Middle East not to re-direct such oil imports to the U.S. In addition to a periodic cut in oil exports, the Arab nations imposed an oil embargo on any non-complying countries. This put Singapore in a precarious position. As high as 90 percent of Singapore's crude oil imports originated from the Middle East while its oil refinery output was responsible for 30.6 percent of Singapore's total industrial production in 1972 (The Straits Times 1973a: 15). A halt in oil shipment from the Arab countries would adversely affect the Singapore economy. Singapore Foreign Minister Rajaratnam explained in January 1974: "Our industries and links with the rest of the world depend on oil and we can't live in a period in which oil prices go up every few month" (The Straits Times 1974b: 1).

Apart from the negative impacts on its economy, the crisis also posed a challenge to Singapore's strategic ties with its key allies like the U.S. and Israel. First, Singapore would have to cease its bilateral arrangement with the U.S. on the provision of logistic support for the refueling of the latter's naval vessels and aircrafts in the region. Second, it would also impact on Singapore's military relations with Israel. Following the island state's separation from Malaysia, Israel was one of the few countries which were willing to provide military training to Singapore. Middle East's demand for an oil embargo on the U.S. therefore placed Singapore in a perilous position. Should the government announce its support for the embargo or risk a cut-off in oil supply from the Arab nations? The Singapore government had to come to a decision which would avoid an impending national crisis, both to its economy as well as its security which depended on its military relations with the U.S. and Israel. The ASEAN solution proved to be an effective one. 
Within Southeast Asia, Indonesia led an initiative for ASEAN to issue a joint declaration to support the Arab nations. For the reasons highlighted above, Singapore displayed initial reservation toward the issuance of such a declaration. At a meeting with Filipino President Marcos in January 1974, Singapore Prime Minister Lee Kuan Yew "expressed regret that ASEAN countries had not taken a joint stand at the beginning of the crisis (U.S. Embassy in Manila 1974d). However, Arab countries were at the same time pushing for recipient countries of Middle East oil imports to announce their support for the oil embargo or face the consequence of a cessation in oil shipment themselves. Singapore, in particular, had been unwilling to go along with such a regional initiative, but would soon realize that a national solution was not tenable.

In a meeting with U.S. Ambassador to Singapore Edwin Cronk on 22 November 1973, Singapore Permanent Secretary for Foreign Affairs George Bogaars was confident that Singapore "would not turn its back on Israel" (U.S. Embassy in Singapore 1973d). Yet, less than a week after the Cronk-Bogaars meeting, the Southeast Asian grouping issued an ASEAN Declaration on 27 November 1973 expressing its condemnation of Israel's "act of territorial expansion by force" into the Arab territories (ASEAN 1973b). The U.S. diplomats were taken by surprise at Singapore's aboutturn decision. When Cronk checked back with Bogaars on the events which led to the change in Singapore's policy, the latter explained that the "Thais and Malaysians had been reluctant to go along with it, but that Indonesia had put heavy pressure on the Government of Malaysia to accede". Bogaars' underlying message to Cronk was that "once Indonesia and Malaysia were in agreement, it was difficult for Singapore to take a different position" (U.S. Embassy in Singapore 1973e). In effect, Singapore 
was using ASEAN as a way to get out of the sticky position that it was inevitably being drawn into. To put out a national statement declaring its support or non-support for the oil embargo would have been a lose-lose outcome for Singapore. The ASEAN statement was sufficient to pacify the Arab nations without overly offending the U.S. That it was a regional pronouncement, rather than a national one, also meant that Singapore did not have to strain its relations with Israel. ASEAN became an effective shield for Singapore to limit the damage to its economy and minimize the fallout with its strategic partners during the oil crisis.

Following ASEAN's declaration on the Arab-Israel conflict, the Singapore government "officially conveyed to the Arab diplomatic representatives a joint statement of ASEAN countries deploring Israeli occupation of Arab territories" (The Straits Times 1973b: 2). The U.S. Embassy in Singapore (1973f) revealed that the Singapore government issued "secret instructions to all oil refineries in Singapore requesting that they not export or re-export oil supplies to Arab-embargoed countries... without consulting the USG". This move led to a cessation of fuel supply for U.S. naval vessels and military aircraft. The U.S. Embassy in Singapore (1973f) reported that "U.S. naval vessels can no longer bunker at Singapore facilities and, with certain exceptions, U.S. military aircraft can no longer refuel in Singapore". To pacify the U.S., the Singapore government made tacit arrangements and undertook special provisions for U.S. military installations to refuel at British bunkers.

The U.S. reported that the Singapore government "previously walked narrow tightrope on mid-east issues, moved quickly to shift its policy... [following] decision to go along with its ASEAN partners in a statement condemning Israel's forcible 
occupation of Arab territories" (U.S. Embassy in Singapore 1973f). This narrative illustrates how Singapore was effectively used ASEAN as a way to placate the Arab nations through the issuance of a regional declaration while not jeopardizing its bilateral relations with the U.S. or Israeli governments. Critical, if the Arab nations had not recognized ASEAN as a legitimate regional body in Southeast Asia, the Middle East would not have been satisfied with the ASEAN declaration. It once again highlighted to Singapore, the usefulness of external recognition for ASEAN and how it could function as a regional front to overcome its national problems. To be sure, it was not the first time that the Singapore government experienced the benefits of external recognition for ASEAN in addressing its national problems. This may be summarized in the following account by Counselor Kesavapany from the Singapore Embassy to Indonesia on 14 May 1974 that

although the synthetic rubber question did not interest the Singaporeans, they had been prepared to join in the joint ASEAN approach for the sake of ASEAN cooperation. On the other hand the EEC trade concessions which related mainly to industrial products benefited Singapore most of all... there was a basic willingness to give and take among the ASEAN members (Australian Embassy in Jakarta 1974b).

The above revelation, while not surprising, is instructive because it meant that if member states were not able to see ASEAN as a means of providing some solutions to national issues, they would have been less willing to invest time or resources to promote regional cooperation in Southeast Asia. It also revealed an unspoken understanding among member states that for regional cooperation to have any meaning, the five governments had to be amenable to each other's use of ASEAN as a platform to solve their respective national problems so long as the outcome was not 
detriment to the rest of the group. In other words, the more national problems ASEAN was able to overcome, the more committed member states were toward regional cooperation. Critical, ASEAN's capacity to provide a solution to national problem was inexorably tied to the forms and substance of recognition it received from the external powers. The deeper and better the quality of external recognition accorded to ASEAN, the more likely that the latter could provide a solution to domestic problems. In this regard, the diplomatic archives in this dissertation have established the prevalence of an intense for recognition in the socialization process between ASEAN and the foreign powers, and demonstrated how the outcome of such a struggle affected the perception of member states toward regional cooperation in Southeast Asia.

\subsection{Recognition model for regions: A revisit}

This section reviews the proposed model for the recognition of regions and assesses the consistency between what the theoretical framework predicts and the archival evidence presented in the earlier chapters. It begins by laying out the key ethos of the proposed theoretical framework before providing a succinct appraisal on the robustness of the three hypotheses designed at the beginning of the dissertation.

The theorizing in $\underline{\text { Chapter } 2}$ has elicited a model for the recognition of regions based on the concepts on personhood and statehood. On the former, existing conditions such as inequality in social status, unfairness in distribution of economic resources, a distorted identity and instances of ill-treatment contribute to an individual's desire for recognition. The rest of the members in the society manipulate recognition in order to 
entrench their hegemony over the subjugated or to maintain their preferred cultural values. The ensuing discussion on statehood in the chapter has highlighted how these observations are similarly reflected in the struggle for recognition in a society of states. Aspiring states seek recognition for a host of factors, including access to economic opportunities, legal rights, prestige and status. Existing states, in turn, endow or withhold recognition to exert their domination over other states and/or to achieve their foreign policy or national objectives. In contrast to statehood, the stark absence of a clear set of internationally accepted norms governing recognition decisions for regions magnifies the critical role that external actors have to play in the development of a regional concept. The analysis (for both statehood and personhood) has also drawn out the importance of cumulative recognition to the success of an entity since each sequential act of recognition raises higher the status and stability of the entity. Moving away from existing scholarship which focuses on the socialization process within a region, the chapter has thus proposed a model to examine the issue of recognition in the relationship between a region and nonmember entities.

From the analysis on the role of recognition in the society of individuals and of states, Chapter 2 has devised a matrix which incorporated the key elements of recognition theories for a person, a state and a region. Reference 1 has set out the conditions in which a region may be said to be undergoing a struggle for recognition. Based on this matrix, the first objective of the archival analysis has been to ascertain if ASEAN's socialization with the international community reflected the characteristics of a region contesting for external recognition. If the struggle for recognition may be determined in the archival exercise, the second objective of the dissertation is to find 
out whether the outcome of such a struggle has any influence on how member states viewed regional cooperation. As illustrated in Reference 3 , the proposed model suggests that increasing external recognition promotes regional cooperation. Accordingly, the next task in the archival analysis is to find out whether the degree of external recognition received by ASEAN affected the level of cooperation within the grouping. Based on the recognition model for regions proposed in this dissertation, Chapter 2 has set out the following three hypotheses:

1. The development of a regional concept depends on the grouping's socialization process with external actors;

2. The supply and demand of recognition between a region and the external actors underpins the socialization process; and

3. The extent of external recognition received by a region influences the attitudes and behaviours among member states toward regional cooperation.

To facilitate the empirical testing of the model, $\underline{\text { Chapter } 2}$ has presented ten pertinent questions which would address the three hypotheses above. The questions, and a summary of the corresponding results from the archival research, are presented below:

i. Were there initiatives by ASEAN to obtain fairer distribution of and equal access to economic resources?

- The archival data on ASEAN-EEC and ASEAN-Australia relations have illustrated how the Southeast Asian grouping sought external recognition in order to extract fairer and better economic deals from these powers. ASEAN was driven by a desire for EEC's recognition so as to enjoy equal treatment, as other developing regions, for its imports 
to the European markets (in the form of GSP). ASEAN also sought Australia's recognition of the grouping to secure financial support for the grouping. Beyond these findings, the archives have also revealed that ASEAN was adept at playing one foreign power over another to secure a bigger slice of economic assistance from these countries. The style of its negotiations with Australia and Japan, followed by EEC and the U.S., has drawn out the value of cumulative recognition for ASEAN.

ii. Were there efforts by ASEAN to raise its status and prestige in Southeast Asia?

- The diplomatic accounts have reflected a strong push by ASEAN for external powers to accord respect and equal status in their dealings with the grouping. To calve out a unique status for the grouping, ASEAN members expended considerable resources and time to fob off pressures for an expanded grouping, curtail their involvement in other forums and withdraw support from competing groupings. Despite its desire for recognition, its rejection of U.S. and Japan's initial overtures and insistence on both powers to respect the grouping's protocols and developmental needs have illustrated the importance that ASEAN attached to the issue of status and prestige.

iii. Were there instances of unfair treatment by any foreign powers toward an ASEAN member?

- The archives have identified several cases of unfair treatment toward ASEAN members. These included EEC's inequitable treatment of the ASEAN region vis-à-vis other developing regions in granting preference trade access to the European markets, the perceived unfair industrial 
practice by the Japanese rubber industry and U.S. refusal to extend GSP privileges to all the ASEAN members.

iv. Did foreign powers create and internalize a distorted image of the ASEAN countries?

- The diplomatic cables have revealed how foreign powers from both the communist and non-communist camps persistently portrayed Southeast Asia as a region that was too weak to defend itself against the threats from the other side. It was an image forced onto ASEAN to justify the necessity for military interventions and installations in the region by the respective foreign powers. The portrayal of such an image of inferiority triggered ASEAN's first attempt in seeking political recognition through its promotion for a zone of peace and neutrality.

v. Were there persistent efforts by foreign powers to exert continued hegemony over ASEAN countries?

- The archival exercise has detected several occasions when the foreign powers attempted to exert their supremacy over the ASEAN countries. To name but a few, U.S. and Japan's preference for bilateral diplomacy for fears that ASEAN would become an economic bloc, Australia's repeated attempts to infiltrate into the ASEAN grouping and EEC's recognition of ASEAN to exert its influence in Southeast Asia at a time when the U.S. military was withdrawing from Vietnam.

vi. Did foreign powers trade recognition with ASEAN for other concessions?

- The cables have shown that foreign powers were adroit at manipulating their recognition policies toward ASEAN in exchange for outcomes which supported their national objectives. Australia traded recognition 
with ASEAN for a role in regional discussion. The Australian government made a concession to ASEAN in the form of an offer for developmental assistance in return for Canberra's participation in ASEAN meetings. Likewise, Japan was compelled to trade recognition with ASEAN for a favorable public response to its industrial practices. U.S. also recognized ASEAN to level with EEC's forays into Southeast Asia and to enable its businesses to bid for ASEAN industrial contracts.

vii. Were there any social struggles and confrontation initiated by ASEAN?

- While there were no substantial evidence from the archives that ASEAN had initiated social struggles and confrontation, there were diplomatic reports of ASEAN raising North-South issues on behalf of other developing countries or other non-aligned nations at international forums.

viii. Did any ASEAN country appeal to the grouping for collective action against an external actor?

- Malaysia's escalation of the rubber issue against the Japanese government epitomizes the tendency of ASEAN countries to appeal for collective action against the external powers. The archival account has detailed how Malaysia organized and led an ASEAN-economic vendetta against Japan when the latter's industrial practice was threatening its vital rubber industry. More importantly, it has shown how the success of such a collective action motivated Malaysian policy makers to increasing view ASEAN as a suitable platform to tackle its national problems. 
ix. Were there any efforts to engage the public sphere in ASEAN's struggle for recognition?

- The anecdotal accounts have highlighted the readiness of ASEAN to exploit the media as a platform in its campaign for recognition. From labelling Japan as an economic "threat" to calling for greater press coverage on ASEAN's relations with the EEC and the U.S. (as opposed to bilateral relations), the findings have revealed ASEAN's adroitness in engaging the public sphere in its struggle for recognition.

$x$. Did the outcome of the struggle for external recognition affect the desire for regional cooperation among ASEAN members and cause them to view the association as a suitable regional platform to solving national problems?

- The archival analysis has found significant evidence suggesting that the level of recognition accorded to ASEAN had an impact on how member states viewed the usefulness of ASEAN. Malaysia's success in organizing ASEAN to secure Japan's cooperation on the rubber issue motivated the Malaysian government to view the grouping in a positive light. On the other hand, Indonesia's hesitation toward economic cooperation in ASEAN was a result of U.S. "incomplete" recognition of the grouping. Further, Singapore's strategy of using ASEAN as a front to overcome the challenges of an oil embargo imposed by the Arab nations reinforced the usefulness of regional cooperation in providing solutions to national problems.

Overall, the findings above have detected an intense struggle for external recognition in ASEAN's socialization with the international community in the 1960-70s. The 
motivations behind foreign powers' decisions - from whether to extend a congratulatory letter to ASEAN, lobby the grouping in the UN, support its call for a zone of neutrality or provide financial assistance - indicated that they were weighing the pros and cons of whether to supply recognition to ASEAN. As for the Southeast Asian grouping, ASEAN's demand for external recognition could be seen in the way it responded to the issues of fairness, aids, respect and status in its dealings with the foreign powers. The outcome of its struggle for recognition depended on the form and substance of foreign powers' recognition policies toward ASEAN. With the U.S., for instance, while ASEAN did not obtain significant financial assistance, U.S. recognition gave ASEAN the prestige and status it desired. The success or failure of ASEAN's struggle for recognition can therefore be determined by examining the grouping's social practices with the international community. This conclusion lends support to Hypothesis 2 that "the supply and demand of recognition between a region and the external actors underpins the socialization process".

It is also clear from the archives that increasing external recognition gave impetus to the commitment of member states toward regional cooperation in ASEAN, as opposed to the "ASEAN Way" or a system of shared norms which some scholars like Acharya have argued. Instead, the ASEAN idea survived its initial years because member states saw the opportunity of using ASEAN as a platform to overcome their national problems. As mentioned earlier, the examples of Malaysia (rubber problem with Japan), Indonesia (trade problem with the U.S.) and Singapore (oil problem with the Arab countries) highlighted in this dissertation have reflected the tendency in member states to find solutions to national problems through ASEAN. Member states are therefore driven by how ASEAN could function as a useful platform to overcome 
the national challenges they faced. The more external powers were recognizing ASEAN, the greater likelihood the regional grouping could provide a solution to national problems. Together, the evidence supports Hypothesis 3 that the "extent of external recognition received by a region influences the attitudes and behaviors among member states toward regional cooperation".

Finally, the diplomatic archives have shown how the concept of ASEAN as a legitimate regional actor in Southeast Asia strengthened with increasing external recognition. Cumulative recognition by non-member states provided ASEAN members greater impetus toward regional cooperation. Hypothesis 2 has observed an exchange of recognition in the interaction between ASEAN and the foreign powers. Hypothesis 3 has detected a positive relationship between the extent of external recognition and the level of members' support for regional cooperation. Together with the conclusions of Hypothesis 2 and 3, the archival evidence presented in this dissertation therefore validates Hypothesis 1 that the "development of a regional concept depends on the grouping's socialization process with external actors". The discussion has proven the importance of external socialization in the development of a regional concept like ASEAN.

\subsection{Recognition: A transformative process}

This dissertation has underlined the usefulness of the recognition model in $\underline{\text { Reference }}$ $\underline{1}$ and $\underline{3}$ to the analysis of regional cooperation. Recognition by the international community reinforces the legitimacy of a newly constructed region like ASEAN. Yet, the development of a regional entity entails an unceasing contest for recognition due 
to the shifting demands imposed by changes in the geo-political and economic landscapes. As highlighted from the onset, the underlying argument in this dissertation is that the struggle for recognition is an ongoing process. The requirements and needs for recognition shift over time. While the forms of recognition change as an entity matures, the motivations driving the exchange of recognition remain the same. Reference 4 illustrates how such a transformative process may occur over the lifetime of a person, a state and a region.

\begin{tabular}{|c|c|c|c|c|}
\hline \multicolumn{5}{|c|}{ Reference 4: The Transformative Process of Recognition } \\
\hline Entity & \multicolumn{3}{|c|}{ Evolution of Recognition } & \\
\hline Personhood & $\begin{array}{l}\text { Nationality } \\
\text { Ethnicity } \\
\text { Gender }\end{array}$ & $\begin{array}{l}\text { Education } \\
\text { qualifications }\end{array}$ & $\begin{array}{l}\text { Career } \\
\text { achievements }\end{array}$ & $\begin{array}{l}\text { Business } \\
\text { associations } \\
\text { Professional } \\
\text { affiliations }\end{array}$ \\
\hline Statehood & $\begin{array}{l}\text { Declaration } \\
\text { Exchange of } \\
\text { letters } \\
\text { UN } \\
\text { membership }\end{array}$ & $\begin{array}{l}\text { Trading posts } \\
\text { Representative } \\
\text { offices } \\
\text { Upgrading of } \\
\text { representation: } \\
\text { consul, consul- } \\
\text { general to } \\
\text { embassy }\end{array}$ & $\begin{array}{l}\text { Memberships } \\
\text { in international } \\
\text { organizations } \\
\text { (IMF, WTO, } \\
\text { WB) }\end{array}$ & $\begin{array}{l}\text { Memberships in } \\
\text { exclusive clubs } \\
\text { (G8, G20, UNSC) } \\
\text { Top appointees in } \\
\text { international } \\
\text { organizations }\end{array}$ \\
\hline Regionhood & $\begin{array}{l}\text { Declaration } \\
\text { Exchange of } \\
\text { letters } \\
\text { Informal } \\
\text { meetings } \\
\text { Foreign } \\
\text { observers }\end{array}$ & $\begin{array}{l}\text { Joint statements } \\
\text { Donor-recipient } \\
\text { relations } \\
\text { Formal and } \\
\text { regular meetings } \\
\text { Dialogue } \\
\text { partners }\end{array}$ & $\begin{array}{l}\text { Memberships } \\
\text { in regional } \\
\text { organizations } \\
\text { (ADB) } \\
\text { Observer } \\
\text { status in } \\
\text { international } \\
\text { organizations } \\
\text { (UN, IMF, } \\
\text { WTO, WB) } \\
\text { Free Trade } \\
\text { Zone }\end{array}$ & $\begin{array}{l}\text { Legal constitution } \\
\text { \& deposition of } \\
\text { charter in the UN } \\
\text { Human rights } \\
\text { body } \\
\text { Formal external } \\
\text { relations } \\
\text { (ASEAN+) } \\
\text { Representative } \\
\text { offices }\end{array}$ \\
\hline
\end{tabular}


The fundamental assumption in the model is that recognition is not a static process. The forms of recognition as outlined in the table are not exhaustive. However, they reflect how the intensity of recognition changes depending on the stages of an entity's development as Hammer (2007: 41) argues:

Thus, recognition can be better understood in a transformative sense, not as a matter of the relationship between politics and law and the manner by which the international system can attempt to combine these two aspects nor solely as an issue of power assertions by state or international actors... Rather the analysis is of the relation itself, what is occurring between the actors as the determinant of the relevant elements and decision that go into the recognition decision.

Each successful acts of recognition reinforces the legitimacy of the entity. For personhood, it begins with the basic recognition of his nationality, race and gender. As the person becomes older, his development depends on the degree of external recognition he obtains based on his educational or career qualifications. For example, the extent of recognition others attach to the prestige of the school he graduated from has an impact on his job prospect. Similarly, when he joins the workforce, external perception of the company he represents or his job level affects his career options and progression, in the same way that the degree of recognition others attaches to his affiliation in certain business or professional groupings shape his personal development. Likewise for statehood, it typically begins with an exchange of letters between the new entity and existing states, or an act of declaration by the latter welcoming the new entity into the community of states. Subsequent acts of recognition such as the creation of a trading post or the appointment of an overseas representative reinforce the legitimacy of the new state. As the state matures, 
admission into international organizations such as the UN, IMF, WTO or WB opens up greater developmental opportunities for the country. As it develops further, membership in exclusive or privilege groupings such as the G8, G20 and UN Security Council (UNSC) or having top appointees in international organizations, such as directorships in the WB or IMF, empowers the state with greater policy options. Even for developed countries, the struggle for recognition is an ongoing process, as evident in Japan's bid for a permanent membership in the UNSC.

For regionhood, the case study on ASEAN has shown that it may begin with an explicit declaration or approval of the existence of a region. It may be followed by an exchange of letters or informal meetings. For the regional grouping to develop further, it calls for concrete acts of recognition toward the various functional areas that the group is promoting. Denial of such acts of recognition, such as the non-recognition of ZOPFAN by the foreign powers, may retard the development of regional cooperation. For example, the case study on ASEAN in this dissertation has shown that foreign powers' recognition of ASEAN as an economic entity in the form of an aid donorrecipient relationship reinforced the development of regional cooperation in Southeast Asia during the formative years. The formalization of dialogue partnerships or accession into international organizations as observers may also serve as concrete acts of recognition, which in the case of ASEAN legitimized its role as the regional voice of Southeast Asia. Likewise, the level of external recognition of a region's free trade zone or legal status also affects the development of regional cooperation. (This will be elaborated in the next section). 
$\underline{\text { Reference } 4}$ therefore highlights the transformative process of recognition in regional cooperation. Given its non-static nature, foreign powers tweak their recognition policy as a region develops over time. To amplify this point, $\underline{\text { Reference } 5}$ illustrates the major milestones of U.S. recognition of ASEAN vis-à-vis the European Union (EU or formerly EEC).

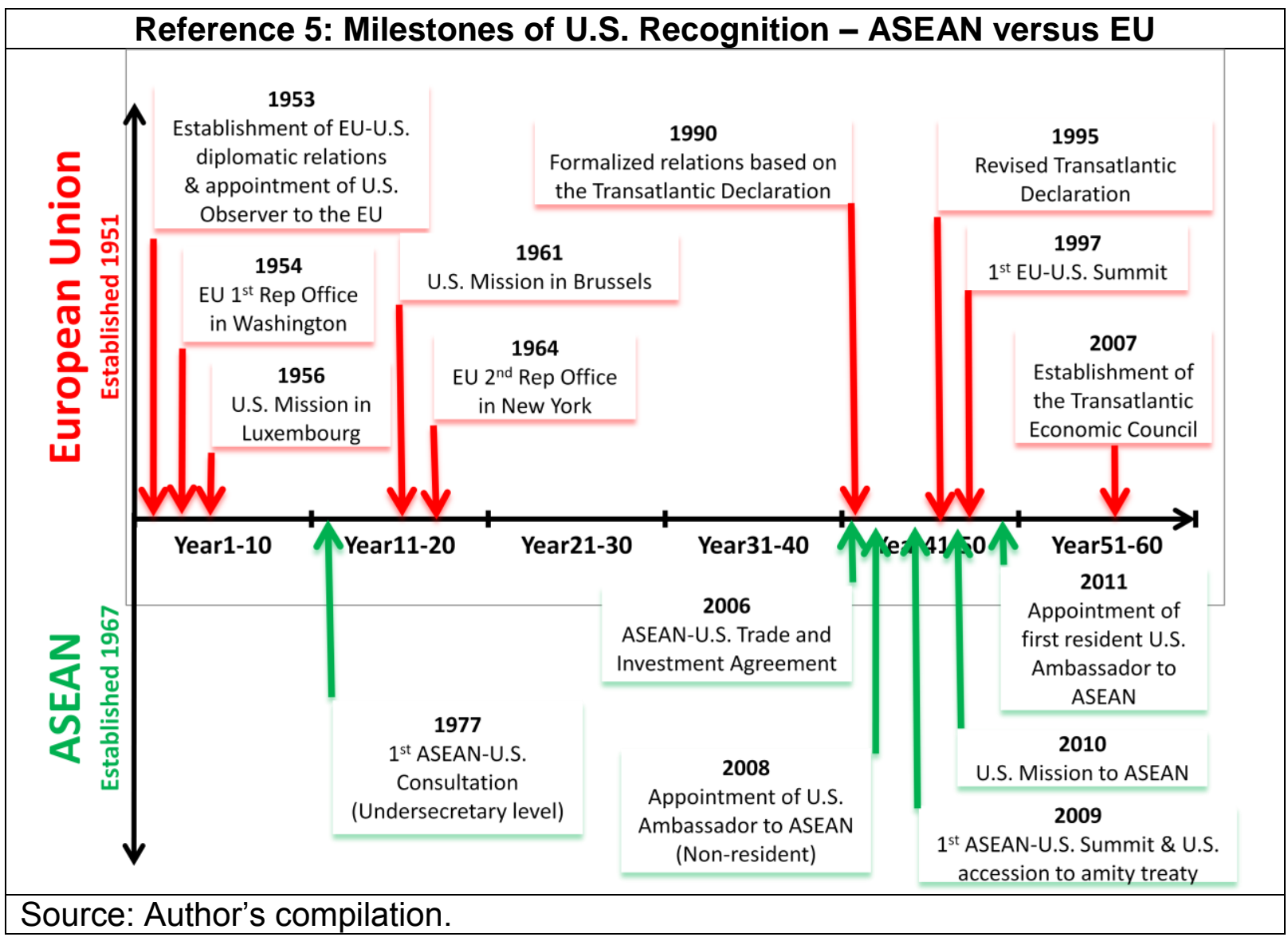

The section above the timeline records the major recognition milestones for the European grouping, formerly known as the European Coal and Steel Community (ECSC) after its formation in 1951. The section below the timeline reflects U.S. recognition of ASEAN, a grouping which was formed 15 years after the ECSC. While the list is not exhaustive, it reflects the critical junctures of U.S. recognition policies toward both regional groupings in the first 50-60 years of their respective existence. It 
serves to highlight the hesitancy and lateness of U.S. recognition toward ASEAN as compared to the EU. More significantly, the illustration is a concrete defense of the underlying assumption in this dissertation that recognition is a continuous process for "regions" rather than one that is static.

Reference 5 indicates that the U.S. government formally recognized the European grouping very soon after its formation in 1951. Diplomatic ties were established between the two sides by U.S. appointment of its observers to the ECSC in 1953. The first decade of ECSC's formation also witnessed the setting up of the first European representative office in Washington in 1954 and U.S. mission in Luxembourg in 1956. In sharp contrast, the U.S. refused to accord ASEAN with any concrete recognition in the first 10 years of ASEAN's formation as the earlier chapters have discussed. The first ASEAN-U.S. economic consultation only took place in the second decade of ASEAN's existence. Even so, the consultation in 1977 was only pegged at the undersecretary-level. In comparison, the second missions of the U.S. and the EEC were set up in Brussels and New York respectively as the European grouping entered into its second decade.

Fast forward into the fortieth year onwards, the U.S. completed a series of formal agreements and held annual summit meetings with the EU but only started to formalize its diplomatic ties with ASEAN. During this period, the U.S. and the EU strengthened their ties by the adoption of the Transatlantic Declaration in 1990, and its subsequent revision in 1995. A landmark recognition exercise, the EU-U.S. declaration instituted regular political dialogues and summit meetings between both sides at all levels and in various areas of cooperation. In stark comparison, it was 
only during this period that the U.S. appointed Scot Marciel as the first U.S. Ambassador to ASEAN in 2008. Even so, Marciel was only a non-resident representative based in Washington. On 15 November 2009, President Obama finally met with leaders of the ten Southeast Asian countries for the first ASEAN-U.S. Summit, 42 years after ASEAN was founded. Nonetheless, it was not until the latter half of the fifth decade of ASEAN's existence that U.S. finally opened its first diplomatic mission in Jakarta and appointed David Lee Carden as the first resident Ambassador to ASEAN in 2010-11.

Apart from highlighting the transformative nature of the recognition process, the aim of Reference 5 is to point out U.S. longstanding reluctance to recognize ASEAN visà-vis EU. In view of the extensive links between the two sides, the European grouping's Directorate-General for External Relations declared that "USA has been a stalwart supporter of integration between the nations of Europe, which is today embodied in the European Union" (European Union 2012). What about ASEAN? The discussion here therefore reinforces the idea that recognition is a non-static process, and more importantly, it highlights the complexity of ASEAN's struggle for recognition since its formation in 1967.

\subsection{Recognition: ASEAN in the $21^{\text {st }}$ century}

The transformative nature of the process of recognition highlights the relevance of the proposed model for the recognition of regions to the study of regional cooperation. It indicates the importance of analyzing a region's struggle for recognition when examining the development of a regional concept. This section identifies three recent 
developments in ASEAN where the proposed model in this dissertation may be drawn on for future academic research. It highlights three applications, namely, ASEAN's pursuit for legal status, EU's shifting recognition policy with the admission of Myanmar into ASEAN and the cumulative effect of China's recognition of ASEAN as a free trade zone. It outlines the key findings from the diplomatic archives in the three areas while identifying aspects of the proposed recognition model which are applicable for future studies.

First, the conclusion and deposition of the ASEAN Charter with the UN in 2008 illustrates the emphasis that the Southeast Asian grouping gave to the issue of recognition. However, it is telling that it has taken ASEAN more than 30 years to realize Filipino Foreign Minister Carlos Romulo's proposal at the Seventh ASEAN Ministerial Meeting for the creation of a "charter or constitution ('a legally binding document') as well as informal machinery which could be used in resolving disputes or differences between ASEAN countries" (U.S. Embassy in Jakarta 1974i). While the meeting in May 1974 recorded Philippines' proposal for the adoption of an ASEAN charter in its communiqué, Malaysia, Singapore and Thailand were not in favor of the recommendation (U.S. Embassy in Jakarta 1974j). Their objection was reflected in the following comments by Singaporean Counselor Kesavapany from the Singapore embassy in Jakarta on 14 May 1974 that

the Filipino suggestions for the adoption of an ASEAN charter and machinery for the settlement of regional disputes were not completely new but they did not have the support of the other members... ASEAN was not ready for nor did it want courts to settle disputes, as the Filipino proposal in its original form 
implied... ASEAN members... did not want to over-formalize the structure of ASEAN with a charter" (Australian Embassy in Jakarta 1974b).

Kesavapany further expressed his hope that the Filipino proposals would "die a natural death". Recalling Reference 1, the acquisition of legal status has been listed as one of the elements in a region's struggle for recognition. The anecdotal evidence has, however, shown that ASEAN clearly did not feel the urgency to obtain legal rights for the grouping during its formative years despite its desire for recognition. While possessing a legal status has a propensity to attract greater external recognition, it is a two-edged sword which may also jeopardize member states' national interests as Kesavapany conceded above. More significantly, the geopolitical and economic environment at that time did not impose on developing regions like ASEAN to take on a legal personality as a condition for recognition.

The archival narration above begs the academic enquiry as to why the Southeast Asian grouping created the ASEAN Charter and deposited it with the UN in 2008. Reflecting on the revelation of Kesavapany, who went on to assume several high profile ambassadorial positions in the Singapore foreign service: Is ASEAN now ready or desired for court settlement in its disputes? Former ASEAN SecretaryGeneral Ong Kheng Yong, who was involved in the drafting of the Charter, gave a hint when he explained: "To convince the external parties that the ten diverse countries of ASEAN are serious about exerting collective strength, a concrete new modus operandi is required" (Ong 2010: 108). Here again, the importance of the Charter serving as a means to obtain greater external recognition is highlighted. According to Ong (2010: 111), the Charter "was intended to be a legal document, creating a distinct legal personality for ASEAN as an inter-governmental regional 
organization". Even so, critics point to the ineffectiveness of the Charter against recalcitrant members given its vaguely worded text. In its assessment of the Charter, for example, Amnesty International (2008) raises the concern that "some member states may view these commitments as little more than a window-dressing exercise, and will try to make sure that the human rights body has no real 'teeth' and is under the control of political interest". The motivation for creating a Charter therefore has to be reexamined in the context of ASEAN's struggle for external recognition. The recognition model proposed in this dissertation could be used to account for such behaviors and maneuverings in ASEAN. The framework works in a way that "allows for external influences and changes as the entity acquires surer footing or becomes a legitimate international actor" (Hammer 2007: 43).

Second, the expansion of ASEAN with the membership of the Indo-china countries in the 1990s has evidently affected the recognition decisions of foreign powers such the EU. Robles (2006: 109) explains:

The EU opposed Burmese membership of ASEAN, and when it failed to prevent Burmese accession in 1997, the EU imposed sanctions that prevented Burma from participating in ASEAN-EU cooperation activities and resulted in the cancellation in 1998 and 1999 of the AEMM [ASEAN-EU Ministerial Meeting] and the JCC [Joint Cooperation Committee], for the first time in the history of ASEAN-EC relations.

With the inclusion of Myanmar's membership, the EU had to adjust its recognition policy to appease the anti-Myanmar elements in the European parliament. Than and Than (2001: 255) observe that the ASEAN-EU interaction has been held "hostage to Myanmar's domestic political problems ... [because of] the lack of progress to break 
the (domestic) political stalemate, the harassment of pro-democracy activists, and the poor human rights record in Myamar". ASEAN, on the other, was upset by EU's discrimination against another ASEAN member state. Former ASEAN SecretaryGeneral Rodolfo Severino defended in 1997:

We feel that nobody should discriminate between ASEAN countries when it comes to dealing with ASEAN as whole. The position that the EU seems to be taking ... seems to be very highly political in nature so we just have to take a stand on it (The Straits Times, 1997: 2).

In this regard, the Southeast Asian grouping's motivations for the establishment of an ASEAN Intergovernmental Commission on Human Rights in October 2009 as stipulated in the ASEAN Charter is the second prospective research area where the application of the model for the recognition of regions will be insightful. In May 2006, EU Trade Commissioner Peter Mandelson explained that the EU "wants to strike a free-trade agreement with the Association of South-east Asian Nations, but human rights issues in Myanmar could be a problem" (Today 2006: 10). Malaysian Trade Minister Rafidah Aziz defended in response that "Myanmar's political crisis should not be used as an excuse to hold up a proposed trade pact between Europe and the Association of Southeast Asian Nations" (The Business Times 2007: 17). Notwithstanding ASEAN's protests, it is evident that the EU has adjusted the forms of its recognition toward the Southeast Asian grouping. In March 2009, EU Trade Commissioner Catherine Ashton conceded: "The process with ASEAN up to now has been very slow. We must now check how we can move forward quicker with individual countries that are prepared to do" (The Business Times 2009: 16). More importantly, the creation of the human rights 
body suggests that ASEAN is also learning to stand up to the new challenges brought about by the evolving nature of its struggle for recognition. It warrants an investigation as to how much of its push for a legal identity in the $21^{\text {st }}$ century is driven by a desire for recognition.

Finally, the third potential research area for the application of the propose model is China's recognition of ASEAN's common market by its offer to conclude a Free Trade Agreement (FTA) with the Southeast Asian grouping in 2000. It is intriguing that it was not the conclusion of the ASEAN Free Trade Area (AFTA) in 1992 which sparked off a flurry of FTA initiatives by foreign powers like Japan and Australia with ASEAN, but Chinese willingness to recognize ASEAN as a free trade zone. This highlights the importance of cumulative recognition in the growth of a regional concept like ASEAN. Cumulative recognition by foreign powers, in turn, incentivized the desire among ASEAN members to work toward promoting regional cooperation as this dissertation has shown.

As a background, the idea for an ASEAN free trade zone was mooted as far back as in 1976 during the first ASEAN Summit when the leaders made "the establishment of preferential trading arrangements" a long term objective of the association (ASEAN 1976c). Singapore Minister for Finance Hon Sui Sen had then shared with U.S. Ambassador to Singapore John Holdridge that Singapore and the Philippines were pushing strongly for the creation of an ASEAN free trade area but Indonesia was strongly opposed to the idea (U.S. Embassy in Singapore 1976j). Holdridge further reported on Hon's conviction that the "U.S. as an outside party could provide the pressure or an inducement (read 'aid') to assist movement 
toward greater economic cooperation". It was a tacit request for the U.S. to nudge the Indonesians forward on the creation of a free trade zone. Singapore was unable to push the idea any further because it would be "obvious to all that Singapore would be a prime beneficiary of any trade liberalization scheme instituted". Indonesian Foreign Minister Malik explained that Indonesia would not have objected to a free trade system, if all ASEAN countries "were on same economic level" (U.S. Embassy in Jakarta 1976i). According to Filipino Ambassador to Singapore Delphin Garcia, Singapore and Philippines were "critical of Indonesian protectionist policy for standing in way of ASEAN free trade zone" (U.S. Embassy in Singapore 1976k). Garcia felt that the "ASEAN states would be at a disadvantage in dealing with major economic powers and groupings elsewhere such as U.S., Japan, EEC and South American and South African economic unions".

In retrospect, contrary to Singapore's expectation that the U.S. had the capacity to boost ASEAN economic cooperation, it was China's recognition of ASEAN's free trade zone which triggered a competition among the foreign powers for similar agreements with the Southeast Asian grouping. Evidently, Chinese recognition of ASEAN's free trade zone has a compounded effect on other foreign powers' recognition decisions. Following on the heels of China's proposal for the creation of the ASEAN-China Free Trade Area during the ASEAN-China Summit on 6 November 2001, Japanese Prime Minister Junichiro Koizumi called for the implementation of "an Initiative for Japan-ASEAN Comprehensive Economic Partnership" in January 2002 (ASEAN 2002). This episode emphasizes the importance of cumulative recognition for ASEAN even in the $21^{\text {st }}$ century. Further, 
if this train of argument holds, the next logical inquiry is whether ASEAN's recent endeavors to create sectoral communities, especially on the political-security front, would invoke greater foreign powers' recognition for the grouping.

Together, the three investigative areas proposed in this section highlight the value of the proposed model for the recognition of regions in future studies. While not exhaustive, the good prospect of the model for further research application reinforces the transformative nature of the process of recognition.

\subsection{Recognition matters: ASEAN's centrality in the regional architecture}

This dissertation has made the case that ASEAN would not have progressed without the qualified recognition from external powers. Put simply, Australia's recognition provided material support, EEC's recognition opened up fairer access to the overseas markets, U.S. recognition gave status and prestige while Japan's recognition enabled members to realize ASEAN's potential as a regional platform to tackle their national problems. The archival exercise in this study has detected an intense struggle by ASEAN for external recognition in its socialization with the foreign powers during its formative years. The greater and deeper the quality of recognition, the more likely member states supported regional cooperation and appreciated its function as a regional tool to resolve domestic problems. The outcome of its struggle for recognition in its founding years has made ASEAN "a factor of some significance in the calculations of both regional and extra-regional states" (Leifer 1989: 140). This

is evident in the shifting recognition policies of the foreign powers toward ASEAN in the 1960-70s. In the words of Weatherbee (2009: 311), "ASEAN has forced the great 
powers to address Southeast Asia as a region in addition to their bilateral relations". Seen from another perspective, the great powers would have maintained the modus operandi of bilateral diplomacy to exert their supremacy if ASEAN had not fought for its recognition. This explains why many regional concepts, even the formalized ones, have come and gone.

This dissertation has also demonstrated the transformative nature of the process of recognition. Its success in the struggle for recognition has put ASEAN right at the center of the radar screen in Asian regional cooperation. Today, foreign powers' recognition of ASEAN has transformed beyond the Southeast Asian grouping's expectation during its formative years. As far back as in 1976, Malaysian Prime Minister Razak declared:

ASEAN is a fact of international political life and ASEAN has entered the international political vocabulary. ASEAN and the concept of Southeast Asian regionalism is central to the preoccupation of our respective governments (U.S. Embassy in Kuala Lumpur 1974f).

In 1974, Indonesian Foreign Minister Malik also warned that "ASEAN should not move towards 'broader-ranged commitments' such as larger Asian-Pacific forums until ASEAN's 'function and continuity' in any larger structure is assured" (U.S. Embassy in Jakarta 1974k). The last decade has witnessed the shift in external recognition of ASEAN away from its Southeast Asia-centered identity to a grouping that carries a far wider regional character and flavor.

Scholars like Møller (2009: 260) predict that the "future of ASEAN will depend on its ability to define a role inside a larger and more powerful East Asian or Asian 
economic body". The often repeated buzzword in the $21^{\text {st }}$ century to describe ASEAN has been its centrality or leading role in the "driver's seat" in regional cooperation. Some commentators now describe the "ASEAN leverage" as the fact that "there can be no East Asian regionalism without ASEAN's participation" (Arase 2010: 815). Fast forward into the new century, it is significant that all the foreign powers covered in this dissertation have at least given their verbal recognition for the centrality of ASEAN in the evolving architecture in the region. The Fourteen ASEAN-China Summit on 18 November 2011 declared: "China reaffirms its continued support for ASEAN's centrality in the evolving regional architecture" (ASEAN 2011a). The Nineteen ASEAN-EU Joint Cooperation Committee Meeting on 12 November 2011 affirmed EU's "support for ASEAN centrality in the evolving regional architecture" (ASEAN 2011b). The Fifteen Anniversary of the ASEAN-Russia Dialogue Partnership on 22 July 2011 announced Russia's continued "support for maintaining ASEAN centrality in the evolving regional architecture" (ASEAN 2011c). The Twelve ASEAN Plus Three Foreign Ministers on 21 July 2011 pledged their "support for ASEAN centrality in the evolving regional architecture" (ASEAN 2011d). The list goes on. It is no coincidence that these verbal expressions of recognition (which are not exhaustive) were couched in the same language and were made in 2011. They marked the beginning of a new phase in ASEAN's struggle for recognition. It remains to be seen if these voices of support will be followed by concrete acts of recognition affirming the central role of ASEAN in the regional architecture.

While the forms of recognition have evolved over time, the substance or motivations driving the struggle for recognition in ASEAN remains the same. Terada (2003: 273) points out that a "major impediment to the creation of an East Asian community is 
ASEAN's fear to be possibly marginalized within the community". Present day ASEAN has shown that the grouping has made substantial inroads in its new struggle for external recognition by calling for foreign powers to respect its central and wider role in the evolving regional architecture. More recently, Leifer (2009: 220) explains that ASEAN is "an acceptable interlocutor to all the major regional powers" but fails to point out that this recognition did not happen by chance. Through its tenacity in the struggle for recognition, ASEAN has succeeded to transform its fear of being marginalized into its strength. It is for this reason that Thai Foreign Minister Thanat (1992: xxi), one of the founding fathers of ASEAN, affirms that "ASEAN should continue to build upon the prestige and recognition that the outside world has accorded it”. It reinforces Hammer's (2007: 29) argument that recognition maintains an important conferring status within the international realm to the extent that states [and regions as this dissertation has shown] seek recognition (if denied) or use recognition for their own political and policy goals.

Recognition matters to ASEAN. This point was reiterated by the foreign ministers at the $11^{\text {th }}$ ASEAN Ministerial Meeting in June 1978 who welcomed the intention of the EEC and the United States to cooperate with ASEAN in further promoting the common interests that ASEAN shares with these two Dialogue partners. They also welcomed the interest shown by the EEC and the United States in supporting the growth and development of ASEAN as a viable and dynamic regional grouping of developing nations (ASEAN 1978).

It is also evident from U.S. Ambassador to Indonesia Newsom's confession to Indonesian Foreign Minister Malik on 21 May 1975 that the former was "frequently 
asked in Indonesia whether U.S. supports ASEAN" (U.S. Embassy in Jakarta 1975I). ASEAN's relations with the U.S., Japan and the EEC, as well as several other foreign powers, were formalized in 1977, a year after its institutionalization. When the ASEAN-U.S. consultation finally took place in September 1977, U.S. UnderSecretary of State for Economic Affairs Richard Cooper, on his arrival in Manila for the inaugural dialogue, affirmed that the purpose of meeting ASEAN "is not to quantify anything but rather to recognize the importance of ASEAN as an emerging regional unit" (The Straits Times 1977b: 32). This dissertation has shown that an intense struggle for the recognition of ASEAN was already taking place before these official links were established, and why it continues to matter even now. 


\section{Reference}

Acharya, A., 2009. Constructing a security community in Southeast Asia: ASEAN and the problem of regional order. New York: Routledge.

Amnesty International, 2008. The ASEAN charter and human rights: Windows of opportunity or window dressing? [Online]. Available at: http://www.amnesty.org/en/library/asset/ASA03/003/2008/en/384b86ba-439311dd-a1d1-2fa8cc41ebbd/asa030032008eng.pdf [Assessed on 8 January 2012].

Arase, D., 2010. Non-traditional security in China-ASEAN cooperation: The institutionalization of regional security cooperation and the evolution of East Asian regionalism, Asian Survey, 50(4), 808-833.

Asahi Shimbun, 1974. Southeast Asian nations expect Japan to play political role more positively. Asahi Shimbun, 24 April, 2.

Association of Southeast Asian Nations (ASEAN), 1971. Zone of peace, freedom and neutrality declaration. [Online]. Available at: http://www.aseansec.org/1215.htm [Accessed on 2 January 2011].

ASEAN, 1972. Joint communique of the fifth ASEAN ministerial meeting. [Online]. Available at: http://www.aseansec.org/1235.htm [Accessed on 13 December 2010].

ASEAN, 1973a. Joint communiqué of the sixth ASEAN ministerial meeting. [Online]. Available at: http://www.aseansec.org/1236.htm [Accessed on 13 December 2010].

ASEAN, 1973b. ASEAN declaration on the Arab-Israel conflict. [Online]. Available at: http://www.aseansec.org/1613.htm [Assessed on 8 January 2012].

ASEAN, 1974a. Joint communiqué of the seventh ASEAN ministerial meeting. [Online]. Available at http://www.aseansec.org/1237.htm [Accessed on 2 January 2011].

ASEAN, 1974b. Joint statement informal meeting of the ASEAN minister and vice president and commissioner of the EC-Commission. [Online]. Available at: http://www.aseansec.org/1514.htm [Accessed on 30 January 2010].

ASEAN, 1976a. Joint communiqué of the ninth ASEAN ministerial meeting. [Online]. Available at: http://www.aseansec.org/1239.htm [Accessed on 2 January 
2011].

ASEAN, 1976b. Joint press statement: The $2^{\text {nd }}$ ASEAN economic ministers meeting. [Online]. Available at: http://www.aseansec.org/1285.htm [Accessed on 2 January 2011].

ASEAN, 1976c. Joint communique of the first ASEAN heads of government. [Online]. Available at: http://www.aseansec.org/1223.htm [Assessed on 8 January 2012].

ASEAN, 1978. Joint press release of the eleventh ASEAN ministerial meeting. [Online]. Available at: http://www.aseansec.org/1241.htm [Accessed on 2 January 2011].

ASEAN, 1980. Coooperation agreement between member countries of ASEAN and European Community. [Online]. Available at: http://www.aseansec.org/1501.htm [Accessed on 1 March 2011].

ASEAN, 2002. ASEAN in East Asia - A sincere and open partnership. [Online]. Available at: http://www.asean.org/2802.htm [Accessed on 3 January 2012].

ASEAN, 2011a. Joint statement of the $14^{\text {th }}$ ASEAN-China summit to commemorate the $20^{\text {th }}$ anniversary of dialogue relations. [Online]. Available at: http://www.aseansec.org/26739.htm [Accessed on 8 January 2012].

ASEAN, 2011b. 19 ${ }^{\text {th }}$ ASEAN-EU joint co-operation committee (JCC) meeting convenes in Bali. [Online]. Available at: http://www.aseansec.org/26722.htm [Accessed on 8 January 2012].

ASEAN, 2011c. Joint statement of the ministers of foreign affairs of the Association of Southeast Asian Nations and the Russia Federation on the occasion of the $15^{\text {th }}$ anniversary of the ASEAN-Russia dialogue partner. [Online]. Available at: http://www.asean.org/documents/44thAMM-PMC-18thARF/ASEAN-RussiaJS.pdf [Accessed on 8 January 2012].

ASEAN, 2011d. Chairman's statement of the $12^{\text {th }}$ ASEAN plus three foreign ministers' meeting. [Online]. Available at: http://www.aseansec.org/20406.htm [Accessed on 8 January 2012].

Australian Department of External Affairs, 1967a. ASPAC. Telegrams to various embassies, A1838, 3004/13/21 Part 2, 29 August. Canberra: National Archives of Australia (NAA).

Australian Department of External Affairs, 1967b. Regional co-operation in South 262 
East Asia. A1838, 3004/13/21 Part 2, 9 August. Canberra: NAA.

Australian Department of External Affairs, 1967c. Association of South East Asian Nations (ASEAN). Telegram to various embassies, A1838, 3004/13/21 Part 2, 5 September. Canberra: NAA.

Australian Department of External Affairs, 1967d. A.S.E.A.N. Telegram to various embassies, A1838, 3004/13/21 Part 2, 9 August. Canberra: NAA.

Australian Department of External Affairs, 1967e. ASPAC. Telegram to various embassies, A1838, 3004/13/21 Part 2, 14 July. Canberra: NAA.

Australian Department of External Affairs, 1967f. Regional co-operation in South East Asia. Telegram to various embassies, A1838, 3004/13/21 Part 2, 9 August. Canberra: NAA.

Australian Department of External Affairs, 1968a. Record of discussions between the foreign minister of Cambodia, His Highness Prince Norodom Phurissara, and the minister for external affairs of Australia. A1838, 3004/13/21 Part 6, 21 February. Canberra: NAA.

Australian Department of External Affairs, 1968b. Current Soviet approach to South East Asia. Telegram to various embassies, A1838, 3004/13/21 Part 6, 21 May. Canberra: NAA.

Australian Department of External Affairs, 1968c. The Association of South-East Asian Nations (ASEAN). Telegram to various embassies, A4359, 3004/13/21 Part 2, 8 April. Canberra: NAA.

Australian Department of External Affairs, 1968d. ASEAN, regional security. Telegrams to various embassies, A1838, 3004/13/21 Part 6, 7 March. Canberra: NAA.

Australian Department of External Affairs, 1968e. Asian and Pacific Council (ASPAC). Telegram to Governor-General of the Commonwealth of Australia, A1838, 3004/13/21 Part 8, 15 November. Canberra: NAA.

Australian Department of External Affairs, 1969a. Australian membership of ASEAN. A1838, 3004/13/21 Part 10, 17 December. Canberra: NAA.

Australian Department of External Affairs, 1969b. Regional security in South East Asia. A1838, 3004/13/21 Part 9. Canberra: NAA.

Australian Department of External Affairs, 1970a. The Association of South-East Asian Nations (ASEAN), A1838, 3004/13/21 Part 11, 2 February. Canberra: 
NAA.

Australian Department of External Affairs, 1970b. ASEAN: Question of Australia's membership. Telegram to various embassies, A9564, 221/4/16, 27 January. Canberra: NAA.

Australian Department of External Affairs, 1971a. Neutralization of Southeast Asia. A1838, 3107/36/9 Part 1, 16 December. Canberra: NAA.

Australian Department of External Affairs, 1971b. Malaysian prime minister visits Indonesia. A1838, 3004/13/21 Part 11. Canberra: NAA.

Australian Department of External Affairs, 1971c. Meeting of ASEAN foreign ministers. Telegram to various embassies, A1838, 3107/36/9 Part 1, 2 December. Canberra: NAA.

Australian Department of External Affairs, 1971d. 678 secret priority. Telegram to Australian Embassy in Cairo, A1838, 3107/36/9 Part 1, 30 November. Canberra: NAA.

Australian Department of External Affairs, 1973a. ASEAN. Telegram to Australian embassies in Moscow and Beijing, A1838, 3002/25 Part 20, 10 July. Canberra: NAA.

Australian Department of External Affairs, 1973b. China and the ASEAN nations. A1838, 3107/36/9 Part 2. Canberra: NAA.

Australian Department of External Affairs, 1973c. Proposal for neutralization and the establishment of a zone of peace, freedom and neutrality in South East Asia prospects and possible implications including possible effects of regional associations, basing arrangements etc. Telegram to Australian Department of External Affairs, A1838, 3002/25 Part 20. Canberra: NAA.

Australian Department of External Affairs, 1973d. ASEAN. A1838, 3103/9/3/7 Part 1. Canberra: NAA.

Australian Department of External Affairs, 1973e. Australian foreign policy: New regional political association. Telegram to various embassies, A1838, 3002/25 Part 20, 5 April. Canberra: NAA.

Australian Department of External Affairs, 1973f. Regional organizations. A1838, 696/1/5/4 Part 1, 22 February. Canberra: NAA.

Australian Department of External Affairs, 1973g. Regional co-operation: Remarks by Mr Kirk. Telegram to Australian High Commission in Wellington, A1838, 
696/1/5/4 Part 1, 7 February. Canberra: NAA.

Australian Department of External Affairs, 1973h. Regional arrangements ASEAN. A1838, 696/1/5/4 Part 1, 26 February. Canberra: NAA.

Australian Department of External Affairs, 1973i. Possible Australian economic assistance to ASEAN; proposed meeting of this; Japan. A1838, 3103/9/3/7 Part 1, 26 September. Canberra: NAA.

Australian Department of External Affairs, 1973j. Item 11: Regional cooperation in the Asia/Pacific area. A1838, 3103/9/3/7 Part 1. Canberra: NAA.

Australian Department of External Affairs, 1974a. Record of conversation with $\mathrm{Mr}$ Yusoff Ariff, ASEAN Secretary-General, Malaysian Ministry of Foreign Affairs. A1838, 3103/9/3/7 Part 1, 18 April. Canberra: NAA.

Australian Department of External Affairs, 1974b. ASEAN-Australia cooperation. A10463, 901/3/1 Part 8, 31 January. Canberra: NAA.

Australian Embassy in Bangkok, 1967. ASEAN - Soviet comment. Telegram to Australian Department of External Affairs, A1838, 3004/13/21 Part 3, 29 August. Canberra: NAA.

Australian Embassy in Bangkok, 1968. Ministerial conference - Bangkok. Telegram to Australian Department of External Affairs, A1838, 3004/13/21 Part 8, 29 November. Canberra: NAA.

Australian Embassy in Bangkok, 1970. President of board of trade's views on Thailand's trading problems. Telegram to Australian Department of External Affairs, A1838, 3004/13/21 Part 11, 3 Feburary. Canberra: NAA.

Australian Embassy in Bangkok, 1972. Future of ASEAN and ASPAC. Telegram to Australian Department of External Affairs, A1838, 3130/9/3/7 Part 1, 28 October. Canberra: NAA.

Australian Embassy in Bangkok, 1973a. From minister of defence. Telegram to Australian Department of External Affairs, A1838, 696/1/5/4 Part 1, 24 March. Canberra: NAA.

Australian Embassy in Bangkok, 1973b. Ministerial conference for economic development in Southeast Asia. Telegram to Australian Department of External Affairs, A1838, 3103/9/3/7 Part 1, 10 July. Canberra: NAA.

Australian Embassy in Bangkok, 1973c. ASEAN. Telegram to Australian Department of External Affairs, A1838, 3103/9/3/7 Part 1, 5 November. Canberra: NAA. 
Australian Embassy in Bangkok, 1973d. 191715 LT. Telegram to Australian Department of External Affairs, A10463, 901/3/1 Part 8, 20 December. Canberra: NAA.

Australian Embassy in Beijing, 1973. Meeting with Premier Chou En-lai. Telegram to Australian Department of External Affairs, A1838, 696/1/5/4 Part 1, 12 May. Canberra: NAA.

Australian Embassy in Jakarta, 1967a. South East Asian association for regional cooperation. Telegram to Australian Department of External Affairs, A4359, 221/5/22 Part 3, 3 May. Canberra: NAA.

Australian Embassy in Jakarta, 1967b. Asean. Telegram to Australian Department of External Affairs, A1838, 3004/13/21 Part 2, 23 August. Canberra: NAA.

Australian Embassy in Jakarta, 1967c. Foreign minister's press conferences ASEAN, Vietnam, China and Taiwan. Telegram to Australian Department of External Affairs, A1838, 3004/13/21 Part 3, 1 September. Canberra: NAA.

Australian Embassy in Jakarta, 1968a. South East Asian ministerial conference on economic development. Telegram to Australian Department of External Affairs, A1838, 3004/13/21 Part 6, 18 April. Canberra: NAA.

Australian Embassy in Jakarta, 1968b. Soeharto on defence problems. Telegram to Australian Department of External Affairs, A1838, 3004/13/21 Part 3, 26 January. Canberra: NAA.

Australian Embassy in Jakarta, 1969a. ASPAC. Telegram to Australian Department of External Affairs, A1838, 3004/13/21 Part 9, 18 July. Canberra: NAA.

Australian Embassy in Jakarta, 1969b. Indonesia's attitude to ASPAC. Telegram to Australian Department of External Affairs, A1838, 3004/13/21 Part 9, 20 April. Canberra: NAA.

Australian Embassy in Jakarta, 1971a. ASEAN. Telegram to Australian Department of External Affairs, A4359, 221/5/22 Part 5, 26 March. Canberra: NAA.

Australian Embassy in Jakarta, 1971b. ASEAN approach to EEC. Telegram to Australian Department of External Affairs, A4359, 221/5/22 Part 5, 7 December. Canberra: NAA.

Australian Embassy in Jakarta, 1972. ASEAN and recognition of the PRC. Telegram to Australian Department of External Affairs, A1838, 3107/26/9 Part 2, 20 July. Canberra: NAA. 
Australian Embassy in Jakarta, 1973a. ASEAN: China policy: internal situation. Telegram to Australian Department of External Affairs, A1838, 3107/36/9 Part 2, 15 February. Canberra: NAA.

Australian Embassy in Jakarta, 1973b. Japan and ASEAN. Telegram to Australian Department of External Affairs, A10463, 901/3/1 Part 8, 21 August. Canberra: NAA.

Australian Embassy in Jakarta, 1973c. ASEAN officials meeting: Jakarta. Telegram to Australian Department of External Affairs, A10463, 901/3/1 Part 8, 20 July. Canberra: NAA.

Australian Embassy in Jakarta, 1974a. ASEAN. Telegram to Australian Department of External Affairs, A10463, 901/3/1 Part 8, 27 May. Canberra: NAA.

Australian Embassy in Jakarta, 1974b. Seventh ASEAN ministerial meeting: Jakarta 7-9 May 1974. Telegram to Australian Department of External Affairs, A10463, 901/3/1 Part 8, 17 May. Canberra: NAA.

Australian Embassy in Manila, 1969. Press release from the Department of Foreign Affairs, Philippines. Telegram to Australian Department of External Affairs, A1838, 3004/13/21 Part 9, 14 August. Canberra: NAA.

Australian Embassy in Manila, 1971. Meeting of ASEAN foreign ministers. Telegram to Australian Department of External Affairs, A1838, 3107/36/9 Part 1, 6 December. Canberra: NAA.

Australian Embassy in Manila, 1973. ASEAN. Telegram to Australian Department of External Affairs, A10463, 901/3/1 Part 8, 2 August. Canberra: NAA.

Australian Embassy in Moscow, 1967. Soviet comment on South East Asia, A.S.E.A.N. Telegram to Australian Department of External Affairs, A1838, 3004/13/21 Part 3, 19 September. Canberra: NAA.

Australian Embassy in Moscow, 1968. 743 confidential. Telegram to Australian Department of External Affairs, A1838, 3004/13/21 Part 8, 12 December. Canberra: NAA.

Australian Embassy in Moscow, 1969. Meeting with Kuznetsov. Telegram to Australian Department of External Affairs, A1838, 3004/13/21 Part 9, 9 May. Canberra: NAA.

Australian Embassy in Moscow, 1973. Australia-Soviet relations. Telegram to Australian Department of External Affairs, A1838, 696/1/5/4 Part 9, 26 April. 
Canberra: NAA.

Australian Embassy in Saigon, 1969. ASEAN. Telegram to Australian Department of External Affairs, A1838, 3004/13/21 Part 11, 24 December. Canberra: NAA.

Australian Embassy in Tokyo, 1968a. Political savingram report no. 16/68 for the period $3^{\text {rd }}$ August to 16 August, 1968. Telegram to Australian Department of External Affairs, A1838, 3004/13/21 Part 7, 16 August. Canberra: NAA.

Australian Embassy in Tokyo, 1968b. ASPAC. Telegram to Australian Department of External Affairs, A1838, 3004/13/21 Part 8, 29 October. Canberra: NAA.

Australian Embassy in Tokyo, 1971a. ASEAN foreign ministers meeting: Japan.

Telegram to Australian Department of External Affairs, A1838, 3107/36/9 Part 1, 3 December. Canberra: NAA.

Australian Embassy in Tokyo, 1971b. Notes of conversation with Mr Shinsaku Hogen, Deputy Vice-Minister, Ministry of Foreign Affairs, Tokyo. Telegram to Australian Department of External Affairs, A1838, 3107/36/9 Part 1, 6 December. Canberra: NAA.

Australian Embassy in Tokyo, 1972. Japan: Asian regional organizations. Telegram to Australian Department of External Affairs, A1838, 3002/25 Part 20, 7 November. Canberra: NAA.

Australian Embassy in Tokyo, 1973a. ASEAN. Telegram to Australian Department of External Affairs, A1838, 3103/9/3/7 Part 1, 6 November. Canberra: NAA.

Australian Embassy in Tokyo, 1973b. Japan/ASEAN: Rubber meeting. Telegram to Australian Department of External Affairs, A1838, 3103/9/3/7 Part 1, 1 December. Canberra: NAA.

Australian Embassy in Tokyo, 1973c. Record of conversation. Telegram to Australian Department of External Affairs, A1838, 3103/9/3/7 Part 1, 29 October. Canberra: NAA.

Australian Embassy in Tokyo, 1974. Japan/ASEAN: Rubber talks. Telegram to Australian Department of External Affairs, A1838, 3103/9/3/7 Part 1, 27 March. Canberra: NAA.

Australian Embassy in Washington, 1967. ASEAN. Telegram to Australian Department of External Affairs, A1838, 3004/13/21 Part 2, 17 August. Canberra: NAA.

Australian Embassy in Washington, 1969. SEATO: Secretary-General's proposal. 
Telegram to Australian Department of External Affairs, A1838, 3004/13/21 Part 9, 13 May. Canberra: NAA.

Australian High Commission in Kuala Lumpur, 1967a. ASA foreign ministers' meeting. Telegram to Australian Department of External Affairs, A1838, 3004/13/21 Part 2, 30 August. Canberra: NAA.

Australian High Commission in Kuala Lumpur, 1967b. Malaysia weekly political savingram. Telegram to Australian Department of External Affairs, A1838, 3004/13/21 Part 3, 29 September. Canberra: NAA.

Australian High Commission in Kuala Lumpur, 1968a. ASEAN. Telegram to Australian Department of External Affairs, A1838, 3004/13/21 Part 6, 8 March. Canberra: NAA.

Australian High Commission in Kuala Lumpur, 1968b. Malaysia - regional cooperation. Telegram to Australian Department of External Affairs, A1838, 3004/13/21 Part 7, 25 July. Canberra: NAA.

Australian High Commission in Kuala Lumpur, 1968c. Malaysia: ASPAC. A1838, 3004/13/21 Part 6, 9 February. Canberra: NAA.

Australian High Commission in Kuala Lumpur, 1968d. Malaysia: Regional security. Telegram to Australian Department of External Affairs, A1838, 3004/13/21 Part 6, 3 February. Canberra: NAA.

Australian High Commission in Kuala Lumpur, 1969a. JIC paper no.6/1969: Developments in Malaysia and Singapore up to 1975 - Malaysia and ASPAC. Telegram to Australian Department of External Affairs, A1838, 3004/13/21 Part 9, 22 August. Canberra: NAA.

Australian High Commission in Kuala Lumpur, 1969b. ASEAN meeting: Vietnam and Singapore; views of Mr Rajaratnam. Telegram to Australian Department of External Affairs, A1838, 3004/13/21 Part 11, 19 December. Canberra: NAA.

Australian High Commission in Kuala Lumpur, 1971a. Record of conversation with Enche Azzat Kamaluddin, Assistant Secretary, Economic and Regional Cooperation, Ministry of Foreign Affairs. Telegram to Australian Department of External Affairs, A4359, 221/5/22 Part 5, 23 August. Canberra: NAA.

Australian High Commission in Kuala Lumpur, 1971b. 3324 confidential priority. Telegram to Australian Department of External Affairs, A1838, 3107/36/9 Part 1, 27 November. Canberra: NAA. 
Australian High Commission in Kuala Lumpur, 1972. Malaysia - relations with PRC. Telegram to Australian Department of External Affairs, A1838, 3107/36/9 Part 1, 21 March. Canberra: NAA.

Australian High Commission in Kuala Lumpur, 1973. ASEAN. Telegram to Australian Department of External Affairs, A1838, 696/1/5/4 Part 1, 25 June. Canberra: NAA.

Australian High Commission in Kuala Lumpur, 1974a. Information meeting in Asia. Telegram to Australian Department of External Affairs, A10463, 901/3/1 Part 8, 14 June. Canberra: NAA.

Australian High Commission in Kuala Lumpur, 1974b. The information report with regard to ASEAN. Telegram to Australian Department of External Affairs, A10463, 901/3/1 Part 8, 3 July. Canberra: NAA.

Australian High Commission in Kuala Lumpur, 1974c. ASEAN-Japan synthetic rubber negotiations. Telegram to Australian Department of External Affairs, A1838, 3103/9/3/7 Part 1, 1 April. Canberra: NAA.

Australian High Commission in New Delhi, 1967. Indian participation in Asian regional economic or other associations. Telegram to Australian Department of External Affairs, A4359, 221/5/22 Part 2, 1 September. Canberra: NAA.

Australian High Commission in New Delhi, 1968a. Indian and regional economic cooperation: South-East Asia development conference. Telegram to Australian Department of External Affairs, A1838, 3004/13/21 Part 6, 29 January. Canberra: NAA.

Australian High Commission in New Delhi, 1968b. Conference of Indian heads of mission from Asia: Indian attitudes to - China, defence arrangements, Soviet Union. Telegram to Australian Department of External Affairs, A1838, 3004/13/21 Part 8, 18 December. Canberra: NAA.

Australian High Commission in Singapore, 1968. Third ministerial conference for economic development of South-East Asia. Telegram to Australian Department of External Affairs, A1838, 3004/13/21 Part 6, 13 April. Canberra: NAA.

Australian High Commission in Singapore, 1972. ASEAN and China. Telegram to Australian Department of External Affairs, A1838, 3107/36/9 Part 1, 21 March. Canberra: NAA. 
Australian Representative to the European Communities, 1974. European Communities: ASEAN. Telegram to Australian Department of External Affairs, A10463, 901/3/1 Part 8, 4 July. Canberra: NAA.

Ba, A., 2009. [Re]negotiating East and Southeast Asia: Region, regionalism, and the Association of Southeast Asian Nations. California: Stanford University Press.

Barkin, J. S., and Cronin, B., 1994. The state and the nation: Changing norms and the rules of sovereignty in international relations, International Organization, 48(1), 107-130.

Beeson, M., 2007. Regionalism \& globalization in East Asia. New York: Palgrave Macmillan.

Blum, L., 1998. Recognition, value, and equality: A critique of Charles Taylor's and Nancy Fraser's accounts of multiculturalism. In: C. Willett, ed. Theorizing multiculturalism: A guide to the current debate. Oxford: Blackwell Publishers Ltd, 73-99.

Bocek, B. A., 2005. International law: A dictionary. Maryland: Scarecrow Press.

Bourne, C. B., 1978. Canadian Yearbook of International Law: Volume 16. Vancouver: University of British Columbia Press.

Breslin, S. and Higgott, R., 2000. Studying regions: Learning from the old, constructing the new, New Political Economy, 5(3), 333-352.

Briggs, H. W., 1949. Recognition of states: Some reflections on doctrine and practice, American Journal of International Law, 43(1), 113-121.

Caballero-Anthony, M., 2005. Regional security in Southeast Asia: Beyond the ASEAN way. Singapore: Institute of Southeast Asian Studies.

Chia, S. Y., 1988. China's economic relations with ASEAN countries. In: K. Joyce et al., eds. ASEAN and China: An evolving relationship. California: Institute of East Asian Studies, University of California, 189-214.

Crawford, J., 2006. The creation of states in international law. Oxford: Oxford University Press.

Dent, C., 2008. East Asian regionalism. Oxon: Routledge.

Deustch, K. W. et al., 1957. Political community in the North Atlantic area. In: K. W. Deustch et al., eds. The European Union: Readings in the theory and practice of European integration. Boulder, Col.: Lynn Rienner, 1998.

Dewi Anwar, F., 1994. Indonesia in ASEAN: Foreign policy and regionalism. 
Singapore: Institute of Southeast Asian Studies.

Dowse, R., and Hughes, J. A., 1979. Political sociology. Kent: John Wiley \& Sons.

Dyde, S. W., 1896. Hegel's philosophy of right. London: George Bell and Sons.

Eaton, S., and Stubbs, R., 2009. Is ASEAN powerful? Neo-realist versus constructivist approaches to power in Southeast Asia. In: A. Acharya and R. Stubbs, eds. Theorizing Southeast Asian relations: Emerging debates. Oxon: Routledge, 11-30.

European Union, 2012. The European Union and the United States: Global partners, global responsibilities. [Online]. Available at: http://www.eurunion.org/partner/euusrelations/EUUSGlobParts.pdf [Assessed on 6 January 2012].

Fraser, N., 1998. From redistribution to recognition? Dilemmas of justice in a "postsocialist" age. In: C. Willett, ed. Theorizing multiculturalism: A guide to the current debate. Oxford: Blackwell Publishers Ltd, 19-49.

Fraser, N., 2003. Social justice in the age of identity politics: Redistribution, recognition, and participation. In: N. Fraser and A. Honneth, eds. Redistribution or recognition? A political-philosophical exchange. London: Verson, 7-109.

Garofano, J., 2002. Power, institutions and the ASEAN Regional Forum: A security community for Asia?, Asian Survey, 42(3), 501-521.

Hamanaka, S., 2009. Asian regionalism and Japan. New York: Routledge.

Hammer, L. M., 2007. A Foucauldian approach to international law: Descriptive thoughts for normative issues. Hamsphire: Ashgate Publishing Limited.

Harris, S., and Bridges, B, 1983. European interests in ASEAN. London: Routledge \& Kegan Paul Ltd.

Hazareesingh, S., and Nabulsi, K., 2008. Using archival sources to theorize about politics. In: D. Leopold and M. Stears, eds. Political theory: Methods \& approaches. New York: Oxford University Press, 150-170.

Higgott, R., and Stubbs, R., 1995. Competing conceptions of economic regionalism: APEC versus EAEC in the Asia Pacific, Review of International Political Economy, 2(3), 516-535.

Honneth, A., 1995. The struggle for recognition: The moral grammar of social conflicts. Cambridge: Polity Press. 
Honneth, A., 2007. Recognition as ideology. In: B. Van Den Brink and D. Owen, eds. Recognition and power: Axel Honneth and the tradition of critical social theory. New York: Cambridge University Press, 323-347.

Ikema, M., 1980. Japan's economic relations with ASEAN. In: R. Garnaut, ed. ASEAN in a changing Pacific and world economy. Canberra: Australian National University Press, 453-473.

Jaffe, L., 1933. Judicial aspects of foreign relations in particular of the recognition of foreign powers. Cambridge: Harvard University Press.

Jones, D. M., and Smith, M. L. R., 2006. ASEAN and East Asian international relations. Cheltenham: Edward Elgar Publishing Limited.

Jönsson, C., and Hall, M., 2005. Essence of diplomacy. New York: Palgrave Macmillan.

Kelsen, H., 1941. Recognition in international law: Theoretical observations, American Journal of International Law, 35(4), 605-617.

Kenny, M., 2004. The politics of identity: Liberal political theory and the dilemmas of difference. Cambridge: Polity Press.

Kesavan, K. V., 1981. ASEAN, Japan and the EEC. In: K. B. Lall and H. S. Chopra, eds. The EEC and the third world. New Delhi: Radiant Publishers, 255-264.

Khaw, G. H., 1992. The evolution of ASEAN, 1967-75. In: K. S. Sandu et al., eds. The ASEAN reader. Singapore: Institute of Southeast Asian Studies, 38-42.

Koehane, R., 1984. After hegemony: Cooperation and discord in the world political economy. New Jersey: Princeton University Press.

Koehane, R., 1998. International institutions: Can interdependence work?, Foreign Policy, 110(Spring), 82-96.

Koehane, R., and Nye, J., 2001. Power and interdependence. New York: Longman.

Kurki, M., 2008. Causation in international relations: Reclaiming causal analysis. New York: Cambridge University Press.

Lauterpacht, E., 1975. International law, being the collected papers of Hersch Lauterpacht. Cambridge: Cambridge University Press.

Leifer, M., 1989. ASEAN and the security of South-east Asia. London: Routledge.

Leifer, M., 2009. The ASEAN Regional Forum. In: S. S. Tan, ed. Regionalism in Asia: Critical issues in modern politics. Oxon: Routledge, 201-252.

Levine, D., 2008. Welfare, right, and the state: A framework for thinking. Oxon: 
Routledge.

Manalo, G. R., 2010. Drafting ASEAN's tomorrow: The Eminent Persons Group and the ASEAN charter. In: T. Koh et al., eds. The Making of the ASEAN Charter. Singapore: World Scientific Publishing, 37-46.

Mearsheimer, J. J., 1994. The false promise of international institutions, International Security, 19(3), 45-49.

Møller, J. Ø., 2009. Political economy in a globalized world. Singapore: World Scientific Publishing.

Moller, K., 1998. Cambodia and Myanmar: The ASEAN way ends here, Asian Survey, 38(12), 1087-1104.

Morris, G., 1887. Hegel's philosophy of the state and of history: An exposition. Chicago: S. C. Griggs and Company.

Narine, S., 1997. ASEAN and the ARF: The limits of the "ASEAN way", Asian Survey, 37(10), 961-978.

Narine, S., 2002. Explaining ASEAN: Regionalism in Southeast Asia. Colorado: Lynne Rienner Publishers.

National Archives and Records Administration (NARA), 2011a. What is the national archives? [Online]. Available at: http://www.archives.gov/about/ [Accessed on 9 August 2011].

NARA, 2011b. Series description [Online]. Available at: http://aad.archives.gov/aad/series-description.jsp?s=4073\&cat=all\&bc=s| [Accessed on 9 August 2011].

New Zealand High Commission in Singapore, 1968. Singapore and ASEAN. Telegram to New Zealand Department of External Affairs, A1838, 3004/13/21 Part 7, 15 August. Canberra: NAA.

Ong, K. Y., 2010. At close quarters with the drafting of the ASEAN charter. In: T. Koh et al., eds. The making of the ASEAN charter. Singapore: World Scientific Publishing, 107-115.

Oppenheim, L., 1955. International law: A treatise. New York: Longmans, Green and Co.

Oxford Dictionaries, 2011. Recognition. [Online]. Available at: http://oxforddictionaries.com/definition/recognition [Accessed on 1 September 2011]. 
Patel, S. R., 1959. Recognition in the law of nations. Bombay: N. M. Tripathi Private Ltd.

Peterson, M. J., 1997. Recognition of government: Legal doctrine and state practice: 1815-1995. London: Macmillan Press Ltd.

Raic, D., 2002. Statehood and the law of self-determination. The Hague: Kluwer Law International.

Ravenhill, J., 2009. A three bloc world? The new East Asian regionalism. In: S. S. Tan, ed. Regionalism in Asia: Critical issues in modern politics. Oxon: Routledge, 88-115.

Robles, A. C., 2004. The political economy of interregional relations: ASEAN and the EU. Burlington: Ashgate Publishing Company.

Robles, A. C., 2006. The Association of Southeast Asian Nations (ASEAN) and the European Union: Limited regionalism. In: $H$. Hänggi et al., eds. Interregionalism and international relations. Oxon: Routledge, 97-112.

Seyersted, F., 2008. Common Law of International Organizations. Leiden: Koninklijke Brill NV.

Shee, P. K., 1977. A decade of ASEAN, 1967-1977, Asian Survey, 17(6), 753-770.

Simon, S., 1995. Realism and neoliberalism: International relations theory and Southeast Asian security, The Pacific Review, 8(1), 5-24.

Snyder, G., 1997. Alliance politics. New York: Cornell University.

Sours, M. H., 1981. ASEAN and U.S. foreign policy. In: J. C. Hsiung and W. Chai, eds. Asia and U.S. foreign policy. New York: Praeger Publishers, 173-190.

Sudo, S., 1992. The Fukuda doctrine and ASEAN. Singapore: Institute of Southeast Asian Studies.

Tan, S. S., 2009. Rescuing constructivism from the constructivists. In: A. Acharya and R. Stubbs, eds. Theorizing Southeast Asian relations: Emerging debates. Oxon: Routledge, 109-129.

Tarling, N., 2006. Regionalism in Southeast Asia. Oxon: Routledge.

Taylor, C., 1992. The politics of recognition. In: A. Gutmann, ed. Multiculturalism and the politics of recognition: An essay by Charles Taylor. Princeton: Princeton University Press, 25-73.

Terada, T., 1998. The origins of Japan's APEC policy: Foreign Minister Takeo Miki's Asia-Pacific policy and current implications, The Pacific Review, 11(3), 337- 
363.

Terada, T., 2000. Directional leadership in institution-building: Japan's approaches to ASEAN in the establishment of PECC and APEC, The Pacific Review, 14(2), 195-220.

Terada, T., 2003. Constructing an 'East Asian' concept and growing regional identity: From EAEC to ASEAN+3, The Pacific Review, 16(2), 251-277.

Than, T. M. M., and Than, M., 2001. ASEAN enlargement and Mynamar. In: M. Than and C. L. Gates, eds. ASEAN enlargement: Impacts and implications. Singapore: Institute of Southeast Asian Studies, 249-261.

Thanat, K., 1986. ASEAN in a regional and global context. In: K. D. Jackson et al., eds. ASEAN in regional and global context. Berkeley: Institute of East Asian Studies, University of California, 9-14.

Thanat, K., 1992. ASEAN: Conception and evolution. In: K. S. Sandu et al., eds. The ASEAN reader. Singapore: Institute of Southeast Asian Studies, xvii-xxii.

The Business Times, 2007. Myanmar should not affect FTA talks. The Business Times. 31 October, 17.

The Business Times, 2009. EU set to change S-E Asian trade policy. The Business Times, 21 March, 16.

The New York Times, 2010. U.S. expands role of diplomats in spying. The New York Times, 28 November, A1.

The Straits Times, 1973a. How oil cut will hit S'pore industry. The Strait Times. 17 December, 15.

The Straits Times, 1973b. Arab stand gets Asean backing. The Strait Times. 1 December, 2.

The Straits Times, 1974a. ASEAN's common stand on trade with EEC. The Straits Times. 15 March, 9.

The Straits Times, 1974b. Oil: New move by S'pore. The Strait Times, 22 January. 1. The Straits Times, 1975a. ASEAN shelves Manila's UN proposal. The Straits Times. 14 November, 10.

The Straits Times, 1975b. S'pore has only minor problems with EEC. The Straits Times. 3 September, 5.

The Straits Times, 1975c. ASEAN study group to keep tabs on EEC. The Straits Times. 7 October, 19. 
The Straits Times, 1976a. Let SEA be peace zone plea to big powers. The Straits Times. 3 October, 1.

The Straits Times, 1976b. Zone of peace concept and the big powers - by Hussein. The Straits Times. 26 February, 28.

The Straits Times, 1976c. ASEAN 'no' to Miki, Fraser. The Straits Times, 11 February, 1.

The Straits Times, 1977a. ASEAN hopes US will match Japan. The Straits Times. 7 September, 1.

The Straits Times, 1977b. US: No firm offers to ASEAN. The Straits Times. 8 September, 32.

The Straits Times, 1978a. Dialogue between ASEAN and the EEC gather momentum. The Straits Times. 5 July, 12.

The Straits Times, 1978b. What the EEC is likely to offer ASEAN. The Straits Times. 16 November, 1.

The Straits Times, 1978c. Mapping out ASEAN-EEC cooperation. The Straits Times. 21 November, 1.

The Straits Times, 1978d. ASEAN will propose cooperation pact with EEC. The Straits Times. 3 September, 15.

The Straits Times, 1982. A formal relationship after 10 years. The Straits Times. 17 June, 15.

The Straits Times, 1997. ASEAN-EU meeting postponed indefinitely. The Straits Times. 14 November, 2.

Thomassen, L., 2011. (Not) Just a piece of cloth: Begum, recognition and the politics of representation, Political Theory, 39(3), 325-351.

Thompson, S., 2006. The political theory of recognition: A critical introduction. Cambridge: Polity Press.

Thompson, S., 2011. The western powers and the development of regional cooperation in Southeast Asia: The international dimension, 1945-67, Global Change, Peace \& Security, 23(1), 75-88.

Today, 2006. EU wants free trade deal with ASEAN. Today. 16 May, 10.

U.S. Consul in Hong Kong 1976. APCAC meeting in Jakarta. Cable to U.S. State Department, 1976HONGK08314, 15 July. Washington: NARA.

U.S. Delegation to the MTN in Geneva, 1976. Ambassador Dent visit to LDC capitals. 
Cable to U.S. State Department, 1976MTNGE06522, 13 August. Washington: NARA.

U.S. Embassy in Bangkok, 1973a. Editorial on neutralization. Cable to U.S. State Department, 1973BANGKO15187, 28 September. Washington: NARA.

U.S. Embassy in Bangkok, 1973b. ASEAN ministerial meeting. Cable to U.S. State Department, 1973BANGKO06179, 19 April. Washington: NARA.

U.S. Embassy in Bangkok, 1973c. ASEAN-EC talks. Cable to U.S. State Department, 1973BANGKO12913, 20 August. Washington: NARA.

U.S. Embassy in Bangkok, 1974a. Thais views of the ASEAN foreign ministers conference. Cable to U.S. State Department, 1974BANGKO08101, 17 May. Washington: NARA.

U.S. Embassy in Bangkok, 1974b. Whitlam visit. Cable to U.S. State Department, 1974BANGKO01981, 5 February. Washington: NARA.

U.S. Embassy in Bangkok, 1974c. Prime Minister Whitlam's press conference. Cable to U.S. State Department, 1974BANGKO02046, 6 February. Washington: NARA.

U.S. Embassy in Bangkok, 1974d. ASEAN coordination and secretariat. Cable to U.S. State Department, 1974BANGKO12855, 8 August. Washington: NARA.

U.S. Embassy in Bangkok, 1974e. US-ASEAN economic consultations. Cable to U.S. State Department, 1974BANGKO13623, 22 August. Washington: NARA.

U.S. Embassy in Bangkok, 1975a. U.S.-ASEAN economic consultations. Cable to U.S. State Department, 1975BANGKO07182, 23 April. Washington: NARA.

U.S. Embassy in Bangkok, 1975b. US/ASEAN economic consultations. Cable to U.S. State Department, 1975BANGKO14810, 22 July. Washington: NARA.

U.S. Embassy in Bangkok, 1975c. US-ASEAN consultations. Cable to U.S. State Department, 1975BANGKO19290, 12 September. Washington: NARA.

U.S. Embassy in Bangkok, 1976a. Pre- $31^{\text {st }}$ UNGA consultations. Cable to U.S. State Department, 1976BANGKO25368, 10 September. Washington: NARA.

U.S. Embassy in Bangkok, 1976b. Press interview with Foreign Minister Pichai Rattakun. Cable to U.S. State Department, 1976BANGKO11494, 26 April. Washington: NARA.

U.S. Embassy in Bangkok, 1976c. Japanese policy towards ASEAN. Cable to U.S. State Department, 1976BANGKO34116, 20 December. Washington: NARA. 
U.S. Embassy in Bangkok, 1976d. ASEAN contacts with the U.S. Cable to U.S. State Department, 1976BANGKO27181, 30 September. Washington: NARA.

U.S. Embassy in Canberra, 1973a. Conversation with Malik. Cable to U.S. State Department, 1973CANBER06081, 8 November. Washington: NARA.

U.S. Embassy in Canberra, 1973b. Australian-Japanese official talks in Canberra, July 30-31. Cable to U.S. State Department, 1973CANBER04454, 10 August. Washington: NARA.

U.S. Embassy in Canberra, 1973c. Whitlam's view of regional association. Cable to U.S. State Department, 1973CANBER01558, 19 March. Washington: NARA.

U.S. Embassy in Canberra, 1973d. Southwest Pacific Consultative Group and visit of Indonesia Foreign Minister Malik. Cable to U.S. State Department, 1973CANBER06163, 13 November. Washington: NARA.

U.S. Embassy in Canberra, 1976a. Codel Morgan. Cable to U.S. State Department, 1976CANBER08442, 22 November. Washington: NARA.

U.S. Embassy in Canberra, 1976b. ASEAN summit. Cable to U.S. State Department, 1976CANBER01052, 12 February. Washington: NARA.

U.S. Embassy in Jakarta, 1973a. Malik on Southeast Pacific Consultative Group. Cable to U.S. State Department, 1973JAKART13494, 16 November. Washington: NARA.

U.S. Embassy in Jakarta, 1973b. GKR desire to join ASEAN. Cable to U.S. State Department, 1973JAKART09468, 8 August. Washington: NARA.

U.S. Embassy in Jakarta, 1973c. Australia Deputy PM and Defense Minister Barnard visits Indonesia. Cable to U.S. State Department, 1973JAKART04267, 10 April. Washington: NARA.

U.S. Embassy in Jakarta, 1973d. Suharto-Razak meeting: Philippine Muslim problem; PRC recognition; Japanese synthetic rubber. Cable to U.S. State Department, 1973JAKART05463, 8 May. Washington: NARA.

U.S. Embassy in Jakarta, 1973e. ASEAN reply to Japan over synthetic rubber. Cable to U.S. State Department, 1973JAKART11487, 26 September. Washington: NARA.

U.S. Embassy in Jakarta, 1973f. EEC official says ASEAN not yet equipped to negotiate with EEC. Cable to U.S. State Department, 1973JAKART09077, 30 July. Washington: NARA. 
U.S. Embassy in Jakarta, 1973g. ASEAN objectives in multilateral trade negotiations. Cable to U.S. State Department, 1973JAKART10449, 31 August. Washington: NARA.

U.S. Embassy in Jakarta, 1973h. Our view of developments in Malaysia, Singapore and Indonesia. Cable to U.S. State Department, 1973JAKART12265, 16 October. Washington: NARA.

U.S. Embassy in Jakarta, 1974a. Indonesia-New Zealand annual talks. Cable to U.S. State Department, 1974JAKART13865, 14 November. Washington: NARA.

U.S. Embassy in Jakarta, 1974b. Secretary Clements meeting with President Suharto. Cable to U.S. State Department, 1974JAKART12129, 1 October. Washington: NARA.

U.S. Embassy in Jakarta, 1974c. ASEAN accepts US\$5 million Australia aid offer. Cable to U.S. State Department, 1974JAKART05758, 10 May. Washington: NARA.

U.S. Embassy in Jakarta, 1974d. Soames meeting with ASEAN minister on EEC/ASEAN trade. Cable to U.S. State Department, 1974JAKART12549, 10 October. Washington: NARA.

U.S. Embassy in Jakarta, 1974e. Possible attendance of GVN at ASEAN May meeting. Cable to U.S. State Department, 1974JAKART05079, 26 April. Washington: NARA.

U.S. Embassy in Jakarta, 1974f. Quarterly assessment of Indonesia: Quarter ending May 31. Cable to U.S. State Department, 1974JAKART06571, 30 May. Washington: NARA.

U.S. Embassy in Jakarta, 1974g. US-ASEAN economic consultations. Cable to U.S. State Department, 1974JAKART10170, 19 August. Washington: NARA.

U.S. Embassy in Jakarta, 1974h. Impact of trade act of 1974 on Indonesia. Cable to U.S. State Department, 1974JAKART15315, 23 December. Washington: NARA.

U.S. Embassy in Jakarta, 1974i. ASEAN ministerial meeting begins. Cable to U.S. State Department, 1974JAKART05642, 8 May. Washington: NARA.

U.S. Embassy in Jakarta, 1974j. Press statement on "informal" discussions of ASEAN foreign ministers in Jakarta during seventh ASEAN ministerial meeting. Cable to U.S. State Department, 1974JAKART05740, 10 May. Washington: 
NARA.

U.S. Embassy in Jakarta, 1974k. Malik statement on Vietnam, Indonesia's international role, GOI foreign economic policy ASEAN. Cable to U.S. State Department, 1974JAKART14955, 12 December. Washington: NARA.

U.S. Embassy in Jakarta, 1975a. Visit of Indonesia Fonmin Don-jo Kim. Cable to U.S. State Department, 1975JAKART02812, 6 March. Washington: NARA.

U.S. Embassy in Jakarta, 1975b. Korean in UNGA. Cable to U.S. State Department, 1975JAKART11859, 25 September. Washington: NARA.

U.S. Embassy in Jakarta, 1975c. GOI views on Cambodia and Vietnam. Cable to U.S. State Department, 1975JAKART04295, 11 April. Washington: NARA.

U.S. Embassy in Jakarta, 1975d. U.S.-ASEAN consultations. Cable to U.S. State Department, 1975JAKART11206, 11 September. Washington: NARA.

U.S. Embassy in Jakarta, 1975e. US-ASEAN economic consultations. Cable to U.S. State Department, 1975JAKART00070, 3 January. Washington: NARA.

U.S. Embassy in Jakarta, 1975f. US-ASEAN economic consultations. Cable to U.S. State Department, 1975JAKART00183, 7 January. Washington: NARA.

U.S. Embassy in Jakarta, 1975g. US-Indonesia trade relations: Ambassador's call on Trade Minister Prawiro. Cable to U.S. State Department, 1975JAKART00750, 18 January. Washington: NARA.

U.S. Embassy in Jakarta, 1975h. Views of minister of communications. Cable to U.S. State Department, 1975JAKART01644, 7 February. Washington: NARA.

U.S. Embassy in Jakarta, 1975i. ASEAN-U.S. consultations. Cable to U.S. State Department, 1975JAKART10102, 19 August. Washington: NARA.

U.S. Embassy in Jakarta, 1975j. US-ASEAN consultations. Cable to U.S. State Department, 1975JAKART11071, 9 September. Washington: NARA.

U.S. Embassy in Jakarta, 1975k. Suharto's meeting with President Ford supplementary suggestions. Cable to U.S. State Department, 1975JAKART07564, 24 June. Washington: NARA.

U.S. Embassy in Jakarta, 1975I. Malik's views on ASEAN foreign ministers' meeting. Cable to U.S. State Department, 1975JAKART06139, 21 May. Washington: NARA.

U.S. Embassy in Jakarta, 1976a. Proposed presidential message for ASEAN summit. Cable to U.S. State Department, 1976JAKART02160, 18 February. 
Washington: NARA.

U.S. Embassy in Jakarta, 1976b. Soviets and Southeast Asia: One year later. Cable to U.S. State Department, 1976JAKART10450, 10 August. Washington: NARA.

U.S. Embassy in Jakarta, 1976c. ASEAN summit. Cable to U.S. State Department, 1976JAKART01000, 23 January. Washington: NARA.

U.S. Embassy in Jakarta, 1976d. Japanese message for ASEAN summit. Cable to U.S. State Department, 1976JAKART02343, 21 February. Washington: NARA.

U.S. Embassy in Jakarta, 1976e. Asian Pacific Council of American Chamber (APCAC). Cable to U.S. State Department, 1976STATE184127, 24 July. Washington: NARA.

U.S. Embassy in Jakarta, 1976f. GOI officials comments on ASEAN and possible US financing. Cable to U.S. State Department, 1976JAKART09793, 27 July. Washington: NARA.

U.S. Embassy in Jakarta, 1976g. ASEAN contacts with the US and establishment of ASEAN secretariat. Cable to U.S. State Department, 1976JAKART12971, 4 October. Washington: NARA.

U.S. Embassy in Jakarta, 1976h. Asian US/ASEAN economic consultations. Cable to U.S. State Department, 1976JAKART16649, 29 December. Washington: NARA.

U.S. Embassy in Jakarta, 1976i. Malik on ASEAN free trade zone. Cable to U.S. State Department, 1976JAKART01522, 3 February. Washington: NARA.

U.S. Embassy in Kuala Lumpur, 1973a. Ghazali Shafie on future of Pacific Basin. Cable to U.S. State Department, 1973KUALA04404, 3 October. Washington: NARA.

U.S. Embassy in Kuala Lumpur, 1973b. Prime Minister Razak on non-aligned conference, Korean item in UNGA and PRC relations. Cable to U.S. State Department, 1973KUALA03776, 24 August. Washington: NARA.

U.S. Embassy in Kuala Lumpur, 1973c. Baguio meeting on SEA neutralization. Cable to U.S. State Department, 1973KUALA02868, 3 July. Washington: NARA.

U.S. Embassy in Kuala Lumpur, 1973d. ASEAN-Japan ministerial meeting on synthetic rubber. Cable to U.S. State Department, 1973KUALA05375, 8 December. Washington: NARA. 
U.S. Embassy in Kuala Lumpur, 1973e. Malaysian and ASEAN strategies for GATT ministerial meeting on MTN Sep 12-14. Cable to U.S. State Department, 1973KUALA03954, 7 September. Washington: NARA.

U.S. Embassy in Kuala Lumpur, 1974a. Assistant Secretary Ingersoll's visit to KL: Highlights. Cable to U.S. State Department, 1974KUALA00626, 14 February. Washington: NARA.

U.S. Embassy in Kuala Lumpur, 1974b. Whitlam visit to Malaysia. Cable to U.S. State Department, 1974KUALA00402, 2 January. Washington: NARA.

U.S. Embassy in Kuala Lumpur, 1974c. ASEAN and mutual security: Remarks by MFA Secgen Zaiton. Cable to U.S. State Department, 1974KUALA02025, 3 May. Washington: NARA.

U.S. Embassy in Kuala Lumpur, 1974d. ASEAN officials to visit EEC secretariat. Cable to U.S. State Department, 1974KUALA05609, 26 November. Washington: NARA.

U.S. Embassy in Kuala Lumpur, 1974e. US-ASEAN economic consultations. Cable to U.S. State Department, 1974KUALA03900, 15 August. Washington: NARA.

U.S. Embassy in Kuala Lumpur, 1974f. Prime Minister Razak opens first joint meeting of all ASEAN committee, October 22-24. Cable to U.S. State Department, 1974KUALA05056, 23 October. Washington: NARA.

U.S. Embassy in Kuala Lumpur, 1975a. Malaysia- FY76 para: The U.S. and the K.L. declaration. Cable to U.S. State Department, 1975KUALA01427, 18 March. Washington: NARA.

U.S. Embassy in Kuala Lumpur, 1975b. Korea in the $30^{\text {th }}$ UNGA. Cable to U.S. State Department, 1975KUALA05714, 25 September. Washington: NARA.

U.S. Embassy in Kuala Lumpur, 1975c. Malaysia rubber price stabilization scheme. Cable to U.S. State Department, 1975KUALA00285, 1 January. Washington: NARA.

U.S. Embassy in Kuala Lumpur, 1975d. Meeting of experts of ASEAN major natural rubber producers, March 3-5. Cable to U.S. State Department, 1975KUALA01220, 6 March. Washington: NARA.

U.S. Embassy in Kuala Lumpur, 1975e. Malaysian concern over new authority for tin disposals from G.S.A. stockpile. Cable to U.S. State Department, 1975KUALA01608, 27 March. Washington: NARA. 
U.S. Embassy in Kuala Lumpur, 1975f. ASEAN-US consultations. Cable to U.S. State Department, 1975KUALA04861, 15 August. Washington: NARA.

U.S. Embassy in Kuala Lumpur, 1975g. US/ASEAN economic consultations. Cable to U.S. State Department, 1975KUALA02604, 13 May. Washington: NARA.

U.S. Embassy in Kuala Lumpur, 1976a. Local press lauds prime minister's visit to Jakarta. Cable to U.S. State Department, 1976KUALA00585, 30 January. Washington: NARA.

U.S. Embassy in Kuala Lumpur, 1976b. Malaysian views on ASEAN. Cable to U.S. State Department, 1976KUALA07486, 29 December. Washington: NARA.

U.S. Embassy in Kuala Lumpur, 1976c. Proposed visit of STR Dent for MTN discussions. Cable to U.S. State Department, 1976KUALA04399, 2 August. Washington: NARA.

U.S. Embassy in Manila, 1973. ASEAN: Results of consultation with Soames. Cable to U.S. State Department, 1973MANILA11049, 28 September. Washington: NARA.

U.S. Embassy in Manila, 1974a. The yellow peril. Cable to U.S. State Department, 1974MANILA06127, 24 May. Washington: NARA.

U.S. Embassy in Manila, 1974b. EEC-ASEAN relations. Cable to U.S. State Department, 1974MANILA11830, 2 October. Washington: NARA.

U.S. Embassy in Manila, 1974c. US-ASEAN economic consultations. Cable to U.S. State Department, 1974MANILA09701, 14 August. Washington: NARA.

U.S. Embassy in Manila, 1974d. Visit of Prime Minister Lee Kuan Yew. Cable to U.S. State Department, 1974MANILA00688, 18 January. Washington: NARA.

U.S. Embassy in Manila, 1975a. Visit of Korean foreign minister to Manila. Cable to U.S. State Department, 1975MANILA02353, 24 February. Washington: NARA.

U.S. Embassy in Manila, 1975b. Visit to the Philippines. Cable to U.S. State Department, 1975MANILA07891, 9 June. Washington: NARA.

U.S. Embassy in Manila, 1975c. Korea in the $30^{\text {th }}$ UNGA. Cable to U.S. State Department, 1975MANILA13579, 26 September. Washington: NARA.

U.S. Embassy in Manila, 1975d. Suharto proposes ASEAN summit. Cable to U.S. State Department, 1975MANILA04230, 4 April. Washington: NARA.

U.S. Embassy in Manila, 1975e. US-ASEAN economic consultations. Cable to U.S. State Department, 1975MANILA00277, 8 January. Washington: NARA. 
U.S. Embassy in Manila, 1975f. U.S.-ASEAN economic consultations. Cable to U.S. State Department, 1975MANILA00106, 3 January. Washington: NARA.

U.S. Embassy in Manila, 1975g. ASEAN/US consultations. Cable to U.S. State Department, 1975MANILA12062, 28 August. Washington: NARA.

U.S. Embassy in Manila, 1975h. ASEAN/US consultations. Cable to U.S. State Department, 1975MANILA10439, 30 July. Washington: NARA.

U.S. Embassy in Manila, 1976a. Marcos remarks on ASEAN. Cable to U.S. State Department, 1976MANILA01502, 29 January. Washington: NARA.

U.S. Embassy in Manila, 1976b. Marcos remarks on ASEAN. Cable to U.S. State Department, 1976MANILA01561, 30 January. Washington: NARA.

U.S. Embassy in Manila, 1976c. Marcos calls for ASEAN-Japan dialogue. Cable to U.S. State Department, 1976MANILA15339, 4 October. Washington: NARA.

U.S. Embassy in Manila, 1976d. US/ASEAN economic consultations. Cable to U.S. State Department, 1976MANILA19360, 13 December. Washington: NARA.

U.S. Embassy in Manila, 1976e. ASEAN contacts with U.S. Cable to U.S. State Department, 1976MANILA15279, 1 October. Washington: NARA.

U.S. Embassy in Manila, 1976f. Proposed visit of STR Dent for MTN discussions. Cable to U.S. State Department, 1976MANILA11132, 28 July. Washington: NARA.

U.S. Embassy in New Delhi, 1973. Indonesian foreign minister's visit. Cable to U.S. State Department, 1973 NEWDE03928, 5 April. Washington: NARA.

U.S. Embassy in New Delhi, 1975. The Indians and Indonesians feel each other out at bi-national seminar. Cable to U.S. State Department, 1975NEWDE05992, 5 May. Washington: NARA.

U.S. Embassy in Seoul, 1974. Fonsec Romulo's visit to Seoul. Cable to U.S. State Department, 1974SEOUL05228, 9 August. Washington: NARA.

U.S. Embassy in Seoul, 1975. Foreign minister's visit to ASEAN countries. Cable to U.S. State Department, 1975SEOUL01648, 13 March. Washington: NARA.

U.S. Embassy in Singapore, 1973a. PM Lee's latest comments on neutralization. Cable to U.S. State Department, 1973SINGAP03084, 7 August. Washington: NARA.

U.S. Embassy in Singapore, 1973b. GOS assessment of ASEAN meeting. Cable to U.S. State Department, 1973SINGAP01776, 1 May. Washington: NARA. 
U.S. Embassy in Singapore, 1973c. ASEAN and MTN. Cable to U.S. State Department, 1973SINGAP03443, 1 September. Washington: NARA.

U.S. Embassy in Singapore, 1973d. Arab effort to promote ASEAN resolution on Middle East. Cable to U.S. State Department, 1973SINGAP04527, 23 November. Washington: NARA.

U.S. Embassy in Singapore, 1973e. ASEAN statement condemning Israel. Cable to U.S. State Department, 1973SINGAP04595, 28 November. Washington: NARA.

U.S. Embassy in Singapore, 1973f. Implications of Arab oil squeeze on Singapore. Cable to U.S. State Department, 1973SINGAP04830, 15 December. Washington: NARA.

U.S. Embassy in Singapore, 1974a. Adm Gayler's call on Defense Minister Goh. Cable to U.S. State Department, 1974SINGAP02395, 1 June. Washington: NARA.

U.S. Embassy in Singapore, 1974b. ASEAN senior officials meeting in Singapore. Cable to U.S. State Department, 1974SINGAP01330, 23 March. Washington: NARA.

U.S. Embassy in Singapore, 1974c. Deputy Secretary Clements meeting with Lee Kuan Yew. Cable to U.S. State Department, 1974SINGAP03951, 30 September. Washington: NARA.

U.S. Embassy in Singapore, 1974d. Whitlam visit to Singapore. Cable to U.S. State Department, 1974SINGAP00612, 11 February. Washington: NARA.

U.S. Embassy in Singapore, 1974e. Possible attendance of GVN at ASEAN May meeting. Cable to U.S. State Department, 1974SINGAP01879, 27 April. Washington: NARA.

U.S. Embassy in Singapore, 1974f. US-ASEAN economic consultations. Cable to U.S. State Department, 1974SINGAP03381, 6 August. Washington: NARA.

U.S. Embassy in Singapore, 1975a. Korea in the $30^{\text {th }}$ UNGA. Cable to U.S. State Department, 1975SINGAP04183, 24 September. Washington: NARA.

U.S. Embassy in Singapore, 1975b. U.S.-ASEAN economic consultations. Cable to U.S. State Department, 1975SINGAP00112, 9 January. Washington: NARA.

U.S. Embassy in Singapore, 1975c. ASEAN senior level meeting, Singapore, Sept. 15-17. Cable to U.S. State Department, 1975SINGAP04127, 22 September. 
Washington: NARA.

U.S. Embassy in Singapore, 1975d. Proposed economic consultations between ASEAN and U.S. Cable to U.S. State Department, 1975SINGAP03152, 23 July. Washington: NARA.

U.S. Embassy in Singapore, 1976a. US/ASEAN economic consultations. Cable to U.S. State Department, 1976SINGAP05752, 27 December. Washington: NARA.

U.S. Embassy in Singapore, 1976b. Japanese Southeast Asian chiefs of mission meeting. Cable to U.S. State Department, 1976SINGAP05473, 6 December. Washington: NARA.

U.S. Embassy in Singapore, 1976c. Yoshino lobbying for Japanese attendance at ASEAN. Cable to U.S. State Department, 1976SINGAP00508, 30 January. Washington: NARA.

U.S. Embassy in Singapore, 1976d. Japanese efforts to promote dialogue with ASEAN and revive MEDSEA. Cable to U.S. State Department, 1976SINGAP04509, 30 September. Washington: NARA.

U.S. Embassy in Singapore, 1976e. ASEAN standing committee meeting, November 17, Singapore. Cable to U.S. State Department, 1976SINGAP05344, 25 November. Washington: NARA.

U.S. Embassy in Singapore, 1976f. ASEAN diesel engine project. Cable to U.S. State Department, 1976SINGAP03952, 20 August. Washington: NARA.

U.S. Embassy in Singapore, 1976g. ASEAN standing committee meeting in Singapore. Cable to U.S. State Department, 1976SINGAP04462, 27 September. Washington: NARA.

U.S. Embassy in Singapore, 1976h. Proposed visit of STR Dent for MTN discussions. Cable to U.S. State Department, 1976SINGAP03623, 29 July. Washington: NARA.

U.S. Embassy in Singapore, 1976i. Brookings fellow A. Doak Barnett's conversation with Prime Minister Lee Kuan Yew. Cable to U.S. State Department, 1976SINGAP05352, 26 November. Washington: NARA.

U.S. Embassy in Singapore, 1976j. ASEAN. Cable to U.S. State Department, 1976SINGAP00074, 7 January. Washington: NARA.

U.S. Embassy in Singapore, 1976k. Marcos-Lee Kuan Yew meeting. Cable to U.S. 
State Department, 1976SINGAP00190, 14 January. Washington: NARA.

U.S. Embassy in Tokyo, 1973a. ASEAN protest to Japan over synthetic rubber. Cable to U.S. State Department, 1973TOKYO11552, 7 September. Washington: NARA.

U.S. Embassy in Tokyo, 1973b. ASEAN-Japan ministerial meeting on synthetic rubber. Cable to U.S. State Department, 1973TOKYO15526, 29 November. Washington: NARA.

U.S. Embassy in Tokyo, 1974a. Second ASEAN-Japan experts meeting on synthetic rubber. Cable to U.S. State Department, 1974TOKYO04099. 28 March. Washington: NARA.

U.S. Embassy in Tokyo, 1974b. Tanaka's tour of SE Asia summary. Cable to U.S. State Department, 1974TOKYO00027, 3 January. Washington: NARA.

U.S. Embassy in Tokyo, 1974c. Sullivan's peril. Cable to U.S. State Department, 1974TOKYO08434, 26 June. Washington: NARA.

U.S. Embassy in Tokyo, 1975. Tokyo ambassadors conference on post Vietnam Asia. Cable to U.S. State Department, 1975TOKYO09888, 22 July. Washington: NARA.

U.S. Embassy in Tokyo, 1976a. Senator Mansfield's conversation with Foreign Minister Miyazawa. Cable to U.S. State Department, 1976TOKYO10553, 12 July. Washington: NARA.

U.S. Embassy in Tokyo, 1976b. Japanese initiative with ASEAN: PM Miki to the ASEAN summit? Cable to U.S. State Department, 1976TOKYO01008, 22 January. Washington: NARA.

U.S. Embassy in Tokyo, 1976c. Fonoff worried about SEA stability. Cable to U.S. State Department, 1976TOKYO01474, 30 January. Washington: NARA.

U.S. Embassy in Tokyo, 1976d. Japan and ASEAN. Cable to U.S. State Department, 1976TOKYO01793, 5 February. Washington: NARA.

U.S. Embassy in Tokyo, 1976e. ASEAN non-invitation to PM Miki. Cable to U.S. State Department, 1976TOKYO02216, 13 February. Washington: NARA.

U.S. Embassy in Tokyo, 1976f. Implications for Japan of ASEAN developments. Cable to U.S. State Department, 1976TOKYO03399, 5 May. Washington: NARA.

U.S. Embassy in Tokyo, 1976g. Japanese pursuit of dialogue with and among 288 
Southeast Asians. Cable to U.S. State Department, 1976TOKYO15498, 15 October. Washington: NARA.

U.S. Embassy in Wellington, 1973a. Wellington. Cable to U.S. State Department, 1973WELLIN01173, 4 May. Washington: NARA.

U.S. Embassy in Wellington, 1973b. Current GNZ views on Asian groupings. Cable to U.S. State Department, 1973WELLIN00773, 27 March. Washington: NARA.

U.S. Embassy in Wellington, 1974. Chiefs of mission conference: Material for Amb

Selden. Cable to U.S. State Department, 974WELLIN03621, 19 November. Washington: NARA.

U.S. Liaison Office in Beijing, 1973. Whitlam's discussions with Chou En-Lai. Cable to U.S. State Department, 1973PEKING01356, 8 November. Washington: NARA.

U.S. Mission in EC Brussels, 1973a. ASEAN-EC talks. Cable to U.S. State Department, 1973ECBRU04859, 24 August. Washington: NARA.

U.S. Mission in EC Brussels, 1973b. Sir Christopher Soames' Far East talks. Cable to U.S. State Department, 1973ECBRU05400, 21 September. Washington: NARA.

U.S. Mission in EC Brussels, 1974a. Closer ties between the EC and Australia and New Zealand and the ASEAN countries. Cable to U.S. State Department, 1974ECBRU07784, 7 October. Washington: NARA.

U.S. Mission in EC Brussels, 1974b. 1975 EC generalized system of preference (GSP). Cable to U.S. State Department, 1974ECBRU09040, 9 November. Washington: NARA.

U.S. Mission in EC Brussels, 1974c. ASEAN-EC talks. Cable to U.S. State Department, 1974ECBRU08394, 25 October. Washington: NARA.

U.S. Mission in EC Brussels, 1975. EC Commission president to visit Southeast Asia. Cable to U.S. State Department, 1975ECBRU07600, 27 August. Washington: NARA.

U.S. Mission in the UN, 1974. Khmer in $29^{\text {th }}$ GA: Outlook as of Oct 25. Cable to U.S. State Department, 1974USUNN04450, 26 October. Washington: NARA.

U.S. Mission in the UN, 1975. Korea in the $30^{\text {th }}$ UNGA. Cable to U.S. State Department, 1975USUNN04430, 23 September. Washington: NARA.

U.S. State Department, 1973a. Handling Soviet Asian collective security system. 
Cable to various embassies, 1973STATE179880, 11 September. Washington: NARA.

U.S. State Department, 1973b. Soviet, Chinese approaches to GOI peace conference delegation. Cable to U.S. Embassy in Jakarta, 1973STATE044555, 10 March. Washington: NARA.

U.S. State Department, 1973c. SEA neutralization proposal for Ambassador Sullivan. Cable to U.S. Embassy in Manila, 1973STATE194571, 29 September. Washington: NARA.

U.S. State Department, 1973d. ASEAN-EEC relations. Cable to U.S. embassies in ASEAN-5 countries and Brussels, 1973STATE161838, 15 August. Washington: NARA.

U.S. State Department, 1974a. September 26 EA press summary. Cable to various U.S. embassies, 1974STATE212875, 26 September. Washington: NARA.

U.S. State Department, 1974b. Non-aligned activities in international organizations. Cable to U.S. State Department, 1974STATE099106, 13 May. Washington: NARA.

U.S. State Department, 1974c. ASEAN economic coordination. Cable to U.S. embassies in ASEAN-5 countries, 1974STATE169116, 2 August. Washington: NARA.

U.S. State Department, 1974d. US-ASEAN economic consultations. Cable to U.S. embassies in Southeast Asia, 1974STATE176399, 13 August. Washington: NARA.

U.S. State Department, 1974e. U.S.-ASEAN economic consultations. Cable to U.S. embassies in ASEAN-5 countries, 1974STATE283832, 31 December. Washington: NARA.

U.S. State Department, 1975a. Request for current reporting on ASEAN regional activities. Cable to U.S. embassies in ASEAN-5 countries, 1975STATE006183, 10 January. Washington: NARA.

U.S. State Department, 1975b. US policy statements on proposed zone of peace, freedom and neutrality (Kuala Lumpur declaration). Cable to U.S. Embassy in Bangkok, 1975STATE070748, 28 March. Washington: NARA.

U.S. State Department, 1975c. US policy statements on proposed zone of peace, freedom and neutrality (Kuala Lumpur declaration). Cable to U.S. Embassy in 
Bangkok, 1975STATE066815, 25 March. Washington: NARA.

U.S. State Department, 1975d. Kuala Lumpur declaration. Cable to ASEAN-5 embassies, 1975STATE066814, 25 March. Washington: NARA.

U.S. State Department, 1975e. UNGA: Korea. Cable to U.S. Embassy in Tokyo, 1975STATE236683, 8 October. Washington: NARA.

U.S. State Department, 1975f. Korea in $30^{\text {th }}$ UNGA. Cable to U.S. Embassy in Jakarta, 1975STATE246947, 17 October. Washington: NARA.

U.S. State Department, $1975 \mathrm{~g}$. Korea in the $30^{\text {th }}$ GA: ASEAN approval. Cable to U.S. Embassy in Bangkok, 1975STATE231036, 27 September. Washington: NARA.

U.S. State Department, 1975h. Trade Act of 1975 - questions on countervailing duties and GSP rules of origin. Cable to U.S. State Department, 1974STATE226894, 18 October. Washington: NARA.

U.S. State Department, 1975i. Visit of EC President Ortoli to Indonesia. Cable to U.S. embassies in ASEAN-5 countries, 1975STATE225592, 22 September. Washington: NARA.

U.S. State Department, 1975j. US-ASEAN economic consultations. Cable to U.S. embassies in ASEAN-5 countries, 1975STATE194749, 16 August. Washington: NARA.

U.S. State Department, 1975k. US-ASEAN economic consultations. Cable to U.S. embassies in ASEAN-5 countries, 1975STATE011518, 17 January. Washington: NARA.

U.S. State Department, 1975I. US/ASEAN economic consultations. Cable to U.S. embassies in ASEAN-5 countries, 1975STATE102360, 1 May. Washington: NARA.

U.S. State Department, 1975m. US-ASEAN economic consultations. Cable to U.S. embassies in ASEAN-5 countries, 1975STATE232607, 7 October. Washington: NARA.

U.S. State Department, 1976a. Congratulatory message to ASEAN. Cable to U.S. Embassy in Jakarta, 1976STATE041774, 21 February. Washington: NARA.

U.S. State Department, 1976b. Japan and ASEAN. Cable to U.S. Embassy in Tokyo, 1976STATE023428, 30 January. Washington: NARA.

U.S. State Department, 1976c. Morning summary of significant reports. Cable to various U.S. embassies, 1976STATE302711, 14 December. Washington: 
NARA.

U.S. State Department, 1976d. ASEAN diesel engine project. Cable to U.S. embassies in ASEAN-5 countries, 1976STATE194311, 5 August. Washington: NARA.

U.S. State Department, 1976e. ASEAN's relations to US private firms. Cable to U.S. embassies in ASEAN-5 countries, 1976STATE276026, 9 November. Washington: NARA.

U.S. State Department, 1976f. US-Indonesian consultations. Cable to U.S. Embassy in Jakarta, 1976STATE166459, 3 July. Washington: NARA.

U.S. State Department, 1976g. US-Indonesian consultations: Staff talks. Cable to U.S. Embassy in Jakarta, 1976STATE166433, 3 July. Washington: NARA.

U.S. State Department, 1976h. Proposed visit of STR Dent: For MTN discussions. Cable to U.S. embassies in ASEAN-5 countries, 1976STATE185876, 27 July. Washington: NARA.

U.S. State Department, 1976i. Ambassador Dent's visit to LDC capitals. Cable to U.S. embassies in ASEAN-5 countries, 1976STATE206745, 19 August. Washington: NARA.

Van Langenhove, L., 2003. Theorising regionhood. UNU/CRIS Working Paper, W2003/1.

Waltz, K., 1979. Theory of international politics. New York: McGraw-Hill.

Warbrick, C., 2003. State and recognition in international law. In: M. Evans, ed. International Law. Oxford: Oxford University Press, 205-267.

Weatherbee, D. E., 2009. International relations in Southeast Asia: The struggle for autonomy. Maryland: Rowman \& Littlefield Publishers.

Wendt, A, 1992. Anarchy is what states make of it: The social construction of power politics, International Organization, 46(2), 397-425.

Wendt, A., 1999. Social theory of international politics. New York: Cambridge University Press.

Worster, W. T., 2009. Law, politics and the conception of the state in state recognition theory, Boston University International Law Journal, 27(1), 115171.

Yamamoto, Y., 2008. Institutionalization in Northeast Asia: Is outside-in regionalization enough? In: M. Timmermann and J. Tsuchiyama, eds. 
Institutionalizing Northeast Asia: Regional steps towards global governance. Tokyo: United Nations University Press, 21-42.

Zakaria, H. A., 1986. ASEAN and the great powers. In: K. D. Jackson et al., eds. ASEAN in regional and global context. Berkeley: Institute of East Asian Studies, University of California, 347-357. 